\title{
AVALIAÇÃO DA ATRATIVIDADE DE NEGÓCIOS EM GERAÇÃO DISTRIBUÍDA E ECONOMIA DE ENERGIA ELÉTRICA Piloto Aplicado dentro dos Estudos do PIR da RAA
}

\author{
Dissertação apresentada à Escola \\ Politécnica da Universidade de São \\ Paulo para obtenção do título de \\ Mestre em Engenharia
}




\section{AVALIAÇÃO DA ATRATIVIDADE DE NEGÓCIOS EM GERAÇÃO DISTRIBUÍDA E ECONOMIA DE ENERGIA ELÉTRICA Piloto Aplicado dentro dos Estudos do PIR da RAA}

Dissertação apresentada à Escola

Politécnica da Universidade de São

Paulo para obtenção do título de Mestre em Engenharia

Área de Concentração:

Sistemas de Potência

Orientador:

Prof. Dr. Miguel Edgar Morales Udaeta 
Este exemplar foi revisado e alterado em relação à versão original, sob responsabilidade única do autor e com a anuência de seu orientador.

São Paulo, de de 2012

Assinatura do autor

Assinatura do orientador

Silva Junior, Barnabé da

Avaliação da atratividade de negócios em geração distribuída e medidas de economia de energia elétrica: piloto aplicado dentro dos estudos do PIR na RAA / B. Da Silva Junior. -- ed.rev. -- São Paulo, 2012. $176 \mathrm{p}$.

Dissertação (Mestrado) - Escola Politécnica da Universidade de São Paulo. Departamento de Engenharia de Energia e Automação Elétricas.

1.Recursos energéticos (Avaliação; Planejamento) 2.Economia de energia (Medidas) I.Universidade de São Paulo. Escola Politécnica. Departamento de Engenharia de Energia e Automação Elétricas II.t. 
Dedico este trabalho à minha esposa Márcia, ao meu filho Gabriel e à doce memória de meus pais: senhor Barnabé e dona Benedita. 


\section{AGRADECIMENTOS}

Agradeço ao professor Miguel Udaeta, pela orientação e pelo constante estímulo transmitido durante todo o trabalho, mostrando-me o caminho, sempre se comportando como um mestre.

Aos professores Dorel Ramos e Cláudio Galvão, da Poli/PEA, que dividiram com o professor Miguel Udaeta a tarefa de comentar, de forma tão contributiva, os resultados preliminares de minhas pesquisas durante o processo de qualificação, auxiliando-me nas correções de rumo.

A todos os demais professores do PEA/Poli pelo privilégio de compartilharem seus conhecimentos e experiências em sala de aula, que muito contribuíram em meus estudos e pesquisas, enfim, com este trabalho.

Ao IEE, na figura do prof. José Aquiles Baeso Grimoni, pelo suporte material incondicional ao desenvolvimento de todas as etapas do trabalho de pesquisa

Ao auxílio financeiro da Fundação de Amparo à Pesquisa do Estado de São Paulo, ao projeto PIR de Araçatuba (FAPESP - Processo 03/064441-7), a partir do qual foi possível o desenvolvimento das pesquisas.

A todos os meus amigos do grupo de pesquisa do GEPEA/EPUSP pelo convívio e pela troca de experiências, durante esta minha etapa de estudos e pesquisas, em especial ao Décio Cicone, Mario Biague, Pascoal Rigolin, Jonathas Bernal e Ricardo Baitelo.

Aos irmãos Gimenes, por me incentivarem a voltar ao ambiente acadêmico e por se mostrarem, realmente, amigos, "segurando em minhas mãos nos primeiríssimos passos da retomada de minha caminhada acadêmica".

À minha esposa e ao meu filho, pela compreensão em suportarem minhas ausências durante estes últimos três anos de estudo.

E finalmente a Deus, por me permitir chegar até onde cheguei. 
Em relação à sustentabilidade ambiental e ações governamentais e empresariais, existe o grupo daqueles que criticam quem prioriza o futuro, alegando que não faz sentido priorizar o futuro se o presente ainda não está resolvido; existe o grupo daqueles que criticam quem prioriza o presente, alegando que não haverá futuro, caso o futuro não tenha sido priorizado no presente. Eu pertenço a um terceiro grupo, que mantém em perspectiva as lições do passado, que age no presente e que acredita que os dois primeiros grupos deveriam parar de criticarem-se mutuamente e passarem a atuar mais em conjunto, e assim superando os paradigmas do curto e do longo prazo da sustentabilidade ambiental [...].

(Anônimo) 


\section{RESUMO}

O objetivo da dissertação foi o desenvolvimento de um modelo de avaliação rápida da atratividade de oportunidades de negócios em recursos energéticos renováveis dentro de uma região geográfica delimitada, valendo-se dos resultados do Planejamento Integrado de Recursos Energéticos (PIR) para a região analisada, complementado com outras bases bibliográficas primárias e secundárias. $\mathrm{O}$ uso dos resultados do PIR propiciou o acesso rápido a avaliações prontas dos recursos energéticos em três dimensões ${ }^{1}$, além da dimensão técnico-econômica, incluindo opiniões e posições da sociedade local e nacional (técnicos e não técnicos). No estudo piloto, o modelo é aplicado em cinco recursos energéticos renováveis dentro da Região Administrativa de Araçatuba (RAA), noroeste do estado de São Paulo. Os recursos avaliados são: (a) de oferta: Geração eólica (EOL); Cogeração por Biomassa de Cana-de-açúcar (BIO); e Pequenas Centrais Hidroelétricas ( $\mathrm{PCH}$ ); (b) de demanda (medidas de economia): Troca de Lâmpadas Incandescentes por Fluorescentes Compactas e Troca de Chuveiros Elétricos por Aquecedores Solares. Os principais resultados do modelo de avaliação foram (i) um modelo de fluxo de caixa funcional para a avaliação dos recursos de geração; (ii) para cada recurso de geração: cálculo das principais Figuras de Mérito Econômico Financeiro (VPL, TIR, PayBack Descontado, preço de equilíbrio ${ }^{2}$ da energia gerada e demanda relevante de capital de giro) ; (iii) para as medidas de economia de energia: cálculo das figuras de mérito econômico-financeiras (Custo do Ciclo de vida anualizado (CCVA) e PayBack Descontado); (iv) pontos notáveis da análise de sensibilidade das figuras de mérito, obtidas pela variação das principais parâmetros de entrada dos modelos matemáticos representativos dos recursos; (v) análise geral dos riscos em empreender os recursos avaliados; e (vi) diagnóstico da atratividade de investimento em cada recurso: não atrativo, atrativo com atenção, e atrativo. No contexto do estudo piloto, o recurso lâmpada fluorescente recebeu diagnóstico de atrativo; os recursos Cogeração por biomassa e coletor solar receberam o diagnóstico de atrativo com atenção, e os recursos Geração eólica e $\mathrm{PCH}$ receberam o diagnóstico de não atrativos para investimento, todos dentro da região do estudo de caso.

Palavras-chave: Planejamento Integrado de Recursos. Recursos energéticos renováveis. Avaliação de negócios em energia. Energia elétrica. Figuras de Mérito Econômico-financeiro.

\footnotetext{
${ }^{1}$ Dimensões Ambiental, Social e Política.

${ }^{2} \mathrm{O}$ preço da energia elétrica pelo qual o Valor Presente do fluxo de caixa do empreendimento é zero: Ponto de indiferença.
} 


\begin{abstract}
The purpose of this work was the expedite assessment of business opportunities attractiveness in renewable energy resources within a limited geographical area, based on the results of the Integrated Resources Planning for Energy (IRP), developed for the same area, and supplemented with other primary and secondary information sources. The use of IRP's information made possible, quickly and easy, the assessments of energy resources in extra three dimensions ${ }^{3}$, beyond the usual technical- economic one, including views and positions of local and national stakeholders (technical and nontechnical). In the pilot study, the model is applied in five renewable energy resources within the Administrative Region of Araçatuba (RAA), northwest of São Paulo state, Brazil. The evaluated energy resources were: (a) supply side: wind generation (EOL); Cogeneration by Biomass of Sugar Cane (BIO); and Small Hydro Power plants (SHP); (b) demand side (measures of energy economy): replacement of Compact Fluorescent Incandescent bulbs by Fluorescent ones and replacement of Electric Showers by Solar Heater ones. The main results of the proposed evaluation model were (i) a functional cash flow model, useful to assess the generation resources; (ii) for each generation resource: the calculation of the main Figures of Economic Merit (NPV, IRR, Discounted Payback, the equilibrium price of generated energy and relevant demand for working capital), (iii) measures of energy economy: the calculation of the main Figures of Economic Merit (Annualized Life Cycle Cost (ALCC) and Payback Discounted (PBD), (iv) points of remarkable sensitivity in the Figures of Economic Merit analysis, obtained by varying the main independent parameters input in the cash flow models that represent the resources, $(v)$ analysis of the risks in adoption of the evaluated resources, and finally, (vi) the attractiveness degree of each resources evaluated : not attractive, attractive with attention, and attractive. Within the context of the pilot study case, the use of compact fluorescent bulb received the degree attractive; biomass cogeneration (BIO) and solar collector received degree attractive, but under attention; wind generation (EOL) and $\mathrm{PCH}$ received the degree not attractive for investment within the study case region.
\end{abstract}

Keywords: Integrated Resource Planning. Renewable Energy Resources. Business attractiveness Evaluation. Electricity. Figures of Economic Merit.

\footnotetext{
${ }^{3}$ Environmental, Social and Political.
} 


\section{LISTA DE FIGURAS}

Figura 1 - Construção da escala para avaliação das figuras de mérito dos REs ................................ 25

Figura 2 - Apresentação gráfica do cálculo da nota média dada ao RE ........................................ 26

Figura 3 - Peso ponderado da figura de mérito na avaliação de atratividade do RE ......................... 27

Figura 4 - Cálculo da nota final do RE usada para avaliação da atratividade .................................... 28

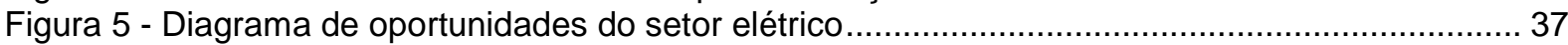

Figura 6 - Mecanismo de liquidação das diferenças no mercado SPOT ........................................... 38

Figura 7 - Ambientes de contratação de energia elétrica no Brasil ................................................. 41

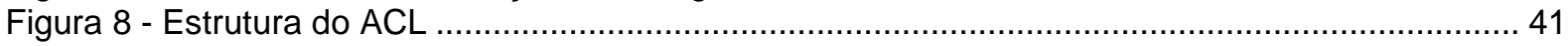

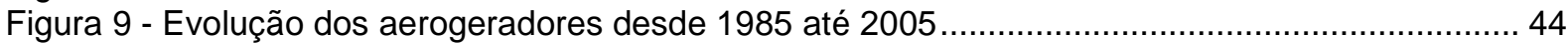

Figura 10 - Taxas e contratos na transmissão ou distribuição (gerador e cliente livre) ....................... 53

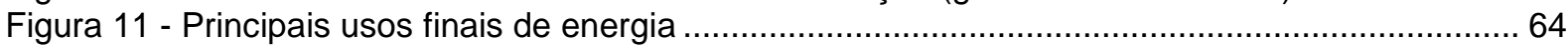

Figura 12 - Velocidade média dos ventos no estado de São Paulo - CEPEL / 2001 ......................... 76

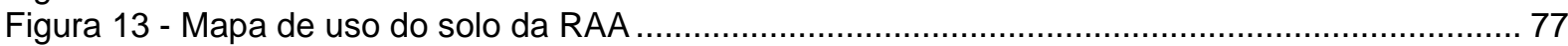

Figura 14 - Mapa hidrológico das bacias e sub-bacias hidrográficas da RAA. ................................. 85

Figura 15 - Mapa altimétrico ou mapa com curvas de níveis da RAA. ............................................ 85

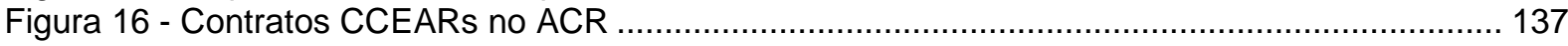

Figura 17 - Composição dos custos das UTEs com contratos por disponibilidade .............................139

Figura 18 - Momentos de venda/contratação de energia elétrica................................................... 141 


\section{LISTA DE TABELAS}

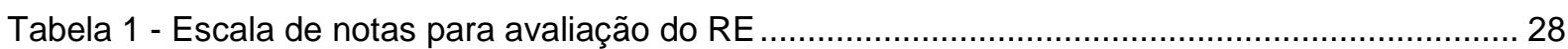

Tabela 2 - Números da geração de energia elétrica no Brasil (tipo) ............................................... 33

Tabela 3 - EPE - Geração:acréscimo previsto de capacidade instalada anual por fonte (MW).......... 34

Tabela 4 - Quantidade de Agentes participantes do CCEE ........................................................... 42

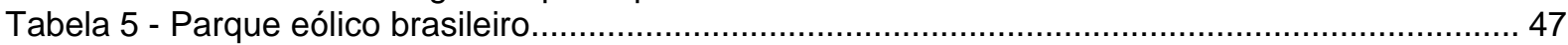

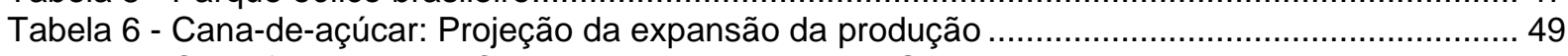

Tabela 7 - Classificação das PCHs , no contexto do PIR-USP .................................................... 51

Tabela 8 - Evolução do parque brasileiro de PCHs (1MW <P<30MW) …....................................... 52

Tabela 9 - Histórico das revisões do Custo Marginal de Expansão do ACR ....................................... 59

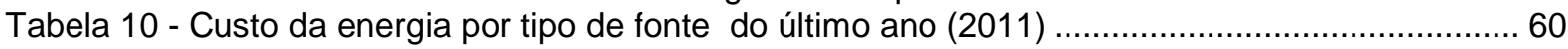

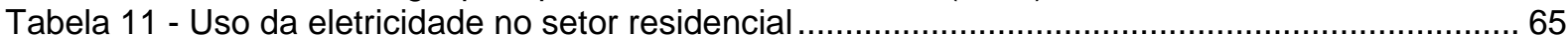

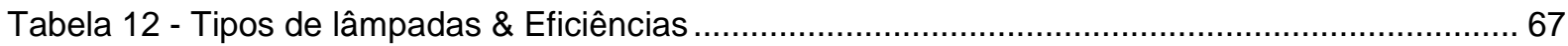

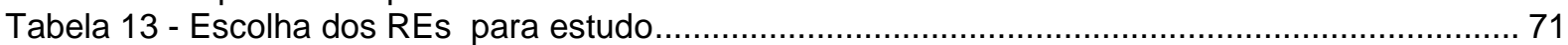

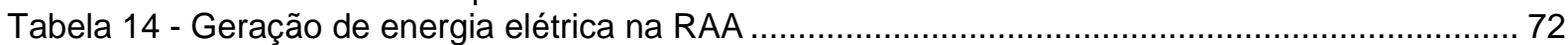

Tabela 15 - Geração de energia elétrica na RAA (tipo de fonte) ................................................... 72

Tabela 16 - Potencial inventariado de energia elétrica inventariados pelo PIR na RAA ...................... 73

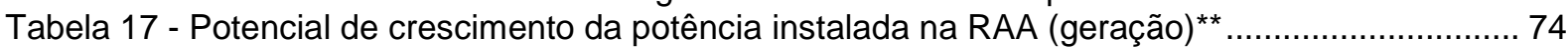

Tabela 18 - Velocidade $x$ frequência medida pelo PIR na RAA a 30 m do solo................................ 75

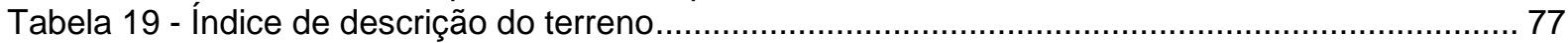

Tabela 20 - Projeção da velocidade do vento para 85 e 98 metros na RAA .................................... 78

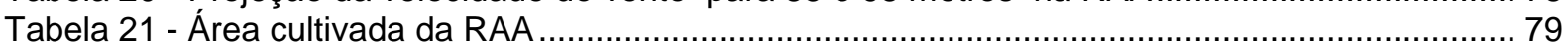

Tabela 22 - Especificações técnicas da turbina Wobben/Enercon E82-E2 ..................................... 80

Tabela 23 - Estimativa da geração anual de energia de 1(um) gerador E82-E2 na RAA ................... 81

Tabela 24 - Estimativa do Fator de Capacidade dos aerogeradores Enercon na RAA ...................... 82

Tabela 25 - Aproveitamentos hidráulicos localizados pelo PIR-USP na RAA ....................................... 87

Tabela 26 - Parâmetros demográficos e comportamentais da RAA utilizados na avaliação ................ 88

Tabela 27 - Parâmetros tecnológicos utilizados na avaliação dos recursos de demanda .................... 88

Tabela 28 - Impactos das medidas de economia de energia na RAA .......................................... 90

Tabela 29 - Figuras de mérito e pontos notáveis da análise de sensibilidade do RE EOL .....................99 97

Tabela 30 - Figuras de mérito e pontos notáveis da análise de sensibilidade do RE de BIO .............. 99

Tabela 31 - Figuras de mérito e pontos notáveis da análise de sensibilidade do RE PCH............... 101

Tabela 32 - Parâmetros financeiros de referência: lâmpada fluorescente ....................................... 103

Tabela 33 - Parâmetros tecnológicos, comportamentais e CCVA: lâmpada fluorescente .................. 103

Tabela 34 - Parâmetros financeiros de referência: Coletor Solar................................................. 103

Tabela 35 - Parâmetros tecnológicos e comportamentais e CCVA: Coletor Solar ........................... 104

Tabela 36 - Figuras de mérito e ptos notáveis da análise de sensibilidade: lâmpada fluorescente... 104

Tabela 37 - Figuras de mérito e pontos notáveis da análise de sensibilidade: Coletores Solares .... 105

Tabela 38 - Pesos atribuídos às FMs de geração para cálculo da recomendação ............................ 112

Tabela 39 - Pesos atribuídos às FMs de medidas de economia para cálculo da recomendação ..... 113

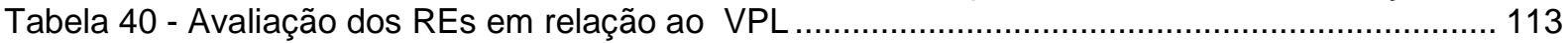

Tabela 41 - Avaliação dos REs em relação ao preço de venda de equilíbrio ................................... 114

Tabela 42 - Avaliação dos REs em relação ao dif. (TIR - CAPM) ……....................................... 114

Tabela 43 - Avaliação dos REs em relação ao PBD.................................................................. 115

Tabela 44 - Avaliação dos $\mathrm{RE}$ em relação à demanda relevante de capital de giro ........................... 115

Tabela 45 - Avaliação dos REs em relação aos riscos gerais ...................................................... 116

Tabela 46 - Resultados parciais da atratividade dos REs Geração .............................................. 116

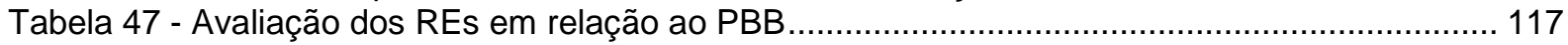

Tabela 48 - Avaliação dos REs em relação ao CCVA ............................................................. 117

Tabela 49 - Avaliação dos REs em relação aos riscos gerais ............................................................. 117

Tabela 50 - Resultados parciais da atratividade dos REs: Medidas de economia........................... 118

Tabela 51 - Resultado final do diagnóstico de avaliação dos REs ..................................................118

Tabela 52 - Modelo de fluxo de caixa para avaliação dos REs de geração ................................... 131

Tabela 53 - Leilões de energia no ACR desde 2005 (exceto leilões de ajuste) .................................... 142

Tabela 54 - Limitação do repasse de energia de leilão do ACR às Distribuidoras............................ 143

Tabela 55 - Energia elétrica - Valor anual de Referência (VR) ..................................................... 143

Tabela 56 - Resumo do levantamento dos locais com potencial hídrico na RAA ............................ 153

Tabela 57 - Parâmetros de referência para os fluxos de caixa dos REs de Geração......................... 154 


\section{LISTA DE GRÁFICOS}

Gráfico 1 - Quantidades de contratos bilaterais negociados no ACL $(2006 / 08)$.................................. 39

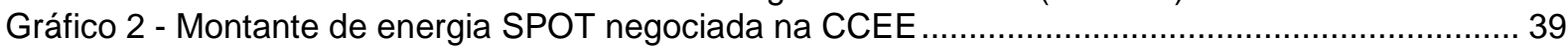

Gráfico 3 - Evolução do número de consumidores Livres/especiais no Brasil ...................................... 42

Gráfico 4 - Preço médio mensal do PLD para o submercado SE.................................................... 56

Gráfico 5 - Velocidade $x$ frequência do vento na RAA a $30 \mathrm{~m}$ do solo ........................................... 75

Gráfico 6 - Previsão das safras de cana de açúcar na RAA ............................................................ 83

Gráfico 7 - Preços do R\$/MWh por tipo de Leilão do ACR ................................................................ 145 


\section{LISTA DE ABREVIAÇÕES}

ABRADEE Associação Brasileira dos Distribuidores de Energia Elétrica

ABRAGE Associação Brasileira das Empresas Geradoras de Energia Elétrica

ABRAGEF Associação Brasileira da Geração Flexível

ABRAGET Associação Brasileira das Geradoras Termelétrica

ACC Avaliação dos Custos Completos

ACL Ambiente de Comercialização Livre

ACR Ambiente de Comercialização Regulada

ANA Agencia Nacional das Águas

ANEEL Agencia Nacional de Energia Elétrica

APINE Associação Brasileira dos Produtores Independentes de Energia Elétrica

APMPE Associação Brasileira de Produtores de Energia Limpa

BIG Banco de Informações de Geração

BIO Biomassa (Geração)

BNDES Banco Nacional de Desenvolvimento Econômico e Social

CAPM Modelo de Precificação de Capitais (Capital Asset Pricing Model)

CCD Contrato de Conexão à Distribuição

CCEAR Contrato de Comercialização de Energia do Ambiente Regulado

CCEE Câmara de Compensação de Energia Elétrica

CCG Contrato de Constituição de Garantia

CCT Contrato de Conexão à Transmissão

CCVA Custo do Ciclo de Vida Anualizado

CCV Custo do Ciclo de Vida

CCVE Contrato de Compra e Venda de Energia

CEC Custo Econômico de Curto Prazo

CEPEL Centro de Pesquisa de Energia Elétrica

CER Contrato de Energia de Reserva

CGH Central Geradora Hidrelétrica

CGU Central Geradora Undi-Elétrica

CME Custo Médio de Expansão (energia)

CMO Custo Marginal de Operação 


\begin{tabular}{ll} 
CMSE & Comitê de Monitoramento do Setor Elétrico \\
COGEN & Associação da Indústria de Cogeração de Energia \\
CONUER & Contrato de Uso da Energia Elétrica \\
COP & Custo Variável de Operação \\
CPFL & Companhia Paulista de Força e Luz \\
CPST & Contrato de Prestação de Serviços de Transmissão \\
CTC & Centro de Tecnologia Canavieira \\
CUSD & Contrato de Uso do Sistema de Distribuição \\
CUST & Contrato de Uso do Sistema de Transmissão \\
D & Distribuição \\
DP & Densidade de Potência \\
DRE & Demonstrativo de Resultado Exercício \\
EIA/RIMA & Estudo de Impacto Ambiental / Relatório de Impacto Ambiental \\
EN-IN & Envolvidos e Interessados \\
EOL & Eólica (Geração) \\
EPC & Engineering Procurement Constrution \\
EPE & Empresa de Pesquisa Energética \\
EPUSP & Escola Politécnica da USP \\
FAPESP & Fundação de Amparo a Pesquisa do Estado de São Paulo \\
FC & Fator de capacidade \\
FCLE & Fluxo de Caixa Livre do Empreendimento \\
FM & Figura de Mérito \\
G & Geração \\
GD & Geração Distribuída \\
GEPEA & Grupo de Energia do Departamento de Engenharia de Energia e \\
IBAMA & Automação Elétricas da Escola Politécnica da Universidade de São Paulo \\
IBGE & Instituto Brasileiro do Meio Ambiente \\
IPCA & Índice de Preços ao Consumidor - Amplo \\
IRPJ & Imposto de Renda de Pessoa Jurídica \\
LI & Licença de Instalação \\
LO & Licença de Operação \\
LP & Licença Prévia \\
\hline
\end{tabular}




\begin{tabular}{ll} 
MAE & Mercado Atacadista de Energia \\
MCSD & Mecanismo de Compensação de Sobras e Déficits \\
MME & Ministério das Minas e Energia \\
O N S & Operador Nacional do Sistema \\
O\&M & Operação e Manutenção \\
OCDE & Organização para o Desenvolvimento Econômico \\
ONG & Organização Não Governamental \\
PAH & Processo Analítico Hierárquico \\
PBD & PayBack Descontado \\
PCH & Pequena Central Hidrelétrica \\
PDE & Plano Decenal de Energia \\
PIB & Produto Interno Bruto \\
PIR & Planejamento Integrado de Recursos (Energéticos) \\
PIR-USP & Planejamento Integrado de Recursos Energéticos em desenvolvimento no \\
PLD & GEPEA/EPUSP \\
PNE & Preço de Liquidação das Diferenças \\
PPA & Plano Nacional de Energia \\
PROCEL & Contrato de Compra de Energia (Power Purchasing Agreement) \\
PROINFA & Programa de Incentivo as Fontes Alternativas (de energia elétrica) \\
RAA & Região Administrativa de Araçatuba \\
RCB & Relação Custo Benefício \\
RE & Recurso Energético \\
RELD & Recursos Energéticos do Lado da Demanda \\
RELO & Recursos Energéticos do Lado da Oferta \\
RER & Recursos Energéticos Renováveis \\
RESEB & Reestruturação do Setor Elétrico Brasileiro \\
RTC & Relatório Técnico Científico \\
SIN & Sistema Interligado Nacional \\
SINPHA & Sistema de Informação de Posses de Eletrodomésticos e Hábitos de \\
SPC & Consumo \\
T & Sociedade de Propósito Específico (Special Purpose Company) \\
\hline
\end{tabular}




$\begin{array}{ll}\text { TIR } & \text { Taxa Interna de Retorno } \\ \text { TUSDg } & \text { Taxa de Uso do Sistema de Distribuição (gerador) } \\ \text { UFV } & \text { Usina Foto Voltaica } \\ \text { UGRHI } & \text { Unidade de Gerenciamento de Recursos Hídricos } \\ \text { UHE } & \text { Usina Hidrelétrica } \\ \text { ÚNICA } & \text { União Nacional da Indústria Canavieira } \\ \text { USP } & \text { Universidade de São Paulo } \\ \text { UTE } & \text { Usina Termo Elétrica } \\ \text { UTN } & \text { Usina Termo Nuclear } \\ \text { VPL } & \text { Valor Presente Líquido } \\ \text { VR } & \text { Valor de Referência }\end{array}$




\section{LISTA DE SÍMBOLOS}

$\begin{array}{ll}\text { A } & \text { Área } \\ \mathrm{g} & \text { Aceleração da Gravidade } \\ \mathrm{GW} & \text { Giga Watt ( } \times 10^{9} \text { Watts) } \\ \mathrm{GWh} & \text { Giga Watt }{ }^{*} \text { hora } \\ \mathrm{H}_{\mathrm{b}} & \text { Queda Bruta } \\ \mathrm{kg} & \text { kilogramas } \\ \mathrm{kW} & \text { kilowatt } \\ \mathrm{m} & \text { massa } \\ \mathrm{m}^{3} & \text { metros cúbicos } \\ \mathrm{MW} & \text { Mega Watt (x10 }{ }^{6} \text { Watts) } \\ \mathrm{MWh} & \text { Mega Watt }{ }^{*} \text { hora } \\ \mathrm{MWmed} & \text { MWh ano / } 8760 \\ \mathrm{P}_{0} & \text { Pressão Atmosférica } \\ \mathrm{Q} & \text { Vazão } \\ \mathrm{R}_{0} & \text { Constante específica do ar } \\ \mathrm{t} & \text { tempo } \\ \mathrm{T} & \text { Temperatura } \\ \mathrm{v} & \text { Velocidade } \\ \mathrm{W} & \text { Watt } \\ \mathrm{Z}_{1}-\mathrm{Z}_{2} & \text { Miferença de cotas } \\ \rho & \text { Massa específica do Ar } \\ \mathrm{N}_{0} & \end{array}$




\section{SUMÁRIO}

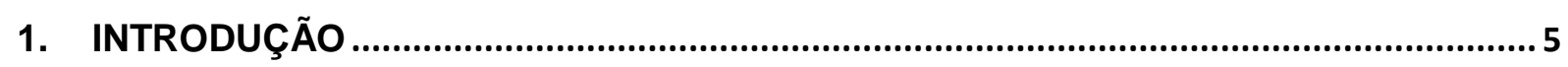

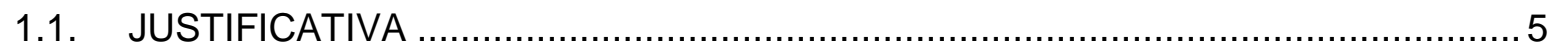

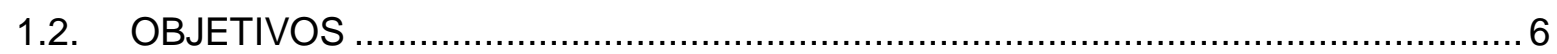

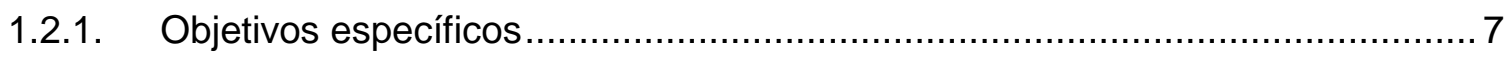

1.3. PONTOS DE VISTAS ESPECÍFICOS DO ESTUDO .................................... 9

1.3.1. PIR-USP para a RAA e a avaliação de oportunidades de negócios.................. 9

1.3.2. Atratividade das oportunidades com os REs avaliados................................ 10

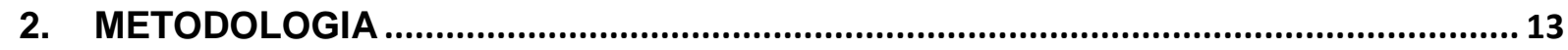

2.1 ESCOLHA DOS RECURSOS AVALIADOS ..................................................... 13

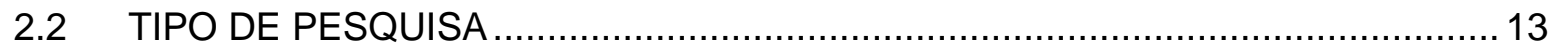

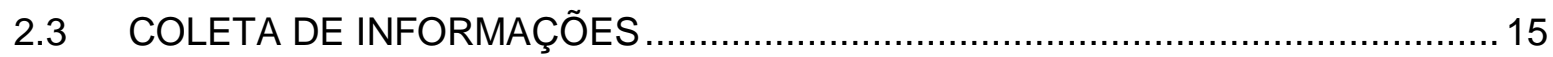

2.4 AMBIENTE DE NEGÓCIOS EM ENERGIA ELÉTRICA ................................... 16

2.5 PIR E A AVALIAÇÃO DE NEGÓCIOS ....................................................... 17

2.6 AVALIAÇÃO DA ATRATIVADE DE NEGÓCIOS E INVESTIMENTOS ..................19

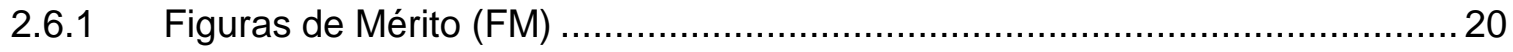

2.6.2 Avaliação de riscos em negócios e investimentos .......................................21

2.7. ALGORITMO PARA AVALIAÇÃO DA ATRATIVIDADE DOS RECURSOS ...........24

2.7.1 Etapa 1 - Escolher a(s) FM(s) para avaliar a atratividade do(s) RE(s) ............24

2.7.2 Etapa 2 - Definir escala para ponderar resultados das FMs dos REs .............24

2.7.3 Etapa 3 - Atribuir uma nota às FMs obtida dos REs...................................25

2.7.4 Etapa 4 - Ponderar a importância dada as FMs .......................................... 26

2.7.5 Etapa 5 - Calcular o resultado da avaliação dos REs ..................................27

2.7.6 Etapa 6 - Classificar os resultados da avaliação dos REs.............................28

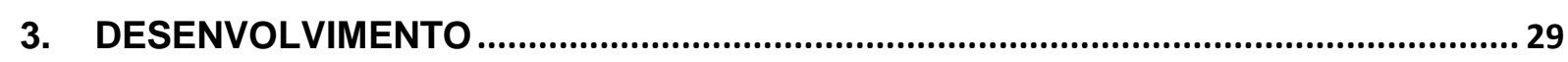

3.1 AMBIENTE DE NEGÓCIOS EM ENERGIA ELÉTRICA NO BRASIL ....................29

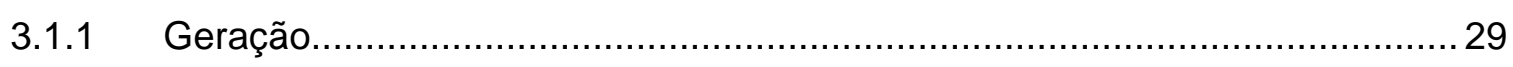

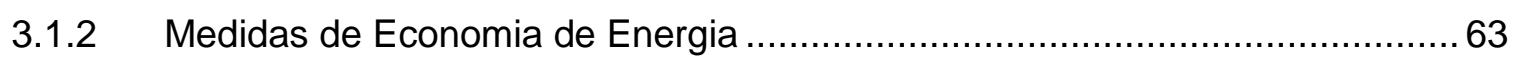

3.2 PIR-USP NA PRÉ-AVALIAÇÃO DE NEGÓCIOS EM ENERGIA NA RAA .............69

3.3 CARACTERIZAÇÃO DOS REs AVALIADOS NA RAA ....................................... 70

3.3.1 Escolha dos recursos para estudo de caso ................................................ 70

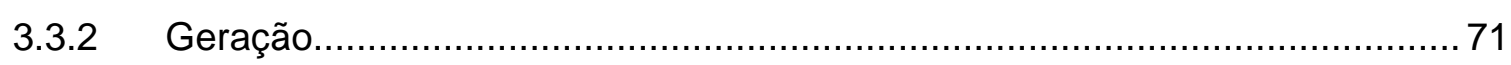

3.3.3 Medidas de economia de energia ....................................................... 87

3.3.4 Delimitação de escopo dos cenários dos estudos de casos ........................90 
4. RESULTADOS 95

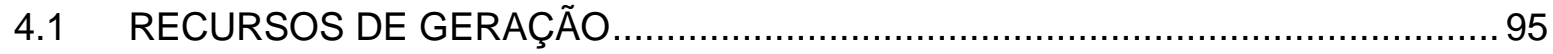

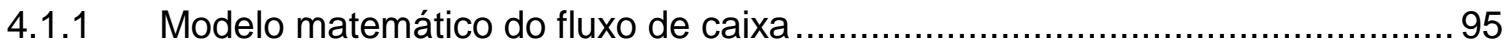

4.1.2 Parâmetros de referência de entrada .......................................................... 95

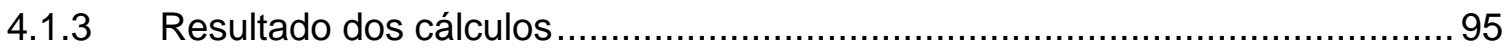

4.2 MEDIDAS DE ECONOMIA DE ENERGIA ELÉTRICA ..................................... 102

4.2.1 Modelo matemático do fluxo de caixa ......................................................... 102

4.2.2 Parâmetros de referência de entrada ......................................................... 102

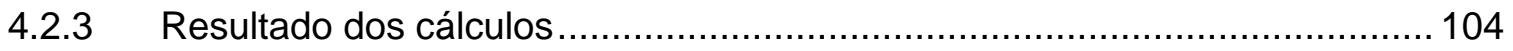

4.3 AVALIAÇÃO QUALITATIVA DE RISCOS .................................................. 106

4.3.1 Recursos de geração........................................................................ 106

4.3.2 Medidas de economia de energia .......................................................... 111

4.4 AVALIAÇÃO DA ATRATIVIDADE DOS 5 RECURSOS ANALISADOS.................112

4.4.1 Escala de importância atribuída às FMEs na avaliação dos REs...................112

4.4.2 Cálculo da atratividade dos recursos .......................................................... 113

4.5 RESULTADO FINAL DAS AVALIAÇÕES DE ATRATIVIDADE..........................118

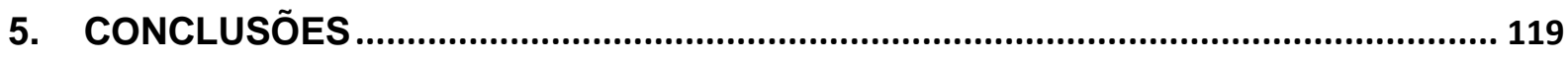

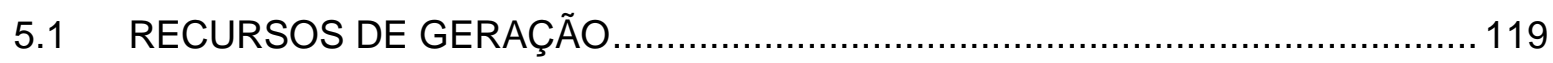

5.2 MEDIDAS DE ECONOMIA DE ENERGIA ELÉTICA....................................... 120

5.3 PIR-USP NA AVALIAÇÃO DA ATRATIVIDADE DE REs .................................. 121

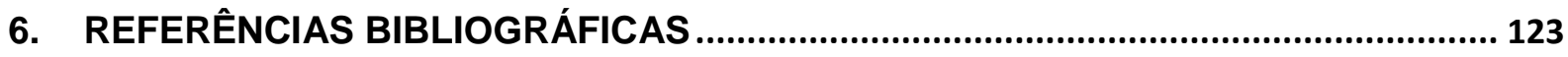

APÊNDICE A - Modelo de fluxo de caixa para recursos de geração ...................................... 131

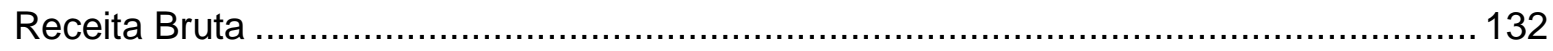

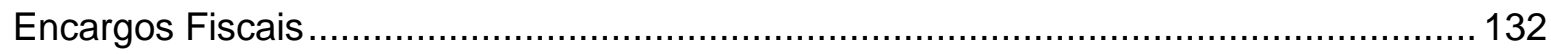

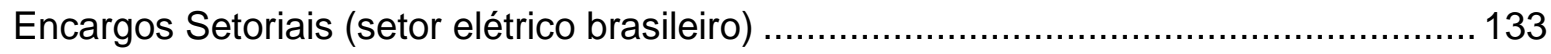

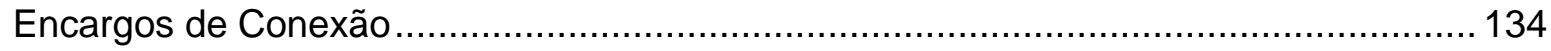

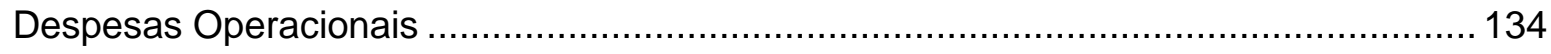

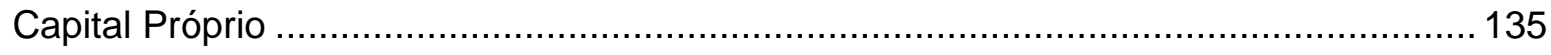

APÊNDICE B - A contratação de Energia no ACR ................................................................. 136

CCEAR - Contrato de Comercialização de Energia no Ambiente Regulado ................... 136

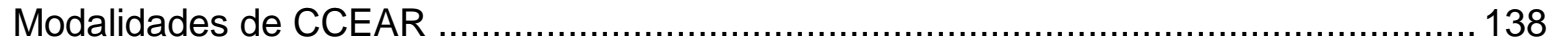

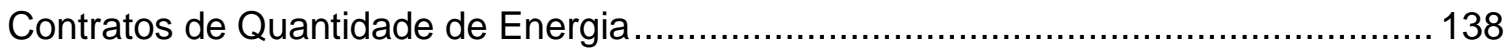

Contratos de Disponibilidade de Energia ........................................................ 138

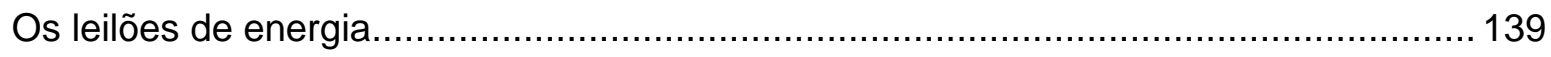

Restrições ao volume de contratação .............................................................. 142 
Energia de Reserva. 144

APÊNDICE C - Evolução dos preços médios da energia elétrica no ACR. 145

APÊNDICE D - Principais tópicos para estruturação de um negócio de Geração 146

Estruturação jurídica do Empreendimento. 146

Registro para Estudo e Projeto (ANEEL). 147

Obtenção da licença prévia (LP) no órgão ambiental .... 147

Caso da PCH: Prova de disponibilidade Hídrica (ANA e Agências Estaduais) ....... 147

Caso EOL: históricas das avaliações anemométricas 148

Estudo de conexão a rede... 148

Execução do estudo de viabilidade 149

Garantias de contratação da energia a ser gerada pelo empreendimento. 149

Estruturação financeira do Empreendimento (Estrutura de Capital) ............................. 150

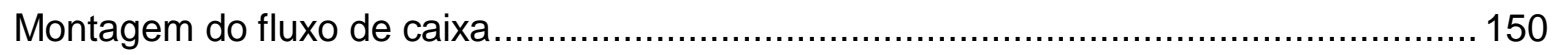

Determinação das figuras de mérito econômico e decisão dos acionistas ..................... 150

Obtenção da Autorização de Exploração (ANEEL) ................................................... 151

Obtenção da Licença de Instalação (LI) no Órgão Ambiental ...................................... 151

Contratação da construção do empreendimento .................................................... 151

Obtenção da licença de Operação (LO) junto ao(s) órgão(s) ambiental(is) .................... 152

APÊNDICE E - Principais Aproveitamentos hídricos da RAA................................................ 153

APÊNDICE F - Parâmetros dos fluxos de caixa dos modelos de geração.............................. 154

ANEXO A - Figuras de Mérito Econômico Financeiro .............................................................. 156

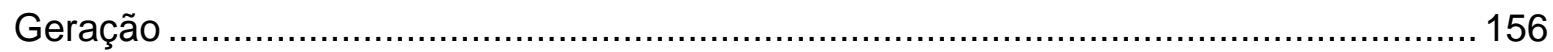

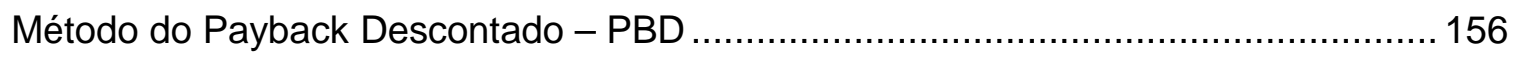

Método do Valor Presente Líquido - VPL ............................................................ 158

Método da Taxa Interna de Retorno - TIR ......................................................... 160

Método da Demanda relevante de capital de Giro .................................................. 161

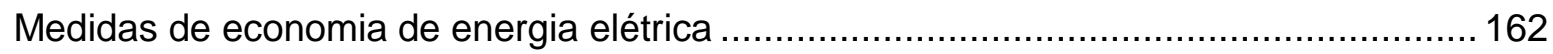

Custo de Ciclo de Vida (CCV) e Custo de Ciclo de Vida Anualizado (CCVA) .............. 162

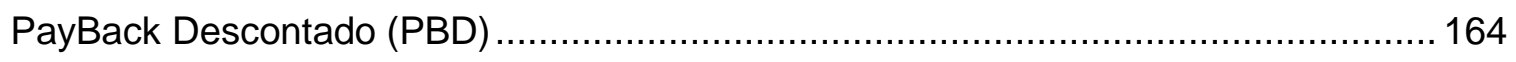

ANEXO B - Instituições e agentes do mercado elétrico brasileiro .......................................... 165

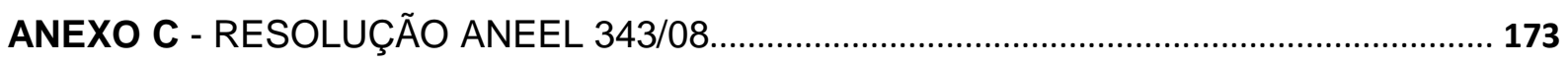

Registro para Elaboração do Projeto Básico ....................................................... 173

Garantias de Registro e Fiel Cumprimento.......................................................... 173

Aceite do projeto básico e seleção do interessado .......................................................... 174

Análise e aprovação do projeto básico ............................................................................. 174 
Outorga da autorização...

175

ANEXO D - Curva de desempenho turbina-gerador Wobben E82-E2.. 176 


\section{INTRODUÇÃO}

\subsection{JUSTIFICATIVA}

Na atual era pós-industrial, o acesso à água potável, a segurança alimentar e a segurança energética apresentam-se como o principal foco estratégico, e desafio, das nações em seus esforços contínuos para promover o progresso econômico e bem estar de seus cidadãos. Em relação à matriz energética, as estratégias adotadas passam, necessariamente, pela reavaliação da participação de cada recurso energético (aqui entendido como fonte primária associada à tecnologia utilizada para sua transformação em energia elétrica) da matriz energética, tendo em perspectiva, os seguintes aspectos: (i) o acesso, e ou posse, à fonte primária do recurso, na sua medida de autossuficiência e custo; (ii) o impacto desta fonte na geração de gases de efeito estufa (aquecimento global); (iii) o grau de poluição apresentado, ou percebido, pelos interessados e envolvidos decorrente da exploração da fonte; (iv) o nível de desenvolvimento local das tecnologias utilizadas para explorar as fontes primárias (autossuficiência tecnológica); (iv) a contribuição líquida, que a exploração do recurso, trás à sociedade e à economia, entendida como as oportunidades de emprego e lucro para o cidadão e empreendedor respectivamente, e, finalmente mas não menos importante, (v) os dividendos que a exploração do recurso trás à classe política (local, estadual e federal).

De uma forma resumida, pode-se dizer que a avaliação de um recurso energético passou a considerar, alem dos aspectos técnicos e econômicos, também aspectos ambientais, sociais e políticos, numa busca por iniciativas sustentáveis no tempo e no espaço.

As questões atuais que se apresentam em relação à exploração dos Recursos Energéticos Renováveis (RER) estão relacionadas com (i) o modelo de financiamento à exploração do recurso, em face da busca da modicidade do preço unitário da energia gerada, uma vez que a escala de exploração dos recursos renováveis, em geral, ainda não é suficiente para fazer frente a dos recursos energéticos de origem fóssil; (ii) o financiamento da pesquisa para o aprimoramento da tecnologia usada para a exploração dos recursos renováveis; e (iii) com as 
divergências entre os interessados e envolvidos na avaliação de impactos ambientais (externalidades), positivos e negativos, decorrentes da sua exploração.

No Brasil, assim como nos demais países do mundo, observa-se um interesse crescente em investimentos focados em RERs, pelas mesmas razões e divergências descritas acima. Constatou-se que a era dos recursos energéticos baratos, renováveis ou não, efetivamente acabou e, a fim de suprir as demandas crescentes de energia, torna-se mandatório incluir a avaliação das opções disponíveis de novas fontes renováveis de energia, de forma recorrente no tempo e no espaço.

O Brasil tem atualmente $82,3 \%$ de sua matriz energética de origem renovável (EPE, 2010), contra $16 \%$ da OCDE. Apenas a Noruega tem, em termos percentuais, uma matriz energética mais limpa que o Brasil. De acordo com a EPE, o Brasil irá demandar, medianamente, de $3 G W$ a $4 G W$ de potência adicional por ano nos próximos 20 anos, em um cenário conservador (EPE, 2009). Para suprir esta crescente demanda por energia elétrica, o Brasil, neste momento, já está enfrentando o dilema de poluir sua matriz elétrica (e por consequência, a matriz energética) com fontes primárias não renováveis (como, Óleo Cru, Diesel, gás natural ou, até mesmo, nuclear). Os maiores, e melhores, "aproveitamentos" hidráulicos (fonte primária dominante na matriz elétrica brasileira) já foram desenvolvidos, e os remanescentes localizam-se na região Amazônica, implicando em todos os tipos de impactos, riscos, desafios e interesses conflitantes associados a sua exploração (EPE, 2010).

Assim, a busca por novas fontes renováveis, e sustentáveis, de recursos energéticos no Brasil justifica-se por si.

\subsection{OBJETIVOS}

Este estudo objetiva apresentar uma metodologia que auxilie pesquisadores, empreendedores e formuladores de políticas públicas na avaliação expedita da atratividade das oportunidades de negócios com energia elétrica, oriundas de cinco diferentes recursos energéticos classificados como renováveis. A metodologia considera sua aplicação em uma região geográfica definida: Região Administrativa de Araçatuba (RAA), que compreende Araçatuba mais 42 municípios do nordeste do estado de São Paulo, Brasil. 
Foram os seguintes os critérios de escolha dos RERs para estudo: (i) ser um RER; (ii) preferencialmente estar relacionado em programas e/ou políticas governamentais de incentivo ao uso e ou exploração; e (iii) ter indicação prévia de potencial explorável dentro da região (baseado no inventário prévio feito na RAA) (UDAETA, 2009g).

De acordo com os critérios acima, recortou-se 5 (cinco) recursos específicos, pela impossibilidade técnica (e limitação de espaço e escopo) em se pesquisar todas as possibilidades, num cenário que se considerasse todos os recursos renováveis da região (todas as combinações possíveis de fonte primária, com tecnologias potencialmente viáveis economicamente), porém, sem perda da generalidade.

Os recursos escolhidos para avaliação foram: (i) pelo lado da oferta: Geração Eólica (EOL); Cogeração por biomassa de cana de açúcar (BIO); e geração hídrica através de Pequenas Centrais Hidrelétricas ( $\mathrm{PCH}$ ); (ii) pelo lado da demanda (medidas de economia de energia): Troca de Lâmpadas incandescentes por fluorescentes Compactas e Troca de Chuveiros Elétricos por Aquecedores solar de Água para banhos humanos dentro das regiões metropolitanas da RAA.

\subsubsection{Objetivos específicos}

Objetiva-se, com esta dissertação, produzir elementos que agilizem as ações de investidores na detecção de oportunidades locais (geração, e medidas de economia de energia elétrica), e ou, no aprofundamento das ações para o seu desenvolvimento, facilitando-os em suas decisões de negócios.

Também, há a intenção de subsidiar os formuladores de políticas públicas na identificação de sinais econômicos que, convenientemente tratados durante a formulação das políticas públicas, possam favorecer a exploração dos recursos energéticos renováveis da região em estudo.

Por último, pretende-se fornecer modelos simplificados, porém robustos, de avaliação econômico-financeira dos recursos de geração avaliados, para que pesquisadores em recursos energéticos, que não tenham fluência em aspectos econômico-financeiros, tenham facilitadas as conduções de suas pesquisas 
quantitativas, ou qualitativas, bastando "adequar" os modelos oferecidos às características de cenário da pesquisa em curso.

De forma resumida, apresentam-se abaixo os principais objetivos específicos a serem atingidos:

- Desenvolver, e popular, modelos de fluxo de Caixa, e ou, Demonstrativo de Resultados de Exercício (DRE), para cenário econômico-financeiro (destacando as respectivas variáveis de referência ${ }^{4}$ de entrada, utilizadas para popular 0 modelo) de cada recurso energético avaliado neste estudo:

- Previsão e determinação dos custos com a aquisição e instalação das tecnologias utilizadas para geração ou economia de energia:

- Custos com O\&M da tecnologia;

- Custos com fontes primárias de energia para geração de energia elétrica (combustível), quando aplicável;

- Rendimento da tecnologia associada à fonte primária de energia.

- Impostos e taxas do setor aplicáveis à exploração do recurso energético;

- Impostos e taxa gerais;

- Receita com a venda de energia;

- Previsão e determinação dos custos chamados "locacionais" (no caso, específicos para a RAA) nos fluxos de caixa/DREs que representam os recursos analisados:

- Impostos;

- Taxas específicas (transmissão e distribuição);

- Energia elétrica

- Geração: referenciais para precificação da energia a ser comercializada;

- Medida de economia: tarifas para consumidor residencial local.

- Calcular as principais figuras de mérito econômico-financeiro (numa análise determinística), para cada um dos fluxos de caixa representativos dos recursos

\footnotetext{
${ }^{4}$ Variáveis independentes de entrada do fluxo de caixa representativo do recurso energético
} 
energéticos avaliados: Valor presente líquido (VPL), Taxa Interna de Retorno (TIR) e PayBack Descontado (PBD), Custo do Ciclo de Vida anualizado (CCVA), e demanda expressiva de Capital de Giro, todas discutidas no anexo A;

- Calcular o preço de equilíbrio dos recursos de geração avaliados ${ }^{5}$., no contexto das variáveis de referência de entrada adotadas nos modelos;

- Comparar as figuras de mérito obtidas dos fluxos de caixa (resultados determinísticos), obtidas depois de "populados" os dos parâmetros de referência nos DREs, versus níveis das figuras de mérito, consideradas como referência pelo mercado (pesquisa bibliográfica primária), para cada recurso energético avaliado;

- Analisar a sensibilidade dos parâmetros de referência de entrada (variáveis independentes) em relação às figuras de mérito geradas pelos modelos de fluxo de caixa proposto;

- Analisar qualitativamente, os principais riscos associados às oportunidades de geração e medidas de economia, relevantes para os planos de negócios. Esta análise geral de riscos é feita com base (i) nos resultados do PIR da RAA feito pelo GEPEA USP; (ii) pesquisa bibliográfica secundária e (iii) análise e sensibilidade nos resultados das figuras de mérito econômico financeiro, calculadas para cada recurso estudado.

\subsection{PONTOS DE VISTAS ESPECÍFICOS DO ESTUDO}

\subsubsection{PIR-USP para a RAA e a avaliação de oportunidades de negócios}

O objetivo do PIR é maximizar a contribuição de um conjunto de Recursos Energéticos em favor do desenvolvimento social e ambiental de forma sustentável, num período de tempo específico e numa região definida (UDAETA,1997)

Já as avaliações de negócios objetivam localizar oportunidades de negócio que produzam lucro, se possível no menor espaço de tempo possível e com menor risco (GITMAN, 1997).

\footnotetext{
${ }^{5}$ Preço que torna o VPL da oportunidade de geração igual a zero, nos modelos matemáticos representativos do recurso.
} 
Assim, o ponto de vista preponderante deste estudo é o econômicofinanceiro, em que as dimensões ambiental, social e política são consideradas na medida exata de seus impactos, riscos, na lucratividade da oportunidade associado com o recurso avaliado.

Neste contexto, o PIR-USP para RAA foi usado com o objetivo de: (i) proporcionar informações para uma rápida convergência na escolha de uma lista de recursos energéticos; (ii) localizar possíveis pontos de atenção e riscos, e suas ponderações em relação à lucratividade versus sustentabilidade socioambiental dos recursos escolhidos; e (ii) servir de balizador primário para avaliação dos potenciais realizáveis ${ }^{6}$ de cada recurso avaliado.

Conclusivamente, o estudo apresentado nesta dissertação fez uso da metodologia desenvolvida pelo PIR-USP com vistas a: (i) quantificar a o grau de aceitação dos recursos pela sociedade local, (ii) avaliar a existência de riscos ocultos na dimensões ambiental, social e política, e (iii) se referenciar ao potencial explorável na região de estudo.

\subsubsection{Atratividade das oportunidades com os REs avaliados}

\subsubsection{Geração}

O ponto de vista adotado para avaliar a atratividade dos negócios em geração foi exclusivamente do investidor, e não o ponto de vista do empreendimento em si ou da sociedade que o circunda. Esse ponto de vista é refletido nos modelos de fluxo de caixa e DRE, desenvolvidos para os recursos de oferta. O que deve ser aclarado, para os propósitos deste estudo, é que as avaliações de atratividade das oportunidades de geração são feitas individualmente, ou seja, não se objetivou determinar qual o mais atrativo dos três recursos de geração para se investir no melhor.

\footnotetext{
${ }^{6}$ Potencial de exploração da fonte primária de energia relacionada que junto com a tecnologia escolhida para explorá-la, determina o potencial realizável do referido recurso, porém, ainda pendente de cálculo do potencial comercial (comercialmente realizável).
} 
A metodologia propõe-se a estabelecer uma graduação de atratividade para investimento dos recursos analisados, fazendo uso do conjunto de figuras de mérito econômico-financeiro calculadas de cada recurso de geração, mais a avaliação global de riscos associados à decisão de explorá-los, tendo como base cenários e referenciais aceitos pelo mercado.

Finalmente, em relação à estratégia de comercialização de energia elétrica gerada, e segundo os cenários desenhados para os três recursos escolhidos, ressalta-se que o ponto de vista deste trabalho é o da comercialização de energia classificada como distribuída, que define que o produtor e o consumidor estão, necessariamente, dentro da área de concessão da distribuidora local de energia. Este ponto de vista, restrito à definição de Geração Distribuída, tem como consequência (benefício) não considerar custos com a Transmissão da energia elétrica a longa distância, vantagem exclusiva de quem gera energia dentro da região de concessão da distribuidora local. De outra maneira, os modelos matemáticos consideram apenas custos com distribuição de energia elétrica, relacionados à distribuidora local, onde ambos, gerador e consumidor, estão localizados.

\subsubsection{Medidas de economia de energia}

O ponto de vista adotado para avaliar a atratividade dos negócios em medidas de economia de energia é o do usuário final, enquanto família morando nas regiões urbanas da Região Administrativa de Araçatuba e consumindo energia elétrica na tarifa residencial. Em outras palavras, o ponto de vista é o do usuário que adquire, e instala uma tecnologia, pressupostamente mais econômica (eficiente) em termos de gastos com energia, em detrimento a uma tecnologia menos econômica (tradicional), visando uma economia de energia que justifique financeiramente 0 investimento adicional feito nessa troca.

As recomendações, avaliações, em relação às medidas de economia serão relacionadas com a medida em si (que considera de forma indissociável, tecnologia tradicional sendo preterida por tecnologia mais eficiente). Assim dizer que uma medida de economia é atrativa significa dizer que a escolha é atrativa. 


\subsubsection{Cogeração com Biomassa de Cana-de-açúcar (BIO)}

$\mathrm{Na}$ avaliação deste recurso de oferta, considera-se que a biomassa de canade-açúcar (o combustível usado por este recurso de geração) é um subproduto natural (by-product) de um empreendimento - A USINA - já estabelecido e produzindo açúcar, álcool ou ambos. Este ponto de vista é importante porque permite avaliar isoladamente o impacto da cogeração para produção de excedente comercializável de energia (nas dimensões técnico-econômica, ambiental, social e política) como um item isolado em termos de riscos, e também como motivador para investimento. Assim, os impactos e riscos de se decidir pela construção da usina, pela plantação da cana para abastecê-la, e riscos ambientais decorrentes do processo de manejo da cana durante seu cultivo, e descartes da produção de açúcar e álcool são afetos exclusivamente a usina, e não ao processo de cogeração para produção de excedentes de energia elétrica e vapor. 


\section{METODOLOGIA}

\subsection{ESCOLHA DOS RECURSOS AVALIADOS}

Considerando os propósitos deste estudo - avaliação de oportunidade de negócios em energia - e com a flexibilidade permitida pela metodologia PIR, os seguintes critérios foram adotados para a escolha dos recursos energéticos préavaliados para decisão de investimento: (i) Ser um recurso energético renovável ${ }^{7}$; (ii) preferencialmente, estar relacionado em políticas públicas e/ou de incentivo governamentais à sua exploração ou uso; (iii) A seleção do recurso deve ser apoio na vocação ${ }^{8}$ da região geográfica em estudo para exploração do recurso (com ênfase ao seu potencial teórico ${ }^{9}$ e ou realizável ${ }^{10}$ circunscrito); (iv) estar dentro do ranking ACC de recursos, desenvolvidos para o PIR-USP para RAA, o que facilitou a coleta de informações nas quatro dimensões da avaliação, considerando a granulação regional (RAA); (v) considerar recursos que incluam recursos de Oferta (geração) e recursos de Demanda (medidas de economia de energia elétrica), o que permite caracterizar a metodologia proposta para avaliar ambos os tipos de recursos; (vi) que tenham tecnologias maduras associadas a sua exploração no curto prazo, indicando histórico, e referenciais (nível de maturidade da rota tecnológica escolhida para explorar a fonte do recurso e fomento ${ }^{11}$ governamental para sua exploração), de investimento para os "stakeholders ${ }^{12 " ;}$

\section{$2.2 \quad$ TIPO DE PESQUISA}

\footnotetext{
${ }^{7}$ Recursos provenientes de fonte primária de energia que sejam renováveis: aproveitamento de cursos de água, biomassa, ventos e raios solares etc., além de medidas de eficiência economia de energia.

${ }^{8}$ Características naturais, geográficas, históricas ou sociais de uma região que fornecem vantagem competitiva à decisão de investimento em determinado $\mathrm{RE}$, circunscrito à região.

${ }^{9}$ Potencial máximo de conversão de energia de uma fonte primária de energia em energia elétrica / secundária

${ }^{10}$ Potencial máximo de conversão de energia da fonte primária de energia em energia secundária / elétrica), para uma dada tecnologia adotada na conversão.

${ }_{11}$ Indicação de exploração nos planos plurianuais do governo PDE 2021 e PNE 2030.

${ }^{12}$ Interessados e envolvidos em investimentos em recursos energéticos renováveis.
} 
Neste tópico, procura-se delinear o processo sistemático de construção do conhecimento que será aplicado neste estudo, sempre buscado qualificá-lo e/ou classificá-lo:

- Pesquisa aplicada, na medida em que objetiva gerar conhecimento para aplicação prática dirigida à solução de problemas específicos, envolvendo interesses locais.

- Pesquisa com uma abordagem predominantemente quantitativa, na medida em que, sempre que possível, traduz em números, e graduações, opiniões e informações para classificá-las e analisá-las. Assim como faz uso de recursos e técnicas matemáticas para produção de resultados. Entretanto faz uso de avaliações qualitativas, em momentos que não foi possível as quantificações, e ou monetização, de aspectos afetos ao tema.

- Nos seus objetivos, a pesquisa é exploratória, pois visa propiciar maior familiaridade com temas e problemas com vistas a torná-los explícitos, assim como envolverá levantamentos bibliográficos, assumindo a forma de pesquisa bibliográfica e estudo de caso.

- Do ponto de vista de procedimentos técnicos a pesquisa tem elementos de uma pesquisa bibliográfica, com estudo de caso: (i) elaborada a partir de material já publicado, constituído principalmente de livros, artigos de periódicos, teses, dissertações e material disponibilizado em sites da internet; (ii) aprofundando-se em alguns poucos pontos, visando um amplo conhecimento dos mesmos.

- A pesquisa tem como palco a oferta e demanda de energia elétrica no contexto do Brasil, particularizando-se no estudo de caso para a RAA. 


\subsection{COLETA DE INFORMAÇÕES}

Neste tópico qualificam-se e classificam-se as bases, e os processos de coleta, de dados acessadas durante a produção da dissertação:

- Bases de dados primárias: Artigos em revistas especializadas, sites de internet de consultorias especializadas, autarquias governamentais, conversas telefônicas e reuniões com interessados e envolvidos no tema etc:

- Coleta de dados sobre parâmetros referenciais de investimentos (planejados e em curso) em recursos energéticos junto a atores locais, nacionais e internacionais (empreendedores, fornecedores de tecnologia e serviços, governos, órgãos públicos, associação de classe e ONGs), sempre objetivando montar cenários de avaliação e planejamento de negócios com parâmetros técnico-econômicos mais realísticos possível: empreendedores, comercializadoras de energia elétrica, fornecedores de tecnologia, produtos, serviços, concessionárias locais de distribuição, MME, ANEEL, EPE, CCEE, Secretaria Estadual de Desenvolvimento do Estado de São Paulo: investimentos iniciais, custos de operação e manutenção, tecnologias adotadas para conversão de energia primária em secundária (energia elétrica), fator de capacidade etc.

- Parâmetros tecnológicos atualizados (investimentos, custos de Operação \& Manutenção de empreendimentos, estado da arte das variáveis tecnológicas versus praticado nos empreendimentos), obtidos e utilizados nos desenvolvimentos dos estudos prévios do PIR, atualizando-os quando necessário.

- Junto a bases de dados secundárias: teses, dissertações, livros técnicos e livros de referência, com ênfase aos relatórios técnicos integrantes do processo FAPESP ํo 03/064441-7 (UDAETA, 2010) 
Com este conjunto de ações para coleta de dados, dentro de uma metodologia racional-comparativa, buscou-se atingir o objetivo de garantir que o projeto esteja utilizando dados atualizados, de cenários realísticos, plenamente justificáveis e alinhados às praticas no segmento de energia e políticas governamentais para o segmento, pretendendo-se produzir modelos, procedimentos e análises atuais e coerentes.

\subsection{AMBIENTE DE NEGÓCIOS EM ENERGIA ELÉTRICA}

Neste tópico apresenta-se uma seleção com algumas das principais leis (marco legal) relacionadas com a geração distribuída e medidas de economia de energia no Brasil (A legislação detalhada pode ser verificada nas referências bibliográficas):

- A Lei no 10.848 de 15/03/2004 (BRASIL, 2004) e o Decreto no 5.163, de 30/07/2004 (BRASIL, 2004), dispõe sobre o ambiente de comercialização de energia elétrica no Brasil, dividindo o mercado em dois ambientes distintos de comercialização de energia elétrica: ACR - Ambiente de Comercialização Regulado pelo governo, com regras transparentes e preços de energia definido em leilões; e o $\mathrm{ACL}$ - Ambiente de Comercialização Livre, onde a energia elétrica é comercializada com preços e condições totalmente livres, definidos entre as partes, e onde existe uma entidade gestora que garante que a energia vendida, será entregue.

- A Resolução normativa ANEEL № 390, de 15 de dezembro de 2009 (ANEEL, 2009) estabelece os requisitos necessários à outorga de autorização para exploração da capacidade instalada de usinas termelétricas, e de outras fontes alternativas de energia, os procedimentos para registro de centrais geradoras com capacidade instalada reduzida e dá outras providências.

- A Resolução normativa ANEEL № 343, de 9 de dezembro de 2008 (ANEEL, 2008) estabelece procedimentos para registro, elaboração, análise, aceite, seleção e aprovação de projetos básicos e para autorização de aproveitamento de potencial de energia hidráulica com características de Pequena Central Hidrelétrica. 
- Portaria Interministerial 1.877 de 30.12 .1985 (BRASIL, 1985) institui o programa nacional de conservação de energia elétrica.

Um maior aprofundamento sobre instituições e agentes do mercado de energia pode ser obtido no anexo $B$ e nas referências bibliográficas.

\subsection{PIR E A AVALIAÇÃO DE NEGÓCIOS}

Segundo Reis e Mielnick (REIS, MIELNICK, 1999):

"O PIR é operacionalizado a partir da harmonização de duas concepções: (i) a visão empresarial, que pretende a realização de lucro, considerando o papel das atribuições do investidor e (ii) a visão institucional, com ênfase na defesa dos interesses coletivos e na atuação dos agentes reguladores dos serviços de infraestrutura."

Entende-se os interesses coletivos como a preocupação com a qualidade da oferta de serviços energéticos oferecidos, a busca da modicidade tarifária, a garantia de sustentabilidade ambiental (medida pelo nível de demanda / degradação / recuperação do meio ambiente e seus serviços - água, ar, solo decorrentes das atividades antropomórficas.), o interesse social (empregos gerados e impactos na saúde publica) e com o interesse político, medido pelo fluxo financeiro \& impostos gerados dentro das fronteiras de uma determinada região.

Segundo Gimenes (GIMENES 2004), o PIR age para tornar investimentos em recursos energéticos viáveis do ponto de vista econômico, social, ambiental, político e tecnológico em projetos que, isoladamente seriam inviáveis em algumas destas vertentes:

"Para a análise de viabilidade e riscos, o investidor dispõe dos mais diversos e modernos métodos, tais como Opções Reais, Simulações Multiagentes, Teoria de Jogos entre diversos outros. Estas metodologias encontram-se plenamente desenvolvidas e contam com ferramentas computacionais comerciais de ampla aplicação. No entanto, este tipo de análise é mais afeito à tomada de decisão segundo parâmetros de mercado e de características específicas do perfil de cada investidor: com apetite a riscos, conservador, com capacidade de alavancagem com recursos próprios, público, privado etc. Entende-se que esta etapa de análise é posterior ao planejamento de longo prazo, o qual deve, na visão aqui defendida, fornecer parâmetros que permitam ao investidor e tomadores de decisão identificar, de maneira prévia, 
as incertezas e fatores de riscos associados a opções de investimento em energia, sejam do ponto de vista tecnológico, sejam do político, social e ambiental entre outros. Como consequência, entende-se que o PIR permite que se possa fazer avaliação de carteira de recursos energéticos a priori, nas fases iniciais do desenvolvimento de planos de negócios, elencando riscos ainda no início, o que permite mitigá-los, economizando-se tempo e recursos financeiros.

(...) Dessa forma, o resultado de tal análise no processo de planejamento tem como objetivo fornecer um panorama completo dos recursos, além de seus custos econômicos, permitindo ao investidor, segundo a metodologia que melhor Ihe satisfaça, avaliar custos, benefícios e riscos associados a cada recurso, para aquela determinada localidade ou, dependendo do tipo de análise, buscar a localidade que melhor se adapte à sua opção de investimento."

Segundo Cicone (CICONE, 2008), as dificuldades em se avaliar recursos energéticos nas quatro dimensões do PIR (técnico-econômico, ambiental, social e política) residem nos obstáculos para se avaliar e comparar, quantitativamente, recursos de oferta e demanda em dimensões que normalmente os quesitos avaliados são de difícil quantificação ou monetarização, dificultando a indicação de políticas públicas que fomentem as iniciativas privadas de investimento. Essa dificuldade é tratada no PIR-USP pelo Processo Analítico Hierárquico (proposto por Saaty (SAATY, 1976) e adaptado pelo grupo do PIR-USP (CICONE, 2008):

"Dentro do PIR se faz necessária a comparação RELOs e RELDs de forma que seja gerado um ranking de sugestão de recursos, indo do mais indicado para o menos indicado. Usualmente essa tomada de decisão é realizada a luz dos dados econômicos e técnicos, porém, os impactos negativos e positivos da adoção dos recursos devem ser considerados de forma que a nota final reflita $o$ maior número de aspectos possíveis. Dentre estes aspectos estão os Ambientais, Sociais e Políticos. As maiores dificuldades de se considerar estes tipos de impactos são a subjetividade e dificuldade de precificação. A precificação acima citada, também conhecida como internalização ou monetarização, é a maneira usual de se tratar aspectos subjetivos nas tomadas de decisões, pois através dela todos os aspectos tornam-se diretamente comparáveis. Por outro lado, o próprio método de precificação utiliza diversas premissas subjetivas sendo que os valores quantitativos gerados podem ser diferentes para cada pessoa que fizer a precificação, dependendo das hipóteses assumidas. Por isso mesmo a utilização da precificação deve ser muito bem pensada e as hipóteses consideradas devem estar muito claras para aqueles que utilizarão essas informações." 


\subsection{AVALIAÇÃO DA ATRATIVADE DE NEGÓCIOS E INVESTIMENTOS}

O objetivo de um plano de negócio é gerar informações que permitam avaliações e tomada de decisões que maximizem o lucro para o empreendedor, ou seja, os planos de negócio e investimentos devem buscar oportunidades que tenham mais valor do que custam para serem executadas (LAPPONI, 2007).

De acordo com Gitman (GITMAN, 1997), todas as medidas de atratividade econômica, avaliações, recomendações, e decisões sobre investimentos devem ser vistas sobre a ótica do retorno esperado e do risco aceito, fazendo uso de técnicas que considerem o valor do dinheiro no tempo:

"A avaliação de uma oportunidade de negocio é o processo que une risco e retorno para determinar o valor de um ativo. É um processo relativamente simples que pode ser aplicado a um fluxo de caixa esperado de um empreendimento, para determinar seu valor em um dado instante no tempo. Para fazer isso, o avaliador deve usar técnicas de valor do dinheiro no tempo".

Assim, para avaliarmos atratividade de um negócio precisamos selecionar os critérios de avaliação, e executá-la segundo estes critérios.

Para os propósitos deste estudo, alguns parâmetros de saída dos modelos matemáticos desenvolvidos para avaliar os REs, chamados amplamente na dissertação de figuras de mérito (FM), foram escolhidos para caracterizar quantitativamente tantos os recursos de geração, quanto as medidas de economia de energia. $O$ conjunto de figuras de mérito escolhidas para cada um dos dois tipos de recursos (geração e medidas de economia de energia) é diferente porque a atratividade procurada na geração deve ser caracterizada pela medida do grau de dificuldade, e risco, de se gerar lucro com a geração de energia elétrica; enquanto que a atratividade das medidas de economia se caracteriza pelo grau de dificuldade, e risco, de se obter economia financeira, nas ações para economizar energia. 


\subsubsection{Figuras de Mérito (FM)}

\subsubsection{Geração}

As figuras de mérito escolhidas para avaliar os recursos de geração foram: PayBack Descontado (PBD), Valor Presente Líquido (VPL), Taxa interna de Retorno (TIR) e necessidade de investimento de capital de Giro. Estas figuras, suas definições e formulação matemática, podem ser vistas no Anexo A deste documento.

Para se obter as figuras de mérito econômico financeiro dos recursos de geração, antes se deve desenvolver o fluxo de caixa representativo deste recurso. Assim, é necessário: (i) projetar o volume de geração de energia elétrica e as receitas com sua venda; (ii) calcular os impostos pagos; (iii) calcular as taxas pagas; (iv) calcular os custos fixos e variáveis de toda natureza, incluindo custos com mão de obra, manutenções e combustível , caso requerido; (v) calcular a depreciação; e (vi) calcular o valor residual do ativo no final da vida útil.

Feito isto, deve-se popular o fluxo de caixa.

O fluxo de caixa de uma oportunidade é uma representação matemática de todas as movimentações financeiras previstas nos itens de (i) a (vi) (parágrafo acima), consolidadas e posicionadas nas datas em que ocorreram, durante a vida útil prevista para o empreendimento.

O modelo de fluxo de caixa dos recursos de geração desenvolvido para este trabalho pode ser visto no apêndice $A$.

O modelo é uma particularização do que se chama de Demonstrativo de Resultados de Exercícios, previsto em legislação ${ }^{13}$, e que visa determinar o lucro/prejuízo líquido durante os exercícios (anos) da vida útil do empreendimento, porém adaptado para geração de energia elétrica. Este fluxo de caixa possibilita calcular uma sequência de lucros, ou prejuízos, de um empreendimento durante intervalos de tempo regulares em que foi dividida a vida útil do recurso. Estes pares ordenados de informações (lucro/prejuízo; intervalo) são a base para o cálculo de

${ }^{13}$ Decreto Lei 3.000/99 
todas as figuras de mérito econômico dos recursos de geração, descrito no parágrafo anterior.

\subsubsection{Medidas de economia de energia elétrica}

As figuras de mérito escolhidas para avaliar as medidas de economia de energia são: Ciclo de Vida Anualizado (CCVA) e PayBack Descontando (PBD), e riscos associados à escolha da tecnologia mais eficiente. Da mesma forma, podem ser vistas no Anexo $A$.

A obtenção das figuras de mérito econômico financeiro das medidas de economia também podem ser obtida através do fluxo de caixa. Entretanto, para as medidas de economia, o modelo de fluxo de caixa é muito mais simples do que para os recursos de geração: simplesmente se posiciona em uma linha de tempo o investimento feito na aquisição da tecnologia, os gastos com energia elétrica decorrentes de sua utilização, mais eventuais gastos com manutenções previstas ao longo da vida útil.

\subsubsection{Avaliação de riscos em negócios e investimentos}

O risco em seu sentido fundamental pode ser definido como a possibilidade de prejuízo financeiro em uma decisão a ser tomada. As decisões que trazem grandes possibilidades de prejuízos são vistas como mais arriscadas que aquelas com menos possibilidade de prejuízo. Mais formalmente, o termo risco é usado alternativamente como incerteza do retorno do investimento feito (GITMAN, 1997).

Os riscos, para os propósitos desta dissertação, podem ser divididos em dois grandes grupos: riscos na fase pré-operacional e riscos na fase operacional.

A avaliação qualitativa global dos riscos pré-operacional e operacional de um determinado recurso, para os propósitos deste estudo, assumiu três possibilidades: negativa, neutra e positiva.

Nos subitens a seguir, apresentam-se os quesitos que deram suporte a avaliação qualitativa global de riscos de um dado recurso (geração e medida de economia) (HEIDEIER, 2009; UTURBEY, 2004). 


\subsubsection{Riscos na geração}

\subsection{Riscos na fase pré-operacional}

São os riscos envolvidos desde o momento da decisão da construção do empreendimento até o momento que se recebe a licença para operação.

Riscos de construção/aquisição: relacionados com a construção do acordo de construção do empreendimento (prazo, preço e qualidade) ou aquisição (preço, qualidade de conformação).

Riscos jurídicos: associados à constituição da sociedade para investir em uma oportunidade.

Riscos de seguros: no caso da geração, relacionados à percepção do agente de seguros em relação aos ativos, seu escopo e prêmio requerido, considerando a complexidade do que se pretende empreender.

Riscos ambientais: relacionado à correta avaliação econômico-financeira das implicações das medidas ambientais solicitadas pelos órgãos ambientais: contingências, impedimentos, natureza do projeto e localização.

Risco regulatório (político): relacionados ao setor de energia elétrica e evolução histórica da legislação, e seus impactos nos fluxos de caixa representativos do recurso.

\subsection{Riscos na fase operacional}

São os riscos envolvidos desde a autorização de operação até final da vida útil do empreendimento de geração. 
No caso das medidas de economia de energia, são os riscos durante a vida útil da tecnologia, de consumir mais energia que o previsto, e durar tempo inferior que o previsto.

Risco operacional: capacidade de gestão, custos de O\&M dentro do previsto, produtividade (energia gerada e medida versus planejada).

Risco de mercado: preço da energia, queda de demanda, concorrência de outras fontes e fatores setoriais.

Risco financeiro: relacionados à estabilidade do Fluxo de Caixa Livre para a Empresa (FCLE), e com eventual descasamento de índices de correção/atualização de receitas e despesas/custos.

\subsubsection{Risco com medidas de economia}

\subsection{Riscos pré-decisão ou pré-operacionais}

Os riscos de pré-decisão são relacionados com a modelagem da situação em que se irá avaliar a economia da solução proposta: hábitos de consumo dos dispositivos de uso final (tempo, ou nível, de uso) e o cálculo incorreto da quantidade de dispositivos, com tecnologia eficiente, equivalentes para garantir o mesmo nível de serviço para ambas as tecnologias, mais eficiente e tradicional.

\subsection{Riscos pós-decisão ou operacionais}

São os riscos relacionados com a qualidade de conformação dos dispositivos de uso final: consumo de energia (planejado e verificado), vida útil (prevista e verificada) e custos associados à assistência pós venda (previsto e verificado. 


\subsection{ALGORITMO PARA AVALIAÇÃO DA ATRATIVIDADE DOS RECURSOS}

Para os propósitos deste estudo, não se pretende escolher o(s) melhor(es), ou mesmo ranquear a lista de recursos energético avaliados, mas sim diagnosticar a atratividade econômico-financeira de cada um dos recursos estudados.

O diagnóstico final da atratividade foi baseado em um algoritmo, descrito a seguir nos itens 2.7.1 a 2.7.6, que envolveu todas as figuras de mérito econômicofinanceiro, calculadas para cada um dos cinco recursos avaliados, mais o risco global de se empreender ${ }^{14}$ cada recurso avaliado. Neste contexto, para todos os efeitos, a avaliação de risco global de cada recurso converteu-se em mais uma figura de mérito, usada na avaliação de atratividade do recurso.

Para os propósitos deste estudo, os seguintes diagnósticos de atratividade foram utilizados para expressar a atratividade de um recurso avaliado: (i) não atrativo; (ii) atrativo com atenção; e (iii) atrativo.

Para avaliar cada recurso energético, o seguinte algoritmo foi utilizado:

\subsubsection{Etapa 1 - Escolher a(s) FM(s) para avaliar a atratividade do(s) RE(s)}

$\mathrm{O}$ avaliador escolhe convenientemente, $\mathrm{k}$ figuras de mérito $(\mathrm{FM})$ que serão usadas na avaliação dos i Recursos (R): Figuras de mérito $F M_{k}$, para avaliar o Recurso $\mathrm{R}_{\mathrm{i}}$

Por decisão metodológica, uma das figuras de mérito a ser usada para determinar a atratividade de um determinado recurso energético $R_{i}$ é a quantificação da avaliação dos riscos associados em empreender o referido recurso.

\subsubsection{Etapa 2 - Definir escala para ponderar resultados das FMs dos REs}

- Para cada Figura de Mérito (FM) o avaliador define um range de g intervalos $\left(\mathrm{IC}_{\mathrm{g}}\right.$ ), não necessariamente do mesmo tamanho (definindo também se os extremos pertencem ao intervalo ou não), nos quais o resultado da $F M_{k}$, obtida do $\mathrm{R}_{\mathrm{i}}$, deverá ser classificada (Figura 1).

\footnotetext{
${ }^{14}$ Decisão de investir em geração ou comprar a tecnologia mais eficiente para economizar energia.
} 
- Para cada intervalo $I_{g}, 0$ avaliador deve atribuir uma nota $N_{g}$, de zero a dez (normalização, com base 10): onde 10 indica a maior relevância do resultado da $\mathrm{FM}_{\mathrm{k}}$ para atratividade do $\mathrm{R}_{\mathrm{i}}$, e zero o oposto.

- Uma a uma, verifica-se em qual $I_{g}$ localiza-se a FM calculada do $R_{i}$.

- A relação de intervalos $\mathrm{IC}_{g} \leftrightarrow F M_{k}$, por construção, é do tipo Injetora, ou seja, obtida uma $F M_{k}$ de um $R_{i}$, ela se "encaixa" em um único $I_{g}$;

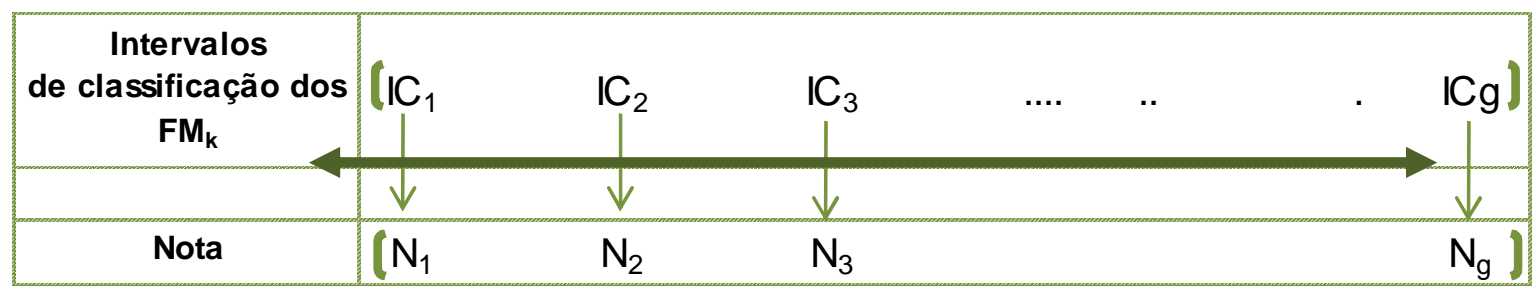

Figura 1 - Construção da escala para avaliação das figuras de mérito dos REs Fonte: elaboração própria

\subsubsection{Etapa 3 - Atribuir uma nota às FMs obtida dos REs}

Constrói-se a matriz $A=a_{i g}$, onde $i$ é igual ao número de recursos $(R)$, do mesmo tipo (de geração, ou de medida de economia), avaliados, e g é o número de intervalos usados para classificar a FM escolhida para avaliar os referidos recursos (Figura 2):

- Se a $F M_{k}$ do Recursos $R_{i}$ está no intervalo $I_{g}$, então $a_{i g}=1$.

- Senão: $a_{i g}=0$.

Obtém-se a nota que cada figura de mérito $F M_{k}$ recebeu no passo 3 , através da operação abaixo, descrita na Figura 2, a seguir:

$$
M_{R_{i}}^{F M_{k}}=\sum_{g=1}^{g} a_{i g} * N_{g}
$$

Onde: 
- $M_{R_{i}}^{F M_{k}}=$ Nota dada à figura de mérito $F M_{\mathrm{k}}$, calculada do Recurso $\mathrm{R}_{\mathrm{i}}$;

- $a_{i g}=$ Número índice da matriz A, com domínio 0 ou 1;

- $\mathrm{i}$ = quantidades de recursos avaliados simultaneamente;

- $\mathrm{g}$ = número de intervalos da escala usada para avaliar $\mathrm{FM}_{\mathrm{k}}$, definido pelo avaliador;

$\mathrm{N}_{\mathrm{g}}=$ Nota, de zero a 10, associada a cada intervalo da escala IC de avaliação do recurso $\mathrm{FM}_{\mathrm{k}}$.

A Figura 2 apresenta graficamente o cálculo de $M_{R_{i}}^{F M_{k}}$

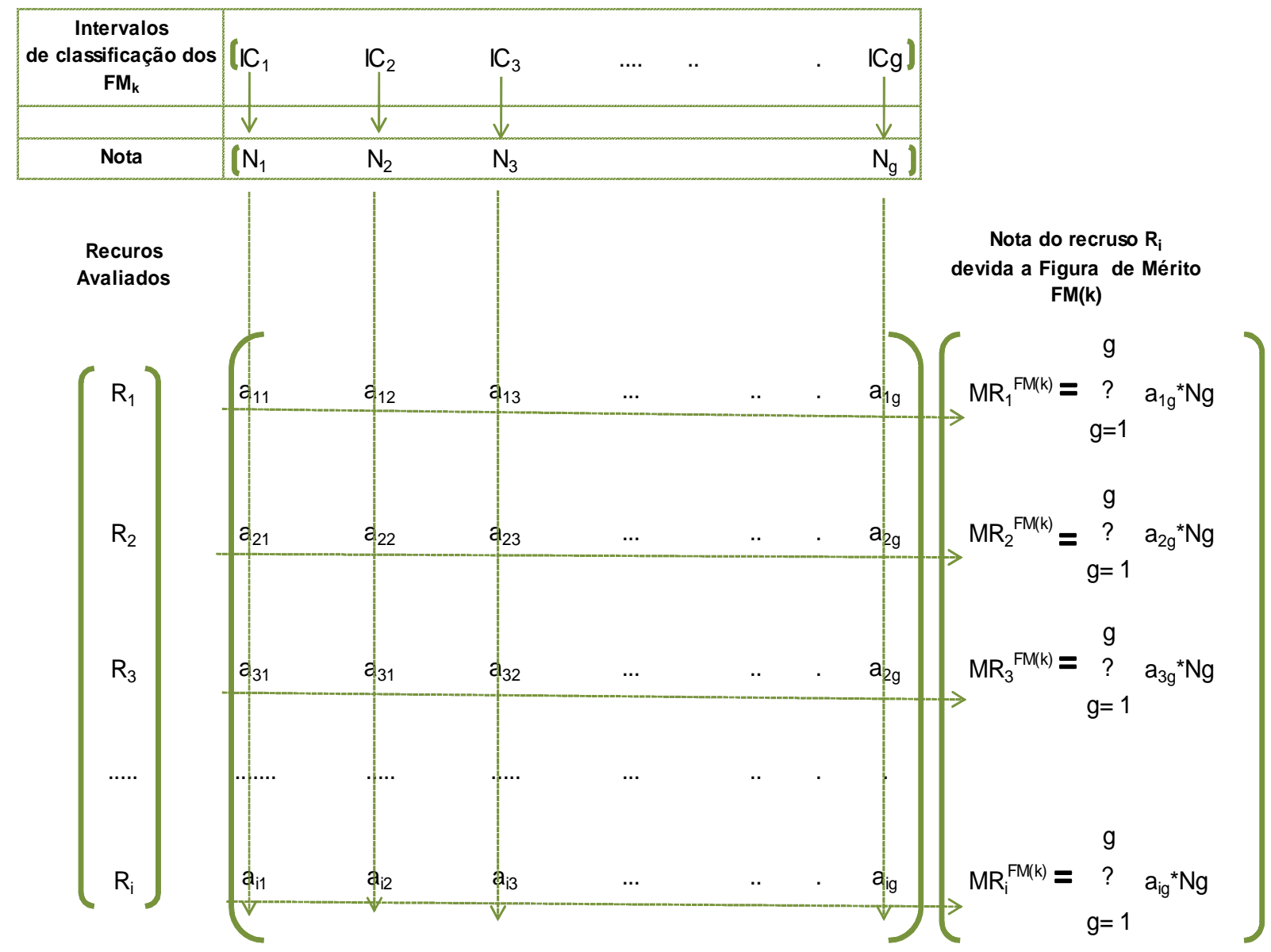

Figura 2 - Apresentação gráfica do cálculo da nota média dada ao RE Fonte: elaboração própria

\subsubsection{Etapa 4 - Ponderar a importância dada as FMs}


$\mathrm{O}$ avaliador associa um grau de importância (peso) $\mathrm{G}_{\mathrm{FM}_{\mathrm{k}}}$ que a $F M_{\mathrm{K}}$ tem para a avaliação (medida da atratividade) do Recurso $R_{i}$, em uma escala que vai de $0 \%$ a $100 \%$ (Figura 3).

Por construção:

$$
\sum_{k=1}^{k} \mathrm{G}_{\mathrm{FM}_{\mathrm{k}}}=100 \%
$$

\begin{tabular}{|c|c|c|c|c|}
\hline Figuras de mérito & $\mathrm{FM}_{1}$ & $\mathrm{FM}_{2}$ & $\mathrm{FM}_{3}$ & $\left.\mathrm{FM}_{\mathrm{k}}\right]$ \\
\hline $\begin{array}{l}\text { Grau de importância } \\
\text { na avaliação }\end{array}$ & $C_{0}$ & $G_{M_{M_{2}}}$ & $\mathrm{G}_{\mathrm{PM}_{\mathrm{g}}}$ & $\mathrm{G}_{\mathrm{FM}_{\mathrm{k}}}$ \\
\hline
\end{tabular}

Figura 3 - Peso ponderado da figura de mérito na avaliação de atratividade do RE Fonte: elaboração própria

\subsubsection{Etapa 5 - Calcular o resultado da avaliação dos REs}

Calcula-se o resultado $A_{R_{i}}$ da avaliação dos $\mathrm{R}_{\mathrm{i}}$, considerando todas as $\mathrm{FM}_{\mathrm{k}}$, ponderadas por $\mathrm{G}_{\mathrm{FM}_{\mathrm{k}}}$, conforme (3) abaixo.

$$
A_{R_{i}}=\sum_{k=1}^{k} M_{R_{i}}^{F M_{k}} * \mathrm{G}_{\mathrm{FM}_{\mathrm{k}}}
$$

- $A_{R_{i}}=$ Nota geral associada ao Recurso $\mathrm{R}_{\mathrm{i}}$

- Observa-se, que por construção $0<A_{R_{i}}<10$, o mesmo domínio de $\mathrm{N}_{\mathrm{g}}$

Na Figura 4 apresenta-se de forma gráfica a obtenção da Nota geral associada ao recurso. 


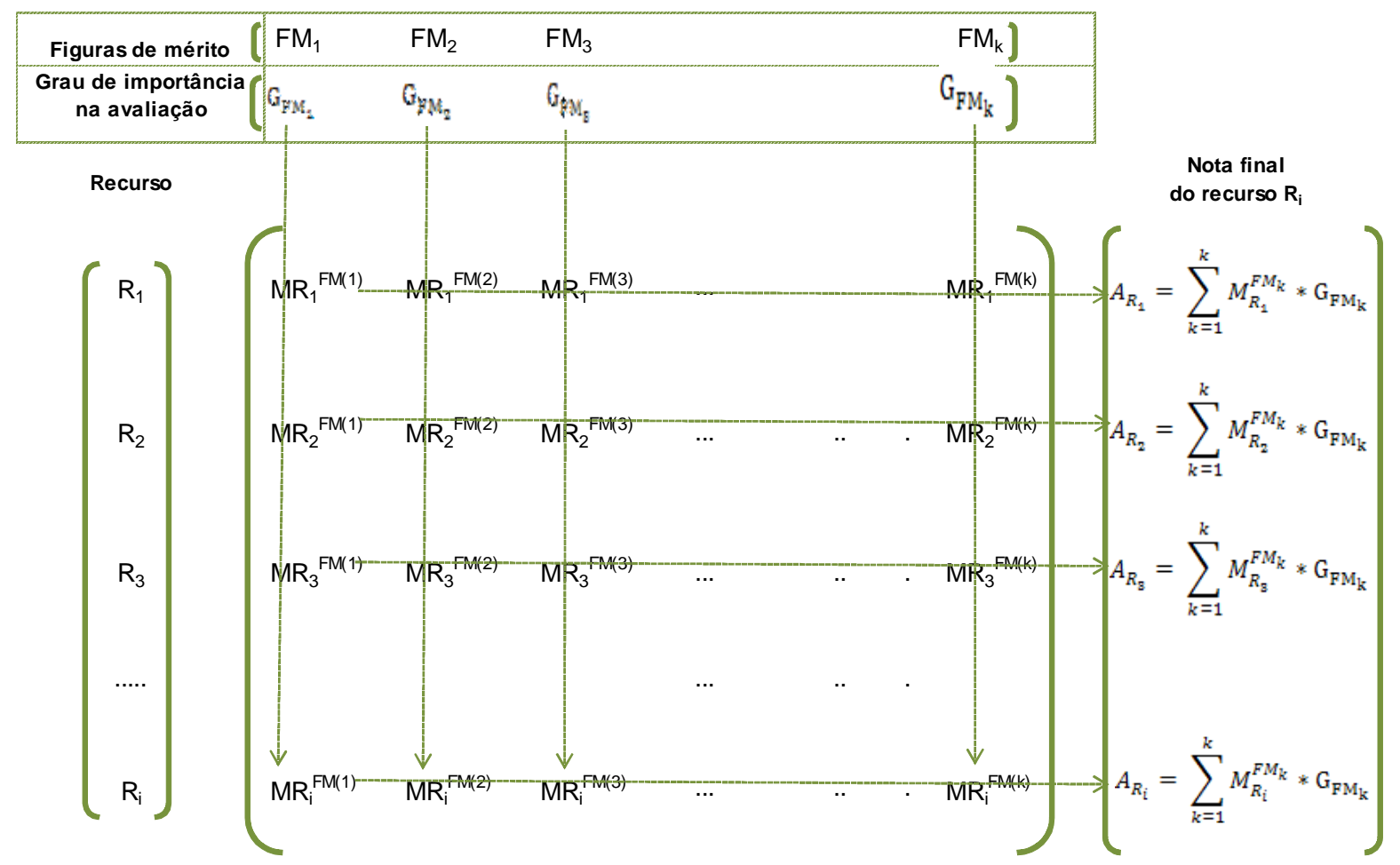

Figura 4 - Cálculo da nota final do RE usada para avaliação da atratividade Fonte: elaboração própria

\subsubsection{Etapa 6 - Classificar os resultados da avaliação dos REs}

Para os propósitos deste estudo estes intervalos foram definidos em:

\begin{tabular}{|c|c|c|c|c|c|}
\hline $\begin{array}{l}\text { Limite } \\
\text { Inferior }\end{array}$ & & $\begin{array}{l}\text { Nota Geral } \\
\text { do Recurso }\end{array}$ & & $\begin{array}{l}\text { Limite } \\
\text { Superior }\end{array}$ & Avaliação \\
\hline 7,5 & $\leq$ & $A_{R_{i}}$ & $\leq$ & 10 & Atrativo \\
\hline 5,0 & $\leq$ & $A_{R_{i}}$ & $<$ & 7,5 & Atrativo com atenção \\
\hline 0 & $\leq$ & $A_{R_{i}}$ & $<$ & 5,0 & Não atrativo \\
\hline
\end{tabular}

Fonte: elaboração própria

Os intervalos da Tabela 1 - Escala de notas para avaliação do RE foram definidos pelo avaliador segundo as suas próprias expectativas.

Para os propósitos genéricos, a exemplo de um estudo acadêmico mais abrangente, existe a opção de pesquisar junto a interessados técnicos quais os pesos atribuídos por cada um e gerar uma escala que represente uma ponderação média. 


\section{DESENVOLVIMENTO}

\subsection{AMBIENTE DE NEGÓCIOS EM ENERGIA ELÉTRICA NO BRASIL}

\subsubsection{Geração}

\subsubsection{Introdução}

A geração de energia elétrica no Brasil é predominantemente hídrica, diferentemente da maioria dos países do mundo, onde é térmica com forte presença fóssil e nuclear. De acordo com a ANEEL, o Brasil possuía em dezembro de 2010 uma capacidade instalada de geração elétrica de 117.893 MW (EPE, 2010), dos quais $82.705 \mathrm{MW}$ são de potência de origem hidrelétrica (Grande Usina Hidrelétrica, Central Geradora Hidrelétrica e Pequena Central Hidrelétrica), representando $71,15 \%$ da potência instalada no Brasil. Ainda de acordo com a ANEEL, 76,9\% da geração elétrica brasileira - um percentual ainda maior que a capacidade instalada foi oriunda de usinas hídricas, apresentando um percentual de participação de geração hidrelétrica, em nível mundial, somente inferior à Noruega. O Brasil importa apenas $8,1 \%$ de sua energia elétrica de países vizinhos. Desse total, $0,2 \%$ foram através de geração eólica ${ }^{15}$ e o restante $14,8 \%$ de fontes de origem térmica (Biomassa 5,4\%, gás natural 2,6\%, derivados de petróleo 2,9\% e nuclear 2,5\%).

Devido a esta predominância de geração de fontes hídricas e térmicas, a geração brasileira é classificada como hidrotérmica. Considerando que três quartos de toda geração é de origem hídrica, em qualquer previsão que se faça sobre geração elétrica, é indispensável considerar o risco hidrológico, e o fato de que no período seco no Brasil (maio a novembro) a potência demandada de energia elétrica possa ser superior à capacidade hídrica, ou seja, a necessidade de geração por outras fontes, diferentes da hídrica. Uma das variáveis relevantes a serem

\footnotetext{
${ }^{15}$ Com os resultados dos leilões de energia elétrica, observados a partir do segundo semestre de 2011, espera-se um salto quantitativo de geração eólica contratada na matriz elétrica brasileira para estes próximos anos, acompanhando uma tendência mundial.
} 
analisadas no contexto de demanda e oportunidades de geração de energia elétrica no Brasil, é o percentual da potência hidrelétrica instalada que pode ser considerada firme: com um Fator de Capacidade $(F C)^{16}$ de 0,55 , a potência hídrica instalada no Brasil de $82.705 \mathrm{MW}$ representa uma potência firme de $45.488 \mathrm{MWmed}^{17}$, enquanto que a demanda de ponta no ano de 2010 (fev/2010) foi $70.450 \mathrm{MWmed}$. Assim, torna-se nítida a necessidade da presença de outras fontes de geração de energia elétrica, de forma complementar, para garantir segurança do sistema como um todo.

O parque gerador hídrico brasileiro atualmente aproveita em torno de $30 \%$ do potencial hidrelétrico inventariado (EPE, 2010). Há ainda cerca $150.000 \mathrm{MW}$ passíveis de serem explorados, dos quais quase 100.000 MW estão na região Norte, em área de planície, com dificuldades de toda ordem para construir grandes reservatórios que permitam acumulação de água (energia).

Nos últimos anos tem havido uma grande dificuldade em se expandir o parque hídrico devido às restrições legais de caráter ambiental, principalmente depois da constituição brasileira de 1988. Entretanto, é importante notar que, apesar da legislação ambiental ter restringido a expansão hídrica, a ausência de grandes reservatórios nas novas usinas é devida a uma questão física: o potencial hídrico nas regiões de planalto já foi explorado e os novos empreendimentos estão localizados em regiões planas do território nacional, inviabilizando a construção de grandes reservatórios reguladores, com a função acumuladora de energia potencial hídrica.

Uma das principais consequências da diminuição relativa dos reservatórios em relação à capacidade hídrica instalada, e ao aumento do consumo de energia elétrica, é a redução do horizonte de planejamento da operação do setor elétrico, saindo de plurianual para bianual. Logo, o Sistema Elétrico Brasileiro fica cada vez mais exposto ao risco hidrológico, ou, às incertezas em relação ao volume de chuvas no período úmido, que ocorre entre dezembro e abril (EPE, 2010).

Até a década de 1980, dada a relação entre potência e reservatórios, a operação do sistema contava com a energia acumulada que permitia enfrentar maiores períodos críticos de seca. Desde os anos 1990, porém, esta possibilidade vem diminuindo, e o sistema elétrico torna-se cada vez mais dependente do nível

\footnotetext{
${ }^{16}$ Quociente entre a energia potencial que passa pela planta de geração e a energia efetivamente gerada.

${ }^{17}$ Unidade de potência média anual equivalente.
} 
pluviométrico do período de chuva no tempo "t". Desta forma, o planejamento tem como horizonte temporal até o período " $t+1$ "18. Esta situação foi evidenciada, com grande clareza, em novembro de 2007: Neste mês, o volume de chuvas situou-se cerca de 50\% abaixo da média histórica (coletada desde 1930). O antecedente relevante, que explicita o tamanho da exposição do sistema hidrelétrico brasileiro ao risco hidrológico, é que no período úmido de 2006-07 (imediatamente anterior), onde o volume de chuvas foi tamanho que todas as UHEs verteram, ${ }^{19}$ quando o nível dos reservatórios chegou a $88 \%$ nas regiões Sudeste e Centro-Oeste. Mesmo com este volume de energia acumulado no ano imediatamente anterior, a energia potencial hídrica acumulada não foi suficiente para atender a demanda de energia no período seco imediatamente seguinte, ou seja, chegar a um nível de acumulação nos reservatórios que fosse suficiente para suportar a diminuição das chuvas em maio do ano de 2007. A solução adotada pelo ONS - Operador Nacional do Sistema elétrico brasileiro - para superar o problema de 2007 foi o acionamento de termelétricas.

A geração elétrica brasileira é coordenada por uma agência central, o Operador Nacional do Sistema (ONS), que promove a coordenação e controle da operação das instalações de geração e transmissão de energia elétrica no Sistema Integrado Nacional (SIN), sob a fiscalização e regulação da Agência Nacional de Energia Elétrica (ANEEL).

O preço da geração hídrica (dos grandes projetos estruturantes, como Itaipu) é, de fato, a primeira, e principal, "âncora referencial" de preços da energia elétrica no Brasil.

A segunda "âncora referencial" de preços da energia elétrica é a aversão ao risco hidrológico (falta água nos reservatórios das hidrelétricas).

A terceira âncora, decorrente das primeira e segunda âncoras, é a definição da forma, e nível, da composição do "mix" de preços de geração, pela inclusão de outras fontes de geração de energia elétrica, não hídricas, para complementação da demanda esperada, em leilões definidos para participação de apenas determinadas fontes de geração.

\footnotetext{
${ }^{18}$ Como já mencionado anteriormente, o planejamento deixou de ser plurianual para se tornar bianual.

${ }^{19}$ Tiveram que abrir suas comportas para diminuir o nível de água acumulada nos seus reservatórios.
} 
O crescimento da demanda por energia elétrica também é determinante do seu preço, e bem mais previsível que a variação hidrológica.

Mais uma vez, é importante relembrar que a maior parte dos aproveitamentos hidrelétricos ainda não explorados localiza-se na região norte do país (bacia amazônica), região que vem enfrentando grande pressão da opinião pública, nacional e internacional, contra projetos que necessitam de grandes intervenções ambientais. Este é o caso típico das hidrelétricas de Belo Monte, Santo Antonio e Jirau, todas localizadas na região amazônica (norte), e com recorrentes reportagens sobre posicionamentos de interessados e envolvidos em meios de comunicação nacionais e internacionais. É neste cenário descrito que as fontes alternativas de geração distribuída de energia elétrica têm potencial de ganhar importância nas estratégias, e políticas, públicas e privadas para o setor, na medida direta que sua inclusão na matriz energética visa evitar que a indisponibilidade na oferta de energia elétrica torne-se um (grande) problema para a economia.

As atuais principais opções à geração hídrica são: térmicas, de origem fóssil, nuclear e fontes alternativas renováveis. A geração fóssil tem sido muito criticada pela sociedade em geral, devido aos impactos na geração de gases de efeito estufa, decorrentes de sua exploração. Já a geração nuclear, segundo a atual legislação, e diferentemente das outras fontes térmicas, tem sua exploração integralmente determinada e conduzida pelo poder público.

No Brasil as principais fontes alternativas, e renováveis, de geração de energia elétrica são: térmica que faz uso de biomassa, vento (Eólica), e PCHs.

Todas estas três fontes gozam de algumas vantagens e vários benefícios e incentivos públicos: (i) as duas primeiras (BIO e EOL) são complementares à hidrelétrica, porque têm seu maior potencial de geração nos períodos secos, ruins para geração hidrelétrica; (ii) $\mathrm{PCH}$ requer, proporcionalmente, investimentos iniciais menores; (iii) no modelo de geração distribuída (GD), todas as três fontes normalmente requererem menos investimento em transmissão, por terem a possibilidade de localizarem-se mais próximo do centro de consumo (centro de carga); (iv) as três fontes gozam de incentivos governamentais (ANEEL, 2010) e (BNDES, 2011); (v) e todas as três fontes preveem tempo de construção bem menores (até 3 anos) que as grandes usinas hidrelétricas dos projetos estruturantes, da ordem de 5 anos. 
Em maior ou menor grau, a geração térmica através de combustíveis fósseis (gás natural, óleo combustíveis, diesel) e a termonuclear mantém seu papel no planejamento energético, e na matriz de geração de energia elétrica, brasileira.

Nota-se que, a geração termoelétrica a gás natural, apesar de não ser renovável, tem previsto um crescimento importante na matriz de geração elétrica brasileira no médio e longo prazo (EPE, 2010). Este fato ocorre devido às jazidas recém descobertas na bacia de Santos (próximo aos grandes centros de consumo de São Paulo e Rio de Janeiro), que, mesmo sendo de origem fóssil, são "consideradas fontes menos poluidoras" que as demais fontes fósseis, e versáteis para participarem do mix de combustíveis junto com outras fontes térmicas renováveis, uma tendência mundial (EPE, 2009).

A Tabela 2 apresenta um resumo dos empreendimentos de geração no Brasil.

Tabela 2 - Números da geração de energia elétrica no Brasil (tipo)

\begin{tabular}{|c|c|c|c|c|c|c|c|c|c|c|c|}
\hline \multicolumn{2}{|l|}{ Tipo de Geração } & \multicolumn{4}{|c|}{$\begin{array}{l}\text { Empreendimentos } \\
\text { em Operação }\end{array}$} & \multicolumn{3}{|c|}{$\begin{array}{l}\text { Empreendimentos } \\
\text { em Construção }\end{array}$} & \multicolumn{3}{|c|}{$\begin{array}{c}\text { Não inciaram construção } \\
(1998-2010)\end{array}$} \\
\hline Descrição & Sigla & Qtd. & $\begin{array}{c}\text { Potência } \\
\text { Outorgada } \\
\text { (kW) }\end{array}$ & \begin{tabular}{|c|} 
Potência \\
Fiscalizada \\
(kW)
\end{tabular} & $\%$ & Qtd. & \begin{tabular}{|c|} 
Potência \\
Outorgada \\
$(\mathrm{kW})$
\end{tabular} & $\%$ & Qtd. & $\begin{array}{c}\text { Potência } \\
\text { Outorgada } \\
\text { (kW) }\end{array}$ & $\%$ \\
\hline Central Geradora Hidrelétrica & CGH & 368 & 214.716 & 211.895 & 0,18 & 1 & 848 & 0 & 63 & 42.436 & 0,18 \\
\hline Central Geradora Eolielétrica & EOL & 72 & 1.561 .338 & 1.450 .792 & 1,24 & 30 & 760.290 & 2,82 & 153 & 4.739 .508 & 20,1 \\
\hline Pequena Central Hidrelétrica & PCH & 418 & 3.873 .709 & 3.829 .007 & 3,28 & 50 & 634.379 & 2,35 & 139 & 1.934 .600 & 8,19 \\
\hline Usina Fotovoltaica & UFV & 6 & 5.087 & 1.087 & & & & & & & \\
\hline Usina Hidrelétrica de Energia & UHE & 180 & 78.706 .073 & 78.277 .779 & 66,97 & 12 & 19.660 .000 & 72,9 & 13 & 5.818 .642 & 24,7 \\
\hline Usina Termelétrica de Energia & UTE & 1.498 & 32.650 .086 & 31.106 .440 & 26,61 & 40 & 4.565 .385 & 16,9 & 158 & 11.072 .942 & 46,9 \\
\hline Usina Termonuclear & UTN & 2 & 2.007 .000 & 2.007 .000 & 1,72 & 1 & 1.350 .000 & 5,01 & & & \\
\hline Central Geradora Unid-Elétrica & CGU & & & & & & & & 1 & 50 & 0 \\
\hline & Total & 2.544 & 119.018 .009 & 116.884 .000 & 100 & 134 & 26.970 .902 & 100 & 527 & 23.608 .178 & 10 \\
\hline
\end{tabular}

Fonte: elaboração própria, com base no BIG/MME - dez/2011

Apresenta-se na Tabela 3 as projeções feitas pela EPE (responsável oficial das projeções do governo) de acréscimo de capacidade instalada anual de energia elétrica, por fonte em 2010 para o Plano Decenal de Energia (PDE 2019). 
Tabela 3 - EPE - Geração:acréscimo previsto de capacidade instalada anual por fonte (MW)

\begin{tabular}{|c|c|c|c|c|c|c|c|c|c|c|c|c|c|}
\hline \multirow[t]{2}{*}{ FONTE } & \multirow{2}{*}{\begin{tabular}{|c|}
2010 \\
Ano base
\end{tabular}} & \multirow[b]{2}{*}{2011} & \multirow[b]{2}{*}{2012} & \multirow[b]{2}{*}{2013} & \multirow[b]{2}{*}{2014} & \multirow[b]{2}{*}{2015} & \multirow[b]{2}{*}{2016} & \multirow[b]{2}{*}{2017} & \multirow[b]{2}{*}{2018} & \multicolumn{2}{|c|}{2019} & \multicolumn{2}{|c|}{ MÉDIA Anual } \\
\hline & & & & & & & & & & no ano & $\begin{array}{c}\text { Acum } \\
\text { 2010-19 }\end{array}$ & Mw & $\%$ \\
\hline Hidro & 83.169 & 2.314 & 812 & 2.204 & 1.182 & 4.975 & 5.820 & 3.675 & 4.447 & 8.101 & 33.530 & 3.726 & $3,8 \%$ \\
\hline Urânio & 2.007 & 0 & 0 & 0 & 0 & 1.405 & 0 & 0 & 0 & 0 & 1.405 & 156 & $6,1 \%$ \\
\hline Gás natural & 8.860 & 496 & 500 & 1.471 & 206 & 0 & 0 & 0 & 0 & 0 & 2.673 & 297 & $3,0 \%$ \\
\hline Carvão & 1.765 & 720 & 720 & 0 & 0 & 0 & 0 & 0 & 0 & 0 & 1.440 & 160 & $6,9 \%$ \\
\hline Óleo combustível & 3.380 & 1.440 & 426 & 3.618 & 0 & 0 & 0 & 0 & 0 & 0 & 5.484 & 609 & $11,3 \%$ \\
\hline Óleo diesel & 1.728 & 175 & -200 & -347 & -207 & 0 & 0 & 0 & 0 & 0 & -579 & -64 & $-4,4 \%$ \\
\hline Gás de processo & 687 & 0 & 0 & 0 & 0 & 0 & 0 & 0 & 0 & 0 & 0 & 0 & $0,0 \%$ \\
\hline Pch & 4.043 & 73 & 0 & 400 & 550 & 500 & 250 & 250 & 350 & 550 & 2.923 & 325 & $6,2 \%$ \\
\hline Biomassa & 5.380 & 703 & 238 & 350 & 400 & 350 & 200 & 150 & 350 & 400 & 3.141 & 349 & $5,2 \%$ \\
\hline Eólica & 1.436 & 0 & 1.805 & 400 & 400 & 400 & 400 & 400 & 400 & 400 & 4.605 & 512 & $17,3 \%$ \\
\hline Total & 112.455 & 5.921 & 4.301 & 8.096 & 2.531 & 7.630 & 6.670 & 4.475 & 5.547 & 9.451 & 54.622 & 6.069 & $4,5 \%$ \\
\hline
\end{tabular}

Fonte: elaboração própria, baseada nas projeções d EPE PDE 2019

Na Tabela 3 pode-se observar que o maior crescimento absoluto previsto por fonte primária é de hidroeletricidade, seguido de óleo combustível e eólico. A fonte eólica está em primeiro lugar no crescimento percentual, superando $\mathrm{PCH}$ e biomassa.

\subsubsection{O modelo institucional}

Durante os anos de 2003 e 2004, o Governo Federal lançou as bases de um novo modelo para o Setor Elétrico Brasileiro, sustentado pelas Leis $\mathrm{n} \cong 10.847$ e 10.848, de 15 de março de 2004 (BRASIL, 2004); e pelo Decreto no 5.163, de 30 de julho de 2004 (BRASIL, 2004). Esta ação deveu-se, em muito, ao racionamento de energia elétrica de 2001, em que, através de uma análise crítica, evidenciaram-se várias deficiências do modelo vigente até então.

Em termos institucionais, o novo modelo definiu a criação de uma entidade responsável pelo planejamento, no longo prazo, do setor elétrico (a Empresa de Pesquisa Energética - EPE); uma instituição com a função de avaliar permanentemente a segurança do suprimento de energia elétrica (o Comitê de Monitoramento do Setor Elétrico - CMSE) e uma instituição para dar continuidade às atividades do MAE (Mercado Atacadista de Energia), relativas à comercialização de energia elétrica no Sistema Interligado (a Câmara de Comercialização de Energia Elétrica - CCEE). 
Outras alterações importantes incluem a definição do exercício do Poder Concedente ao Ministério de Minas e Energia (MME) e a ampliação da autonomia do Operador Nacional do Sistema (ONS).

Em relação à comercialização de energia, foram instituídos dois ambientes para celebração de contratos de compra e venda de energia: o Ambiente de Contratação Regulada (ACR), do qual participam os Agentes de Geração e de Distribuição de energia; e o Ambiente de Contratação Livre $(A C L)$, do qual participam Agentes de Geração, Comercializadores, Importadores e Exportadores de energia e Consumidores Livres.

O novo modelo do setor elétrico visou atingir três objetivos principais:

- Garantir a segurança do suprimento de energia elétrica;

- Promover a modicidade tarifária;

- Promover a inserção social no Setor Elétrico Brasileiro, em particular pelos programas de universalização de atendimento.

O modelo também prevê um conjunto de medidas a serem observadas pelos agentes, como: (i) a exigência de contratação de totalidade da demanda por parte das distribuidoras de energia elétrica e dos consumidores livres; (ii) nova metodologia de cálculo do lastro de energia elétrica ${ }^{20}$ para venda, e contratação de usinas hidrelétricas e termelétricas em proporções que assegurem 0 melhor equilíbrio entre garantia e custo de suprimento e (ii) o monitoramento permanente da continuidade e da segurança de suprimento, visando detectar desequilíbrios conjunturais entre oferta e demanda.

Em termos de modicidade tarifária, o modelo prevê a compra de energia elétrica pelas distribuidoras no ambiente regulado (ACR) por meio de leilões públicos, observado o critério de menor tarifa para o usuário final (modicidade tarifária), ou seja, a busca pela redução do custo de aquisição da energia elétrica a ser repassada para a tarifa dos consumidores chamados cativos (modicidade tarifária).

Em termos da inserção social, o modelo busca promover a universalização do acesso e uso do serviço de energia elétrica, criando condições para que os

\footnotetext{
${ }^{20}$ Lastro de energia elétrica: Energia firme (que tem efetivamente capacidade de ser gerada) de um determinado empreendimento gerador.
} 
benefícios da eletricidade sejam disponibilizados aos cidadãos que ainda não contam com esse serviço. Ainda, o modelo visa garantir subsídios para os consumidores de baixa renda, de tal forma que estes possam arcar com os custos de seu consumo de energia elétrica.

As instituições do setor elétrico brasileiro estão relacionadas e descritas no Anexo $\mathrm{B}$ e referências bibliográficas.

\subsubsection{Modelo de negócio}

Até 1995 o "negócio energia elétrica" no Brasil, compreendendo Geração(G), Transmissão(T), Distribuição(D) e Comercialização(C), era uma atividade de monopólio estatal, sem a possibilidade de participação de agentes privados.

A partir de 1995 (Lei 9.074, de 7 de julho de 1995) com as empresas públicas do setor descapitalizadas e portanto sem capacidade de investimento, o governo iniciou um estudo para flexibilização do monopólio estatal visando atender cinco aspectos principais: (i) incentivar o investimento privado no setor; (ii) introduzir a competição na indústria de energia elétrica; (iii) desverticalizar (segregar) as empresas que até então atuavam na área ${ }^{21}$; (iv) promover o livre acesso às empresas geradoras (atuais e novas) de energia elétrica ao restante do sistema elétrico com vistas a suprir os usuários finais elegíveis ou agentes distribuidores de energia elétrica e $(v)$ privatizar as empresas estatais.

Este estudo culminou em um marco legal de 2004 (Lei 10.848, de 15 de março de 2004). A partir do marco legal de 2004, segrega-se a Geração (G), a Transmissão(T), a Distribuição(D) e a Comercialização (C), assim como se definem os elementos que regulam os negócios com energia elétrica.

Resumidamente, de 1995 até o marco legal de 2004, estabeleceu-se que a Transmissão(T) e a Distribuição(D) passam a ser monopólios naturais ("serviço fio"), com caráter público e regulado pelo estado, e Geração (G) e Comercialização(C) passam a se constituírem de atividades competitivas.

\footnotetext{
${ }^{21}$ Até então, as empresas estatais eram verticalizadas, ou seja, a geração, a transmissão e a distribuição normalmente eram exercidas por uma mesma empresa.
} 
De forma transversal, verifica-se um ambiente desregulado para oportunidades de consultoria e treinamento no ambiente de oferta (geração e transmissão).

Já no lado da demanda (usos finais e medidas de economia de energia), o mercado continuou totalmente desregulado e competitivo, em todos os seus níveis.

Observando a Figura 5, a seguir, é oportuno relembrar que o foco deste estudo se concentra em três negócios relacionados à geração de energia elétrica (eólica, biomassa e PCH) e dois negócios em recursos de usos finais (iluminação e aquecimento de água) a serem discutidos com mais profundidade, a frente.
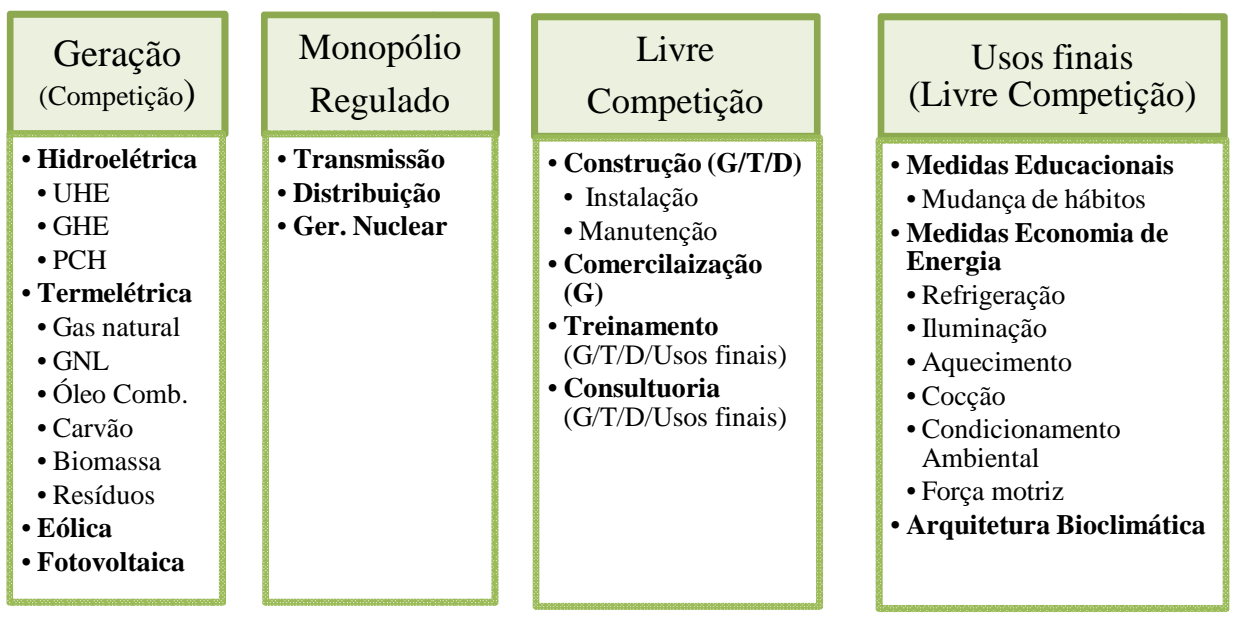

Figura 5 - Diagrama de oportunidades do setor elétrico Fonte: elaboração própria

Os agentes participantes do mercado de energia elétrica também são abordados no Anexo B com mais profundidade.

\subsubsection{Ambientes de contratação de energia elétrica}

No Brasil, toda geração de energia elétrica em que há a comercialização (de qualquer forma ou natureza), ou transporte de energia, por lei, deve ser registrada na CCEE.

O Processo de Comercialização de Energia Elétrica ocorre de acordo com parâmetros estabelecidos pela Lei nำ 10848/2004, pelos Decretos no 5163/2004 e no 5.177/2004 (o qual instituiu a CCEE) e pela Resolução Normativa ANEEL oㅜ 109/2004, que instituiu a Convenção de Comercialização de Energia Elétrica. 
As relações comerciais entre os agentes participantes (associados) da CCEE são regidas predominantemente por contratos de compra e venda de energia, e todos os contratos celebrados entre os Agentes, no âmbito do Sistema Interligado Nacional, devem ser registrados na CCEE. Esse registro inclui as partes envolvidas, os montantes de energia e o período de vigência. Os preços de energia definidos nos contratos não são registrados, sendo de conhecimento apenas das partes envolvidas em suas liquidações financeiras bilaterais.

É de se notar que este aspecto, a não obrigatoriedade do registro dos valores na CCEE, em termos práticos, torna toda informação sobre preços de energia regida por sigilo, pois é considerada vantagem competitiva. Assim, normalmente, preços de energia (exceto preços de leilões públicos do ACR), somente são obtidos através de fontes primárias de informação, e com pedido de anonimato da fonte.

A CCEE contabiliza as diferenças (físicas de energia) entre o que foi produzido, consumido, e o que foi contratado. As diferenças financeiras, positivas ou negativas, são liquidadas no Mercado de Curto Prazo e valoradas ao preço chamado de PLD (Preço de Liquidação das Diferenças), preço este determinado semanalmente para cada patamar de carga e para cada submercado, tendo como base o custo marginal de operação $(\mathrm{CMO})^{22}$ do sistema, este limitado (lei) por um preço mínimo e por um preço máximo definido no início de cada ano civil.

Dessa forma, pode-se dizer que o mercado de curto prazo é o mercado das diferenças entre montantes contratados e montantes medidos, conforme a Figura 6.

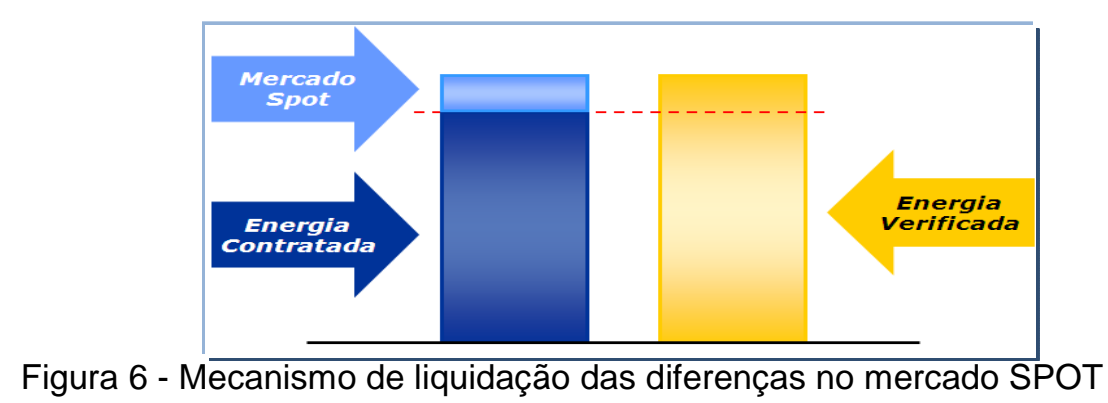

Fonte: CCEE

Assim, existe um estoque de energia elétrica "em papel", chamada de energia contratada, e um estoque de energia elétrica "efetivamente gerada", chamada de

\footnotetext{
${ }^{22}$ Um conceito definido como sendo o custo de geração (MWh) do gerador mais caro que despacha na semana em que o Preço foi definido. A determinação deste valor, leva em consideração uma série de fatores, em um processo estocástico, que considera, inclusive o valor futuro da água armazenada em reservatório.
} 
energia verificada. A diferença (posição dos estoques em papel e gerada) é zerada semanalmente na CCEE a preços chamados preços spot, ou PLD (Preços de Liquidação da Diferença).

A título de ilustração e referencia, no Gráfico 1 e no Gráfico 2, a seguir, apresenta-se o histórico dos montantes, quantidade de contratos e quantidade de energia, que passaram pela CCEE entre os anos de 2006 e 2008.

Quantidade de Contratos Bilaterais (n. ${ }^{\circ}$ )
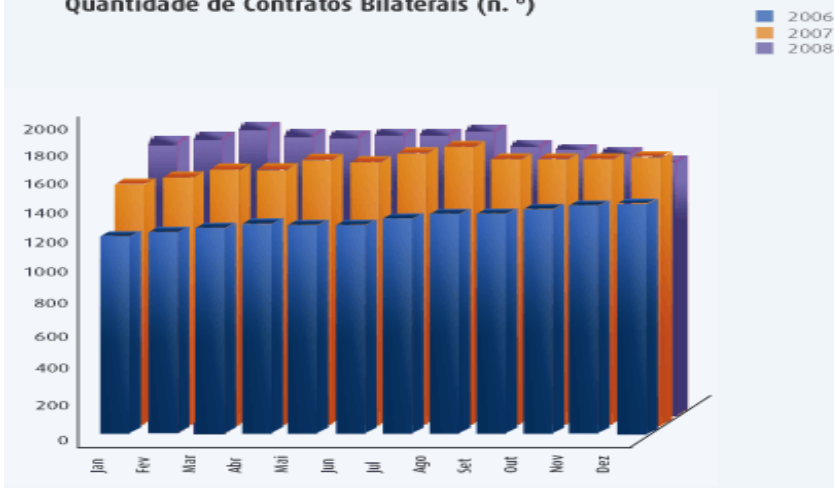

Gráfico 1 - Quantidades de contratos bilaterais negociados no ACL (2006/08)

Fonte: CCEE.

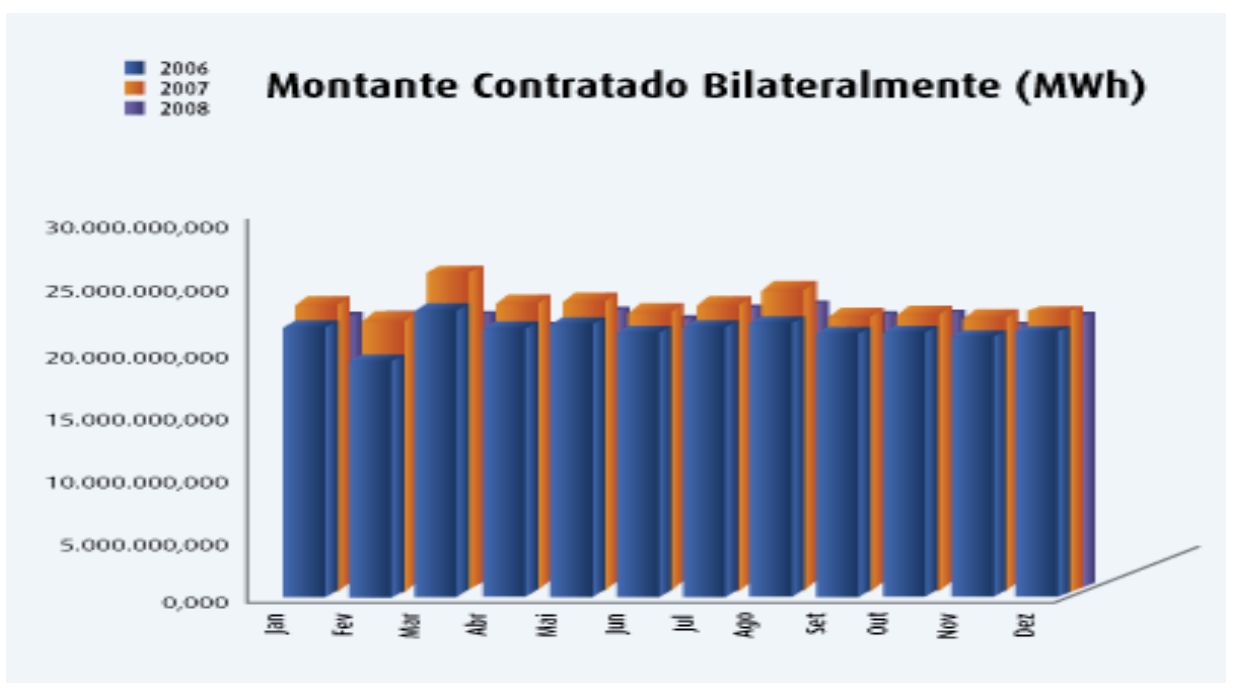

Gráfico 2 - Montante de energia SPOT negociada na CCEE Fonte: CCEE. 


\subsection{Ambientes de Contratação regulada ACR}

Como já escrito, o novo modelo do setor elétrico prevê que a comercialização de energia elétrica seja realizada em dois ambientes de mercado, o ACR e o ACL.

A contratação no ACR é formalizada através de contratos bilaterais regulados por lei, denominados Contratos de Comercialização de Energia Elétrica no Ambiente Regulado (CCEAR), celebrados entre agentes vendedores (comercializadores, geradores, produtores independentes ou autoprodutores) e Compradores (distribuidoras), que participam dos leilões de compra e venda de energia elétrica, os primeiros vencedores dos leilões e os últimos compradores.

Simplificadamente, todas as distribuidoras se organizam para fazer compras conjuntos de energia, em datas pré-definidas, chamadas de leilões do ACR, que por sua vez são gerenciados pela CCEE e EPE. Nestes leilões, os geradores inscritos, e habilitados, vendem sua energia (papel) para os compradores. A quantidade e valores de compra e venda são públicos.

Já no $A C L$ há a livre negociação entre os Agentes Geradores, Comercializadores, Consumidores Livres, Importadores e Exportadores de energia, sendo que os acordos de compra e venda de energia são pactuados por meio de contratos bilaterais. $O$ acesso a informações financeiras dos contratos é tratado como sigilo comercial.

Os Agentes de geração, Produtores Independentes de energia ou Autoprodutores, ou mesmo Comercializadores, podem vender energia elétrica nos dois ambientes, mantendo o caráter competitivo da geração. Todos os contratos são registrados na CCEE, e servem de base para a contabilização e liquidação das diferenças no mercado de curto prazo.

No ACL ocorre a transação bilateral entre comprador e vendedor, e apenas o montante de energia transacionado é registrado para a "conciliação" semanal do estoque de energia contratado com estoque verificado. A relação comercial é de inteira responsabilidade do comprador $e$ vendedor, cabendo às partes a responsabilidade pela garantia da conciliação do estoque em papel (contratado) e do estoque físico (verificado) junto a CCEE a preços PLD.

A comercialização de energia, envolvendo os dois ambientes de contratação, é apresentada na Figura 7. 


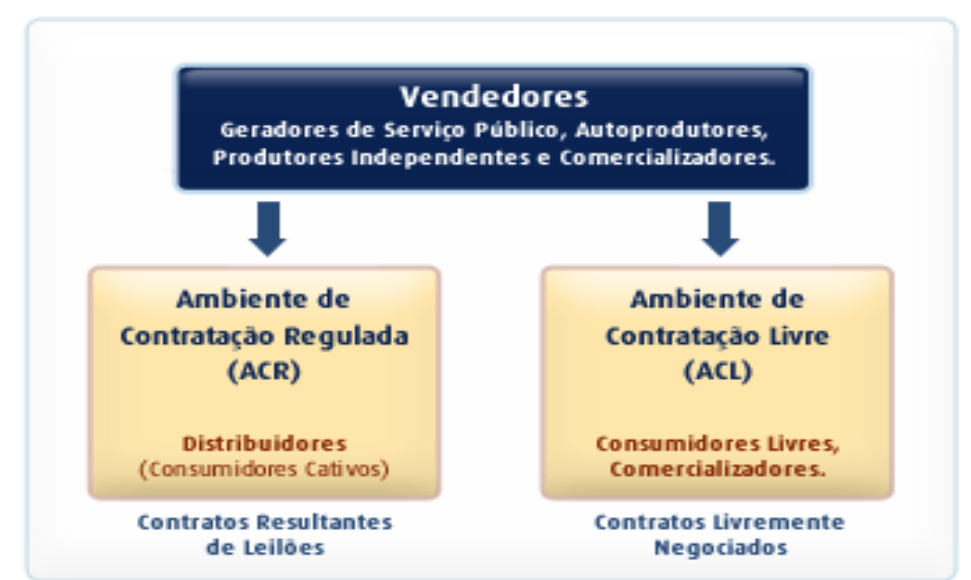

Figura 7 - Ambientes de contratação de energia elétrica no Brasil

Fonte: CCEE

No apêndice B são detalhados os modelos de contratação do ACR

\subsection{Ambiente de Contratação Livre - ACL}

No Ambiente de Contratação Livre ( $A C L$ ) participam agentes de geração, comercializadores, importadores e exportadores de energia elétrica e consumidores livres. Nesse ambiente há liberdade para se estabelecer volumes de compra e venda de energia, prazos de fornecimento e seus respectivos preços, sendo as transações pactuadas através de contratos bilaterais, devidamente registrados na CCEE.

A Figura 8 apresenta os agentes do Ambiente de Contratação Livre

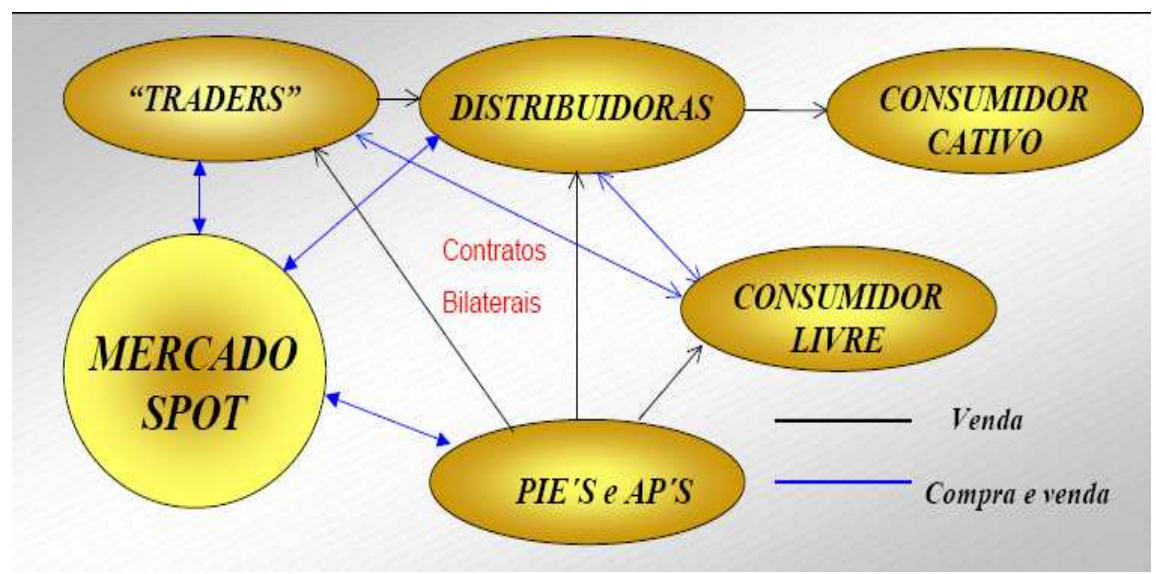

Figura 8 - Estrutura do ACL

Fonte: www.ccee.org.br 
A Tabela 4 discrimina as quantidades de agentes do ambiente de contratação livre.

Tabela 4 - Quantidade de Agentes participantes do CCEE

\begin{tabular}{|l|c|}
\hline TIPO DE AGENTE & QUANTIDADE \\
\hline Auto Produtores & 35 \\
\hline Comercializadores & 98 \\
\hline Consumidores Livres & 971 \\
\hline Distribuidoras & 45 \\
\hline Exportador & 0 \\
\hline Geradores & 28 \\
\hline Importador & 1 \\
\hline
\end{tabular}

Fonte: CCEE de março/2011

Ainda, pela Tabela 4 acima, verifica-se que existiam em março/2011 um total de 1452 "atores" no Ambiente de Comercialização Livre - ACL, divididos em 4 submercados distintos em termos de contabilização de volumes e preços de energia.

O Gráfico 3, a seguir, apresenta a evolução do número de consumidores livres associados à CCEE.

\section{$N^{\circ}$ Consumidores Livres e Especiais}

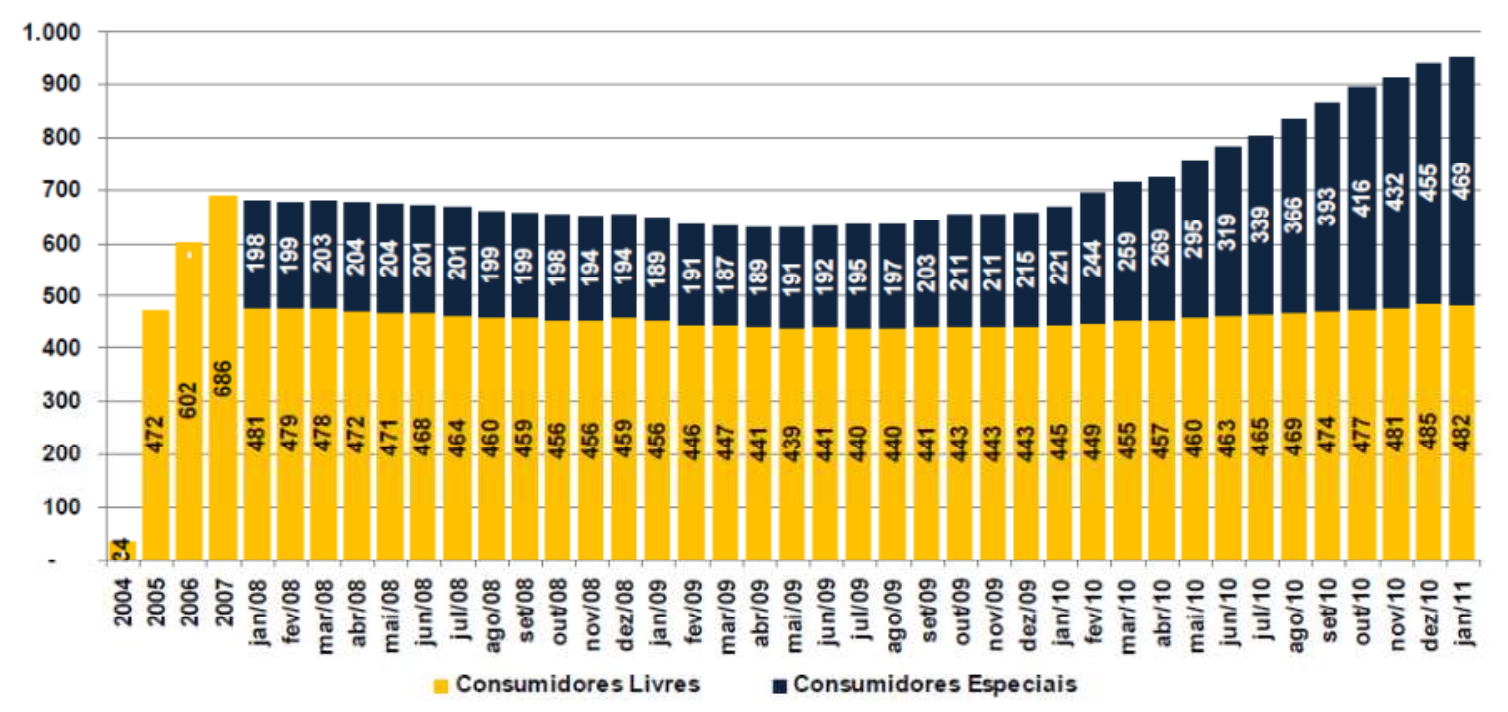

Gráfico 3 - Evolução do número de consumidores Livres/especiais no Brasil

Fonte: CCEE/Março 2011. 
Várias opções e estratégias de comercialização de energia elétrica são descritas em Pellegrini (PELLEGRINI, 2002) e podem ser úteis no desenvolvimento de planos táticos para ambos os agentes, compradores e vendedores de energia.

\subsubsection{Recursos avaliados no estudo de caso}

\subsection{Geração Eólica (EOL)}

O primeiro registro histórico da utilização da energia eólica para o bombeamento de água e moagem de grãos através de cata-ventos é proveniente da Pérsia, por volta de $200 \mathrm{AC}$. Este tipo de moinho de eixo vertical veio a se espalhar pelo mundo islâmico sendo utilizado por vários séculos. Acredita-se que antes da invenção dos cata-ventos na Pérsia, a China (por volta de 2000 a.C.) e o império Babilônico (1700 a.C.) também utilizava cata-ventos rústicos para irrigação. $\mathrm{Na}$ Holanda, entre os séculos XVII a XIX, o uso de moinhos de vento em grande escala esteve amplamente relacionado com a drenagem de terras cobertas pelas águas. $O$ declínio do cata-vento como provedor de força motriz coincidiu com a revolução industrial, e as máquinas a vapor (CHESF-BRASCEP, 1987).

$O$ início ${ }^{23}$ da adaptação dos cata-ventos para a geração de energia elétrica teve início no final do século XIX. Em 1888, Charles F. Bruch, um industrial voltado para eletrificação rural, ergueu na cidade de Cleveland, Ohio, o primeiro cata-vento destinado à geração de energia elétrica. Trata-se de uma cata-vento de $12 \mathrm{~kW}$ em corrente contínua para carregamento de baterias, destinadas à geração de energia elétrica.

Um dos primeiros passos para o desenvolvimento de aerogeradores de grande porte, para aplicações elétricas, foi dado na Rússia em 1931. O aerogerador Balaclava (assim chamado) era um modelo avançado de $100 \mathrm{~kW}$ conectado, por uma linha de transmissão de 6,3 kV de $30 \mathrm{~km}$, a uma usina termelétrica de $20 \mathrm{MW}$.

\footnotetext{
${ }^{23} \mathrm{http}: / /$ www.cresesb.cepel.br/content.php?task=print\&cid=201
} 
O comércio de aerogeradores no mundo se desenvolveu rapidamente em tecnologia e tamanhos durante os últimos 15 anos. A Figura 9 - Evolução dos aerogeradores desde 1985 até 2005, mostra o desenvolvimento do tamanho e a potência dos aerogeradores desde 1985.

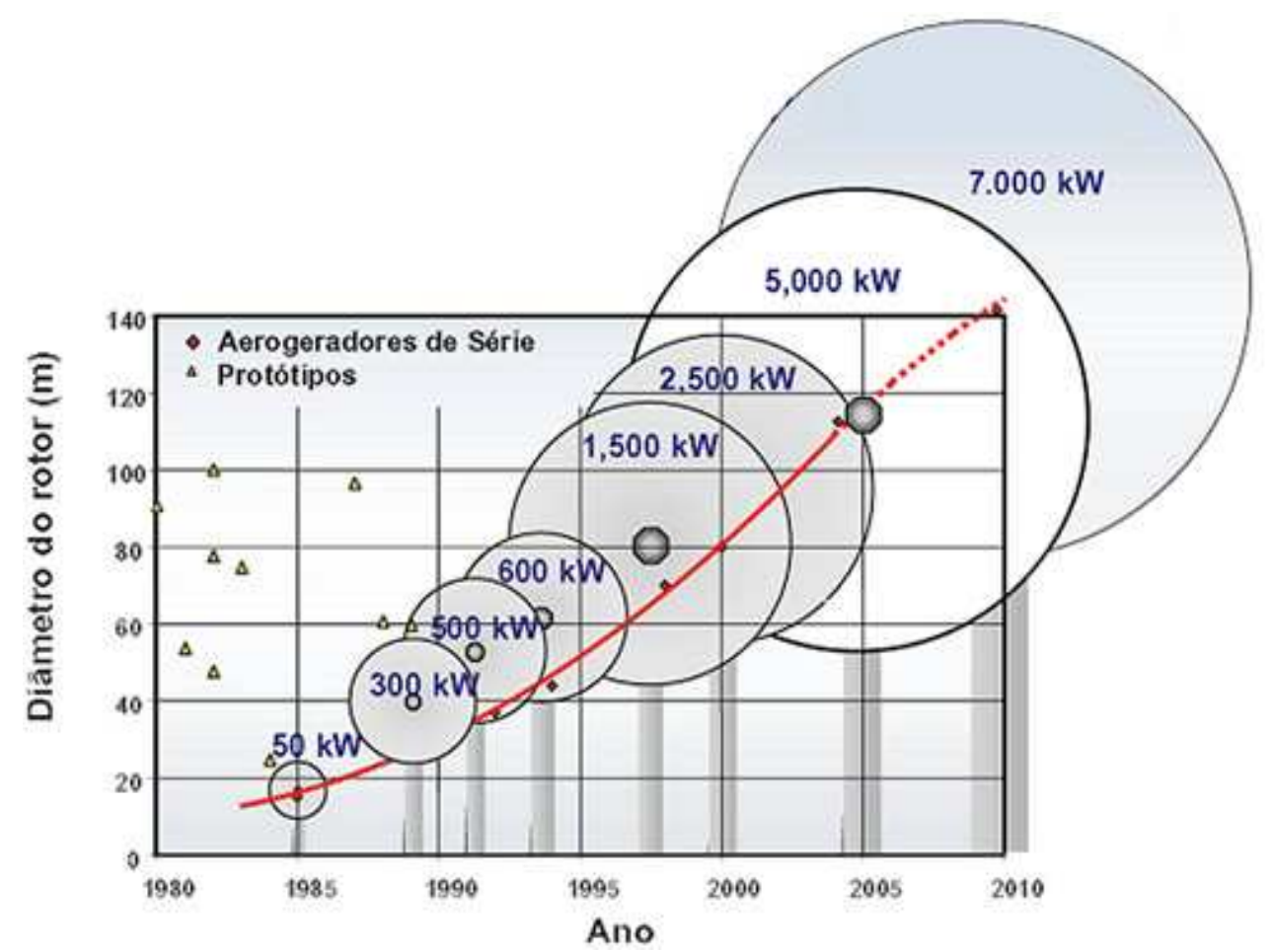

Figura 9 - Evolução dos aerogeradores desde 1985 até 2005 Fonte: WEC, 2010

A energia eólica provém da radiação solar uma vez que os ventos são gerados pelo aquecimento não uniforme da superfície terrestre. Uma estimativa da energia total disponível dos ventos ao redor do planeta pode ser feita a partir da hipótese de que, aproximadamente, $2 \%$ da energia solar absorvida pela Terra são convertidas em energia cinética dos ventos. Este percentual, embora pareça pequeno, representa centena de vezes a soma da potência anual instalada de todas as centrais elétricas do mundo.

A seguir, é apresentado o cálculo do potencial teórico de energia eólica no território brasileiro. 
A potência de geração dos ventos é dada pela equação abaixo:

$$
\mathrm{P}=\frac{1}{2} \dot{\mathrm{m}} \cdot \mathrm{V}^{2}[\mathrm{~W}]
$$

Onde:

- $\mathrm{P}=$ potência do vento, [W] (Watts);

- $\dot{\mathrm{m}}=$ massa de ar por unidade de tempo, $[\mathrm{kg} / \mathrm{s}] ; \mathrm{e}$

- $\mathrm{V}=$ velocidade do vento, $\mathrm{em} \mathrm{m} / \mathrm{s}$

Sendo que a massa do ar, por unidade de tempo, que atravessa o aerogerador com a velocidade $v$ expressa por:

$$
\dot{\mathrm{m}}=\rho \cdot \mathrm{A} \cdot \mathrm{V} \cdot[\mathrm{Kg} / \mathrm{s}](2)
$$

Onde:

- $\rho=$ massa específica do ar, $\left[\mathrm{kg} / \mathrm{m}^{3}\right]$;

- $A=$ área da seção transversal que intercepta o fluxo de ar, $\left[\mathrm{m}^{2}\right]$;

- $\mathrm{V}=$ velocidade do vento, $[\mathrm{m} / \mathrm{s}] ; \mathrm{e}$

A massa específica do ar é uma função da pressão e da temperatura do ar, que por sua vez, variam com a altitude. Sendo assim, pode-se dizer que:

$$
\rho=\mathrm{P}_{0} /(\text { R. T }) \exp \left(- \text { g. } \frac{\mathrm{z}}{\mathrm{RT}}\right)\left[\mathrm{kg} / \mathrm{m}^{3}\right](3)
$$

Onde:

- $\mathrm{P}_{0}=$ pressão atmosférica padrão ao nível do mar, $\left[\mathrm{kg} / \mathrm{m}^{2}\right]$;

- $\mathrm{R}=$ Constante especifica do ar, [J/kmol];

- $\mathrm{T}=$ Temperatura, $\left[{ }^{\circ} \mathrm{K}\right]$

- $g=$ aceleração da gravidade, $\left[\mathrm{m} / \mathrm{s}^{2}\right] ; \mathrm{e}$

- $\mathrm{z}=$ altitude, $[\mathrm{m}]$. 
Combinando as equações (1) e (2) tem-se que:

$$
\mathrm{P}=\frac{1}{2} \cdot \text { A. } \rho \cdot \mathrm{V}^{3}[\mathrm{~W}](4)
$$

A equação (4) também pode ser reescrita por unidade de área, definindo, desta forma, a densidade de potência DP, ou fluxo de potência:

$$
\mathrm{DP}=\frac{\mathrm{P}}{\mathrm{A}}=\frac{1}{2} \cdot \rho \cdot \mathrm{V}^{3} \quad\left[\mathrm{~W} / \mathrm{m}^{2}\right](5)
$$

A DP (5) é muito utilizada, pois basta conhecer a área e a velocidade do vento, para se obter uma estimativa do potencial eólico de uma região.

A partir dessas equações, pode-se perceber que a potência da saída das turbinas eólicas varia na forma direta e proporcional ao cubo da velocidade do vento. Assim, a variação de uma unidade na velocidade do vento implica em um aumento do cubo da potência disponível. Dessa maneira, a avaliação técnica do potencial eólico exige um conhecimento bem detalhado do comportamento do vento.

Os dados relativos ao comportamento do vento, que auxiliam na determinação do potencial eólico da região, são relativos à intensidade da velocidade e à direção do vento (dados vetoriais). Para obter esses dados, é necessário também analisar os fatores que influenciam o regime dos ventos na localidade do empreendimento, dentre eles o relevo, a rugosidade do solo e outros obstáculos distribuídos ao longo da região.

Os dados do comportamento dos ventos no Brasil estão sendo coletados, considerando médias anuais, mensais, diárias e sazonais, amostradas a cada 10 minutos.

Estas informações são importantes, porém, para determinação do potencial eólico para geração elétrica, será necessária a coleta e a análise desses dados durante vários anos.

O PNE-2030, revisão 2007, estimou o potencial de geração eólica do Brasil em 143,5 GW podendo gerar 272, 2 TWh/ano com geradores eólicos instalados em 
torres de $50 \mathrm{~m}$ de altura. Medidas mais recentes indicam um potencial acima de 300 $\mathrm{GW}^{24}$.

A seguir, na Tabela 5 apresenta-se a situação do parque eólico brasileiro.

Tabela 5 - Parque eólico brasileiro

\begin{tabular}{|c|c|c|}
\hline Geração Eólica & QTD. & $\begin{array}{l}\text { Pot. Instalada } \\
\text { MW }\end{array}$ \\
\hline Instalado e operando & 72 & 1.450 \\
\hline Em construção & 30 & 760 \\
\hline Outorgado & 153 & 4.740 \\
\hline Total & 255 & 6.950 \\
\hline
\end{tabular}

Fonte: BIG/MME jan/2012

\subsection{Biomassa de Cana (BIO)}

O setor sucroalcooleiro figura entre as mais tradicionais e antigas indústrias não extrativas de manipulação e processamento da biomassa no Brasil. A cana-deaçúcar é, desde o período colonial, uma cultura amplamente desenvolvida e o açúcar foi um produto de exportação básico para a economia brasileira durante alguns séculos. Do século $X V I$ ao século $X V I I I$, esta atividade tinha absoluta preponderância sobre todas as outras atividades econômicas desenvolvidas no país.

A cultura da cana-de-açúcar ganhou novo impulso em 1976, após a primeira crise dos preços do petróleo, quando foi instituído o Proálcool, programa do governo federal cujo objetivo na primeira fase era de expandir o uso do álcool anidro na gasolina. Após o segundo choque dos preços do petróleo, em 1979, iniciou-se uma segunda fase do programa visando à produção de álcool hidratado para ser usado como substituto da gasolina, baseando-se principalmente em destilarias autônomas e na expansão das áreas plantadas. A cana-de-açúcar é plantada principalmente no Sudeste e Nordeste, além do recente crescimento na região Centro-Oeste (MT, MS e GO). As maiores plantações estão no estado de São Paulo.

O conceito de cogeração, para o melhor aproveitamento da energia térmica para processos produtivos, pela geração de energia térmica e mecânica, com 
aproveitamento do calor residual é conhecido, e utilizado, desde o começo do século $\mathrm{XX}$, pois os grandes e médios empreendimentos industriais não tinham alternativas senão instalarem seus próprios sistemas de atendimento energético. Naquela época era significativa a participação desta tecnologia no atendimento das necessidades energéticas do setor produtivo. Assim como nos dias de hoje, plantas de cogeração já eram empregadas como forma de otimizar a geração de calor e força motriz, necessários à operação das indústrias e eram denominadas "plantas de energia total".

Neste contexto, considerando as peculiaridades de desenvolvimento do setor sucroalcooleiro no Brasil, bem como a necessidade de descartar o bagaço de canade-açúcar, até então subproduto considerado como um resíduo indesejável, iniciaram-se as primeiras iniciativas em geração de energia elétrica. A princípio, a energia gerada era apenas para consumo próprio (autossuficiência), sendo desenvolvidas tecnologias que não geravam mais do que $20 \mathrm{kWh}$ a $30 \mathrm{kWh}$ por tonelada de cana moída. Só recentemente (década de 1970), com a adoção de níveis de pressão mais elevada no vapor das caldeiras (chamado vapor vivo) e com turbinas mais eficientes, os ciclos a vapor passaram a produzir na ordem de $80 \mathrm{kWh}$ por tonelada de cana moída. Atualmente, considerando-se tecnologias ainda em processo de viabilização comercial no Brasil e no Mundo, pode-se produzir entre 340 e $500 \mathrm{kWh}$ de energia elétrica por tonelada de biomassa de cana (bagaço e parte das folhas e pontas) (ANDRADE CANELLAS, 2007). Este tipo de cogeração é ambientalmente limpa, com baixo ou nenhum impacto na produção de gases de efeito estufa.

$\mathrm{Na}$ cultura de cana-de-açúcar no Brasil, a safra se desenvolve predominantemente entre abril e novembro, ou seja, a maior produção de biomassa para cogeração ocorre nos meses mais secos, permitindo a complementaridade com geração hídrica.

Os principais gargalos existentes para geração de eletricidade, através da biomassa, devem ser solucionados, persistidos os esforços regulatórios. O custo de conexão das usinas de biomassa ao sistema elétrico nacional, que pelas regras vigentes são de responsabilidade do gerador, são considerados altos para um único produtor. Prevê-se poder compartilhá-los entre vários produtores no médio prazo, via ativos de conexão compartilhados. As discussões atuais se focam no modelo de 
negócios para geração de energia elétrica, segundo sua fonte primária e seus impactos na precificação da bioeletricidade.

Para se ter uma estimativa do potencial brasileiro de bioeletricidade a biomassa de cana, basta estimar a produção de cana-de-açúcar.

A Tabela 6, a seguir apresenta a projeção de expansão do mercado de bioeletricidade, de biomassa de cana, feita pela ÚNICA ${ }^{25}$ e COGEN ${ }^{26}$.

Tabela 6 - Cana-de-açúcar: Projeção da expansão da produção

\begin{tabular}{|l|c|c|c|c|}
\cline { 2 - 5 } \multicolumn{1}{c|}{} & Unidade & $\mathbf{2 0 1 0}$ & $\mathbf{2 0 1 5}$ & $\mathbf{2 0 2 0}$ \\
\hline Produção de cana-de-açúcar & $\mathbf{1 0}^{\mathbf{6}} \mathbf{x}$ ton & 605 & 829 & 1.038 \\
\hline Açúcar & $\mathbf{1 0}^{\mathbf{6}} \mathbf{x}$ ton & 33 & 41,3 & 45 \\
\hline Consumo Interno e estoque & $\mathbf{1 0}^{\mathbf{6}} \mathbf{x}$ ton & 8,9 & 11,4 & 12,1 \\
\hline Excedente para exportação & $\mathbf{1 0}^{\mathbf{6}} \mathbf{x}$ ton & 24,1 & 29,9 & 32,9 \\
\hline Etanol & $\mathbf{1 0}^{\mathbf{9}} \mathbf{x}$ litros & 26 & 46,9 & 65,3 \\
\hline Consumo Interno e estoque & $\mathbf{1 0}^{9} \mathbf{x}$ litros & 22,9 & 34,6 & 49,6 \\
\hline Excedente para exportação & $\mathbf{1 0}^{\mathbf{9}} \mathbf{x}$ litros & 3,1 & 12,3 & 15,7 \\
\hline Bioeletricidade ${ }^{*}$ ) & MW médios & 1.800 & 8.158 & 13.158 \\
\hline Participação na matriz energética & \% & $3 \%$ & $11 \%$ & $14 \%$ \\
\hline
\end{tabular}

Fonte: ÚNICA/COGEN 04/2010

$\left({ }^{*}\right)$ Biomassa $=75 \%+25 \%$ de palhas e pontas

\subsubsection{3 $\quad \mathrm{PCH}$}

O início da produção de energia elétrica através de $\mathrm{PCH}$ no Brasil data do final do século XIX, mais precisamente no ano de 1883. Neste ano o primeiro aproveitamento hidrelétrico, denominado "Ribeirão do Inferno", de propriedade da mineração Santa Maria, no município de Diamantina/MG, iniciou sua operação. Em seguida, foi implantada a Usina Bernardo Mascarenhas, de $250 \mathrm{~kW}$, no município de Juiz de Fora/MG: tinham como objetivo o atendimento da indústria têxtil daquela região. Até a primeira metade do século $\mathrm{XX}$, a modalidade de geração por $\mathrm{PCH}$ estava ligada, quase que exclusivamente, ao atendimento de sistemas isolados de pequenas indústrias, ou mesmo das prefeituras, e, consequentemente, o seu desenvolvimento e empreendimento estavam ao encargo da indústria ou do poder

\footnotetext{
25 União Nacional da Indústria de cana-de-açúcar

${ }^{26}$ Associação da Indústria de Cogeração de Energia
} 
público municipal. O crescimento da demanda para atendimento de sistemas isolados da indústria, e também dos próprios municípios nas condições citadas permaneceu em forte crescimento até a década de 1940, quando se iniciou um novo ciclo importante para o setor elétrico brasileiro. Este foi o principal motivo para o estabelecimento de diversas companhias de eletricidade, sendo que no ano de 1941 eram centenas de PCHs, mas poucas tinham um porte superior a de $3.000 \mathrm{~kW}$. Assim, pode-se dizer que as $\mathrm{PCH}$ foram as precursoras da matriz hidroenergética brasileira. A partir de então foi o início do investimento em grandes obras de geração, buscando economia de escala, sendo quase abandonados os investimentos em pequenas plantas, e sendo mantidas em operação somente as $\mathrm{PCH}$ que fossem estratégicas para suprimento de energia. (CARNEIRO, 2010).

Somente a partir da década de 1980, iniciou-se um processo longo na tentativa de reorganizar e incentivar a criação de $\mathrm{PCHs}$, sendo que o governo federal, por meio do Programa Nacional de Pequenas Centrais Hidrelétricas (PNPCH) do Ministério de Minas e Energia, promovem estudos, cursos, subsídios técnicos e legais para o desenvolvimento de iniciativas em investimento em PCHs. Desde 1984 diversos programas governamentais foram criados para incentivar a construção de pequenas centrais hidrelétricas.

O principal objetivo destes programas era reduzir o consumo de óleo, desenvolver a tecnologia local e o desenvolvimento das áreas rurais. No entanto, nos últimos 20 anos, apesar do lançamento de outros programas para promover a instalação de pequenas centrais hidrelétricas, a geração de energia a partir destas fontes não aumentou significativamente; pelo contrário: a geração por energia térmica, com ênfase em UTEs a derivados de petróleo, foi utilizada para suprir a demanda de áreas rurais ou isoladas e também os picos de falta de energia da rede.

Segundo a Lei 9.648 , de 27/05/1998, fixou-se o limite de potência de 30MW para a geração hidrelétrica ser classificada como PCH (ANEEL, 1998).

Pela Resolução ANEEL 652/2003, a definição de PCH é flexibilizada através de (6) que envolve a área alagada pelo reservatório da $\mathrm{PCH}$, a potência instalada e sua queda bruta:

$$
\mathrm{A} \leq \frac{14,3 * \mathrm{P}}{\mathrm{Hb}}
$$


Sendo:

- P: potência elétrica instalada [MW];

- A: área alagada do reservatório, $\left[\mathrm{km}^{2}\right]$;

- Hb: queda bruta, em metros, definida como a diferença entre os níveis d'água máximo normal de montante e normal de jusante, [m]

A tabela 7 apresenta as definições de porte de hidrogeração consideradas para este estudo.

Tabela 7 - Classificação das PCHs, no contexto do PIR-
\begin{tabular}{|l|c|}
\hline Classificação & Potência $($ KW $)$ \\
\hline Micro & $\mathrm{P}<100$ \\
\hline Mini & $100<\mathrm{p}<1.000$ \\
\hline Pequenas & $1.000<\mathrm{p}<30.000$ \\
\hline Médias & $30.000<\mathrm{p}<100.000$ \\
\hline Grandes & $\mathrm{p}>100.000$ \\
\hline
\end{tabular}

Fonte: UDAETA, 2008c

A Tabela 8 apresenta a evolução do parque instalado de PCHs no Brasil, a partir do ano 2000.

É interessante notar que a partir da resolução 343/2008 da ANEEL, que aumentou as exigências legais para outorga de $\mathrm{PCH}$, tivemos uma queda de 829 PCHs no estoque total no intervalo que vai de 2009 a 2010, passando de 3.158 para 2.329 PCHs em estoque, o que também pode ser observado na Tabela 8. 
Tabela 8 - Evolução do parque brasileiro de $\mathrm{PCHs}(1 \mathrm{MW}<\mathrm{P}<30 \mathrm{MW})$

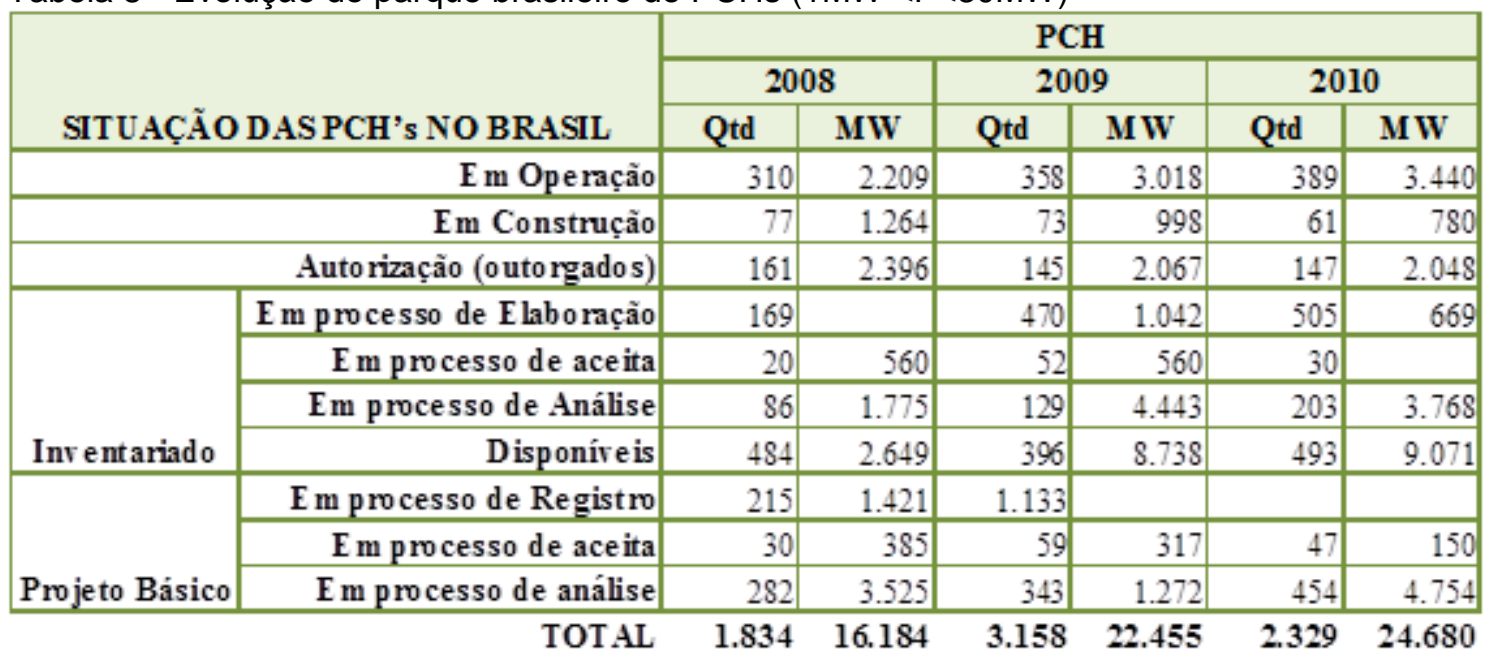

Fonte: BIG - ANEEL 07/2010

Essencialmente, o maior impacto se deveu à drástica diminuição do estoque de PCHs com status <Projeto Básico em processos de análise> decorrente das novas exigências estabelecidas ${ }^{27}$.

Em 2008 as regras de exploração de aproveitamentos tipo $\mathrm{PCH}$ foram modificadas através da resolução ANEEL 343/2008, que ampliou as exigências legais para se obter a licença prévia para exploração de aproveitamentos tipo $\mathrm{PCH}$. Detalhes da resolução podem ser vistos no Anexo C

\subsubsection{Taxas de transporte de energia na Geração Distribuída}

\subsection{Conexão e transporte de energia}

Devido à falta de normalização dos requisitos de conexão e dos deveres do acessante e do acessado na legislação vigente no Brasil, o estudo de viabilidade econômica de um sistema de geração distribuída, em caso de venda de excedentes, é muito dependente das regras da concessionária local, pois a legislação vigente (Resolução ANEEL no 281 de 01 de outubro de 1999, com algumas alterações) não é suficiente para dividir as responsabilidades do gerador e do distribuidor quanto ao acesso do primeiro à rede do segundo.

${ }^{27}$ Garantias exigidas na Resolução Normativa 343/08. 
Além das exigências variarem geograficamente, os valores pagos para a utilização do sistema de distribuição varia, assim como os possíveis contratos fixados entre as partes. Na Figura 10 estão apresentados os diversos contratos possíveis para compra/venda de energia elétrica.

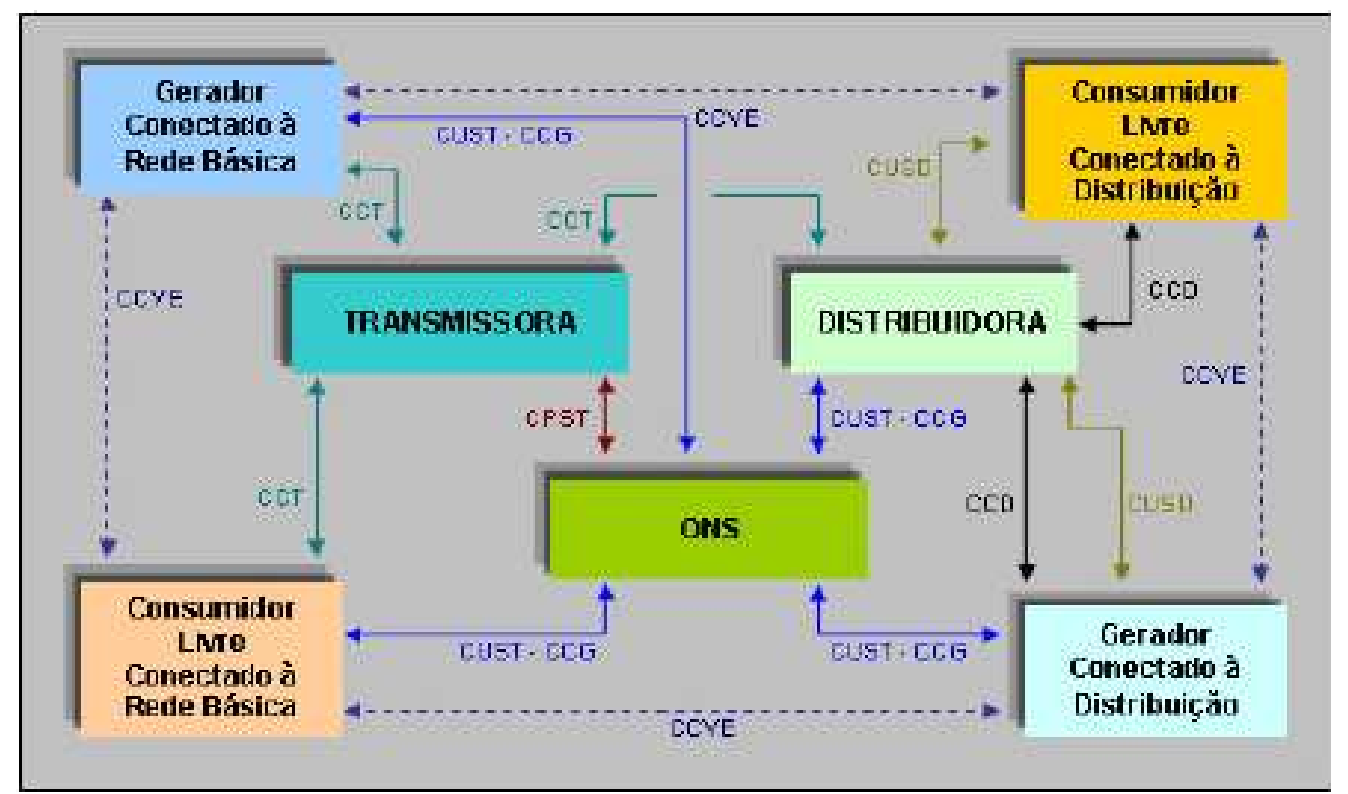

Figura 10 - Taxas e contratos na transmissão ou distribuição (gerador e cliente livre) Fonte: EPE/2010

Abaixo, apresentam-se as siglas presentes nas linhas da Figura 10.

Sigla

$\begin{array}{ll}\text { CPST } & \text { Contrato de Prestação de Serviços de Transmissão } \\ \text { CUST } & \text { Contrato de Uso do Sistema de Transmissão } \\ \text { CCT } & \text { Contrato de Conexão à Transmissão } \\ \text { CCG } & \text { Contrato de Constituição de Garantia } \\ \text { CUSD } & \text { Contrato de Uso do Sistema de Distribuição } \\ \text { CCD } & \text { Contrato de Conexão à Distribuição } \\ \text { CCVE } & \text { Contrato de Compra e Venda de Energia }\end{array}$

No cenário proposto para os recursos de geração avaliados neste estudo (geração distribuída de fonte incentivada), com consumidor e gerador conectados apenas à rede da distribuidora local, os contratos e taxas envolvidas são: (i) CCD para ambos, gerador e consumidor; (ii) CUSD, também para ambos, em que as fontes incentivadas têm desconto de $50 \%$ para ambos os lados, o que vem a ser 
uma vantagem competitiva para ambas as partes (Resolução ANEEL 247); (i) e 0 contrato bilateral entre ambas as partes, CCVE, devidamente registrado na CCEE.

\subsection{Demais taxas}

A única taxa adicional à conexão, que está sujeita a fonte distribuída incentivada do cenário proposto, é a Taxa de Fiscalização de Serviços de Energia Elétrica, pelo Decreto 2.410 de 28/11/1997 (BRASIL, 1997).

\subsubsection{Referências de preços de venda competitivos de energia na Geração Distribuída}

Um dos principais direcionadores da competitividade econômico-financeira de oportunidades em geração de energia elétrica é o preço que se consegue vender a energia gerada (SILVA, 2001; RAMOS, 2006).

No cenário proposto para os recursos de geração - 100\% geração distribuída de fonte incentivada - há três opções básicas para dispor da energia elétrica: a energia é comercializada no ACR (GD para ajuste da distribuidora, limitados a 10\% da carga), ou a energia é comercializada no ACL (dentro da área da concessionária local), ou a energia é destinada para consumo próprio.

Nas premissas do cenário de geração proposto nesta dissertação, a energia gerada será comercializada no modelo geração distribuída para outrem, logo, não será produzida para autoconsumo, principalmente porque os empreendimentos de geração serão SPC para produção e comercialização da energia. A energia também não será disponibilizada no ACR (com ordens de despacho central), pois, sendo GD, necessariamente será consumida dentro da região geográfica da Distribuidora local.

Assim, de acordo com o cenário proposto, ou a energia será vendida para a própria distribuidora local, ou a energia será comercializada para algum cliente livre, ou potencialmente livre, ambos ligados à distribuidora local.

Isto posto, passa-se à discussão sobre a escolha de um preço competitivo para a energia gerada, e que será utilizado nos modelos de fluxo de caixa representativos dos empreendimentos de geração avaliados. 


\subsection{Preços nos leilões do ACR}

Apenas nos modelos de avaliação de negócios que focam a venda de energia nos leilões do ACR é que os empreendedores podem ter a certeza do preço da energia comercializada antes de investir, e num longo prazo (de 20 até 35 anos). Por estas razões, os preços determinados nos leilões do ACR são os mais competitivos.

No ACR, o empreendedor que participa de um leilão público, mesmo antes do leilão, já tem um preço máximo (teto) definido. Então, o empreendedor, pressupostamente, tem a opção de só dar um determinado lance em leilão se considerar que o mesmo esteja dentro de limites de valores por ele aceitáveis, e, nesta condição, o lance dado pode ser entendido como de risco aceito a priori, já que, na data do leilão, o empreendimento ainda não recebeu investimentos.

Se um lance dado no leilão do ACR é vencedor, o empreendedor terá em mãos um contrato de compra de energia, por um período definido e normalmente longo, a preço que, apesar de ainda trazer riscos ${ }^{28}$, são conhecidos e pesados; sendo o contrato, CCEAR, amplamente aceito como garantia para o financiamento do empreendimento.

Como já exposto anteriormente, o preço da energia elétrica, definido em um leilão do ACR, passa efetivamente a afetar o preço médio da energia do ACR entre 3 (três) e 5 (anos) a partir da data do leilão, dependendo da data prevista no edital do leilão para início de entrega.

\subsection{Preço no Mercado spot}

O Preço de Liquidação das diferenças (PLD) é um preço determinado semanalmente para energia elétrica, e representa a percepção do conjunto de incertezas e riscos de curtíssimo prazo (mercado spot) que afetam a geração de energia em um determinado submercado de energia. Os únicos limitantes do PLD são os valores máximos e mínimos definido pelo CCEE no início de cada ano (para

${ }^{28}$ Caso o investidor utilize o EPC (Engineering Procurement and Constrution), os riscos de construção são, quase integralmente, repassados à empresa contratada para o EPC. 
o ano de 2011 o máximo foi de $R \$ 689,18 / \mathrm{MWh}$ e o mínino de $R \$ 12,08$ por $M W h$, respectivamente). Na prática, os preços sofrem grande variação ${ }^{29}$.

No gráfico 4 é apresentada a variação mensal do PLD para o submercado Sudeste, ao qual pertence a região em estudo.

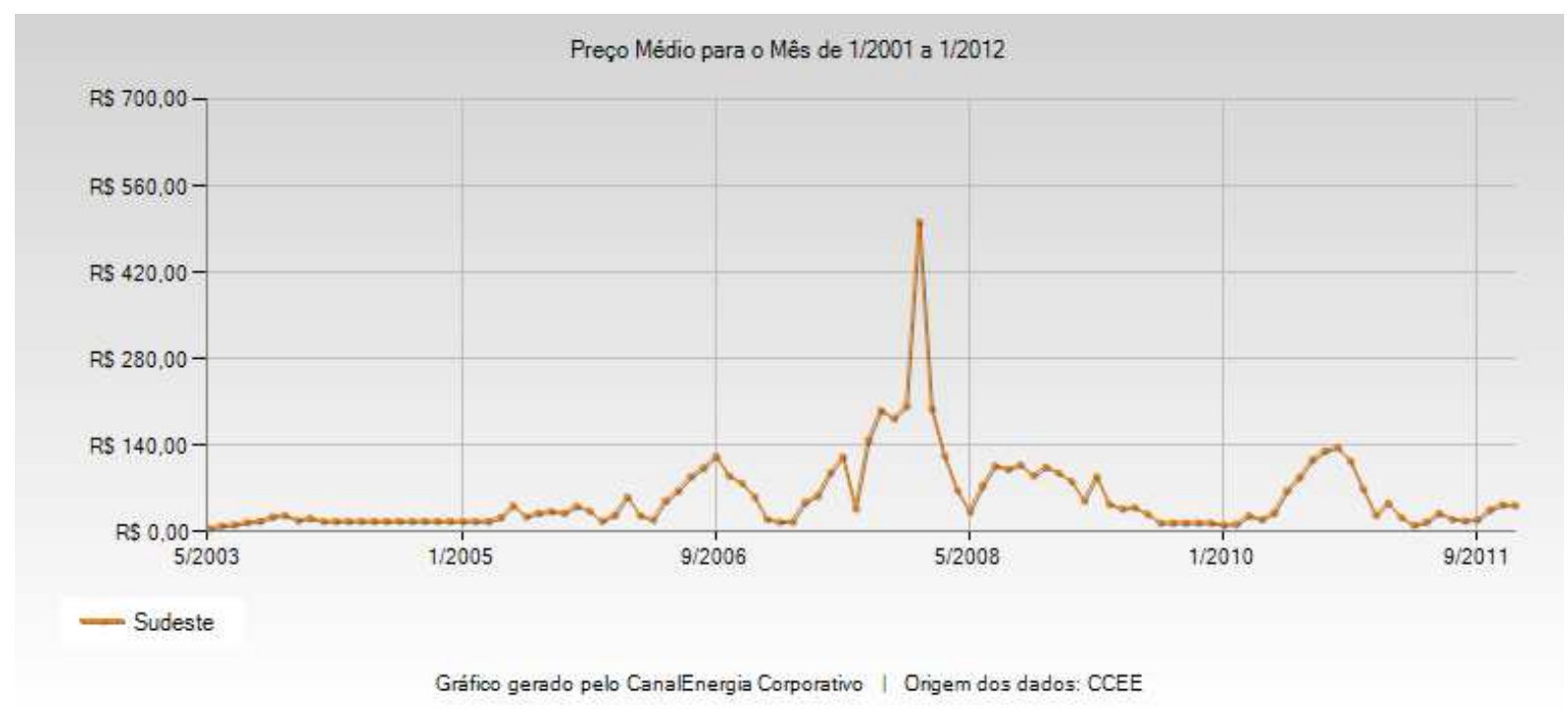

Gráfico 4 - Preço médio mensal do PLD para o submercado SE Fontes: www.ccee.org.br acessado em 12.12.2011

Como pode ser observado no gráfico 4, o PLD se mantém próximo dos valores mínimos de forma consistente. Sua ascensão para patamares superiores coincide com períodos secos, e baixos volumes de água nos reservatórios das usinas hidroelétricas. Observa-se também que o PLD mantém uma estreita correlação com o Custo Marginal de Operação $^{30}$ (CMO) do submercado.

Considerar o PLD para precificação da energia no médio e longo prazo não é estratégia que possa trazer vantagens para um gerador, considerando sua volatilidade.

\subsection{Valor de Referência de Energia Elétrica (VR)}

O valor de referência representa o maior valor de repasse de custo da energia que a distribuidora pode contratar nos leilões ajuste $(A-1)$ de energia, proveniente de

\footnotetext{
${ }^{29}$ www.ccee.org.br

${ }^{30}$ Custo calculado para produzir mais um MWh adicional de energia elétrica
} 
fontes de geração distribuída, portanto ele será outro balizador de preço para a geração distribuída, previsto no cenário de comercialização definido para esta dissertação. $O$ valor de referência da energia elétrica para um determinado ano $A$, é definido como a média ponderada entre a energia contratada no leilão $A-5$ e no leilão A-3.

A expressão matemática do VR (EPE, 2010) é:

$$
V R_{t}=\frac{E A C L_{(t-5)} * P U A C L_{(t-5) I P C A t}+E A C L_{(t-3)} * P U A C L_{(t-3) I P C A t}}{E A C L_{(t-5)}+E A C L_{(t-3)}}(7)
$$

Onde

- $\mathrm{t}=$ ano associado ao Valor de Referência calculado;

- $\mathrm{VR}_{\mathrm{t}}=$ Valor de Referência da energia do ACL no ano $\mathrm{t}$;

- $\mathrm{EACL}_{(\mathrm{t}-5)}=$ Total de energia contratada nos leilões de $\mathrm{A}-5$;

- $\operatorname{EACL}_{(\mathrm{t}-3)}=$ Total de energia contratada nos leilões de A-3;

- $\operatorname{PUACL}_{(t-5) \operatorname{PCA}}=$ Preço médio unitário da energia contratada nos leilões A-5, atualizada para o ano t através do IPCA;

- PUACL $(t-3)$ IPCAt $=$ Preço médio unitário da energia contratada nos leilões A-3, atualizada para o ano t através do IPCA.

A Tabela 55 - Energia elétrica - Valor anual de Referência (VR), apresentada no apêndice $B$ deste documento, apresenta os valores de referência calculados pela EPE até o ano de 2011.

\subsection{Preço médio no ACL}

Outro balizado do preço de comercialização de energia é o preço médio ponderado de toda energia, de todas as fontes e de todos os tipos, comercializada nos leilões de ACR.

A expressão matemática do preço médio da energia no ACR (EPE, 2010) é dada por: 


$$
P M A C L_{t}=\frac{\sum_{L=1}^{n} P U A C L_{t}^{L} * M W h_{t}^{L}}{\sum_{L=1}^{n} M W h_{t}^{L}}
$$

Onde:

- $\mathrm{t}=$ ano em que ocorreu o leilão;

- $L=$ Tipo do Leilão no ACR;

- $\mathrm{PMACL}_{\mathrm{t}}=$ Preço médio da energia elétrica no ano $\mathrm{t}$;

- $P U A C L_{t}^{L}=$; preço médio unitário da energia elétrica do Leilão $L$, no ano $t$

- $M W h_{t}^{L}=$ Energia do leilão $\mathrm{L}$, alocada para o ano $\mathrm{t}$;

- $\mathrm{n}=$ total de leilões no ano $\mathrm{t}$.

Atualizando o PMACL até a data da avaliação:

$$
\text { PMACLee }_{t(\text { IPCA atualizado })}=\text { PMACL }_{t} * \text { IPCA (9) }
$$

Onde:

IPCA atualizado é o IPCA entre a data do leilão e a data do cálculo do PMACL.

O gráfico com os preços médios dos leilões do ACR desde 2005 pode ser visto no apêndice $C$.

O preço médio de toda energia comercializada no ACR também é um balizador importante, porque fornece uma forte indicação da tendência. Pelo gráfico do apêndice C, observa-se que a tendência é de queda do preço a partir de 2014.

\subsection{Custo marginal de expansão da energia (CME)}

O Custo Marginal de Expansão da Energia (CME) representa o acréscimo de custo para suprir um aumento unitário na demanda, considerando ajustes no programa de obras, ou seja, representa a expectativa de custo da expansão do parque de geração de energia elétrica. Na hipótese de expansão ótima e contínua, o CME será o custo do empreendimento obtido da curva de custo de expansão ao qual se fica indiferente entre construir um novo projeto ou operar o sistema a fim de atender à demanda adicional. 
Matematicamente, o CME é a média ponderada dos preços esperados da energia por tipo de fonte (EPE, 2009).

$$
C M E=\frac{\sum_{i}\left(E g f_{i} * C_{i}\right)}{\sum_{i} E g f_{i}}
$$

Onde:

- $\quad \mathrm{CME}=$ Custo Marginal de Expansão $(\mathrm{R} \$ / M W h)$

- $\mathrm{Egf}_{\mathrm{i}}=$ Expansão da Garantia Física, prevista para Fonte i, para todo o Período (MWmed).

- $\mathrm{C}_{\mathrm{i}}=$ Custo estimado para fonte $\mathrm{i}(\mathrm{R} \$ / \mathrm{MWh})$

A Tabela 9 apresenta o CME projetado pela EPE, nos históricos revisados dos planos decenais, elaborado pela EPE.

Tabela 9 - Histórico das revisões do Custo Marginal de Expansão do ACR

\begin{tabular}{|c|c|l|}
\hline \multicolumn{1}{|c|}{ ESTUDO } & $\begin{array}{c}\text { CME } \\
\text { (R\$/MWh) }\end{array}$ & \multicolumn{1}{c|}{ CRITÉRIO } \\
\hline PDE 2006-2015 & 118,00 & $\begin{array}{l}\text { Preço médio (ponderado pelos lotes vendidos) do produto 2010 do LEN A-5 } \\
\text { de 2005. O preço máximo (130,00 R\$/MWh) foi utilizado como tolerância no } \\
\text { ajuste. }\end{array}$ \\
\hline PDE 2007-2016 & 138,00 & $\begin{array}{l}\text { Preço máximo do LEN A-5 de 2006. O estudo foi convergido a 138,00 } \\
\text { R\$/MWh (sem tolerância). }\end{array}$ \\
\hline PDE 2008-2017 & 146,00 & $\begin{array}{l}\text { Preço máximo nos leilões realizados ao longo do ano de 2008. Foi } \\
\text { utilizada tolerância de 3\% ( 4,00 R\$/MWh) para convergência do estudo. }\end{array}$ \\
\hline PDE 2019 & 113,00 & $\begin{array}{l}\text { Preço médio dos LEN de 2008 + Leilão de Projetos Estruturantes (UHE } \\
\text { Jirau e Santo Antônio). Não considera o LER. }\end{array}$ \\
\hline PDE 2020 & 113,00 & $\begin{array}{l}\text { Mantido o CME do PDE 2019, ou seja, obtido pelo preço médio dos LEN } \\
\text { de 2008 + Leilão de Projetos Estruturantes (UHE Jirau e Santo Antônio). } \\
\text { Não considera o LER. }\end{array}$ \\
\hline
\end{tabular}

Fonte: EPE-DEE-RE-091/2011-r0

Uma revisão posterior da EPE, já trabalhando o PDE 2021, indica um CME em queda para $\mathrm{R} \$ 102,0 / \mathrm{MWh}^{31}$.

O CME é um referencial de piso do custo da energia, considerando que seu cálculo leva em conta todo ACR, que representa $75 \%$ de toda energia elétrica gerada no país, com arranjos definidos em contratos de mais longo prazo ${ }^{32}$.

\footnotetext{
${ }^{31}$ EPE-DEE-RE-091/2011-r0

32 Superiores a cinco anos.
} 


\subsection{Preços dos leilões ano anterior (Base 2010)}

Normalmente valores médios representam bem a tendência de preço da energia elétrica gerada.

Entretanto, no biênio 2010-11 verificou-se uma queda importante de preços da energia nos leilões do ACR, principalmente relativos às fontes, alternativas, Eólica e Biomassa. Por esta razão, a EPE começou a desenvolver mais este indicador (leilão anterior), justificando-se pela tendência de leilões ACR específicos por fonte (EPE, 2011).

Apresenta-se a seguir a Tabela $10 \mathrm{com}$ preços de leilão, por tipo de fonte, relativos ao ano de 2011.

Tabela 10 - Custo da energia por
tipo de fonte do último ano $(2011)$
\begin{tabular}{|l|c|}
\hline \multicolumn{1}{|c|}{ Fonte } & $\begin{array}{c}\text { Custo } \\
\mathbf{( R \mathbf { M W h }} \mathbf{\text { MWh }}\end{array}$ \\
\hline Estruturante & 87,00 \\
\hline Hidrelétrica & 107,00 \\
\hline PCH & 156,00 \\
\hline Eólica & 100,00 \\
\hline Biomassa & 102,00 \\
\hline
\end{tabular}

Fonte: EPE-DEE-RE-091/2011-r0

\subsection{Preços no Ambiente de Contratação Livre (ACL)}

Os contratos bilaterais do $\mathrm{ACL}$, livremente praticados entre o comprador e o vendedor, não seguem regra comercial preestabelecida. As únicas exigências são que os contratos sejam registrados na CCEE, indicando volumes negociados e prazos. O registro das informações sobre os preços praticados não é exigido, e o volume registrado não é público. Estas informações - volumes e preços e de contratos bilaterais no ACL - são consideradas segredos comerciais. Assim, informações sobre eles só podem ser obtidas de fontes primárias, via de regra, sujeitas ao anonimato. 


\subsection{Preço de venda competitivo usado nos estudos de caso da Geração Distribuída}

Para os propósitos deste estudo, e com vistas a uma adequada escolha do preço de venda da energia gerada pelos recursos de Geração Distribuída com fontes incentivadas, foram feitas as seguintes considerações:

- O preço do MWh no ACR, referencial de mercado, apresenta, efetivamente, uma tendência de queda futura, já indicado pelos preços médios dos últimos leilões, como indica o gráfico do Apêndice $\mathrm{C}$.

- Os contratos de energia, negociados nos leilões do ACR, são de grande monta, de prazo longo (de 15 a 30 anos) e de grande liquidez. Isto indica importante poder de "barganha" do comprador, refletindo em preços menores, se comparados com os contratos de menor volume e menor prazo do ACL.

- A renegociação da energia velha no ACR, agora sem a necessidade de carregar a amortização dos investimentos iniciais, a partir de 2013 deverá reforçar a tendência de queda dos preços da energia no atacado, com efeitos de médio prazo.

- Não há, por parte da EPE, uma clara indicação de que a diferenciação do preço da energia por tipo de fonte permaneça como diretriz, a crédito da modicidade tarifária.

Considerando o conjunto de balizadores de preço competitivo da energia, mencionados no item anterior, e as razões expostas no parágrafo acima, este estudo adotou a seguinte orientação, conservadora, em relação aos preços de venda da energia gerada pelos três recursos de geração avaliados, no contexto da GD: O preço de venda da energia utilizado para popular os modelos matemáticos de avaliação da atratividade da geração distribuída das fontes alternativas foi de $R$ \$ $135,15 / \mathrm{MWh}$, o que corresponde a $85 \%$ do valor médio da energia pago pelas distribuidoras no ACR em 2011 (Apêndice C).

Esta redução de $15 \%$ do valor médio da energia no ACR representa a posição média dos preços atuais do ACL, obtido de fontes primárias em conversas e palestras. O preço adotado é inferior ao VR (preço máximo que a Distribuidora pode 
repassar para a tarifa de clientes cativos), superior ao CME (piso do ACL) e, por construção, conservadoramente abaixo do atual valor médio de referência de mercado (média do ACR), dada a tendência de queda futura observada.

Para avaliação do grau de competitividade do empreendimento, que quanto mais distante o preço de equilíbrio (preço para VPL=0) da geração, obtido dos modelos matemáticos que representam o empreendimento analisado, for do $\mathrm{CME}$ (R\$ 113,00/MWh no PDE 2010-19) menos atrativa é a geração .

\subsubsection{Taxa de atratividade utilizada para avaliar os recursos de geração}

A taxa mínima de atratividade do investidor pode ser entendida como a menor taxa de retorno aceitável pelos potenciais investidores para que se proponham a correr o risco associado a um ativo ou projeto, em um determinado setor da economia. Esta taxa é usada para atualizar os fluxos de caixas dos empreendimentos no tempo.

A forma clássica e consolidada de se fazer todas essas considerações é por meio do cálculo do CAPM (sigla em inglês para Modelo de precificação de capitais). (DAMODARAN, 2009; BREALEY E MYERS, 2003).

O cálculo do CAPM é bastante simples de ser feito, bastando a aplicação da seguinte fórmula:

$$
\mathrm{CAPM}=\mathrm{R}_{f}+\beta^{*}\left(\mathrm{R}_{\mathrm{m}}-\mathrm{R}_{\mathrm{f}}\right)(11)
$$

Onde:

$\mathbf{R}_{\mathrm{f}}=$ Taxa de retorno de um ativo livre de risco;

Para efeitos deste estudo, será a cotação dos títulos do tesouro dos Estados Unidos de 30 anos, descontada sua inflação interna, foi de zero\% (valor médio de 2011)

$\boldsymbol{\beta}=$ Risco sistêmico do Empreendedor (risco do investimento em comparação ao mercado)

$O \beta$ de um ativo representa a somatória do risco associado à atividade desempenhada pela empresa (risco do negócio ou da operação) e do risco associado à sua estrutura de capital, ou, de uma forma matemática, a covariância dos retornos dos ativos (ou projeto) em comparação com a média de mercado no Brasil. Para empresas de geração distribuída incentivada no Brasil, este trabalho considerou $\beta=2,45$ (calculado através do $\beta$ desalavancado de empresas americanas no mesmo ramo, visto que não há dados históricos confiáveis no Brasil).

$\left(\mathbf{R}_{\mathbf{m}}-\mathbf{R}_{\mathfrak{f}}\right)=$ Taxa média de retorno do mercado para o segmento de geração, descontada a taxa livre de risco.

Para o mercado americano, considerando séries históricas de 1928 a $2004^{33}$, obtém-se, para a diferença acima, o valor de $6,25 \%$ (media do retorno de ações das empresas americanas do mesmo segmento - $\mathrm{T}$ bounds do governo dos Estados Unidos em um período de 30 anos)

\footnotetext{
${ }^{33}$ http://pages.stern.nyu.edu/ adamodar/ acessado em 13.01.2012
} 
CAPM $_{\text {Geração }}$ Brasil 02/2012 $^{=} 0+2,45^{*}(6,25 \%-0)=15,31 \%$

\subsubsection{Roteiro para desenvolvimento de negócios em Geração}

Resumindo a legislação vigente, e melhores práticas, com vistas a dar uma visão geral, listou-se no Apêndice $D$ os principais cuidados e preocupações com um projeto de um empreendimento de geração.

\subsubsection{Medidas de Economia de Energia}

\subsubsection{Introdução}

O principal objetivo do uso da energia (usos finais) é assistir na satisfação das necessidades e desejos do ser humano. O que se deseja, porém, não é a energia em si, mas os serviços energéticos proporcionados pelas tecnologias de uso final.

Estes serviços são responsáveis pelo suprimento das principais necessidades sociais, como o condicionamento ambiental, o aquecimento de água, a iluminação, a cocção, o transporte e a força motriz, concretizados através de tecnologias de uso final, como lâmpadas, fogões, refrigeradores, veículos, entre outros, alimentados por energias secundárias como a elétrica ou de óleos combustíveis.

A Figura 11 apresenta o um quadro com os principais usos finais de energia. 


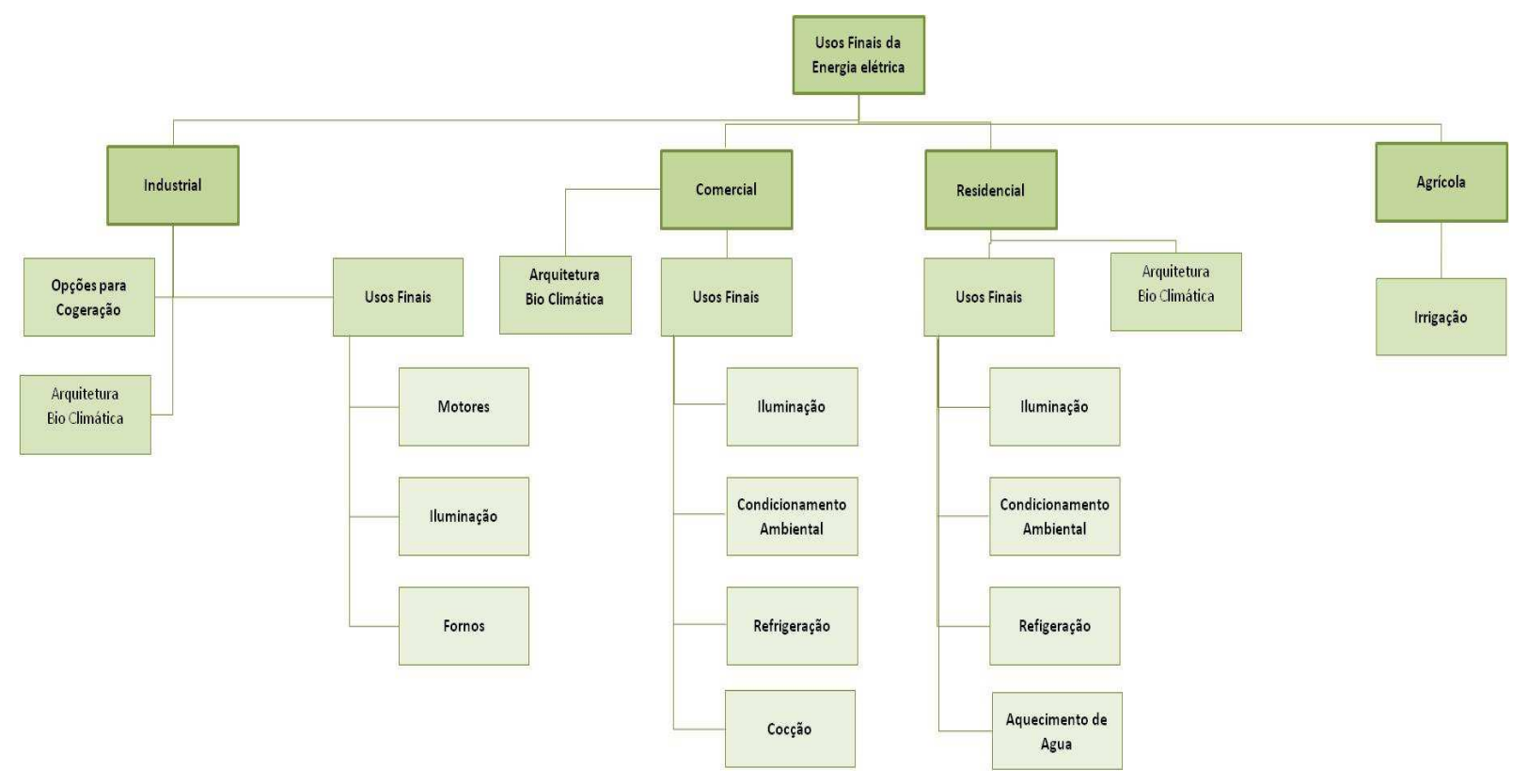

Figura 11 - Principais usos finais de energia

Fonte: elaboração própria, baseado EPE, 2010.

No âmbito estudo, os negócios de usos finais de energia são subdivididos em Medidas Educacionais (Mudança de hábitos), Medidas de Economia de Energia (Refrigeração, lluminação, Aquecimento e Cocção, Condicionamento Ambiental, Força motriz) e Arquitetura Bioclimática.

As oportunidades de negócio em medidas de economia de energia estão relacionadas com a (i) demanda por novas tecnologias, mais econômicas, em substituição de tecnologias menos econômicas, visando economia de energia, mantendo o mesmo nível de serviço; (ii) consultoria e treinamento para determinação das medidas de economia e ou mudanças de hábito; (iii) consultoria em projetos, novos materiais e mão de obra para implementação de estratégias arquitetônicas de economia de energia.

A ANEEL, através da resolução no 176/2005, determina que as distribuidoras de energia elétrica destinem, no mínimo, $60 \%$ de $0,50 \%{ }^{34}$ da receita operacional líquida $(\mathrm{ROL})$ para projetos voltados às comunidades de baixa renda. Tais projetos, segundo a mesma resolução, devem, ao mesmo tempo, atender aos critérios de apresentar, no máximo, uma Relação Custo-Benefício (RCB) igual a 0,80 e resultados de economia de energia equivalente a, no mínimo, 0,10\% (dez

\footnotetext{
${ }^{34}$ Caso a distribuidora comercialize menos de $1 \mathrm{GWh}$ /ano este percentual reduz-se para $0,25 \%$.
} 
centésimos por cento) do mercado consumidor de energia da concessionária ou permissionária. Esta abordagem - a avaliação de oportunidades de negócio em medidas de economia pelo lado da Distribuição - não é o foco deste estudo, mas é importante ser mencionado, como possibilidade de estudos futuros.

\subsubsection{Medidas de economia de energia em uma residência}

A Tabela 11 apresenta o Balanço de Energia Útil de 2005 (BEU, 2005), produzido pela EPE em 2006, com destinação específica para o segmento residencial, foco desta pesquisa. Neste balanço podemos verificar os números, e potenciais, nacionais associados a aquecimento direto e iluminação, respectivamente, coletores solares e lâmpadas fluorescentes, objeto deste estudo.

Tabela 11 - Uso da eletricidade no setor residencial

\begin{tabular}{|l|r|r|r|r|r|r||r|}
\hline & F.M. & C.P & A.D & REFRIG & ILUMIN. & OUTRAS & TOTAL \\
\hline Coeficientes de destinação & 0,03 & 0,26 & 0,08 & 0,32 & 0,24 & 0,07 & 1,000 \\
\hline Distribuição da energia final (GWh) & 2.357 & 20.430 & 6.286 & 25.145 & 18.858 & 5.500 & 78.576 \\
\hline Coeficientes de eficiência energética & 0,75 & 1 & 0,7 & 0,6 & 0,09 & 1 & 0,622 \\
\hline Coeficientes de eficiência de referência & 0,83 & 1 & 0,8 & 0,7 & 0,172 & 1 & 0,752 \\
\hline Distribuição de energia útil (GWh) & $1.768,0$ & $20.430,0$ & $4.400,3$ & $15.086,8$ & $1.697,3$ & $5.500,4$ & $48.882,8$ \\
\hline Potencial de economia de energia & 227,2 & & 785,8 & $3.592,10$ & $8.990,70$ & n.d & $13.595,8$ \\
\hline Economia & $\mathbf{9 , 6 0 \%}$ & & $\mathbf{1 2 , 5 0 \%}$ & $\mathbf{1 4 , 3 0 \%}$ & $\mathbf{4 7 , 7 0 \%}$ & n.d & $\mathbf{1 7 , 3 0 \%}$ \\
\hline
\end{tabular}

Fonte: Balanço Energia Útil 2005/ MME

\section{Legenda da Tabela 11}

F. M.: Força Motriz

C. P.: Calor de Processo

A.D.: Aquecimento Direto

REFRIG.: Refrigeração

ILUMIN.: Iluminação

OUTRAS: Outras
Energia consumida em motores estacionários.

Energia consumida em aquecedores de água.

Energia consumida em fornos de micro-ondas.

Energia consumida em geladeiras, freezers e aparelhos de ar condicionado.

Energia consumida em iluminação de interiores e externo.

Outros usos da energia como computadores, telecomunicação e equipamentos eletrônicos. 


\subsubsection{Medidas de economia avaliadas no estudo de caso}

Considerando o foco deste estudo em duas medidas de economia de energia - troca de lâmpadas e aquecedores solares de água para uso humano - na visão do usuário final, passa-se, a seguir, para um maior aprofundamento destas duas tecnologias.

\subsection{Iluminação}

A iluminação é um dos mais expressivos usos finais, respondendo por cerca de $40 \%$ do consumo de eletricidade no setor comercial e acima de $20 \%$ do consumo total de energia elétrica no setor residencial (EPE, 2010). No setor público, dois terços da eletricidade consumida são destinados à iluminação pública.

O emprego de uma dada fonte de iluminação está condicionado tanto à sua eficiência energética quanto à eficiência prática e adequação à atividade específica requerida. Como parte de equipamentos e tecnologias de iluminação, temos lâmpadas, luminárias, reatores, circuitos de iluminação e dispositivos de controle. As lâmpadas se dividem em dois grandes grupos: as incandescentes e as de descarga.

As lâmpadas de descarga produzem luz por meio de descarga elétrica contínua em um gás ou vapor ionizado. Funcionam com equipamentos auxiliares como reatores e ignitores.

O grupo de lâmpadas de descarga de baixa pressão abarca as lâmpadas fluorescentes, nas quais a luz é produzida por pós-fluorescentes ativados por radiação ultravioleta de descarga.

As lâmpadas fluorescentes compactas são capazes de substituir as incandescentes em diversas aplicações, apresentando o mesmo fluxo luminoso a partir de potências expressivamente menores (100W contra 500W de lâmpadas incandescentes), resultando em uma economia de energia de até $80 \%$, um enorme acréscimo de vida útil (até 8.000 horas contra 1.000 horas de lâmpadas incandescentes) e uma boa definição de cores .

$\mathrm{Na}$ Tabela 12 pode-se observar um resumo das lâmpadas descritas, por faixa de eficiência. 
Tabela 12 - Tipos de lâmpadas \& Eficiências

\begin{tabular}{|l|l|l|l|}
\hline \multicolumn{2}{|c|}{ INCANDESCENTE } & \multicolumn{2}{c|}{ DESCARGA } \\
\hline TIPO DE LÂMPADA & EFICIÊNCIA & TIPO DE LÂMPADA & EFICIÊNCIA \\
\hline COMUM & 8 a $18 \mathrm{Im} / \mathrm{W}$ & FLUORESCENTE & 56 a $75 \mathrm{Im} / \mathrm{W}$ \\
\hline HALÓGENA & 17 a $22 \mathrm{Im} / \mathrm{W}$ & $\begin{array}{l}\text { VAPOR DE } \\
\text { MERCÚRIO }\end{array}$ & 40 a $55 \mathrm{Im} / \mathrm{W}$ \\
\hline $\begin{array}{l}\text { HALÓGENA } \\
\text { DICRÓICA }\end{array}$ & $19 \mathrm{Im} / \mathrm{W}$ & VAPOR METÁLICO & $\begin{array}{l}68 \text { a } 100 \\
\mathrm{Im} / \mathrm{W}\end{array}$ \\
\hline LUZ MISTA & 19 a $27 \mathrm{Im} / \mathrm{W}$ & VAPOR DE SÓDIO & $\begin{array}{l}80 \text { a } 125 \\
\mathrm{Im} / \mathrm{W}\end{array}$ \\
\hline
\end{tabular}

Fonte: BAITELLO , 2011

\subsection{Aquecimento de água para uso humano}

O aquecimento de água é um dos principais usos finais do setor residencial e sua participação na matriz de consumo residencial conta com uma média nacional de $17 \%$, podendo chegar a $30 \%$ em regiões mais frias do país ${ }^{35}$.

Aquecedores elétricos funcionam pelo contato da água com resistências. Podem ser de passagem ou possuir reservatórios de acumulação, sendo o primeiro tipo o mais disseminado, por disponibilizar água a qualquer período de demanda apesar das perdas de calor. É representado majoritariamente pelo uso do chuveiro elétrico.

O principal componente do chuveiro é a resistência elétrica, sendo que a maioria dos chuveiros funciona sob tensão elétrica de $220 \mathrm{~V}$ e com duas potências diferentes, associadas a duas possibilidades de aquecimento, inverno e verão. A posição inverno corresponde à potência mais elevada e consequentemente, a um maior aquecimento.

O chuveiro elétrico, do ponto de vista energético, possui uma alta eficiência da ordem de $90 \% 36$, com uma alta taxa de conversão de energia elétrica em calor e baixo desperdício, visto que apenas a água a ser imediatamente utilizada é aquecida.

Apesar desta alta eficiência, as exigências de conforto de banho por parte dos usuários têm provocado uma elevação nas potências dos chuveiros.

\footnotetext{
${ }^{35}$ PROCEL, 2005

${ }^{36}$ www.eletrobras.com/procel
} 
A questão da utilização dos chuveiros, do ponto de vista das concessionárias de energia elétrica, também é de extrema importância, uma vez que o uso do chuveiro elétrico amplia consideravelmente a potência média instalada demandada e o pico de demanda residencial. Assim, apesar do baixo custo para o usuário final, o uso do chuveiro elétrico representa um elevado investimento em distribuição para as concessionárias, além do óbvio investimento em geração de pico.

A participação dos chuveiros na demanda em horário de ponta gira entre $20 \%$ e $25 \%$ (PROCEL), ou seja, o baixo fator de carga do equipamento produz uma pequena participação no faturamento das concessionárias, apesar de um elevado investimento associado ao atendimento da demanda máxima.

Pode-se concluir, portanto, que o potencial brasileiro de conservação de energia no aquecimento de água é bastante significativo, e a aplicação em larga escala dos aquecedores solares representa uma opção viável e competitiva para casos de alta demanda de água quente e bons níveis de insolação. Seu funcionamento consiste no bombeamento da água fria até o aquecedor, e posteriormente a um acumulador. Pode-se acionar um aquecedor convencional se a temperatura da água vinda do acumulador não estiver no intervalo de conforto do usuário.

A substituição da eletricidade pela energia solar, em aplicações para aquecimento de água, permite retirar a demanda (potência requerida) devida ao uso de chuveiro elétrico de um consumidor residencial, usualmente no período da ponta do sistema elétrico.

Seu campo de aplicação vai desde o fornecimento de água quente para o uso doméstico, aquecimento de piscinas, podendo ser utilizados inclusive em aplicações de climatização e refrigeração de alimentos (TOLMASQUIM, 2003).

\subsubsection{Taxas de atratividade usada nas medidas de economia de energia}

De acordo o cenário proposto para a avaliação das medidas de economia, o ponto de vista é o de uma família residente dentro da RAA, que irá decidir sobre realizar investimentos inferiores a $R \$ 5.000,00$. Nesta situação, foi considerada como taxa de desconto a média anual dos ganhos reais da poupança nos últimos 5 
anos (Jan/2006 a dez/2011), medidas como o ganho nominal da poupança, menos o IPCA do período. O valor médio calculado foi de 1,25\% a.a.

\subsection{PIR-USP NA PRÉ-AVALIAÇÃO DE NEGÓCIOS EM ENERGIA NA RAA}

O Planejamento Integrado de Recursos energéticos (PIR) é uma proposta metodológica para um Planejamento Energético Sustentável, criada e referenciada por quem tem preocupação com o uso racional da energia no longo prazo, na medida em que propõe avaliar status e sugerir caminhos e alternativas. No PIR, a geração e uso da energia são tratados nas dimensões técnico-econômica, ambiental, social e política, e sempre de forma integrada e a priori. Neste contexto, um time de pesquisadores do GEPEA/EPUSP revisitou o escopo do modelo de PIR histórico ${ }^{37}$, adequando-o às particularidades do Brasil e tornando-o mais efetivo na avaliação de uma determinada região geográfica e num determinado horizonte de tempo. Esta proposta metodológica é conhecida como PIR-USP.

O resultado final do PIR-USP para a RAA é a elaboração de um plano de ação para a produção e uso da energia de forma sustentável, após uma avaliação extensiva de uma determinada região geográfica, num dado tempo.

O PIR-USP para a RAA apresenta uma metodologia que: (i) produz conhecimentos abrangentes dos recursos energéticos na região geográfica em estudo; (ii) inclui ações que garantem a participação ampla da sociedade (que, na metodologia, é representada pelos Envolvidos e Interessados (acrônimo En-In) em temas relacionados a energia; (iii) considera as principais rotas tecnológicas disponíveis para exploração da fonte do recurso energético, sempre avaliando-as em quatro dimensões; (iv) classifica os recursos energéticos segundo um método de graduação quantitativo (Análise do Custo Completo, ou simplesmente ACC), obtido da avaliação extensiva, pesada e integrada, dos recursos nas quatro dimensões (REINIG, 2008; CICONE,2008; BAITELO 2011).

Para os propósitos deste estudo, a consulta ao PIR-USP para RAA permitiu: (i) de uma forma ampla, rapidamente levantar os potenciais teóricos e realizáveis dos recursos na região em estudo (ii) consultar a escala de avaliação ACC

\footnotetext{
${ }^{37}$ Modelo desenvolvido primeiramente na América do Norte (Canadá e Califórnia)
} 
(ranqueamento dos recursos energéticos, através da metodologia $\mathrm{PAH}^{38}$ ), especificamente para RAA, proporcionando uma graduação de risco/aceitabilidade da exploração do recurso; (iii) acessar dados utilizados para produção deste ranqueamento, para compor parâmetros e para análise de risco mais ampla.

Estas informações foram muito úteis nas avaliações dos recursos, na medida em que melhoraram a qualidade e economizaram tempo de busca das informações. Estas atividades são críticas nas etapas de pré-seleção e seleção de oportunidades de negócios a serem avaliadas, escopo deste estudo.

$\mathrm{Na}$ bibliografia de referência, apresentam-se as pesquisas, dissertações e teses realizadas no escopo do desenvolvimento do PIR-USP para RAA e do convênio FAPESP para o PIR-USP para a RAA relacionados nas referências bibliográficas (UDAETA, 2010).

\subsection{CARACTERIZAÇÃO DOS RES AVALIADOS NA RAA}

\subsubsection{Escolha dos recursos para estudo de caso}

$\mathrm{Na}$ Tabela 13 apresentam-se os recursos energéticos escolhidos, e justificados, para a pré-avaliação que se propõe nesta dissertação. Observe-se que a escolha abaixo não é a única possível, considerando os critérios metodológicos propostos para a escolha no parágrafo anterior, mas uma escolha reforçada também pela sua atual importância no cenário energético nacional dos recursos.

\footnotetext{
38 Avaliação dos Custos Completos através de um algoritmo chamado de Processo Analítico Hierárquico (CICONE, 2008)
} 
Tabela 13 - Escolha dos REs para estudo

\begin{tabular}{|c|c|c|c|}
\hline $\begin{array}{c}\text { Tipo } \\
\text { do } \\
\text { Recurso }\end{array}$ & Recurso & Jus tificativa & $\begin{array}{c}\text { Classificação } \\
\text { Ge ral na } \\
\text { ACC } \\
\text { do PIR-USP } \\
\text { para RAA }\end{array}$ \\
\hline \multirow{3}{*}{$\begin{array}{c}\text { GERAÇÃA } \\
\text { (Oferta) }\end{array}$} & PCH & $\begin{array}{l}\text { Recurso renovável, com boa avaliação da ACC do } \\
\text { PIR/USP para RAA. Aproveitamentos detetados na } \\
\text { região. Incentivado pelo governo (taxas de } \\
\text { transmissão e distribuição subsidiadas) e processo de } \\
\text { aprovação ambiental simplificado. Rota tecnológica de } \\
\text { exploração madura e dominada localmente. }\end{array}$ & $5^{\circ}$ \\
\hline & $\begin{array}{c}\text { Coge ração } \\
\text { Biomassa de } \\
\text { Cana }\end{array}$ & $\begin{array}{l}\text { Recurso renovável, com boa avaliação na ACC do } \\
\text { PIR/USP para RAA. Importantes aproveitamentos na } \\
\text { região. Incentivado pelo governo (taxas de transmissão } \\
\text { e distribuição reduzidas) e facilidades para aprovação } \\
\text { ambiental (os maiores impactos foram considerados na } \\
\text { aprovação da usina de açúcar e álcool e não para o } \\
\text { empreendimento em co-geração). Rota tecnológia de } \\
\text { exploração madura e dominada localmente. }\end{array}$ & $11^{\circ}$ \\
\hline & $\begin{array}{l}\text { Faze nda } \\
\text { Eólica }\end{array}$ & $\begin{array}{l}\text { Recurso renovável, com boa avaliação na ACC do } \\
\text { PIR/USP para RAA,importante aproveitamento na } \\
\text { região, incentivado pelo governo (taxas de transmissão } \\
\text { e distribuição reduzidas e facilidades para aprovação } \\
\text { ambiental (de fato os maiores impactos foram para } \\
\text { aprovação. }\end{array}$ & $8^{\circ}$ \\
\hline $\begin{array}{c}\text { MEDIDAS } \\
\text { DE ECONOMIA } \\
\text { DE E.E } \\
\text { (UsOS Finais) }\end{array}$ & $\begin{array}{l}\text { Coletor } \\
\text { Solar }\end{array}$ & $\begin{array}{l}\text { Medidas de economia de energia são recursos } \\
\text { renovaveis por definição. } 1^{\circ} \text { na avaliação do ACC do } \\
\text { PIR/USP para a RAA. A região tem uma temperatura } \\
\text { ambiente média alta (privilegiada pela insolação). } \\
\text { Governos Municipais e Distribuidoras têm incentivado } \\
\text { a troca, principalmente na baixa renda. A região tem } \\
\text { produção local de coletores e acumuladores, o que } \\
\text { incentiva o nível de emprego.Rota tecnologia de } \\
\text { exploração madura e dominada localmente. }\end{array}$ & $1^{0}$ \\
\hline
\end{tabular}

Fonte: elaboração própria

\subsubsection{Geração}

Pelos dados colhidos da RAA na ANEEL (ano base 2010) e corroborados pelo PIR-USP para RAA, a região é responsável por $47 \%$ da produção de energia elétrica do estado de São de Paulo. A fonte primária preponderante para produção de energia na Região é a hídrica de grande porte, através do aproveitamento dos cursos de água da região. Entretanto, nos últimos anos constata-se o crescimento do potencial da cogeração com uso da biomassa de cana para geração de energia elétrica.

Os resultados do levantamento do atual parque gerador da RAA são apresentados na Tabela 14. 
Tabela 14 - Geração de energia elétrica na RAA

\begin{tabular}{|c|c|c|c|c|c|c|c|c|c|}
\hline MUNICIPIO & GERADOR & $\begin{array}{c}\text { POTENCIA } \\
\text { INSTALADA } \\
\text { MW }\end{array}$ & COMBUSTIVEL & $\begin{array}{c}\text { GERADOR } \\
\text { TIPO }\end{array}$ & STATUS & TIPO & RECURSO & $\begin{array}{c}\text { BACIA } \\
\text { HIIDROGRÁFICA }\end{array}$ & URGH \\
\hline Andradina & Gasa & 82,000 & Bagaço de Cana & PIE & Operando & UTE & Renovável & & \\
\hline \multirow{4}{*}{ Araçatuba - ERP } & Alcooazul & 7,400 & Bagaço de Cana & APE & Operando & UTE & Renovável & & \\
\hline & Destivale & 3,200 & Bagaço de Cana & Registro & Operando & UTE & Renovável & & \\
\hline & Nestle & 0,725 & Oleo Diesel & Registro & Operando & UTE & Fossil & & \\
\hline & Santa Casa de Misericordia & 0,704 & Oleo Diesel & Registro & Operando & UTE & Fossil & & \\
\hline Avanhandava & Diana & 2,900 & Bagaço de Cana & Registro & Operando & UTE & Renovável & & \\
\hline Bento de Abreu & Benalcool & 4,200 & Bagaço de Cana & Registro & Operando & UTE & Renovável & & \\
\hline \multirow{2}{*}{ Brejo Alegre } & Biopav II & 65,000 & Bagaço de Cana & PIE & Construção & UTE & Renovável & & \\
\hline & Chapadão Agroenergia & 92,000 & Bagaço de Cana & PIE & Outorga & UTE & Renovável & & \\
\hline Buritama & Nova Avanhadava & 347,500 & Agua & PIE & Operando & UHE & Renovável & Baixo Tietê & 19 \\
\hline \multirow{2}{*}{ Castilho } & Aeroporto de Urubupunga & 0,018 & Oleo Diesel & Registro & Operando & UTE & Fossil & & \\
\hline & Viralcol Castilho & 15,500 & Bagaço de Cana & APE & Outorga & UTE & Renovável & & \\
\hline Clementina & Clealco & 11,200 & Bagaço de Cana & APE & Operando & UTE & Renovável & & \\
\hline General Salgado & Generalco & 3,800 & Bagaço de Cana & Registro & Operando & UTE & Renovável & & \\
\hline \multirow{2}{*}{ Guararapes } & Menu & 3,000 & Oleo Diesel & Registro & Operando & UTE & Fossil & & \\
\hline & Unialco & 38,000 & Bagaço de Cana & PIE & Operando & UTE & Renovável & & \\
\hline Illha Solteira & Ilha Solteira & $3.444,000$ & Agua & SP & Operando & UHE & Renovável & São José dos Dourados & 18 \\
\hline \multirow{2}{*}{ Pereira Barreto } & Interlagos & 40,000 & Bagaço de Cana & PIE & Operando & UTE & Renovável & & \\
\hline & Três Irmãos & 807,000 & Agua & SP & Operando & UHE & Renovável & Baixo Tietê & 19 \\
\hline \multirow{3}{*}{ Sud Mennucci } & Pioneiros & 32,000 & Bagaço de Cana & PIE & Operando & UTE & Renovável & & \\
\hline & Pioneiros II & 50,000 & Bagaço de Cana & $\mathrm{PIE}$ & Construção & UTE & Renovável & & \\
\hline & TOTAL & $5.050,147$ & & & & & & & \\
\hline
\end{tabular}

Fonte: elaboração própria, baseada em UDAETA, 2010

\section{A Tabela 15 apresenta a Geração de Energia Elétrica na RAA por tipo de} fonte.

Tabela 15 - Geração de energia elétrica na RAA (tipo de fonte)

\begin{tabular}{|c|c|c|c|c|c|}
\hline & & \multicolumn{2}{|c|}{ Empreendimentos } & \multicolumn{2}{|c|}{ MW Instalado } \\
\hline & & Núme ro & $\%$ & MW & $\%$ \\
\hline \multirow{3}{*}{ Tipo de Usina } & UTE & 18 & $85,71 \%$ & 451,647 & $8,94 \%$ \\
\hline & UHE & 3 & $14,29 \%$ & $4.598,500$ & $91,06 \%$ \\
\hline & $\mathrm{PCH}$ & 0 & $0,00 \%$ & 0,000 & $0,00 \%$ \\
\hline \multirow{2}{*}{ Tipo de Fonte } & Renovável & 17 & $80,95 \%$ & $5.045,700$ & $99,91 \%$ \\
\hline & Fossil & 4 & $19,05 \%$ & 4,447 & $0,09 \%$ \\
\hline \multirow{4}{*}{ Tipo de Gerador } & PIE & 8 & $38,10 \%$ & 746,500 & $14,78 \%$ \\
\hline & $\mathrm{APE}$ & 3 & $14,29 \%$ & 34,100 & $0,68 \%$ \\
\hline & Serviço Público & 2 & $9,52 \%$ & $4.251,000$ & $84,18 \%$ \\
\hline & Registro & 8 & $38,10 \%$ & 18,547 & $0,37 \%$ \\
\hline \multirow{3}{*}{ Tipo de Combustível } & Água & 3 & $14,29 \%$ & $4.598,500$ & $91,06 \%$ \\
\hline & Bagaço de Cana & 14 & $66,67 \%$ & 447,200 & $8,86 \%$ \\
\hline & Óleo Diesel & 4 & $19,05 \%$ & 4,447 & $0,09 \%$ \\
\hline \multirow{3}{*}{ Status } & Operando & 17 & $80,95 \%$ & $4.827,647$ & $95,59 \%$ \\
\hline & Outorga & 2 & $9,52 \%$ & 107,500 & $2,13 \%$ \\
\hline & Construção & 2 & $9,52 \%$ & 115,000 & $2,28 \%$ \\
\hline
\end{tabular}

Fonte: elaboração própria, baseada nos levantamentos do site da ANEEL/ BIG (Dez 2010) 
Como pode ser observado nas tabelas 14 e 15, a RAA tem instalado mais de 5.000 MW de geração de energia elétrica dentro de suas divisas. Observa-se que não há nenhum aproveitamento de $\mathrm{PCH}$, nem tão pouco Eólico, em produção ou em construção. Observa-se também que $91 \%$ do parque de geração é de hidrelétricas, e o restante é termelétrico. Ainda considerando o parque de geração da região, $8,86 \%$ é termelétrica a biomassa de cana e $0,09 \%$ é de termelétrica movida por combustível fóssil. Exatamente $99,1 \%$ do parque instalado na região é composto de recursos renováveis e apenas $0,09 \%$ é de origem fóssil. Apenas 4,41\% do parque instalado está em outorga (2,13\%) ou construção $(2,28 \%)$, o restante já está em plena produção. Plantas de geração públicas representam $84,18 \%$ do parque instalado. O restante é privado.

Outro aspecto em relação à geração térmica renovável da RAA é que, dos 447,2 MW de geração com biomassa de cana, 12,9 MW são exclusivamente para geração própria, sem previsão de exportação (Gerador tipo registro, na Tabela 14).

$\mathrm{Na}$ Tabela 16 apresentam-se os potenciais de geração dentro da RAA.

Tabela 16 - Potencial inventariado de energia elétrica inventariados pelo PIR na RAA

\begin{tabular}{|c|c|c|c|c|c|c|c|}
\hline \multirow{3}{*}{ Recurso } & \multirow{2}{*}{\multicolumn{3}{|c|}{ Produtos }} & \multicolumn{2}{|c|}{ Potencial Teórico } & \multicolumn{2}{|c|}{ Potencial Realizável } \\
\hline & & & & \multirow{2}{*}{ MWh/ano } & \multirow{2}{*}{ tEP/ano } & \multirow{2}{*}{ MWh/ano } & \multirow{2}{*}{ tEP/ano } \\
\hline & Tipo & Faixa de Potência & Qtd pontos & & & & \\
\hline \multirow{6}{*}{ Hídricos } & Pico Geração & $1 \mathrm{Kw}<\mathrm{P}<100 \mathrm{Kw}$ & 6 & 8.173 & 685 & n.d. & n.d. \\
\hline & Micro Geração & $100 \mathrm{Kw}<\mathrm{P}<1 \mathrm{Mw}$ & 86 & 425.736 & 35.686 & n.d. & n.d. \\
\hline & Mini Geração & $1 \mathrm{Mw}<\mathrm{p}<10 \mathrm{Mw}$ & 160 & 3.273 .086 & 274.358 & n.d. & n.d. \\
\hline & PCH's & $10 \mathrm{Mw}<\mathrm{P}<30 \mathrm{Mw}$ & 2 & n.d. & n.d. & 175.200 & 14.686 \\
\hline & $\begin{array}{l}\text { Grande } \\
\text { Geradoras }\end{array}$ & Acima de $30 \mathrm{Mw}$ & já instaladas & 51.077 .066 & 4.391 .837 & 51.077 .066 & 4.391 .837 \\
\hline & & & Total & 54.784 .061 & 4.702 .566 & 51.252 .266 & 4.406 .523 \\
\hline \multirow{10}{*}{ Biomassa } & \multirow{5}{*}{$\begin{array}{l}\text { Resíduos } \\
\text { Agrícolas }\end{array}$} & \multirow{4}{*}{ Cana-de-açúcar(*) } & Bagaço & n.d. & n.d. & \multirow{2}{*}{3.198 .000} & \multirow{2}{*}{268.064} \\
\hline & & & Pontas e Folhas & n.d. & n.d. & & \\
\hline & & & Vinhoto & n.d. & n.d. & n.d. & n.d. \\
\hline & & & Total & n.d. & n.d. & 3.198 .000 & 268.064 \\
\hline & & \multicolumn{2}{|c|}{ Outras plantações } & 3.323 .057 & 285.731 & n.d. & n.d. \\
\hline & \multicolumn{3}{|c|}{ Resíduos Animais } & 1.548 .709 & 133.165 & n.d. & n.d. \\
\hline & \multicolumn{3}{|c|}{ Lixo Urbano } & 63.160 & 5.294 & n.d. & n.d. \\
\hline & \multicolumn{3}{|c|}{ Esgoto } & 222.127 & 18.619 & 66.638 & 5.586 \\
\hline & \multicolumn{3}{|c|}{ Biodiesel } & 385.000 & 13.241 & 15.400 & 1.291 \\
\hline & \multicolumn{3}{|c|}{ Álcool } & 3.628 .440 & 311.975 & 1.814 .220 & 152.072 \\
\hline \multirow{2}{*}{ Solar/ano } & \multicolumn{3}{|c|}{ Fototérmico [Conservação por coletores solares] $\left.{ }^{* \star *}\right)$} & 255.400 & 22.602 & 178.780 & 15.821 \\
\hline & \multicolumn{3}{|c|}{ Fotovoltáico por $\mathrm{m}^{2}$} & $0,23 /$ por $\mathrm{m}^{2}$ & 0,02 por $\mathrm{m}^{2}$ & 0,034 por $\mathrm{m}^{2}$ & 0,0029 por $\mathrm{m}^{2}$ \\
\hline Eólico(**) & \multicolumn{3}{|c|}{ Vento } & n.d. & n.d. & 7.923 .760 & 701.218 \\
\hline $\begin{array}{c}\text { Medidas de }\left({ }^{* \star *}\right) \\
\text { Economia/ano }\end{array}$ & \multicolumn{3}{|c|}{ Troca de Lâmpadas incandescentes por fluorescentes } & 81.887 & 7.247 & 57.321 & 5.073 \\
\hline
\end{tabular}

(*) Pontencial baseado na produção de biomassa de cana, apenas das usinas existentes - sem crescimento de área plantada : Retrofit

(**) FC 24\%, ocupando 1,5\% area da RAA com 1.900 turbinas de $82 \mathrm{~m}$ de diâmetro e $\mathrm{h}=98 \mathrm{~m}$

$\left.{ }^{* \star *}\right)$ Potencial realizável $=70 \%$ da População Urbana de 675.000 pessoas residindo em 164.000 residências urbanas

Fonte: elaboração própria, com base em UDAETA, 2008c

Considerando os dados dos potenciais já instalados, e os realizáveis, respectivamente Tabela 15 e Tabela 16, é apresentado na Tabela 17 a estimativa do 
potencial de expansão de geração de energia elétrica na RAA, segundo as pesquisas do PIR-USP. Por estas estimativas, e apenas considerando os recursos analisados no âmbito deste estudo, verifica-se um potencial de incremento da potência instalada de $90 \%$.

Tabela 17 - Potencial de crescimento da potência instalada na RAA (geração) ${ }^{* *}$

\begin{tabular}{|c|c|c|c|c|c|c|}
\hline \multirow[t]{2}{*}{ Recurso } & \multirow[t]{2}{*}{ Produto } & $\begin{array}{l}\text { Potencial } \\
\text { Realizável }\end{array}$ & \multirow[t]{2}{*}{ FC } & $\begin{array}{l}\text { Potência } \\
\text { Instalável }\end{array}$ & $\begin{array}{l}\text { Potência } \\
\text { Instalada }\end{array}$ & $\begin{array}{c}\text { Potencial estimado } \\
\text { de Crescimento }\end{array}$ \\
\hline & & MWh & & MW & MW & MW \\
\hline Hídrico & $\begin{array}{c}\mathrm{PCH} \\
1 \mathrm{MW}<\mathrm{P}<30 \mathrm{MW}\end{array}$ & 175.200 & $60,0 \%$ & 33,3 & 0 & 33,3 \\
\hline Vento & Fazenda Eólica & 7.923 .760 & $24,0 \%$ & $3.768,9$ & 0 & $3.768,9$ \\
\hline Biomassa $\left.^{*}\right)$ & Biomassa de Cana & 3.198 .000 & $54,5 \%$ & 669,6 & 447,2 & 222,4 \\
\hline
\end{tabular}

$\left.{ }^{(*}\right)$ Potencial estimado de crescimento = Potência Instalável - Potência instalada

Fonte: elaboração própria, com base em UDAETA, 2008c

\subsubsection{Geração Eólica (EOL)}

\subsection{Medição da velocidade do vento na RAA pelo PIR-USP}

Com vistas a estimar o potencial eólico da RAA, o time do PIR-USP para RAA, com ajuda financeira da FAPESP (através do projeto FAPESP oํ 03/06441-7) instalou na cidade de Araçatuba (sede da RAA) uma estação meteorológica. Esta estação mediu a intensidade dos ventos locais, além de temperatura e pressão, por 1 (um) ano, e a uma altura de 30 metros do solo, a intervalos de 10 em 10 minutos.

Como resultado obteve-se os seguintes resultados apresentados na Tabela 18. 
Tabela 18 - Velocidade $x$ frequência medida pelo PIR na RAA a $30 \mathrm{~m}$ do solo

\begin{tabular}{|c|c|c|c|}
\hline $\begin{array}{l}\text { Velocidade } \\
(\mathrm{m} / \mathrm{s}) *\end{array}$ & $\begin{array}{l}\text { Frequência } \\
\text { (horas) }\end{array}$ & $\begin{array}{c}\text { Frequência } \\
\%\end{array}$ & $\begin{array}{l}\text { Probabilidade } \\
\text { acumulada }\end{array}$ \\
\hline 1 & 155 & $2,00 \%$ & $99,1150 \%$ \\
\hline 2 & 715 & $8,00 \%$ & $94,1500 \%$ \\
\hline 3 & 1493 & $17,00 \%$ & $81,5490 \%$ \\
\hline 4 & 1764 & $20,00 \%$ & $62,9600 \%$ \\
\hline 5 & 1696 & $19,00 \%$ & $43,2130 \%$ \\
\hline 6 & 1328 & $15,00 \%$ & $25,9560 \%$ \\
\hline 7 & 840 & $10,00 \%$ & $13,5840 \%$ \\
\hline 8 & 429 & $5,00 \%$ & $6,3420 \%$ \\
\hline 9 & 202 & $2,00 \%$ & $2,7390 \%$ \\
\hline 10 & 82 & $1,00 \%$ & $1,1180 \%$ \\
\hline 11 & 33 & $0,00 \%$ & $0,4590 \%$ \\
\hline 12 & 17 & $0,00 \%$ & $0,1690 \%$ \\
\hline 13 & 6 & $0,00 \%$ & $0,0370 \%$ \\
\hline 14 & 0 & $0,00 \%$ & $0,0020 \%$ \\
\hline 15 & 0 & $0,00 \%$ & $0,0000 \%$ \\
\hline
\end{tabular}

Fonte: BERNAL, 2010 apub UDAETA 2008c

De acordo com a Tabela 18, calculou-se a velocidade média do vento, medida pela estação meteorológica gerenciada pelo PIR-USP na RAA, como sendo de 4,74 $\mathrm{m} / \mathrm{s}$, com uma variância de $3,31 \mathrm{~m} / \mathrm{s}$, a 30 metros do solo ${ }^{39} \mathrm{em}$ um período de 1 ano.

O Gráfico 5 apresenta os mesmos dados da Tabela 18.

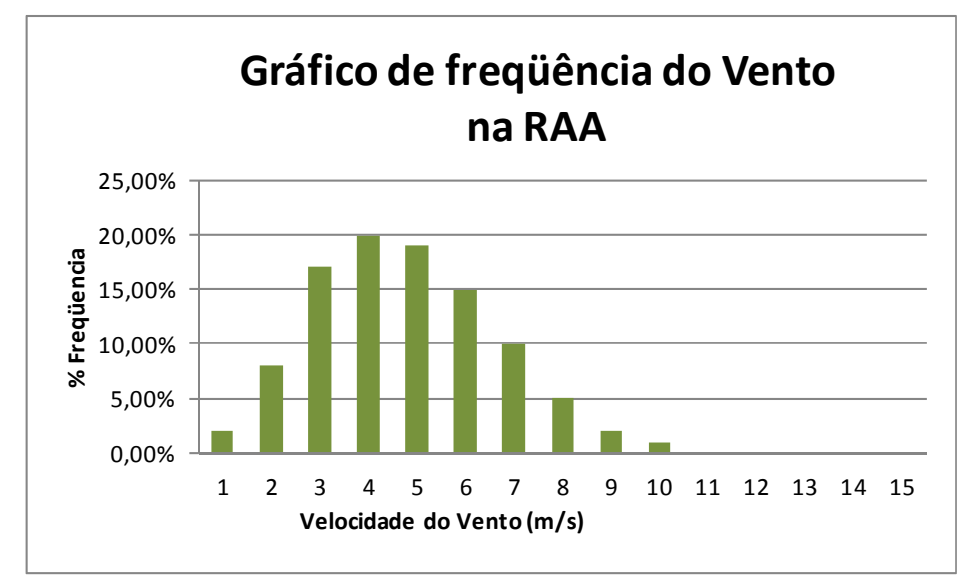

Gráfico 5 - Velocidade x frequência do vento na RAA a $30 \mathrm{~m}$ do solo Fonte: elaboração própria, baseada em Bernal, 2010

Como pode ser observado na Figura 12 - Velocidade média dos ventos no estado de São Paulo - CEPEL / 2001 as velocidades obtidas pelo equipamento do PIR-USP para RAA mantêm correlação com as medidas feitas para o mapa eólico brasileiro de 2001. 


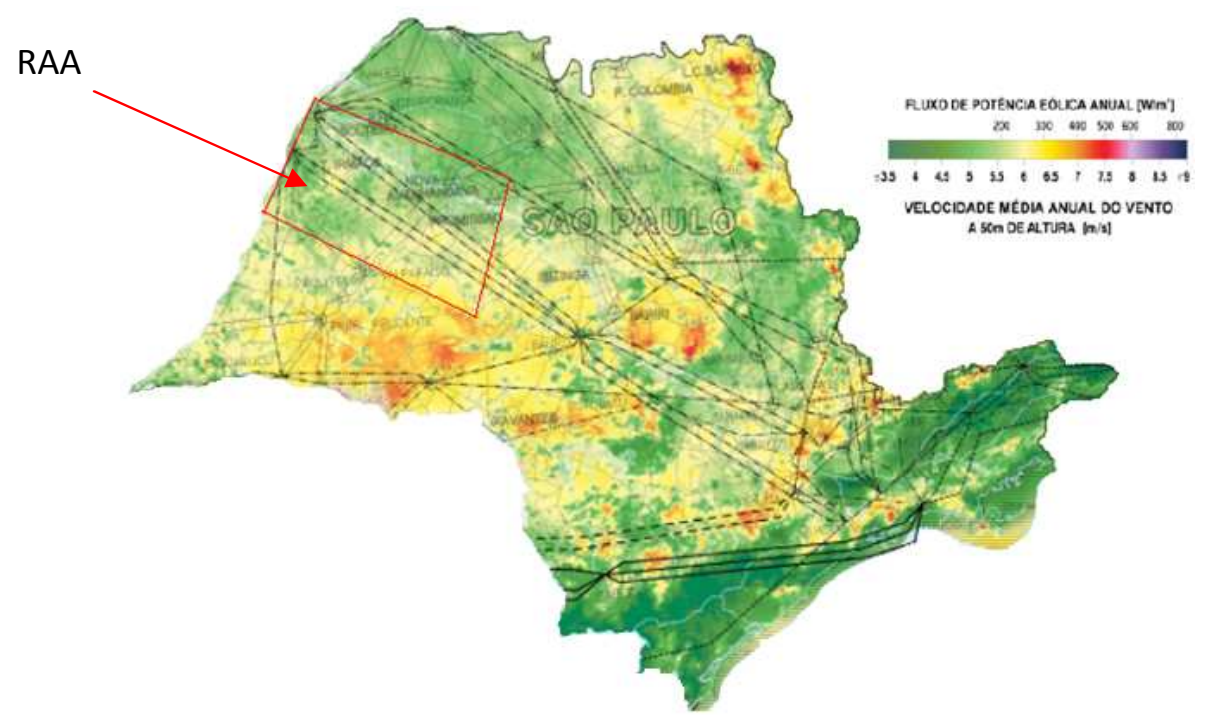

Figura 12 - Velocidade média dos ventos no estado de São Paulo - CEPEL / 2001 Fonte: Mapa Eólico Brasileiro - CEPEL 2001.

\subsection{Projetando a velocidade dos ventos para $85 \mathrm{~m}$ e $98 \mathrm{~m}$}

A equação (15) projeta uma determinada velocidade do vento para uma determinada altura, conhecendo-se a velocidade do vento em outra altura:

$$
V_{h}=V_{r}\left(\frac{H_{h}}{H_{r}}\right)^{n}
$$

Onde:

- $\mathrm{V}_{\mathrm{h}}$ é a velocidade à altura em que se quer determinar o potencial $(\mathrm{m})$;

- $\mathrm{V}_{\mathrm{r}}$ é a velocidade conhecida na altura de referência $\mathrm{Hr}(\mathrm{m} / \mathrm{s})$;

- $H_{h}$ é a altura a se determinar o potencial $(\mathrm{m} / \mathrm{s})$;

- $H_{r}$ é a altura em que já foi feita medida $(\mathrm{m} / \mathrm{s})$;

- $\mathrm{n}$ é o índice de descrição do terreno, determinado pela Tabela 19. 
Tabela 19 - Índice de descrição do terreno

\begin{tabular}{|l|c|}
\hline \multicolumn{1}{|c|}{ Indice de descrição do Terreno } & $\mathrm{n}$ \\
\hline Terreno sem Vegetação & 0,1 \\
\hline Terreno Gramado & 0,12 \\
\hline Terreno Cultivado & 0,19 \\
\hline Terreno com Poucas Árvores & 0,23 \\
\hline Terrenos com Muitas Árvores, cercas vivas ou poucas edificações & 0,26 \\
\hline Florestas & 0,28 \\
\hline Zonas Urbanas sem Edificações Altas & 0,32 \\
\hline
\end{tabular}

Fonte : UDAETA, 2008c apub FADIGAS 2007

Considerando a Figura 13 verifica-se que a melhor descrição para o terreno da RAA é entre Terreno Cultivado e o Terreno com poucas árvores, visto que a maioria dos terrenos da RAA ou são terras cultivadas ou terras de pasto. Assim, pode-se assumir que $n_{\text {RAA }}=0,20$

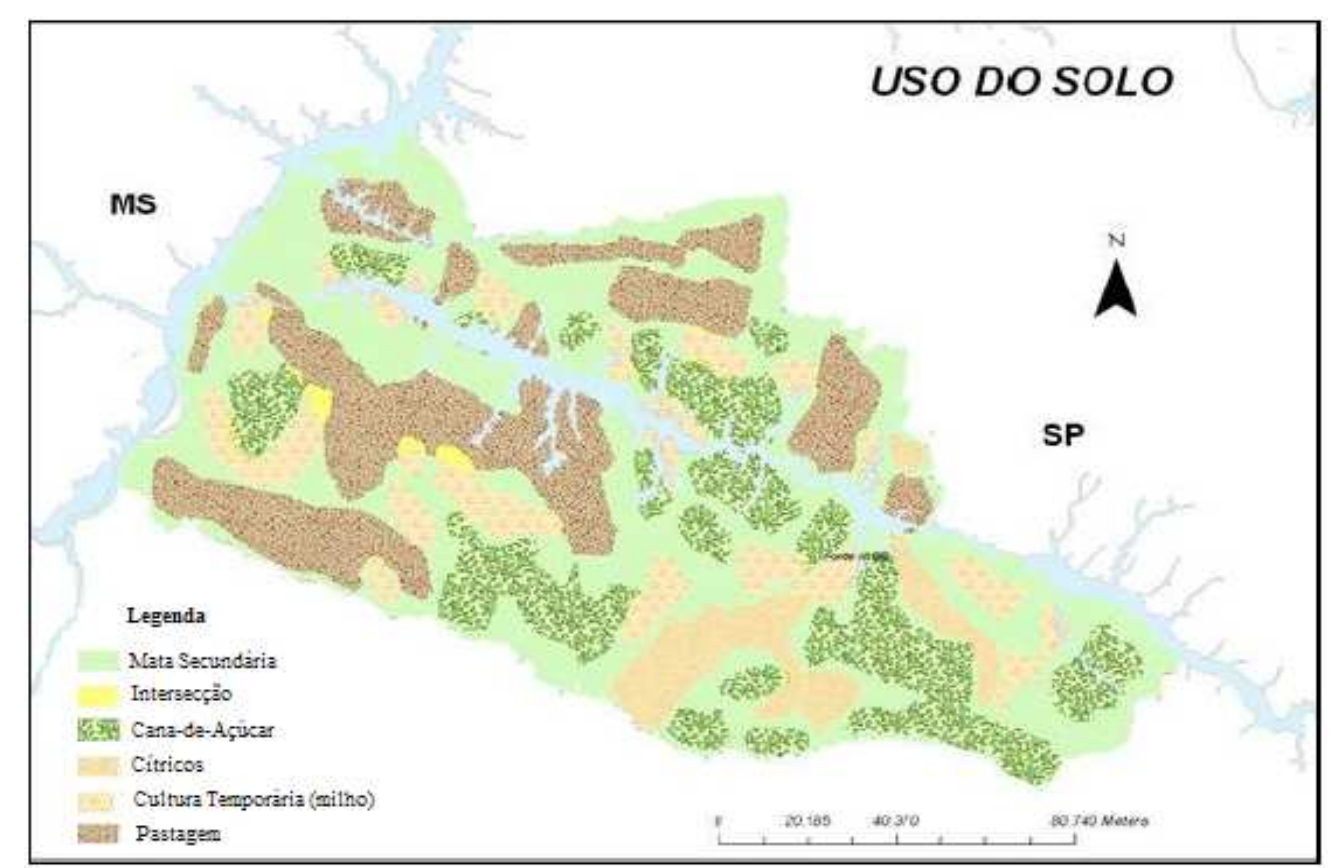

Figura 13 - Mapa de uso do solo da RAA Fonte: BERNAL, 2010

A Tabela 20 apresenta o cálculo das velocidades do vento na RAA para as alturas de $85 \mathrm{~m}$ e $98 \mathrm{~m}$, dada a velocidade medida a $30 \mathrm{~m}$ de altura. 
Tabela 20 - Projeção da velocidade do vento para 85 e 98 metros na RAA

\begin{tabular}{|c|c|c|c|}
\hline \multicolumn{2}{|c|}{$\begin{array}{c}\text { Vento } \\
\text { em Araçatuba } \\
\text { a } 30 \text { m de altura } \\
\text { [Medido] }\end{array}$} & $\begin{array}{c}\text { Velocidade } \\
\text { do Vento } \\
\text { Altura } 85 \mathrm{~m} \\
\text { [Projetado] }\end{array}$ & $\begin{array}{c}\text { Velocidade } \\
\text { do Vento } \\
\text { Altura 98 m } \\
\text { [Projetado] }\end{array}$ \\
$\begin{array}{c}\text { Velocidade } \\
(\mathrm{m} / \mathrm{s})\end{array}$ & $\begin{array}{c}\text { Frequência } \\
\text { (horas) }\end{array}$ & & \\
\hline 1 & 155 & 1,23 & 1,27 \\
\hline 2 & 715 & 2,46 & 2,53 \\
\hline 3 & 1493 & 3,69 & 3,80 \\
\hline 4 & 1764 & 4,93 & 5,07 \\
\hline 5 & 1696 & 6,16 & 6,34 \\
\hline 6 & 1328 & 7,39 & 7,60 \\
\hline 7 & 840 & 8,62 & 8,87 \\
\hline 8 & 429 & 9,85 & 10,14 \\
\hline 9 & 202 & 11,08 & 11,40 \\
\hline 10 & 82 & 12,32 & 12,67 \\
\hline 11 & 33 & 13,55 & 13,94 \\
\hline 12 & 17 & 14,78 & 15,21 \\
\hline 13 & 6 & 16,01 & 16,47 \\
\hline 14 & 0 & 17,24 & 17,74 \\
\hline 15 & 0 & 18,47 & 19,01 \\
\hline
\end{tabular}

Fonte: elaboração própria

A energia contida neste fluxo (vento) contínuo é dada por:

$$
E_{E o l}=\frac{1}{2} \rho \cdot A \cdot v^{3}
$$

Onde:

- $\rho$ é a densidade característica do ar de $1,225 \mathrm{~kg} / \mathrm{m}^{3}$, na pressão de $760 \mathrm{~mm}$ de $\mathrm{Hg}$ e na temperatura de $288^{\circ} \mathrm{K}\left(15^{\circ} \mathrm{C}\right)$;

- A é a área varrida pelas pás do gerador eólico $\left(\mathrm{m}^{2}\right)$;

- $\mathbf{v}$ é velocidade do vento $(\mathrm{m} / \mathrm{s})$. 


\subsection{Escolha dos parâmetros tecnológicos para o modelo de avaliação}

O aproveitamento da fonte eólica é feito de forma simples: a energia cinética dos ventos movimenta hélices, que por sua vez fazem girar o eixo de um gerador elétrico. Como a velocidade do vento não pode ser nula ao sair da hélice da turbina eólica, apenas uma fração da energia contida pode ser aproveitada. A fração máxima de aproveitamento mecânico da energia é conhecida por Limite de Betz e é igual a 16/27 (CASTRO, 2007).

O potencial máximo de aproveitamento deve levar em conta: (i) o Limite de Betz; (ii) o fator de capacidade associado à melhor tecnologia; (iii) e a distribuição ótima de turbinas na região, considerando que um gerador deve sempre guardar considerável distância para outro gerador para que a turbulência gerada neste não tenha maiores influências na geração do outro. $O$ usual de uma distribuição criteriosa é o resguardo de uma distância 5 a 9 vezes o tamanho do diâmetro da turbina na direção predominante do vento e de 3 a 5 vezes na direção perpendicular (CASTRO, 2007).

Para a RAA, o potencial máximo de aproveitamento deve levar em conta a área possível de instalação de fazendas eólicas. Para os propósitos desta dissertação, considerou-se o máximo de $1,5 \%{ }^{40}$ da área cultivada. Se considerarmos a área cultivada da RAA, Tabela 21 temos um total de $314 \mathrm{~km}^{2}$.

Tabela 21 - Área cultivada da RAA

\begin{tabular}{|l|c|c|c|}
\hline \multirow{2}{*}{ Uso do Solo } & \multirow{2}{*}{$\begin{array}{c}\text { Área } \\
\left(\mathrm{Km}^{2}\right)\end{array}$} & \multicolumn{2}{|c|}{$\begin{array}{c}\text { Intersecç̃oes } \\
\left(\mathrm{Km}^{2}\right)\end{array}$} \\
\cline { 3 - 4 } & & Milho & Cana de Açúcar \\
\hline Milho & 2.398 & & \\
\hline Cana-de-açúcar & 5.866 & 34 & \\
\hline Citricos & 1.296 & 6 & \\
\hline Pastagem & 4.627 & 108 & 7 \\
\hline Mata secundária & 5.155 & & \\
\hline Área alagada & 1.576 & & \\
\hline
\end{tabular}

Total $\quad 20.917 \quad 148$

Fonte: BERNAL, 2009

${ }^{40}$ BERNAL, 2010. 
Se forem utilizados conjuntos turbina-gerador de $82 \mathrm{~m}$ de diâmetro - Modelo Wobben E82-E2 - em apenas 1,5\% da área cultivável da RAA, (aproximadamente $300 \mathrm{Km}^{2}$ ) - será possível instalar, conservadoramente, 1.900 turbinas eólicas (E82E2) na RAA sem comprometer a ocupação do solo.

$\mathrm{Na}$ Tabela 22 apresentam-se as especificações técnicas da turbina Wobben, modelo E82-E2.

Tabela 22 - Especificações técnicas da turbina Wobben/Enercon E82-E2

\begin{tabular}{|r|c|}
\hline Potência nominal & $2.050 \mathrm{~kW}$ \\
\hline Diâmetro do Rotor & $82 \mathrm{~m}$ \\
\hline Altura do Hub & $78 \mathrm{~m} / 85 \mathrm{~m} / 98 \mathrm{~m} / 108 \mathrm{~m} / 132 \mathrm{~m}$ \\
\hline Área das pás & $5.281 \mathrm{~m}^{2}$ \\
\hline Celocidade de corte do vento & $28-34 \mathrm{~m} / \mathrm{s}$ \\
\hline Conceito WEC & Assíncrona, com velocidade variável \\
\hline Fator de disponibilidade técnica & 3 \\
\hline Fator de perdas técnicas no conjunto & $98 \%$ \\
\hline turbina-gerador-transformador & $98 \%$ \\
\hline
\end{tabular}

Fonte: Wobben/Enercom.

O Anexo D apresenta a curva de desempenho do conjunto turbina-gerador Wobben/Enercon E82-E2, fornecido pelo fabricante.

Considerando a tabela de velocidade $x$ frequência do vento (Anexo D) e considerando as especificações técnicas (tecnologia) da turbina, o potencial eólico da RAA a ser utilizado neste estudo, pode ser obtido da equação 15 (Wind Energy Explained, 2002):

$$
\begin{gathered}
\boldsymbol{E a}=\left[\sum_{i-1}^{v_{c}} P_{i}\left(V_{i} z r^{\prime}\right) * P c_{i}\right] * N T * F D * F P \\
E a=\left[\text { Energia }_{1 \text { gerador/ano }}{ }^{*} \mathrm{FD}{ }^{*} \mathrm{FP}\right]{ }^{*} \mathrm{NT}
\end{gathered}
$$


Onde:

- Ea: Estimativa da Energia Elétrica realizável na RAA;

- Vc: Velocidade de corte das pás dos aero geradores;

- $\mathrm{P}_{\mathrm{i}}(\mathrm{Vzr})$ : Frequência relativa dos ventos a velocidade $\mathrm{V}_{\mathrm{i}}$, da Tabela 20

- $\quad P_{C_{i}}$ : Curva de potência da turbina eólica, da Tabela 22;

- NT: Número de cataventos (turbina-gerador-transformador) passíveis de serem instaladas na RAA (1.900);

- FD: Fator de disponibilidade técnica forçada e programada do conjunto turbina-gerador (98\%);

- FP: Fator de perda técnica do conjunto catavento (98\%).

A Tabela 23 apresenta as estimativas de geração anual de energia de 1(um) gerador Wobben/Enercon E82-E2 ${ }^{41}$.

Tabela 23 - Estimativa da geração anual de energia de 1(um) gerador E82-E2 na RAA

\begin{tabular}{|c|c|c|c|c|c|c|c|c|c|c|}
\hline \multicolumn{2}{|c|}{$\begin{array}{c}\text { Frequencia do vento } \\
\text { a } 30 \mathrm{~m} \text { de altura } \\
\text { [Medido] }\end{array}$} & \multicolumn{3}{|c|}{$\begin{array}{c}\text { Torre a } 85 \text { metros de altura } \\
\text { [Projetado] }\end{array}$} & \multicolumn{3}{|c|}{$\begin{array}{c}\text { Torre a } 98 \text { metros de altura } \\
\text { [Projetado] }\end{array}$} & \multicolumn{3}{|c|}{$\begin{array}{c}\text { Torre a } 138 \text { metros de altura } \\
\text { [Projetado] }\end{array}$} \\
\hline $\begin{array}{l}\text { Velocidade } \\
\text { do vendo }\end{array}$ & Frequência & $\begin{array}{l}\text { Velocidade } \\
\text { do Vento }\end{array}$ & $\begin{array}{c}\text { Potência util } \\
\text { Extraida } \\
\text { Turbina } 2.000 \mathrm{KW} \\
\text { WOBBEN E82 }\end{array}$ & $\begin{array}{l}\text { Energia } \\
\text { Gerada }\end{array}$ & $\begin{array}{l}\text { Velocidade } \\
\text { do Vento }\end{array}$ & $\begin{array}{c}\text { Potência util } \\
\text { Extraida } \\
\text { Turbina } 2.000 \mathrm{KW} \\
\text { WOBBEN E82 }\end{array}$ & $\begin{array}{l}\text { Energia } \\
\text { Gerada }\end{array}$ & $\begin{array}{l}\text { Velocidade } \\
\text { do Vento }\end{array}$ & $\begin{array}{c}\text { Potência } \\
\text { útil } \\
\text { Extraida } \\
\text { Turbina } \\
2.000 \mathrm{KW} \\
\text { WOBBEN } \\
\text { E82 }\end{array}$ & $\begin{array}{l}\text { Energia } \\
\text { Gerada }\end{array}$ \\
\hline $\mathrm{m} / \mathrm{s}$ & horas/ano & $\mathrm{m} / \mathrm{s}$ & $\mathrm{kW}$ & kWh/ano & $\mathrm{m} / \mathrm{s}$ & $\mathrm{kW}$ & kWh/ano & $\mathrm{m} / \mathrm{s}$ & $\mathrm{kW}$ & $\mathrm{kWh} / \mathrm{ano}$ \\
\hline 1 & 155 & 1,23 & 0 & 0 & 1,27 & 0,00 & 0 & 1,36 & 1,08 & 0 \\
\hline 2 & 715 & 2,46 & 13 & 9.009 & 2,53 & 14,66 & 10.067 & 2,71 & 18,62 & 10.482 \\
\hline 3 & 1493 & 3,69 & 64 & 92.241 & 3,80 & 70,60 & 101.232 & 4,07 & 88,44 & 105.406 \\
\hline 4 & 1764 & 4,93 & 168 & 283.871 & 5,07 & 184,29 & 312.214 & 5,43 & 237,21 & 325.088 \\
\hline 5 & 1696 & 6,16 & 355 & 577.847 & 6,34 & 392,74 & 639.710 & 6,78 & 485,58 & 666.087 \\
\hline 6 & 1328 & 7,39 & 642 & 819.286 & 7,60 & 701,80 & 895.084 & 8,14 & 866,10 & 931.990 \\
\hline 7 & 840 & 8,62 & 1.041 & 840.054 & 8,87 & $1.132,55$ & 913.669 & 9,50 & $1.380,00$ & 951.342 \\
\hline 8 & 429 & 9,85 & 1.520 & 626.258 & 10,14 & $1.612,20$ & 664.245 & 10,86 & $1.777,80$ & 691.634 \\
\hline 9 & 202 & 11,08 & 1.824 & 353.780 & 11,40 & $1.878,00$ & 364.334 & 12,21 & $1.994,70$ & 379.356 \\
\hline 10 & 82 & 12,32 & 2.002 & 157.695 & 12,67 & $2.026,90$ & 159.624 & 13,57 & $2.050,00$ & 166.206 \\
\hline 11 & 33 & 13,55 & 2.050 & 64.971 & 13,94 & $2.050,00$ & 64.971 & 14,93 & $2.050,00$ & 67.650 \\
\hline 12 & 17 & 14,78 & 2.050 & 33.470 & 15,21 & $2.050,00$ & 33.470 & 16,28 & $2.050,00$ & 34.850 \\
\hline 13 & 6 & 16,01 & 2.050 & 11.813 & 16,47 & $2.050,00$ & 11.813 & 17,64 & $2.050,00$ & 12.300 \\
\hline 14 & 0 & 17,24 & 2.050 & 0 & 17,74 & $2.050,00$ & 0 & 19,00 & $2.050,00$ & 0 \\
\hline 15 & 0 & 18,47 & 2.050 & 0 & 19,01 & $2.050,00$ & 0 & 20,35 & $2.050,00$ & 0 \\
\hline \multirow{2}{*}{\multicolumn{2}{|c|}{8.760}} & & & i & & & $\begin{array}{c}4.170 .432 \\
\downarrow\end{array}$ & & & $\stackrel{4.342 .390}{\downarrow}$ \\
\hline & & Potência realizável & kWmed & 442 & & & 476 & & & 496 \\
\hline
\end{tabular}

Fonte: elaboração própria.

${ }^{41}$ www.wobben.com.br 
Considerando o Gerador E82E2 instalado na montagem de $98 \mathrm{~m}$ e considerando a quantidade de energia calculada para 1 gerador na Tabela 23 calcula-se o potencial realizável de Energia Eólica na RAA:

$$
\text { Energia Eólica } \text { realizável RAA }=1.900 \text { * 4.170,4 MWh /ano = 7.923,76 GWh/ano (16) }
$$

A Tabela 24 apresenta a estimativa do Fator de Capacidade do aerogerador escolhido, segundo o regime de ventos medido.

Tabela 24 - Estimativa do Fator de Capacidade dos aerogeradores Enercon na RAA

\begin{tabular}{|r|c|c|c|c|}
\hline & Unidade & E82 (85m) & E82(98m) & E82(138) \\
\hline Potência Instalada & KW & 2.000 & 2.000 & 2.000 \\
\hline Potência realizável & KWmed & 442 & 476 & 496 \\
\hline Fator capacidade estimado & Fracionário & 0,22 & 0,24 & 0,25 \\
\hline
\end{tabular}

Fonte: elaboração própria.

Como resultado decorrente, também se pode calcular o Fator de Capacidade (FC) da tecnologia escolhida, em 0,24 para a altura de $98 \mathrm{~m}$ do solo.

\subsubsection{Biomassa de cana (BIO)}

\subsection{Disponibilidade do combustível: biomassa de cana}

A biomassa de cana-de-açúcar é a principal fonte primária utilizada para cogeração de energia elétrica na RAA. Na safra 2006/07, segundo a Única ${ }^{42}$, foram colhidos 21 milhões de toneladas de cana na RAA. Também segundo a Única, a área plantada de cana no Brasil deverá crescer 71,5\% (5,5\% ao ano) no decênio 2006/2007 - 2016/2017, apenas para suportar a previsão de demanda dos veículos flexfuel, sem considerar o aumento da demanda interna e aumento de contratos de exportação de álcool e açúcar.

Segundo a $\mathrm{CTC}^{43}$, cada tonelada de cana, produz $250 \mathrm{~kg}$ de bagaço, e a mesma quantidade de pontas e palha, num total de $500 \mathrm{~kg}$ de biomassa, caso o

\footnotetext{
42 União Nacional da Indústria Canavieira

${ }^{43}$ Centro de Tecnologia Canavieira
} 
processo de colheita da cana seja mecanizado, ou seja, não fazendo uso das tradicionais queimadas. No Gráfico 6 apresenta-se o histórico passado e previsão futura da safra de cana (amarelo) na RAA.

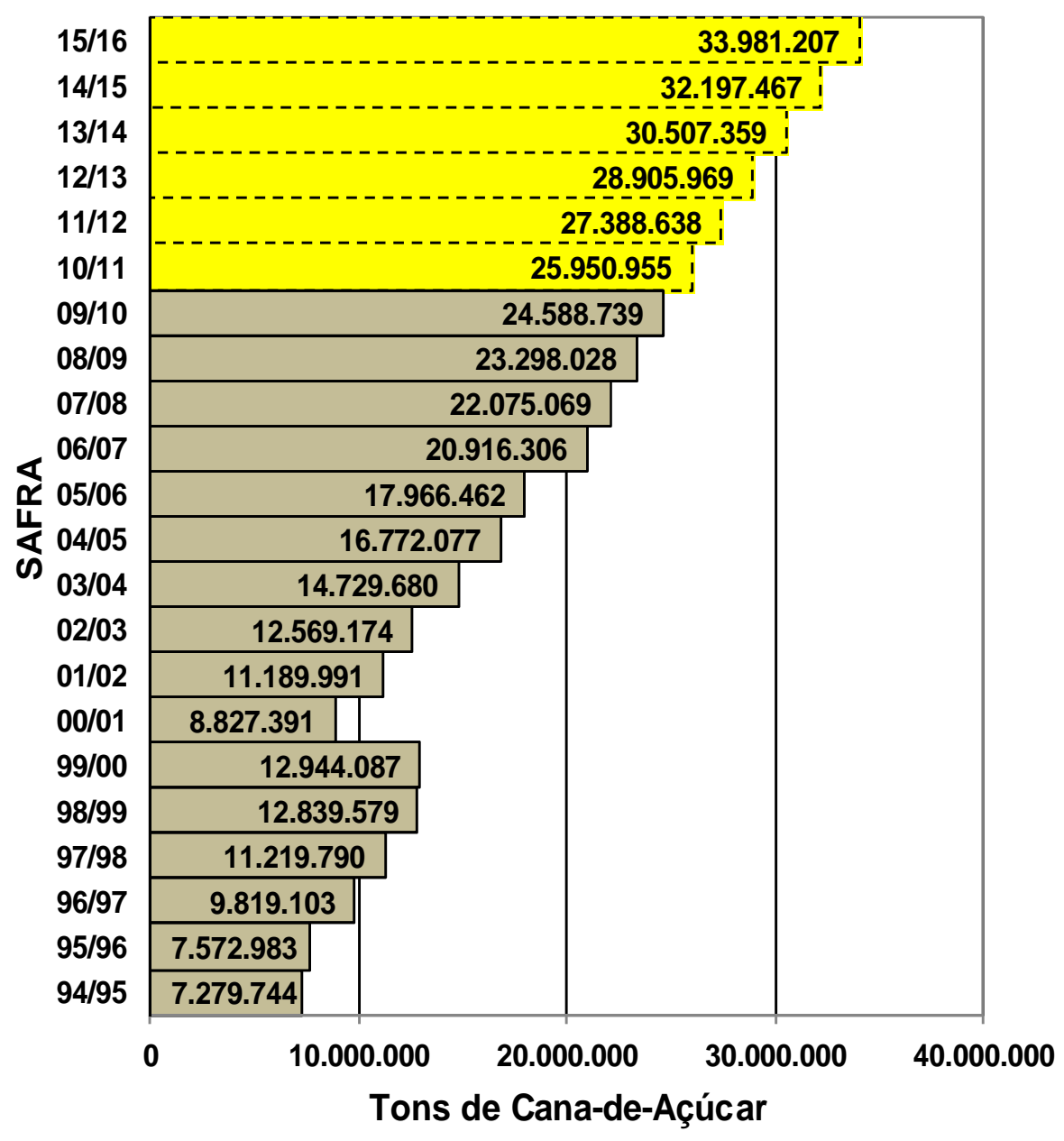

Gráfico 6 - Previsão das safras de cana de açúcar na RAA Fonte: UDOP.

\subsection{Estimativas do potencial realizável de geração na RAA}

- Disponibilidade de combustível: Safra de 25.950 .000 toneladas de cana $=$ $2,595 \times 10^{7}$ toneladas de cana;

- Combustível para geração térmica: $75 \%$ bagaço e $25 \%$ palha em peso;

- Taxa de produção de biomassa: 1 tonelada de cana gera $400 \mathrm{~kg}$ de biomassa (bagaço, folha e palha) (CENBIO, 2003); 
- Tecnologia adotada: Configuração caldeira gerador de extração e condensação de 65 bar (configuração com maior frequência de retrofit / novas instalações) (ANDRADE \& CANELLAS, 2007);

- Desempenho da tecnologia: geração de excedente de $140 \mathrm{kWh}$ por cada 400 $\mathrm{kg}$ de biomassa, em cogeração, ou 172 kWh por cada $400 \mathrm{~kg}$ de biomassa, em geração pura (ANDRADE \& CANELLAS, 2007);

- Cálculo de referência - Geração em cogeração: excedente de $2,46 \times 10^{7} \times$ 0,140 Mwh = 3.198 GWh (Base safra 2010/2011) (17)

- MWmed /ano $=3.198 \mathrm{GWh} \div 8766 \mathrm{~h}=364,8$ (18)

- $\mathrm{MWmed} / \mathrm{safra}=3.198 \mathrm{GWh} \div 5530 \mathrm{~h}=578$ (19)

\subsubsection{Geração hídrica de pequeno porte (PCH)}

No contexto do PIR-USP para a RAA, para o levantamento dos locais, e cotas, com potenciais aproveitamentos para $\mathrm{PCHs}$ foram utilizados os mapas com curvas de níveis, mapas hidrológicos das bacia UGRHI 19, a principal bacia da RAA. A rigor, a fim de considerar um trabalho completo, é necessário considerar também as bacias UGRHI-16 e UGRHI-20 e seus potenciais.

\subsection{Potencial teórico de PCH na RAA}

Para a determinação das cotas utilizou-se os mapas hidrológico e altimétrico, Figura 14 e Figura 15. Foram levantadas todas as cotas em sub-bacias delimitadas pela UGRHI-1944. Após o levantamento, foi calculada a diferença entre as cotas para determinação do potencial teórico deste recurso na região.

\footnotetext{
${ }^{44}$ A rigor, a fim de considerar o potencial completo da região, é necessário considerar também as bacias UGRHI-16 e UGRHI-20 e seus potenciais que, em menor escala, também cortam a região.
} 


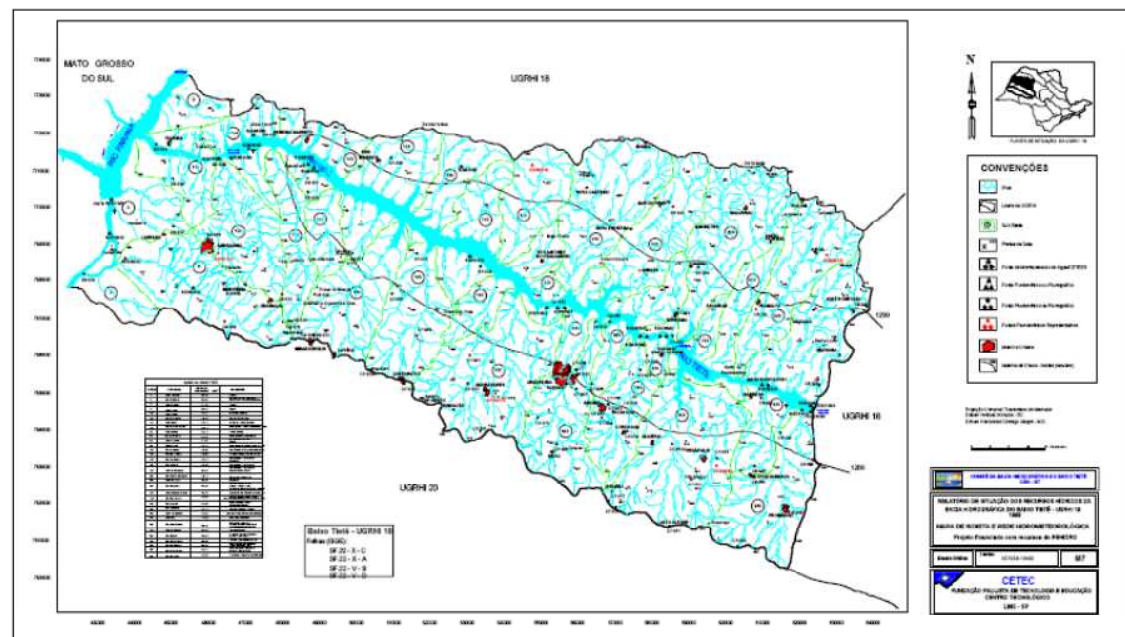

Figura 14 - Mapa hidrológico das bacias e sub-bacias hidrográficas da RAA. Fonte: UDAETA, 2008c

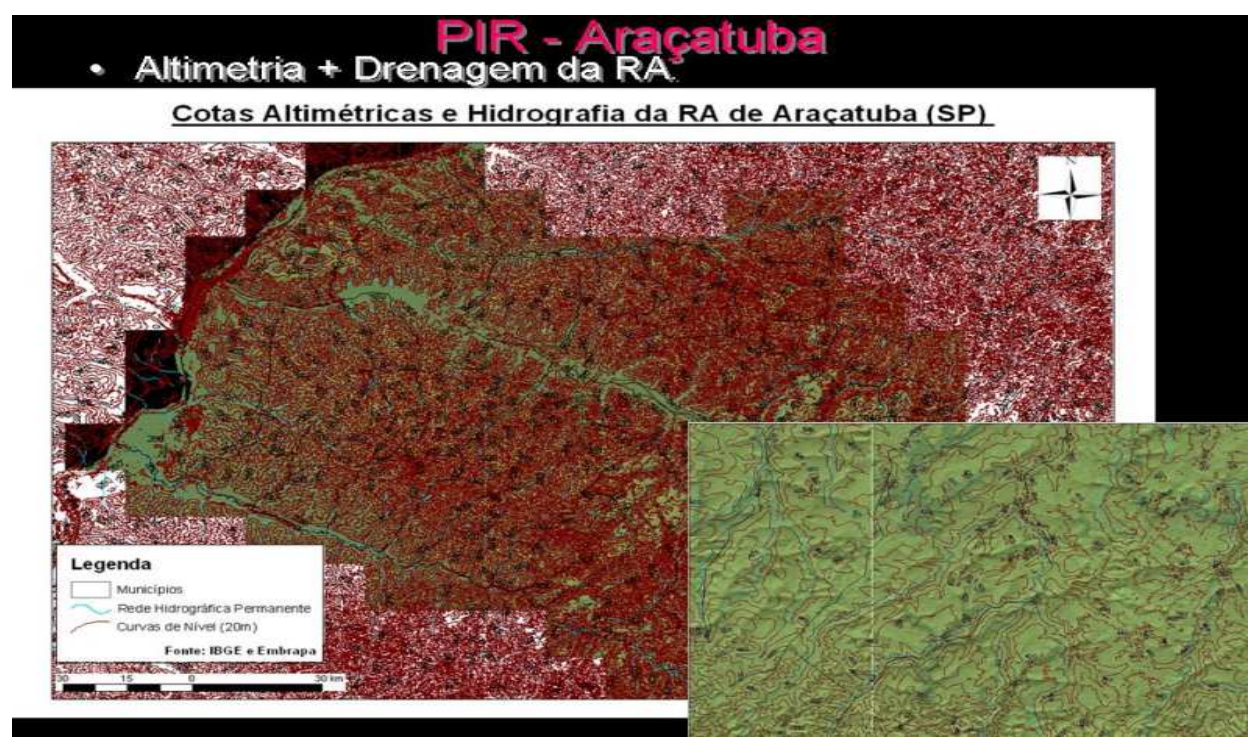

Figura 15 - Mapa altimétrico ou mapa com curvas de níveis da RAA.

Fonte: UDAETA, 2008c.

Em seguida, através das cotas levantadas, calculou-se o potencial teórico deste recurso, utilizando a fórmula (20).

$$
P=\rho \cdot g \cdot \eta \cdot Q \cdot H,[k W],
$$

- $P$ - Potência instalada da usina, $[\mathrm{kw}]$

- $\boldsymbol{\rho}$ - Peso específico de água;

- $\mathbf{g}$ - Aceleração da gravidade, $\left[\mathrm{m} / \mathrm{s}^{2}\right]$;

- $n$ - Rendimento do gerador 
- Q - Vazão $\left(\mathrm{m}^{3} / \mathrm{s}\right)$

- H - Queda Bruta, [m]

Ou seja

$$
\begin{gathered}
P=9,81 \cdot Q \cdot H \cdot \eta,[\mathrm{kW}] \\
H=\Delta Z=Z 2-Z 1
\end{gathered}
$$

Sendo que:

- $Z_{1}$ e $Z_{2}$ : definíveis em um canal ou num rio, $[\mathrm{m}]^{45}$.

A vazão que é dada $Q$ :

$$
\mathrm{Q}=\left[\mathrm{m}^{3} \text { de água } / \mathrm{s}\right],(22)
$$

Conhecendo todas as variáveis acima, para todos os afluentes da sub-bacia UGRHI-19, calculou-se o potencial teórico total ${ }^{46}$ da região, chegando ao valor de 447,26 MW.

Para o levantamento, apenas, dos principais locais com potenciais apresentados no Apêndice E, foram utilizados os mapas com curvas de níveis, mapas hidrológicos da região. Foram levantados os dados dos postos de medição das vazões e pluviometria através dos quais se calculou as vazões das sub-bacias hidrográficas em toda região Administrativa de Araçatuba.

Assim, considerando as definições de $\mathrm{PCH}$ para os propósitos deste estudo ( $>50 \mathrm{~m}$ e $10 \mathrm{MW}<\mathrm{P}$ teórica $<30 \mathrm{MW}$ ), Tabela 7 - Classificação das PCHs, e considerando os dados da Tabela 25, a seguir, conclui-se o potencial teórico de aproveitamentos classificados como PCH para a RAA é de 24,09 MW. 
Para os propósitos de estudo de caso, foi utilizado como referência para avaliação o aproveitamento do Ribeirão do Lajeado, na cota de referência 378 m, conforme assinalado em verde no Apêndice $\mathrm{E}$.

\subsection{Tecnologia adotada na determinação do potencial realizável PCH}

$\mathrm{Na}$ base dos resultados, apresentados no Apêndice $\mathrm{E}$, procedeu-se com a classificação das faixas de potências para depois se fazer a escolha das tecnologias adequadas para o desenvolvimento destes potenciais.

Tabela 25 - Aproveitamentos hidráulicos localizados pelo PIR-USP na RAA

\begin{tabular}{|c|c|c|c|c|c|c|c|c|c|}
\hline \multirow{2}{*}{ Faixas de Potencias } & \multirow{2}{*}{$\begin{array}{c}\text { Potencial } \\
\text { Realizável } \\
\text { MW }\end{array}$} & \multirow{2}{*}{$\begin{array}{c}\text { Quantidade de } \\
\text { Locais } \\
\text { Identificados }\end{array}$} & \multicolumn{3}{|c|}{ Quedas } & \multicolumn{4}{|c|}{$\begin{array}{c}\text { Tipo de Tecnologias } \\
\text { (Turbina) }\end{array}$} \\
\hline & & & Baixa & Média & Alta & Banki & Pelton & Francis & Kaplan \\
\hline \multicolumn{10}{|l|}{$\begin{array}{c}\text { Pico Geração } 1 \\
0<\mathrm{P}<1 \mathrm{~kW}\end{array}$} \\
\hline $\begin{array}{l}\text { Pico Geração 2, } \\
1 \mathrm{~kW}<\mathrm{P}<100 \mathrm{~kW}\end{array}$ & 0,933 & 6 & 5 & 1 & & $\mathrm{X}$ & $\mathrm{X}$ & & \\
\hline $\begin{array}{l}\text { Micro Geração, } \\
100 \mathrm{KW}<\mathrm{P}<1 \mathrm{MW}\end{array}$ & 48,6 & 86 & 25 & 56 & 5 & $\mathrm{X}$ & $\mathrm{X}$ & & \\
\hline $\begin{array}{c}\text { Mini Geração, } \\
1 \mathrm{MW}<\mathrm{P}<10 \mathrm{MW}\end{array}$ & 373,64 & 160 & 1 & 55 & 104 & & & $\mathrm{X}$ & $\mathrm{X}$ \\
\hline $\begin{array}{c}\text { Pequena Geração, } \\
10<\mathbf{P}<30 \text { MW }\end{array}$ & 24,09 & 2 & & & 2 & & & $\mathrm{X}$ & $\mathrm{X}$ \\
\hline
\end{tabular}

Fonte: UDAETA, 2009d.

$\mathrm{Na}$ Tabela 25 a letra "X" que popula as colunas tipo de tecnologia de geração hídrica, indica que a tecnologia de geração hídrica também é aplicável para esta faixa de potência.

Avaliando a Tabela $25 \mathrm{com}$ base no aproveitamento hídrico (queda d'água) escolhido para o estudo de caso, escolheu-se turbinas tipo Francis, com fator de capacidade da ordem de $55 \%$.

\subsubsection{Medidas de economia de energia}

Primeiramente é importante relembrar que os recursos de demanda escolhidos, no contexto desde estudo são: (a) troca de lâmpadas incandescentes por lâmpadas fluorescentes e (b) aquecimento de água para banhos humanos em 
residências da área urbana da RAA. Assim, o objetivo deste estudo é avaliar a atratividade de oportunidades de negócio economia de energia elétrica, e o enfoque adotado para esta avaliação é a visão do usuário final, mantenedor de uma residência familiar dentro da RAA, se beneficiando, monetariamente, com a economia de energia elétrica, decorrente da adoção de tecnologias mais econômicas.

\subsubsection{Parâmetros demográficos e tecnológicos}

A Tabela 26 e a Tabela 27 apresentam os principais parâmetros demográficos e tecnológicos dos recursos de demanda (medidas de economia) a serem avaliados, já com dados da região em estudo, a serem utilizados nos modelos matemáticos desenvolvidos para a avaliação da atratividade das duas medidas de economia de energia avaliadas.

Tabela 26 - Parâmetros demográficos e comportamentais da RAA utilizados na avaliação

\begin{tabular}{|l|c|c|c|c|}
\hline \multicolumn{1}{|c|}{ ITEM } & UNIDADE & VALOR & Origem & INDEX \\
\hline Moradores de Centros Urbanos & $\#$ & 742.251 & SEADE 2010 & $\mathrm{a}$ \\
\hline Média de Moradores por residência & $\#$ & 3,30 & IBGE 2006 & $\mathrm{b}$ \\
\hline Residências Urbanas & $\#$ & 224.925 & $\mathrm{a} / \mathrm{b}$ & $\mathrm{C}$ \\
\hline Média de Lâmpadas por residência & $\#$ & 8,79 & Sudeste - PROCEL 2007 & $\mathrm{d}$ \\
\hline Média de horas lâmpada ligada/dia & $\mathrm{h}$ & 6,00 & Sudeste - SINPHA 2006 & $\mathrm{e}$ \\
\hline Media de banhos diários por Morador & $\#$ & 1,21 & Baldacci , 2009 & $\mathrm{f}$ \\
\hline Tempo médio de um banho & $\mathrm{min}$. & 10,00 & PROCEL 2007 & $\mathrm{g}$ \\
\hline Tarifa Energia Elétrica Residencial (CPFL 06/2010) & $\mathrm{R} \$ / \mathrm{MWh}$ & 445,94 & $\mathrm{CPFL}$ & $\mathrm{h}$ \\
\hline
\end{tabular}

Fonte:elaboração própria.

Tabela 27 - Parâmetros tecnológicos utilizados na avaliação dos recursos de demanda

\begin{tabular}{|c|c|c|c|c|c|c|}
\hline \multirow{2}{*}{\multicolumn{2}{|c|}{ ITEM }} & \multirow{2}{*}{$\begin{array}{c}\text { Preço } \\
\text { R\$ }\end{array}$} & \multirow{2}{*}{\begin{tabular}{|l} 
Custo de \\
Instalação \\
R\$
\end{tabular}} & \multirow{2}{*}{$\begin{array}{c}\text { Consumo } \\
\text { W.h } \\
\end{array}$} & \multicolumn{2}{|c|}{ Vida Útil } \\
\hline & & & & & Unidade & Qtd. \\
\hline \multirow{2}{*}{ Iluminação } & Lâmpada Fluorescente (C\&C 12/2010) & 9,00 & 0,00 & 15 & Horas & 6.000 \\
\hline & Lâmpada Incandescente (C\&C 12/2010 & 2,50 & 0,00 & 60 & Horas & 1.000 \\
\hline \multirow{4}{*}{$\begin{array}{l}\text { Aquecimento } \\
\text { Direto }\end{array}$} & Chuveiro Elétrico (C\&C 12/2010) & 200,00 & 0,00 & 4.400 & Meses & 60 \\
\hline & Sistema aquecimento $400 \mathrm{~L} / 4 \mathrm{M}^{2}$ de placas (C\&C 12/2010 & $2.800,00$ & \multirow{3}{*}{700,00} & \multirow{3}{*}{0} & \multirow{3}{*}{ Meses } & \multirow{3}{*}{180} \\
\hline & Boiler 400 litros & $1.600,00$ & & & & \\
\hline & Coletor $4 M^{\wedge} 2$ & $1.200,00$ & & & & \\
\hline
\end{tabular}

Fonte: elaboração própria.

Do ponto de visto do investidor (no caso, usuário final) a economia de energia, obtida pela diferença de consumo de energia entre dois tipos de recursos 
avaliados (tecnologias) de forma mutuamente exclusiva, será a base para avaliação da atratividade das medidas de economia.

Pesquisas de hábitos e posses do SINPHA, feitas no ano de 2006, indicaram que na região Sudeste $49,3 \%$ das residências ainda não contam com nenhuma lâmpada fluorescente. Por outro lado, pela portaria interministerial no 1007 de 31/12/2010, o governo brasileiro estabeleceu um cronograma progressivo de banimento das lâmpadas incandescentes, cronograma este baseado em níveis de eficiência das lâmpadas permitidas para comercialização, o que, indiretamente, significa o banimento das lâmpadas incandescentes. O cronograma inicia-se em junho de 2012 e termina em julho de 2016.

Apenas 18,2 \% dos usuários residenciais têm intenção, ou condição, de trocar o chuveiro elétrico por um sistema de aquecimento solar na região Sudeste, segundo a pesquisa SINPHA 2006. Pela mesma pesquisa SINPHA 2006, se o tema custo de aquecedor elétrico não for um impedimento para o usuário final, a intenção de posse sobe para $25,79 \%$.

$\mathrm{Na}$ mesma linha do que ocorreu para lâmpadas incandescentes, existem várias iniciativas estaduais e municipais para o incentivo à troca de chuveiros elétricos por coletores solares. Na RAA, a cidade de Birigui já conta com legislação de incentivo a adoção de coletores solares em substituição a chuveiros elétricos desde 2007 e Araçatuba aguarda aprovação de projeto. Em vários estados, já existem linhas de crédito subsidiadas para atendimento de população de baixa renda em sua intenção de posse de coletores solares.

Segundo o site Cidades Solares ${ }^{47}$, hoje existem 26 estados/municípios com legislação de incentivo a coletores solares já aprovadas, e 31 com projetos/tramitação.

Assim, o potencial comercial de ambas as medidas de economia de energia é bem menor que o realizável, acima, porém, as condições de crescimento já estão postas.

\footnotetext{
${ }^{47}$ www.cidadessolares.com.br
} 


\subsubsection{Impacto regional das medidas de economia escolhidas}

As medidas de economia, se adotadas por uma parte das famílias da RAA, também trazem impactos financeiros positivos, na medida em que permitem postergar investimentos em toda a cadeia de energia elétrica (geração, transmissão e distribuição). No limite, significa poder direcionar o valor do investimento evitado para outras utilidades, sem comprometer (ou mantido) o nível de serviço prestado, no caso, iluminação e aquecimento de água para banhos humanos.

$\mathrm{Na}$ sua forma mais ampla, a eficiência energética, como uma opção de investimento no planejamento da expansão do setor energético brasileiro, não faz parte do escopo deste trabalho. A título de informação complementar, são apresentados na Tabela 28 os resultados finais das estimativas de economia feitas para a região de Araçatuba $^{48}$ alinhada com resultados do PIR-USP.

Tabela 28 - Impactos das medidas de economia de energia na RAA
\begin{tabular}{|l|c|c|}
\hline \multicolumn{1}{|c|}{ RECURSO } & $\begin{array}{c}\text { Redução Potencial } \\
\text { de demanda na } \\
\text { ponta* }^{*}\end{array}$ & $\begin{array}{c}\text { Potencial de } \\
\text { Energia* } \\
\text { economizada }\end{array}$ \\
\cline { 2 - 3 } & $\mathrm{MW}$ & MWh/ano \\
\hline Lâmpadas Fluorescentes $^{49}$ & 28,14 & 74.364 \\
\hline Coletores Solares $^{50}$ & 88,49 & 93.964 \\
\hline
\end{tabular}

Fonte: BAITELO, 2011

${ }^{*}$ Ano base $=2010$

\subsubsection{Delimitação de escopo dos cenários dos estudos de casos}

Por uma limitação técnica, (possibilidades ilimitadas), delimitam-se o escopo dos cenários de negócios (restrições) nos quais serão feitas as avaliações dos recursos energéticos.

\footnotetext{
${ }^{48}$ BAITELO, 2011

${ }^{49}$ BAITELO, 2011 p. 369

${ }^{50}$ BAITELO, 2011 p. 365
} 


\subsubsection{Geração}

Para todos os recursos de geração avaliados, o cenário delimitado é a geração distribuída de recursos energéticos renováveis por fontes alternativas $(\mathrm{PCH}$, EOL e BIO), com as seguintes premissas:

- a potência instalada nas plantas de geração é necessariamente, igual ou inferior a 30MW, para se beneficiarem dos incentivos a fontes alternativas;

- a energia é consumida, necessariamente, dentro da área de abrangência da concessionária de distribuição local ( $\mathrm{CPFL}$ ): a geração não demandará circuitos de transmissão de longa distância para transporte de energia;

- os recursos escolhidos gozam de $50 \%$ de desconto no preço da tarifa de distribuição de energia TUSDg;

- a distância entre a planta de geração e a conexão com a distribuidora local é de $10 \mathrm{~km}$;

- as possibilidades de comercialização da energia se reduzem, basicamente, a quatro: (i) diretamente com a distribuidora local, desde que o volume total contratado pela distribuidora não supere o $10 \%$ de seu total, (ii) autoconsumo; (iii) junto a cliente livre, ou potencialmente livre, e também dentro da concessão da CPFL; (iv) permuta, ou equivalente, com outro agente, também classificado como geração distribuída, desde que como carteira comercializada exclusivamente dentro da concessão da CPFL.

A estrutura societária de todos os empreendimentos é baseada no modelo de Sociedade de Propósito Especifico (SPC), pessoa jurídica constituída, exclusivamente para geração e comercialização de energia, desvinculada de quaisquer outros propósitos. Este modelo além de simplificar o fluxo de caixa representativo do empreendimento, é o mais utilizado, tendo em vista que para se eleger as fontes públicas de financiamento (BNDES), é exigido este modelo.

Considerando um estudo prévio realizado em todos os recursos avaliados, este indicou lucros tributáveis acima de $R \$ 240.000,00 / a n o$, assim enquadrando o IRPJ no regime de lucro real, com apuração anual à alíquota de $25 \%$. 
É importante lembrar mais uma vez que, por premissa, os cenários não foram montados para definir empreendimentos que irão competir entre si na montagem de uma posição de portfólio de um investidor. A competição dos empreendimentos será contra parâmetros econômicos (figuras de mérito econômico financeiro) minimamente aceitos pelo mercado. Desta forma, não há obrigação de cenários absolutamente idênticos para avaliação dos recursos de geração.

\subsection{Eólica (EOL)}

O contexto utilizado na avaliação da geração eólica:

- Previsto um investimento em uma fazenda de geração nova, de pequeno para médio porte: $30 \mathrm{MW}$ instalados, com vista a aproveitar os incentivos de geração incentivada prevista em lei.

- 12 torres de 2,5 MW (Enercon), instaladas a 98 metros de altura;

- Em terras alugadas, onde a geração convive junto com algum cultivo local.

- Todo investimento será feito para montagem da fazenda geradora e interligação com a distribuidora local.

- A estrutura de capital do empreendimento será definida como $20 \%$ dos investidores e $80 \%$ de financiamentos externos.

\subsection{Biomassa (BIO)}

O contexto utilizado na avaliação da geração por biomassa (cogeração):

- Cenário com uma planta de cogeração, com investimentos específicos para modernização de estrutura existente, para um patamar tecnológico mais eficiente, sendo alimentada a partir do aproveitamento de parte da biomassa de cana gerada na safra de cana destinada integralmente a produção de açúcar e álcool. 
- Da mesma forma que o cenário para geração eólica, a planta de cogeração será estruturada como uma SPC, que irá comprar biomassa de cana da usina de açúcar e álcool (combustível), vender calor e energia elétrica para o processo de produção de açúcar e álcool, e o excedente de energia elétrica será comercializado.

- Todo investimento será feito para atualização da planta de geração (caldeiras, geradores e tubulação) e interligação com a distribuidora local.

- A estrutura de capital do empreendimento será definida como $20 \%$ dos investidores e $80 \%$ de financiamentos externos, de linhas de crédito específicas para geração incentivada.

- A planta de cogeração terá $30 \mathrm{MW}$ instalados, com vistas a aproveitar os incentivos da geração incentivada, prevista em lei:

- O tamanho médio de uma safra de cana-de-açúcar de uma usina da região é de dois milhões e oitocentas mil toneladas de cana, entretanto apenas a biomassa de um pouco mais de 800 mil toneladas de cana (40\% da safra) será moída e queimada na planta destinada para geração/cogeração de excedentes de energia elétrica. O restante será moído e queimado nas instalações mais antigas da usina, que não tem rendimento que permita a geração de excedentes de energia elétrica.

- Fora da safra, que normalmente ocorre de maio a novembro, não está previsto ocorrer geração excedente de energia elétrica para comercialização pelo empreendimento.

\subsection{PCH}

O contexto utilizado na avaliação da PCH é:

- Prevista uma planta nova, montada para o maior aproveitamento localizado, e ainda não explorado, no Ribeirão do Lajeado (UGRHI 19, sub-bacia 800) dentro da RAA, com um potencial teórico de 13.2 MW (Apêndice E).

- A planta foi dimensionada para $13 \mathrm{MW}$, considerando que não foi localizado nenhum aproveitamento hídrico maior que este. 
- É uma Sociedade de Propósito específico, com o objetivo de geração de energia elétrica para comercialização, para se aproveitar de linhas oficiais de crédito subsidiado.

- A estrutura de capital do empreendimento será definida como $20 \%$ dos investidores e $80 \%$ de financiamento externos, de linhas específicas para geração incentivada (BNDES,2011).

- A sociedade é proprietária de toda terra, e área alagada do reservatório.

- Todo investimento será feito para construção das instalações de geração, barragem, preparação do reservatório e interligação com a distribuidora local.

\subsubsection{Medidas de economia de energia elétrica}

O contexto de avaliação das medidas de economia de energia nesta dissertação se refere a uma tecnologia, chamada de eficiente, sendo comparada com uma tecnologia, chamada tradicional. Neste contexto será avaliado o custo total de aquisição e propriedade de cada uma das tecnologias, com vistas a escolher a mais barata.

Por premissa, a avaliação será feita para os serviços demandados pelo recurso em uma família média da região. Diferentemente dos recursos de geração, na avaliação das medidas de economia de energia há a competição entre os recursos e o cenário foi planejamento para a comparação, partindo-se da premissa que os recursos competidores têm que oferecer o mesmo nível de serviço ao usuário final. 


\section{RESULTADOS}

\subsection{RECURSOS DE GERAÇÃO}

\subsubsection{Modelo matemático do fluxo de caixa}

No Apêndice A é apresentado o modelo de fluxo de caixa desenvolvido para a avaliação dos três recursos de geração.

Este modelo foi desenvolvido com base nas regras contábeis das sociedades por ações (Lei no 6.404 de 15 de dezembro de 1976), sendo adaptado com base na legislação derivada do RE-SEB (Reestruturação do Setor Elétrico Brasileiro), no que se refere à geração de energia elétrica.

O modelo foi desenvolvido para ser aplicado de forma ampla, podendo ser utilizado tanto para cenários com geração distribuída quanto para cenários com despacho centralizados, ou mistos.

A Customização do modelo genérico de geração para geração distribuída, de fonte alternativa incentivada, na RAA ocorreu quando se populou os parâmetros de referência de entrada de cada recurso no modelo.

\subsubsection{Parâmetros de referência de entrada}

As variáveis de referência de geração, populadas no modelo de fluxo de caixa dos recursos de geração, podem ser encontradas no apêndice $F$.

\subsubsection{Resultado dos cálculos}

A seguir, são apresentados os resultados das figuras de mérito econômicofinanceiro obtidas para os três recursos de geração avaliados, junto com a análise 
de sensibilidade, feita a partir de variações de parâmetros de referência específicos do cenário de referência.

O formato da tabela que apresenta os resultados dos cálculos das figuras de mérito econômico, e análise de sensibilidade dos recursos geração, é padrão.

Nas tabelas onde se apresentam os resultados, a seguir, a coluna <Cenário de Referência> indica os valores dos parâmetros de entrada ${ }^{51}$ assumidos no cenário de referência, e utilizados para calcular as figuras de mérito econômico-financeiro deste cenário.Todas as células desta coluna estão com fundo amarelo.

Cada uma das colunas encabeçadas pela célula <Análise de Sensibilidade> definem cenários diferentes do cenário de referência, onde as células com fundo amarelo representam valores notáveis (limites máximos, ou mínimos, também em fundo amarelo) dos parâmetros de cenário, obtidos quando se "força" a figura de mérito definida na linha <figura de mérito de equilíbrio> a assumir um determinado valor. O valor forçado também esta com o fundo em amarelo.

Assim, por exemplo, mantidos os parâmetros de entrada de referência iguais ao cenário de referência, exceto o preço de venda da energia, calcula-se: qual o menor preço de venda da energia elétrica (parâmetro de entrada) que leva o VPL a zero. Neste cenário, o preço de venda da energia representa o valor notável chamado de "preço de venda equilíbrio da energia", do recurso avaliado.

\subsubsection{Eólica}

\subsection{Figuras de mérito econômico-financeiro}

$\mathrm{Na}$ Tabela 29 são apresentados os resultados dos cálculos das figuras de mérito para os recursos de geração EOL, assim como os valores notáveis das variáveis de entrada, que produzem $\mathrm{VPL}=0$ :

51 Preço da energia vendida, custo do kW instalado, Fator de Capacidade e Distância ao ponto de conexão da distribuidora. 
Tabela 29 - Figuras de mérito e pontos notáveis da análise de sensibilidade do RE EOL

\begin{tabular}{|c|c|c|c|c|c|c|c|}
\hline \multirow{3}{*}{$\begin{array}{l}\text { PARÂMETRO } \\
\text { DE REFERÊNCIA }\end{array}$} & \multirow{3}{*}{ UNIDADE } & \multirow{3}{*}{$\begin{array}{c}\text { Cenário } \\
\text { de } \\
\text { Referência }\end{array}$} & \multicolumn{5}{|c|}{ ANALISE DE SENSIBILIDADE } \\
\hline & & & $\begin{array}{c}\text { Parâmetro } \\
\text { de } \\
\text { Equilibrio }\end{array}$ & $\begin{array}{c}\text { Preço } \\
\text { da } \\
\text { energia }\end{array}$ & $\mathrm{KW} /$ inst & FC & $\begin{array}{c}\text { Acrescimo } \\
10 \% \\
\text { no FC }\end{array}$ \\
\hline & & & $\begin{array}{l}\text { Fig. Mérito } \\
\text { Equilibrio }\end{array}$ & VPL=0 & VPL=0 & VPL=0 & VPL $=0$ \\
\hline Preço da energia vendida & $\mathrm{R} \$ / \mathrm{MWh}$ & 135,15 & & 278,92 & 135,15 & 135,15 & 253,66 \\
\hline Custo do KW/Instalado & $R \$ / K W_{\text {inst }}$ & $2.600,00$ & & $2.600,00$ & $1.011,03$ & $2.600,00$ & $2.600,00$ \\
\hline Fator de capacidade & Frac. & $24,00 \%$ & & $24,00 \%$ & $24,00 \%$ & $49,75 \%$ & $26,40 \%$ \\
\hline Distancia do ponto de Conexão Distribuidora & Km & 10 & & 10 & 10 & 10 & 10 \\
\hline \multicolumn{8}{|l|}{ FIGURAS DE MÉRITO OBTIDAS } \\
\hline VPL & $\mathbf{R} \$$ & $(26.816 .400,00)$ & & 0 & 0 & 0 & 0 \\
\hline TIR & $\%$ & $\mathrm{ND}^{*}$ & & $15,43 \%$ & $15,43 \%$ & 15,43 & 15,43 \\
\hline PBD & anos & $\mathrm{ND}^{*}$ & & 20 & 20 & 20 & 20 \\
\hline Demanda de pico do capital de giro à VPL & $\mathbf{R} \$$ & $(4.087 .000,00)$ & & 0 & 0 & 0 & 0 \\
\hline
\end{tabular}

Fonte: elaboração própria.

$\left({ }^{*}\right) \mathrm{ND}=$ Não encontrado durante o horizonte de 20 anos

\subsection{Análise de sensibilidade}

Segue abaixo a leitura dos resultados da Tabela 29 produto da observância de pontos notáveis da análise de sensibilidade.

No cenário de referência, durante a vida útil da oportunidade:

- o VPL é negativo e não se obteve TIR e PBD no horizonte da vida útil definida de 20 anos;

- adicionalmente, demanda-se um pico de aporte de capital de giro da ordem de 4 milhões de reais (ou 5\% dos investimentos iniciais, apresentados no Apêndice F) para cumprir com as obrigações da operação.

Nos cenários alternativos criados para determinar os pontos notáveis da análise de sensibilidade, observa-se que:

- para se atingir o ponto de indiferença do investimento (VPL=0), o preço mínimo de venda da energia deveria ser de $\mathrm{R} \$ 278,92 / \mathrm{MWh}$, mantidos os demais parâmetros do cenário de referência; 
- para se atingir o ponto de indiferença do investimento (VPL=0), o custo mínimo de do $\mathrm{kW} / \mathrm{inst}$. poderia ir a $\mathrm{R} \$ 1.001 / \mathrm{kW}_{\text {inst }}$, mantidos os demais parâmetros do cenário de referência (redução improvável de $61 \%$ em relação ao custo do cenário de referência);

- para se atingir o ponto de indiferença do investimento (VPL=0), o Fator de capacidade mínimo deveria ser de $49,75 \%$, mantidos os demais parâmetros do cenário de referência (aumento improvável de $207 \%$ em relação ao FC do cenário de referência);

- e num cenário alternativo, considerando-se que o fator de capacidade tenha um acréscimo de $10 \%$ em relação ao cenário de referência, o preço de equilíbrio da venda da energia sairia de $R \$ 278,92$ (referência) para $R \$$ 253,66/MWh, ainda muito superior ao VR (Tabela 55 - Energia elétrica - Valor anual de Referência (VR)).

\subsubsection{Biomassa de cana-de-açúcar}

\subsection{Figuras de mérito econômico-financeiro}

$\mathrm{Na}$ Tabela 30 são apresentados os resultados dos cálculos das figuras de mérito para os recursos de geração $\mathrm{BIO}$, em dois cenários distintos (geração apenas na safra de cana, e geração 11 meses por ano) assim como os valores notáveis das variáveis de entrada, que produzem $\mathrm{VPL}=0$ para os dois cenários. 
Tabela 30 - Figuras de mérito e pontos notáveis da análise de sensibilidade do RE de BIO

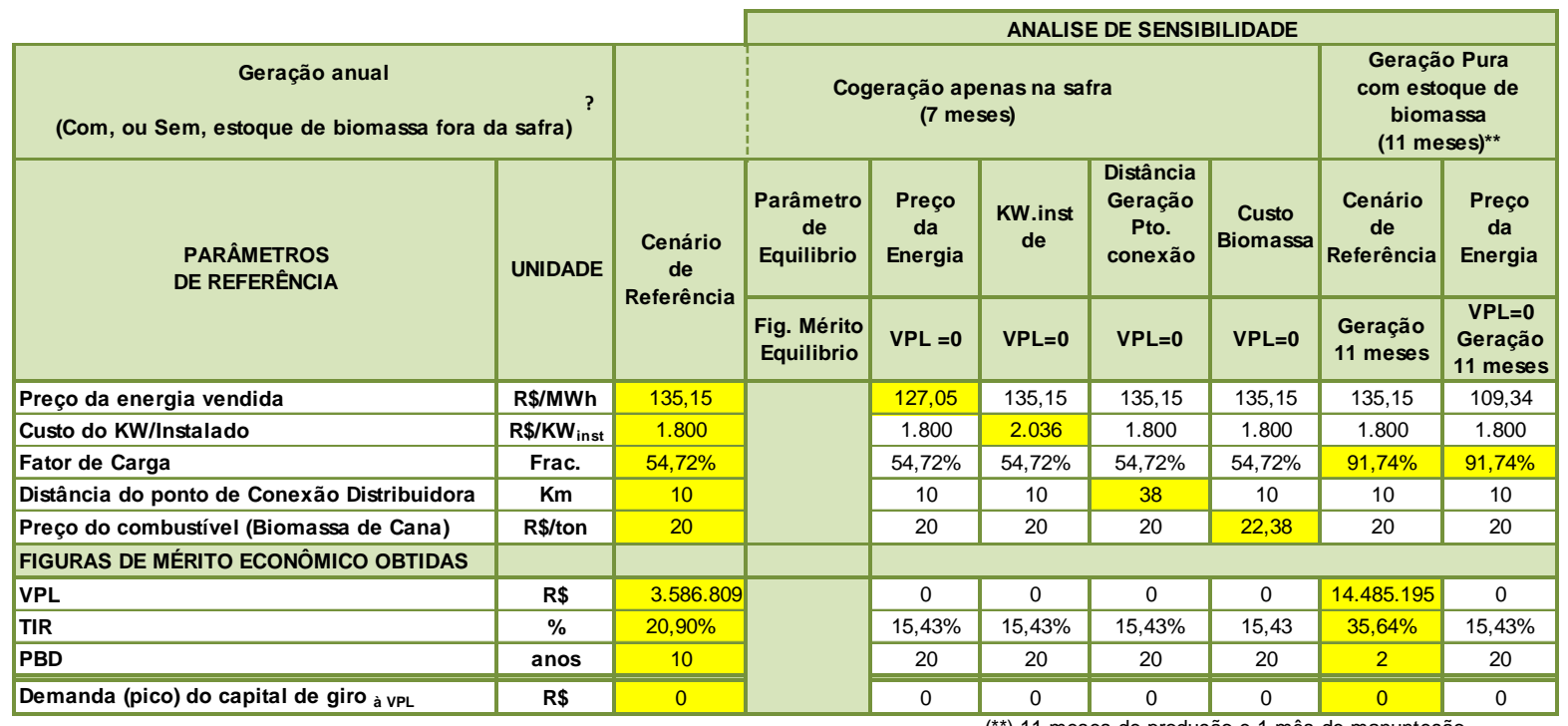

Fonte: elaboração própria.

\subsection{Análise de sensibilidade}

Segue abaixo a leitura dos resultados da Tabela 30, produto da observância de pontos notáveis da análise de sensibilidade no recurso.

No cenário de referência, cogeração durante a safra (7 meses), durante a vida útil da oportunidade:

- o VPL é positivo em R\$3, 5 milhões, com TIR de 20,90\% e PBD de 10 anos;

- não há necessidade de aporte relevante de capital de giro para cumprir com as obrigações da operação.

Em variações do cenário de referência, criados para determinar os pontos notáveis da análise de sensibilidade, observa-se que:

- para se atingir o ponto de indiferença do investimento (VPL=0), o preço mínimo de venda da energia deveria ser de $\mathrm{R} \$ 127,05 / \mathrm{MWh}$, mantidos os demais parâmetros do cenário de referência;

- para se atingir o ponto de indiferença do investimento (VPL=0), o custo máximo do $\mathrm{KW} /$ inst. deveria ser de $\mathrm{R} \$ 2.036 / \mathrm{kW}_{\text {inst }}$, mantidos os demais parâmetros do cenário de referência; 
- para se atingir o ponto de indiferença do investimento ( $\mathrm{VPL}=0)$, a distância máxima da geração ao ponto de conexão da distribuidora local não pode ser superior a 38 quilômetros;

- para se atingir o ponto de indiferença do investimento ( $\mathrm{VPL}=0$ ), e mantidos os demais parâmetros do cenário original de referência, o custo de oportunidade da biomassa de cana não poderia ser superior a $\mathrm{R} \$ 22,38 /$ ton. Se o bagaço apresentar um aumento de $10 \%$ no seu custo de oportunidade, o empreendimento encontra seu ponto de indiferença ao investimento.

Em um cenário alternativo ${ }^{52}$, com geração pura de energia, durante 11 meses do ano, criado para determinar os pontos notáveis da análise de sensibilidade, observa-se que:

- o VPL da oportunidade vai a $R \$ 14,4^{53}$ milhões, a TIR vai a $35,64 \%$ e o PBD vai a 2 anos;

- para se atingir o ponto de indiferença do investimento $(\mathrm{VPL}=0)$ neste mesmo cenário, o preço mínimo de venda da energia vai a $\mathrm{R} \$ 109,34 / \mathrm{MWh}$, mantidos os demais parâmetros do cenário de referência.

\subsubsection{3 $\mathrm{PCH}$}

\subsection{Figura de mérito econômico-financeiro}

Na Tabela 31 são apresentados os resultados dos cálculos das figuras de mérito para os recursos de geração $\mathrm{PCH}$ em dois cenários (o de referência e o cenário pressupondo uma melhoria tecnológica que permita um FC de 57\%) assim como os valores notáveis das variáveis de entrada, que produzem $\mathrm{VPL}=0$

\footnotetext{
${ }^{52}$ Desconsiderando a receita com venda de vapor de processo e energia para a produção de álcool e açúcar, disponibilizando a biomassa exclusivamente para produção de energia para exportação.

${ }^{53}$ Já considerada a perda de receita da venda de vapor de processo.
} 
Tabela 31 - Figuras de mérito e pontos notáveis da análise de sensibilidade do RE PCH

\begin{tabular}{|c|c|c|c|c|c|c|}
\hline \multirow{3}{*}{$\begin{array}{l}\text { PARÂMETRO } \\
\text { DE REFERÊNCIA }\end{array}$} & \multirow{3}{*}{ UNIDADE } & \multirow{3}{*}{$\begin{array}{c}\text { Cenário } \\
\text { de } \\
\text { Referência }\end{array}$} & \multicolumn{4}{|c|}{ ANÁLISE DE SENSIBILIDADE } \\
\hline & & & $\begin{array}{c}\text { Parâmetro } \\
\text { de } \\
\text { Equilíbrio }\end{array}$ & $\begin{array}{l}\text { Preço da } \\
\text { energia de }\end{array}$ & kW/inst & $\begin{array}{c}\text { Melhora da } \\
\text { Tenologia }\end{array}$ \\
\hline & & & $\begin{array}{c}\text { Condição } \\
\text { de } \\
\text { Equilíbrio }\end{array}$ & VPL=0 & VPL=0 & $\mathrm{FC}=57 \%$ \\
\hline Preço da energia vendida & $\mathbf{R} \$ / \mathbf{m W h}$ & 135,15 & & 139,94 & 135,15 & 135,15 \\
\hline Custo do kW/Instalado & $R \$ / \mathbf{k W}_{\text {inst }}$ & 3.150 & & 3.150 & 3.031 & 3.150 \\
\hline Fator de capacidade & Frac. & $55,00 \%$ & & $55,00 \%$ & $55,00 \%$ & $57,00 \%$ \\
\hline Distância do ponto de Conexão Distribuidora & Km & 10 & & 10 & 10 & 10 \\
\hline \multicolumn{7}{|l|}{ FIGURAS DE MÉRITO OBTIDAS } \\
\hline VPL & $\mathbf{R} \$$ & -862.691 & & 0 & 0 & 13.849 \\
\hline TIR & $\%$ & $13,85 \%$ & & $15,43 \%$ & $15,43 \%$ & 15,43 \\
\hline PBD & anos & $\mathrm{ND}^{*}$ & & $\mathrm{ND}^{*}$ & 20 & 20 \\
\hline Capital de giro Demandando à VPL & $\mathbf{R} \$$ & 0 & & 0 & 0 & 0 \\
\hline
\end{tabular}

Fonte: elaboração própria.

(*) ND = Não encontra do durante o horizonte de 20 anos

\subsection{Análise de sensibilidade}

Segue abaixo a leitura dos resultados da Tabela 31, produto da observância de pontos notáveis da análise de sensibilidade no recurso.

No cenário de referência, durante a vida útil da oportunidade:

- o VPL é negativo (R\$ 862.691) com uma TIR de 13,85\%, abaixo do CAPM e PBD não definido no período;

- não se verifica a necessidade de aporte de capital de giro para cumprir com as obrigações da operação.

Nos cenários alternativos criados para determinar os pontos notáveis da análise de sensibilidade, observa-se que:

- para se atingir o ponto de indiferença do investimento (VPL=0), o preço mínimo de venda da energia deveria ser de $\mathrm{R} \$ 139,94 / \mathrm{MWh}$, mantidos os demais parâmetros do cenário de referência;

- para se atingir o ponto de indiferença do investimento (VPL=0), o custo máximo do $\mathrm{kW} / \mathrm{inst}$. deveria ser de $\mathrm{R} \$ 3.031 / \mathrm{kW}_{\text {inst, }}$ mantidos os demais parâmetros do cenário de referência; 
- para se atingir o ponto de indiferença do investimento (VPL=0), o fator de capacidade mínimo deveria ser de $57 \%$, mantidos os demais parâmetros do cenário de referência, ou seja, um acréscimo de 3,64\% no FC.

\subsection{MEDIDAS DE ECONOMIA DE ENERGIA ELÉTRICA}

\subsubsection{Modelo matemático do fluxo de caixa}

Em função da simplicidade dos cenários de avaliação dos recursos concorrentes (lâmpada fluorescentes versus incandescente, e chuveiro elétrico versus coletor solar), onde se observa apenas os gastos com energia, constantes no tempo, a solução adotada para avaliação das medidas de economia não requereu desenvolver um fluxo de caixa, diferentemente dos recursos de geração, para se obter as figuras de mérito econômico.

Assim, partiu-se diretamente para o cálculo das figuras de mérito econômicofinanceiro das medidas de economia de energia: Custo do Ciclo de Vida Anualizado (CCVA) e PayBack Descontado (PBD). A conceituação das figuras de mérito e os modelos matemáticos para medidas de economia de energia encontram-se no Anexo A. Aplicando-se os modelos do Anexo A às duas medidas de economia, obtêm-se as Tabela 32 , Tabela 33, Tabela 34 e Tabela 35, a seguir.

\subsubsection{Parâmetros de referência de entrada}

\subsubsection{Iluminação}

As tabelas 32 e 33, apresentam os parâmetros de referência de entrada de modelo matemático utilizadas para o cálculo das figuras de mérito da medida de economia iluminação com lâmpadas fluorescentes. 
Tabela 32 - Parâmetros financeiros de referência: lâmpada fluorescente

\begin{tabular}{|c|c|c|}
\hline Taxa de & a.a & $\%$ a.m \\
\cline { 2 - 3 } desconto & $1,25 \%$ & $0,10 \%$ \\
\hline (d) & $\begin{array}{c}\text { Preço da } \\
\text { Energia } \\
\left(\mathbf{P}_{\mathbf{n}}\right)\end{array}$ & \multicolumn{2}{|c|}{$\mathrm{R} \$ / \mathrm{MWh}$} \\
\cline { 2 - 3 } & \multicolumn{2}{|c|}{474,9261} \\
\hline
\end{tabular}

Fonte: elaboração própria.

Tabela 33 - Parâmetros tecnológicos, comportamentais e CCVA: lâmpada fluorescente

\begin{tabular}{|c|c|c|c|c|c|c|c|c|c|c|c|}
\hline \multirow[b]{3}{*}{$\begin{array}{l}\mathrm{I} \\
\mathrm{L} \\
\mathrm{U}\end{array}$} & \multirow{2}{*}{\multicolumn{6}{|c|}{ Tecnologia }} & \multicolumn{5}{|c|}{ Energia Consumida } \\
\hline & & & & & & & \multirow[b]{2}{*}{$\begin{array}{l}\text { Qtd. } \\
\text { Lâmp. } \\
\text { Resid. }\end{array}$} & \multicolumn{2}{|c|}{ Horas funcion. } & \multicolumn{2}{|c|}{ Gasto Mensal } \\
\hline & \multirow[t]{2}{*}{ Tipo } & \multirow{2}{*}{$\begin{array}{c}\text { Custo } \\
\text { Unitário }\end{array}$} & \multirow{2}{*}{$\begin{array}{c}\text { Custo } \\
\text { total } \\
\text { (C) }\end{array}$} & \multirow{2}{*}{$\begin{array}{l}\text { Pot. } \\
\text { W }\end{array}$} & \multicolumn{2}{|c|}{$\begin{array}{l}\text { Vida útil } \\
\text { (VN) }\end{array}$} & & dia & mês & Energia & (E) \\
\hline M & & & & & horas & meses & & $\mathrm{h}$ & $\mathrm{h}$ & MWh & $\mathrm{R} \$$ \\
\hline N & $\begin{array}{c}\text { Lâmpada } \\
\text { Fluores. }\end{array}$ & $(9,00)$ & $(79,11)$ & 15 & 6.000 & 33 & & & & 0,024065 & $(11,43)$ \\
\hline ç & & & & & & & 8,79 & 6,00 & $1.604,35$ & & \\
\hline $\begin{array}{l}\tilde{A} \\
0\end{array}$ & $\begin{array}{l}\text { Lâmpada } \\
\text { Incan. }\end{array}$ & $(2,50)$ & $(21,98)$ & 60 & 1.000 & 6 & & & & 0,096261 & $(45,72)$ \\
\hline
\end{tabular}

Fonte: elaboração própria.

\subsubsection{Aquecimento de água}

As tabelas 34 e 35 apresentam os parâmetros de referência de entrada de modelo matemático utilizadas para o cálculo das figuras de mérito da medida de economia iluminação com lâmpadas fluorescentes.

Tabela 34 - Parâmetros financeiros de referência: Coletor Solar

\begin{tabular}{|c|c|c|}
\hline Taxa de & a.a & $\%$ a.m \\
\cline { 2 - 3 } desconto & $1,25 \%$ & $0,10 \%$ \\
\hline (d) & $\begin{array}{c}|c| \\
\text { Preço da } \\
\text { Energia } \\
\left(\mathbf{P}_{\mathbf{n})}\right.\end{array}$ & \multicolumn{2}{|c|}{$\mathrm{R} \$ \mathrm{MWh}$} \\
\cline { 2 - 3 } & \multicolumn{2}{|c|}{474,9261} \\
\hline
\end{tabular}

Fonte: elaboração própria. 
Tabela 35 - Parâmetros tecnológicos e comportamentais e CCVA: Coletor Solar

\begin{tabular}{|c|c|c|c|c|c|c|c|c|c|}
\hline \multirow{7}{*}{$\begin{array}{ll}A & \\
Q & \\
\text { U } & \\
\text { E } & D \\
C & \text { I } \\
\text { I } & R \\
M & E \\
M & T \\
E & 0 \\
N & \\
T & \\
O & \end{array}$} & \multirow{2}{*}{\multicolumn{4}{|c|}{ Tecnologia }} & \multicolumn{5}{|c|}{ Energia Consumida } \\
\hline & & & & & \multirow[b]{2}{*}{$\begin{array}{c}\text { Banhos } \\
\text { Dia }\end{array}$} & \multirow[b]{2}{*}{$\begin{array}{c}\text { Duração } \\
\text { de um } \\
\text { Banho }\end{array}$} & \multirow[b]{2}{*}{$\begin{array}{c}\text { Utilização } \\
\text { mês }\end{array}$} & \multicolumn{2}{|c|}{ Gasto Mensal } \\
\hline & \multirow[t]{2}{*}{ Tipo } & $\begin{array}{l}\text { Custo } \\
\text { total } \\
\text { (C) }\end{array}$ & Potência & $\begin{array}{c}\text { Vida útil } \\
\text { (VN) }\end{array}$ & & & & Energia & $\begin{array}{c}\text { Valor } \\
\text { (E) }\end{array}$ \\
\hline & & $\mathrm{RS}$ & W & meses & & $h$ & $\mathrm{~h}$ & MWh/mês & R\$ \\
\hline & $\begin{array}{c}\text { Coletor } \\
\text { Solar }\end{array}$ & $-3.507,02$ & $440^{*}$ & 180 & \multirow{3}{*}{3,99} & \multirow{3}{*}{0,17} & \multirow{3}{*}{20,24} & 0,008908 & 4,23 \\
\hline & & & & & & & & & \\
\hline & $\begin{array}{l}\text { Chuveiro } \\
\text { Elétrico }\end{array}$ & $-200,00$ & 4.400 & 60 & & & & 0,089076 & 42,30 \\
\hline
\end{tabular}

Fonte: elaboração própria.

$\left({ }^{*}\right)$ Consumidos para energizar as resistências de apoio ao coletor.

\subsubsection{Resultado dos cálculos}

\subsubsection{Lâmpadas fluorescentes}

\subsection{Figuras de mérito e pontos notáveis da análise de sensilidade}

A Tabela 36 apresenta os resultados dos cálculos das figuras de mérito para a medida de economia lâmpada fluorescente.

Tabela 36 - Figuras de mérito e ptos notáveis da análise de sensibilidade: lâmpada fluorescente

\begin{tabular}{|c|c|c|c|c|c|c|c|}
\hline \multirow[b]{2}{*}{ PARAMETRO DE REFERÊNCIA } & \multirow[b]{2}{*}{ Tecnologia } & \multirow[b]{2}{*}{ Unid. } & \multirow[b]{2}{*}{$\begin{array}{l}\text { Cenário } \\
\text { de Referência }\end{array}$} & \multicolumn{4}{|c|}{ ANÁLISE DE SENSIBILIDADE } \\
\hline & & & & $\begin{array}{l}\text { Condição } \\
\text { de ? } \\
\text { Equilibrio }\end{array}$ & $\begin{array}{c}\text { CCVA }_{\text {fluor. }}-\text { CCVA }_{\text {incan. }}=0 \\
\text { (econ. Mensal zero) }\end{array}$ & $\begin{array}{c}\text { PBD }=1 / 2 \\
\text { vida } \\
\text { útil }^{\star \star}\end{array}$ & $\begin{array}{l}\mathrm{PBD}=1 \\
\text { vida } \\
\text { útil }\end{array}$ \\
\hline \multirow{2}{*}{ Custo Unitário da tecnologia } & Fluorescente & $\mathrm{R} \$ /$ Unit. & 9,00 & & 140,05 & 46,73 & 71,27 \\
\hline & Incandescente & $\mathrm{R} \$ /$ Unit. & 2,50 & & 2,50 & 2,50 & 2,50 \\
\hline \multicolumn{8}{|l|}{ FIGURAS DE MÉRITO ECONÔMICO OBTIDAS } \\
\hline Economia mensal $=\mathrm{CCVA}_{\text {fluor }}-\mathrm{CCVA}_{\text {incan. }}$ & & $\mathrm{R} \$ /$ mês & 35,52 & & 0 & 25,3 & 18,64 \\
\hline PBD (Custos tecnologia $x$ economia mensal) & & meses & 1,61 & & ND* & 15,50 & 33,00 \\
\hline
\end{tabular}

Fonte: elaboração própria. 
A seguir, apresenta-se a leitura dos resultados da Tabela 36, produto da observância de pontos notáveis da análise de sensibilidade no recurso lâmpada fluorescente:

- A adoção da tecnologia eficiente leva a uma economia mensal de $R \$ 35,52$ com um PBD de 1,61 meses, mantidos os demais parâmetros do cenário.

- Para que a decisão de adoção fosse indiferente (zero economia) o custo unitário da tecnologia eficiente precisaria elevar-se a, não realísticos, $R \$ 140,04$, mantidos os demais parâmetros de referência.

- O custo unitário da tecnologia eficiente poderia ser elevado, no máximo, a $R \$$ 46,73 para considerar uma decisão de adoção indiferente, tendo como referência o PBD $<=$ meia vida da referida tecnologia.

- O custo unitário da tecnologia eficiente pode ser elevado, no máximo, a $R \$ 71,27$ para considerar uma decisão de adoção indiferente, no ponto uma vida útil da referida tecnologia.

\subsubsection{Coletores Solares}

\subsection{Figuras de mérito e pontos notáveis da análise de sensibilidade}

A Tabela 37 apresenta os resultados dos cálculos das figuras de mérito para a medida de economia coletor solar.

Tabela 37 - Figuras de mérito e pontos notáveis da análise de sensibilidade: Coletores Solares

\begin{tabular}{|c|c|c|c|c|c|c|c|}
\hline \multirow[b]{2}{*}{ PARÂMETRO DE REFERÊNCIA } & \multirow[b]{2}{*}{ Tecnologia } & \multirow[b]{2}{*}{ Unid. } & \multirow[b]{2}{*}{$\begin{array}{c}\text { Cenário } \\
\text { de Referência }\end{array}$} & \multicolumn{4}{|c|}{ ANÁLISE DE SENSIBILIDADE } \\
\hline & & & & $\begin{array}{c}\text { Condição } \\
\text { de ? } \\
\text { Equilibrio }\end{array}$ & $\begin{array}{c}\text { CCVA }_{\text {col... }}-\text { CCVA }_{\text {chuv. }}=0 \\
\text { (econ. Mensal zero) }\end{array}$ & $\begin{array}{c}\text { PBD }=1 / 2 \\
\text { vida } \\
\text { útil }{ }^{\star \star}\end{array}$ & $\begin{array}{c}\text { PBD = } 1 \\
\text { vida } \\
\text { útil }^{\star \star}\end{array}$ \\
\hline \multirow{2}{*}{ Custo Unitario da tecnologia } & Coletor Solar & $\mathrm{R} \$ /$ Unit. & $3.500,00$ & & $6.814,04$ & $2.472,00$ & $3.507,02$ \\
\hline & Chuveiro Elétrico & $\mathrm{R} \$ /$ Unit. & 200,00 & & 200,00 & 200,00 & 200,00 \\
\hline \multicolumn{8}{|l|}{ FIGURAS DE MÉRITO ECONÔMICO OBTIDAS } \\
\hline Economia mensal $=\mathrm{CCVA}_{\text {coletor }}-\mathrm{CCVA}_{\text {chuveiro }}$ & & $\mathrm{R} \$ / \mathrm{mês}$ & 20,19 & & 0 & 26,45 & 20,15 \\
\hline PBD (Custos tecnologia $x$ economia mensal) & & meses & 179,16 & & $N D^{*}$ & 90,00 & 180,00 \\
\hline
\end{tabular}

Fonte: elaboração própria. 
Segue abaixo, a leitura dos resultados da Tabela 37 produto da observância de pontos notáveis da análise de sensibilidade no recurso:

- uma economia mensal de $R \$ 20,19$ entre uma configuração e a outra, com um PBD de 179,16 meses, mantida os demais parâmetros do cenário;

- para que a decisão de adoção fosse indiferente (zero economia), o custo unitário da tecnologia eficiente poderia, no máximo, elevar-se a $R \$ 6.818,04$, mantidos os demais parâmetros de referência. Entretanto, este cenário não produziria resultado dentro da vida útil da tecnologia.

- o custo unitário da tecnologia eficiente precisa reduziu-se a $R \$ 2.472,00$ para considerar uma decisão de adoção indiferente à meia vida da referida tecnologia;

- o custo unitário da tecnologia eficiente precisa ser, no máximo, $R \$ 3.507,02$ para considerar uma decisão indiferente de adoção, a uma vida da referida tecnologia.

\subsection{AVALIAÇÃO QUALITATIVA DE RISCOS}

\subsubsection{Recursos de geração}

De forma geral, os maiores riscos associados a empreender em geração distribuída por fonte alternativa, uma vez decidido investir são : (i) o comportamento do preço da energia no ACR; (ii) a racionalidade do comportamento dos clientes livres, ou potencialmente livres, na busca de contratos ACR e/ou ACL e a (iii) energia verificada coincidir com a energia planejada.

As tendências são: (i) dos preços do ACR tenderem suavemente a valores mais baixos nos próximos 5 anos (Apêndice $C$ ), observando as curvas de preço médio da energia no ACR; (ii) geração verificada abaixo do planejamento (EPE, 2010).

Os riscos regulatórios são baixos, uma vez que se observa uma intensificação do legislador em melhorar as condições de atratividade da geração por fonte 
alternativa, em um cenário demandante de alinhamento da matriz elétrica com a geração sustentável e de baixo, ou nenhum, impacto no aquecimento global.

O risco de subdimensionamento dos custos de interconexão (paralelismo) é presente em toda a região. Apesar de não influenciar o cenário desta avaliação (não faz parte do escopo visto tratarmos de geração distribuída), os riscos de transmissão são de médio para alto na RAA.

Finalmente, nas avaliações feitas dos recursos de geração, considerou-se um valor de energia gerada com sendo um valor determinado ao longo da vida útil do projeto, de $\mathrm{R} \$ 135,15 / \mathrm{MWh}$. Strictu sensu para tomada de decisão, e não uma avaliação expedita, dever-se-á elaborar modelos em que as variáveis, preços e volume da energia gerada sejam tratados de forma estocástica, com níveis de riscos aceitos/determinados previamente.

A seguir, passa-se a uma avaliação dos riscos para oportunidades de geração localizadas na RAA, com base nos resultados do PIR para RAA e com base nas fontes adicionais, ambos utilizados para o desenvolvimento desta dissertação.

\subsubsection{Eólica}

\subsection{Riscos pré-operacionais}

Os principais riscos pré-operacionais relacionados com oportunidades em geração eólica na RAA são: (i) elaboração de um projeto bem definido, com uma avaliação robusta da disponibilidade da fonte primária (o vento); e (ii) dificuldades de interligação da planta de geração eólica com a rede do distribuidor SIN, face ao comportamento da velocidade do vento ao longo do tempo.

O custo da tecnologia para transformar o potencial teórico em realizável na região se apresenta como alto, considerando o Fator de Capacidade calculado: a distribuição de frequência de velocidades do vento na RAA (produziu o cálculo do fator de capacidade médio de FC $=24 \%$, Tabela 24 - Estimativa do Fator de Capacidade dos aerogeradores Enercon na RAA) considerado baixo para o aproveitamento econômico dos ventos com as atuais tecnologias em estágio comercial. Outras regiões do país, como alguns locais da costa atlântica e o 
Nordeste, apresentam projeções do FC na ordem de 50\% para as mesmas tecnologias. A implicação direta deste baixo FC para a EOL na RAA é a produção de uma energia cara, e não competitiva.

Outro risco pré-operacional está relacionado com a aquisição da tecnologia: o país ainda não é autossuficiente na tecnologia de geração eólica, e, portanto está sujeito ao risco cambial decorrente da importação da tecnologia.

Os demais riscos (ambientais, sociais e políticos) foram avaliados como baixo (CICONE, 2008), o que gerou a 8 a $^{\mathbf{a}}$ posição no Ranking ACC. Os maiores riscos ambientais da exploração do potencial eólico estão relacionados à poluição visual e auditiva das torres de aerogeradores: ambos os riscos devem merecer um capítulo especial em "business plans" que vise avaliar oportunidades reais em Eólica.

O risco regulatório é baixo, na perspectiva dos eventos de curto prazo ${ }^{54}$, até onde se observa, com atuações do governo que vem paulatinamente melhorando a atratividade da geração eólica no capítulo regulatório.

Um ponto digno de nota é que não há nenhum aproveitamento EOL registrado no BIG/MME até 2011.

\subsection{Riscos na fase operacional}

O principal risco da fase operacional da geração eólica é o nível de produção de energia ficar abaixo do planejado (já discutido no item risco pré-operacional, na discussão relativa ao desenvolvimento do projeto). A experiência da histórica dos empreendimentos PROINFA, em regiões com FC superior ao da RAA, demonstra que este é um risco real, com energia medida em torno de $80 \%$ da contratada.

Os riscos de mercado, relacionados à concorrência de outras fontes, são grandes, considerando as projeções de preço de equilíbrio de energia eólica para a oportunidade avaliada na RAA: apresentou o maior preço de equilíbrio dentre as fontes de geração avaliadas para a região, sendo muito superior ao valor médio ponderado da energia no ACR, ao Valor de Referência (VR) e do preço no último leilão por tipo fonte.

54 Até cinco anos. 
Os custos de arrendamento, e/ou oportunidade, do terreno necessário à implantação do empreendimento (que no modelo estão incluídos no custo de O\&M), observam tendências de aumento superior à inflação.

Como decorrência dos parágrafos anteriores, o risco financeiro também é grande, dados os impactos da receita decorrente de uma geração abaixo do previsto no fluxo de caixa.

\subsection{Resultado da avaliação qualitativa de risco}

$\mathrm{Na}$ avaliação qualitativa de riscos, este recurso recebe um grau negativo para a RAA.

\subsubsection{Biomassa de cana-de-açúcar}

\subsection{Riscos pré-operacionais}

A dificuldade de acesso ao combustível (biomassa) é de baixo risco, visto que, por cenário, tem demanda prevista de biomassa como sendo uma fração da produzida em uma safra de um empreendimento médio de açúcar e álcool da RAA.

Apenas o risco da interconexão com a distribuidora é digno de menção, em uma pré-análise. A tecnologia de cogeração é conhecida, testada e a experiência dos fornecedores locais é robusta.

\subsection{Riscos na fase operacional}

Os principais riscos operacionais de um empreendimento de cogeração a biomassa de cana são (i) interrupção do processamento de cana-de-açúcar, decorrente de condições climáticas desfavoráveis à colheita, com a consequente interrupção do fornecimento de combustível e (ii) paradas não programadas do conjunto de geração. 


\subsection{Resultado da avaliação qualitativa de risco}

$\mathrm{Na}$ avaliação qualitativa de riscos, este recurso recebe um grau positivo para a RAA, pela abundância de combustível, pelo domínio tecnológico local em produzir bons projetos, e pela de médio, para baixo, risco de falta de biomassa para geração.

\subsubsection{3 $\mathrm{PCH}$}

\subsection{Riscos pré-operacionais}

Considerando o cenário proposto para geração hídrica $\mathrm{PCH}$ na RAA, o maior risco pré-operacional é a obtenção da licença de operação (LO), que, segundo pesquisa do Banco Mundial (BAITELO, 2011), no Brasil pode chegar em média a 2.335 dias (6,4 anos), dos quais 958 (2,6 anos) para se obter a licença prévia.

O segundo maior risco desta categoria é a posse do aproveitamento hídrico; segundo as regras de concessão do uso da água, uma vez que foram mapeados pelo PIR-USP para RAA apenas 2 aproveitamentos com escala para ser uma $\mathrm{PCH}$.

A tecnologia de geração hídrica de porte $\mathrm{PCH}$ é conhecida, e dominada por fornecedores internos, não indicando riscos tecnológicos, e tão pouco perspectivas de melhorias tecnológicas que levem a um aumento da eficiência dos conjuntos geradores hídricos no curto prazo.

O terceiro risco é relacionado à subavaliação dos custos de mitigação de danos ambientais com barragens e reservatório em tempo de projeto, mesmo sabendo que as restrições impostas ao tamanho do reservatório diminuem este tipo de risco.

Como no caso eólico, um ponto digno de nota é que não há nenhum aproveitamento $\mathrm{PCH}$ registrado no BIG/MME até 2011. 


\subsection{Riscos operacionais}

O principal risco da fase operacional da geração $\mathrm{PCH}$ é o nível de produção de energia ficar abaixo do planejado, decorrente de períodos secos prolongados, principalmente considerando a baixa capacidade de armazenamento determinada para os reservatórios de um aproveitamento classificado como $\mathrm{PCH}$.

Um agravante é que, pelo fato da PCH também depender da hidrologia, como as grandes hidrelétricas, caso a seca seja severa, acima das expectativas, recorrer à compra de energia no PLD para conciliação do medido \& comercializado, por motivo de seca, será sempre na pior situação, no caso da $\mathrm{PCH}$.

\subsection{Resultado da avaliação qualitativa de risco}

$\mathrm{Na}$ avaliação qualitativa de riscos, este recurso recebe um grau negativo para a RAA, considerando as poucas opções de aproveitamentos hidrológicos, e pelas incertezas de condução do processo de licenciamento ambiental, além da limitação de tamanho/porte dos aproveitamentos mapeados.

\subsubsection{Medidas de economia de energia}

Medidas de economia de energia foram avaliadas como o melhor tipo de recurso energético na pesquisa do PIR-USP para RAA, que se fundamentou nas opiniões dos especialistas e na opinião da sociedade em geral (CICONE, 2008).

No contexto da avaliação das medidas de economia de energia, uma vez considerada a indicação de investimento, em acordo com os critérios de avaliação dos resultados das figuras de mérito econômico-financeiro do recurso, o único risco operacional digno de menção é a sobre avaliação do nível de demanda do recurso. Exemplificando: se, ao calcular as figuras de mérito do recurso de demanda (CCV e CCVA), a economia absoluta de energia for inferior à projetada, a adoção da tecnologia mais eficiente pode não pagar o custo adicional (ao da tecnologia tradicional) para sua aquisição, durante sua vida útil da tecnologia eficiente, 
evidenciando a importância da figura de mérito PBD para as medidas de economia de energia.

\subsubsection{Resultado da avaliação qualitativa de risco}

$\mathrm{Na}$ avaliação qualitativa de riscos, ambos os recursos de demanda (medida de economia de energia) receberam o grau positivo para a RAA.

\subsection{AVALIAÇÃO DA ATRATIVIDADE DOS 5 RECURSOS ANALISADOS}

\subsubsection{Escala de importância atribuída às FMEs na avaliação dos REs}

\subsubsection{Recursos de Geração}

Para os recursos de geração, as figuras de mérito usadas para avaliação foram: (i) VPL; (ii) [TIR-CAPM] ${ }^{55}$; (iii) PBD; (i) preço de equilíbrio de venda da energia $(\mathrm{VPL}=0)$; (iv) se o recurso apresenta demanda expressiva de capital de giro durante a vida útil; e (v) avaliação global de risco do recurso.

Os pesos atribuídos a cada parâmetro no cálculo da nota de avaliação dos recursos (média ponderada) de geração, e usada para emissão da recomendação, estão na Tabela 38.

Tabela 38 - Pesos atribuídos às FMs de geração para cálculo da recomendação

\begin{tabular}{|c|c|c|c|c|c|c|}
\hline VPL & $\begin{array}{c}\text { Preço } \\
\text { Equilibrio }\end{array}$ & TIR & PBD & $\begin{array}{c}\text { Capital } \\
\text { de Giro }\end{array}$ & $\begin{array}{c}\text { Risco } \\
\text { Geral }\end{array}$ & Total \\
\hline $35 \%$ & $35 \%$ & $10 \%$ & $5 \%$ & $5 \%$ & $10 \%$ & $100 \%$ \\
\hline
\end{tabular}

Fonte: elaboração própria.

55 Adotou-se o critério (TIR - CAPM) para bonificar recursos que, no cenário de referência, apresentaram uma TIR "em torno", ou superior, ao CAPM, a menor taxa de retorno aceita pelo investidor. Ou seja, mesmo que o TIR obtido seja inferior ao CAPM, porém dentro de um intervalo de variação previamente definido, o recurso recebe uma bonificação na sua avaliação de atratividade. 


\subsubsection{Medidas de economia de energia}

Para as medidas de economia de energia, as figuras de mérito usadas para avaliação foram: (i) CCVA; (ii) PBD; (iii) e avaliação global de risco do recurso.

Os pesos atribuídos a cada parâmetro no cálculo da média ponderada, para emissão da recomendação dos recursos de medida de economia, estão na Tabela 39.

\section{Tabela 39 - Pesos atribuídos às FMs de medidas de economia para cálculo da recomendação}

\begin{tabular}{|c|c|c|}
\hline PBD & CCVA & $\begin{array}{c}\text { Risco } \\
\text { Geral }\end{array}$ \\
\hline $50 \%$ & $40 \%$ & $10 \%$ \\
\hline
\end{tabular}

Fonte: elaboração própria.

\subsubsection{Cálculo da atratividade dos recursos}

\subsubsection{Geração}

Nos subitens a seguir, apresentam-se os resultados da avaliação de atratividade das figuras de mérito dos recursos de geração, considerando o algoritmo e critérios adotados nesta dissertação, conforme descrito no item 2.7

\subsection{VPL}

$\mathrm{Na}$ Tabela 40 apresentam-se os resultados da avaliação dos recursos de geração em relação a FM VPL

Tabela 40 - Avaliação dos REs em relação ao VPL

\begin{tabular}{|r|c|c|c|c|}
\hline Recurso & \multicolumn{3}{|c|}{ VPL } & \multirow{2}{*}{ Resultado } \\
\cline { 1 - 4 } Critério & zero $<$ & zero & >zero & \\
\cline { 1 - 2 } Nota & 0 & 5 & 10 & \\
\hline Eólica & $(\mathbf{R} \$ \mathbf{2 6 , 8 M})$ & & & 0 \\
\hline Biomassa & & & $\mathbf{R \$ 3 , 5} \mathbf{M}$ & 10 \\
\hline PCH & $\mathbf{( R \$ 0 , 8 6 M )}$ & & & 0 \\
\hline
\end{tabular}

Fonte: elaboração própria. 


\subsection{Preço de equilíbrio da energia vendida}

$\mathrm{Na}$ Tabela 41 apresentam-se os resultados da avaliação dos recursos de geração em relação a FM preço de venda de equilíbrio

Tabela 41 - Avaliação dos REs em relação ao preço de venda de equilíbrio

\begin{tabular}{|c|c|c|c|c|c|c|c|c|}
\hline \multirow{2}{*}{ Recurso } & \multicolumn{7}{|c|}{$\begin{array}{l}\text { Preço de equil ĺbro da energia } \\
\text { no cenário de referência } \\
\text { ( } R \$ / M W h)\end{array}$} & \multirow{4}{*}{ Resultado } \\
\hline & & $\begin{array}{l}\text { Média } \\
\text { Ult. Leilão } \\
\text { ACR }\end{array}$ & & CME & & VR & & \\
\hline Critério & 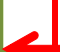 & 102,00 & & 113,00 & & 154,87 & & \\
\hline Nota & 10 & 10 & 7,5 & 7,5 & 2,5 & 2,5 & 0 & \\
\hline Eólica & & & & & & & 278, 92 & 0 \\
\hline Biomassa & & & & & 127,05 & & & 2,5 \\
\hline $\mathrm{PCH}$ & & & & & 139,15 & & & 2,5 \\
\hline
\end{tabular}

Fonte: elaboração própria.

\subsection{Diferença (TIR - CAPM)}

$\mathrm{Na}$ Tabela 42 apresentam-se os resultados da avaliação dos recursos de geração em relação a FM diferença (TIR-CAPM)

Tabela 42 - Avaliação dos REs em relação ao dif. (TIR - CAPM)

\begin{tabular}{|r|c|c|c|c|c|c|}
\hline Recurso & \multicolumn{5}{|c|}{ Diferença (TIR - CAPM) } & \multirow{2}{*}{ Resultado } \\
\cline { 1 - 6 } Critério & $<-2 \%$ & $-2 \%$ & & zero & >zero & \\
\cline { 1 - 6 } Nota & 0 & 2,5 & 5 & 5 & 10 & \\
\hline Eólica & ND & & & & & 0 \\
\hline Biomassa & & & & & $\mathbf{5 , 4 7 \%}$ & 10 \\
\hline PCH & & & $-1,58 \%$ & & & 5 \\
\hline
\end{tabular}

Fontes: elaboração própria

\subsection{PBD}

$\mathrm{Na}$ Tabela 43 apresentam-se os resultados da avaliação dos recursos de geração em relação a FM PBD 
Tabela 43 - Avaliação dos REs em relação ao PBD

\begin{tabular}{|c|c|c|c|c|c|c|}
\hline \multirow{2}{*}{$\begin{array}{r}\text { Recurso } \\
\text { Criério }\end{array}$} & \multicolumn{5}{|c|}{$\begin{array}{c}\text { PBD } \\
\text { no cenário de referência } \\
\text { (anos) }\end{array}$} & \multirow{3}{*}{ Resultado } \\
\hline & & $\begin{array}{c}1 / 2 \\
\text { Vida útil } \\
\text { (10 anos) }\end{array}$ & & $\begin{array}{c}1 \\
\text { Vida útil } \\
\text { (20 anos) }\end{array}$ & & \\
\hline Nota & 10 & 10 & 5 & 5 & 0 & \\
\hline Eólica & & & & & ND & 0 \\
\hline Biomassa & & 10 & & & & 10 \\
\hline $\mathrm{PCH}$ & & & & & ND & 0 \\
\hline
\end{tabular}

Fonte: elaboração própria.

\subsection{Demanda relevante de capital de giro}

$\mathrm{Na}$ Tabela 44 apresentam-se os resultados da avaliação dos recursos de geração em relação à demanda relevante de capital de giro

Tabela 44 - Avaliação dos RE em relação à demanda relevante de capital de giro

\begin{tabular}{|r|c|c|c|}
\hline Recurso & \multicolumn{2}{|c|}{$\begin{array}{c}\text { Estimativa Relevante de } \\
\text { Capital de Giro } \\
\text { (Pico) }\end{array}$} & \multirow{2}{*}{ Resultado } \\
\hline Critério & Sim & Não & \\
\hline Nota & 0 & 10 & 0 \\
\hline Eólica & $\begin{array}{c}\text { (R\$ 4 M } \\
\text { no ano 16) }\end{array}$ & & 10 \\
\hline Biomassa & & $\mathbf{R} \mathbf{0}$ & 10 \\
\hline PCH & & $\mathbf{R} \$ \mathbf{0}$ & 10 \\
\hline
\end{tabular}

Fonte: elaboração própria.

\subsection{Riscos qualitativos Gerais}

$\mathrm{Na}$ Tabela 45 apresentam-se os resultados da avaliação dos recursos de geração em relação aos riscos gerais: 
Tabela 45 - Avaliação dos REs em relação aos riscos gerais

\begin{tabular}{|r|c|c|c|c|}
\hline \multirow{2}{*}{ Recurso } & \multicolumn{3}{|c|}{$\begin{array}{c}\text { Avaliação qualitativa } \\
\text { de riscos }\end{array}$} & \multirow{2}{*}{ Resultado } \\
\cline { 1 - 4 } Critério & positiva & neutra & Negativa & \\
\cline { 1 - 4 } Nota & 10 & 5 & 0 & \\
\hline Eolica & & & $\mathrm{x}$ & 0 \\
\hline Biomassa & $\mathrm{x}$ & & & 10 \\
\hline PCH & & & $\mathrm{x}$ & 0 \\
\hline
\end{tabular}

Fonte: elaboração própria.

\subsection{Resultados parciais}

Na Tabela 46 apresentam-se os resultados parciais da avaliação dos três recursos de geração escolhidos no estudo.

Tabela 46 - Resultados parciais da atratividade dos REs Geração

\begin{tabular}{|l|c|c|c|c|c|c|c|}
\hline Parâmetro & VPL & $\begin{array}{c}\text { Preço } \\
\text { Equilibrio }\end{array}$ & TIR & PBD & $\begin{array}{c}\text { Capital } \\
\text { de Giro }\end{array}$ & $\begin{array}{c}\text { Risco } \\
\text { Geral }\end{array}$ & $\begin{array}{c}\text { Média } \\
\text { Geral }\end{array}$ \\
\hline Peso & $35 \%$ & $35 \%$ & $10 \%$ & $5 \%$ & $5 \%$ & $10 \%$ & \\
\hline Eólica & 0 & 0 & 0 & 0 & 0 & 0 & 0 \\
\hline Biomassa & 10 & 2,5 & 10 & 10 & 10 & 10 & 7,375 \\
\hline PCH & 0 & 2,5 & 5 & 0 & 10 & 0 & 1,875 \\
\hline
\end{tabular}

Fonte: elaboração própria.

\subsubsection{Medidas de economia de energia}

Nos subitens a seguir, apresentam-se os resultados da avaliação de atratividade das figuras de mérito das medidas de economia, considerando o algoritmo, e critérios, adotado nesta dissertação, conforme descrito no item 2.7.

\subsection{PBD}

$\mathrm{Na}$ Tabela 47 apresentam-se os resultados da avaliação medidas de economia em relação ao PBD 
Tabela 47 - Avaliação dos REs em relação ao PBB

\begin{tabular}{|c|c|c|c|c|c|c|c|}
\hline Parâmetro & \multicolumn{6}{|c|}{ PBD } & \multirow{3}{*}{ Resultado } \\
\hline \multirow[t]{2}{*}{ Recurso } & Critério & & $\begin{array}{c}1 / 2 \\
\text { Vida útil } \\
\text { (33 meses) }\end{array}$ & & $\begin{array}{c}1 \\
\text { Vida útil }\end{array}$ & $\begin{array}{c}>1 \\
\text { Vida úti }\end{array}$ & \\
\hline & Nota & 10 & 10 & 5 & 5 & 0 & \\
\hline Lâmpada Fluores. & & 1,61 & & & & & 10 \\
\hline Coletores Solar & & & & 179,16 & & & 5 \\
\hline
\end{tabular}

Fonte: elaboração própria.

\subsection{CCVA}

$\mathrm{Na}$ Tabela 48 apresentam-se os resultados da avaliação medidas de economia em relação ao CCVA

Tabela 48 - Avaliação dos REs em relação ao CCVA

\begin{tabular}{|r|c|c|c|}
\hline Parâmetro & \multicolumn{2}{|c|}{ CCVA } & \multirow{2}{*}{ Resultado } \\
\cline { 1 - 3 } Critério & $<$ ZERO & $>$ ZERO & Reta \\
Nota & 0 & 10 & \\
\hline Lâmpada Fluores. & & $\mathrm{R} \$ 35,52$ & 10 \\
\hline Coletores Solar & & $\mathrm{R} \$ 20,19$ & 10 \\
\hline
\end{tabular}

Fonte: elaboração própria.

\subsection{Riscos qualitativos gerais}

$\mathrm{Na}$ Tabela 49 apresentam-se os resultados da avaliação medidas de economia em relação aos riscos gerais em investir nas medidas de economia escolhidas no estudo

Tabela 49 - Avaliação dos REs em relação aos riscos gerais

\begin{tabular}{|r|c|c|c|c|}
\hline \multicolumn{1}{|c|}{ Paramêtro } & \multicolumn{3}{|c|}{ Avaliação qualitativa } & \multirow{2}{*}{ de riscos } \\
\cline { 2 - 3 } & \multicolumn{3}{|c|}{ Resultado } \\
\hline Critério & positiva & neutra & Negativa & \\
\hline Nota & 10 & 5 & 0 & \\
\hline Lâmpada Fluores. & $\mathrm{x}$ & & & 10 \\
\hline Coletores Solar & $\mathrm{x}$ & & & 10 \\
\hline
\end{tabular}

Fonte: elaboração própria 


\subsection{Resultados parciais}

$\mathrm{Na}$ Tabela 50 apresentam-se os resultados parciais da avaliação das duas medidas de economia de energia escolhidas no estudo:

Tabela 50 - Resultados parciais da atratividade dos REs:
Medidas de economia
\begin{tabular}{|l|c|c|c|c|}
\hline Parâmetro & PBD & CCVA & $\begin{array}{c}\text { Riscos } \\
\text { Geral }\end{array}$ & $\begin{array}{c}\text { Média } \\
\text { Geral }\end{array}$ \\
\hline Peso & $50 \%$ & $40 \%$ & $10 \%$ & \\
\hline Lâmpada Fluores. & 10 & 10 & 10 & 10,00 \\
\hline Coletores Solar & 5 & 10 & 10 & 7,50 \\
\hline
\end{tabular}

Fonte: elaboração própria.

\subsection{RESULTADO FINAL DAS AVALIAÇÕES DE ATRATIVIDADE}

$\mathrm{Na}$ Tabela 51 apresenta-se o quadro com a avaliação final da atratividade para negócios dos cinco (5) recursos renováveis, segundo os cenários e critérios propostos por este estudo. E, segundo os critérios definidos na Tabela 1 - Escala de notas para avaliação do $\mathrm{RE}$, segue os resultados finais da medida de atratividade dos recursos avaliados.

Tabela 51 - Resultado final do diagnóstico de avaliação dos REs

\begin{tabular}{|l|c|c|}
\hline Recurso & Média Geral & Atratividade \\
\hline Geração Eólica & 0 & não atrativo \\
\hline Cogeração Biomassa & 7,375 & atrativo com atenção \\
\hline PCH & 1,875 & não atrativo \\
\hline Lâmpadas Fluorescentes compactas & 10,00 & atrativo \\
\hline Coletores Solares & 7,50 & atrativo com atenção \\
\hline
\end{tabular}

Fonte: elaboração própria, baseada nos resultados das tabelas 46 e 50. 


\section{CONCLUSÕES}

\subsection{RECURSOS DE GERAÇÃO}

Os cenários de avaliação da atratividade dos REs de oferta (geração) foram desenhados com vistas a medir atratividade das principais fontes incentivadas no contexto da geração distribuída:

- o parâmetro de referência capacidade instalada dos três recursos foi escolhido considerando o máximo permitido por lei para gozar dos benefícios de fonte incentivada (30MW), ou o maior aproveitamento da fonte primária presente na RAA (caso da $\mathrm{PCH}$, com $13 \mathrm{MW}$ ), desde que menor que $30 \mathrm{MW}$;

- a estruturação jurídica e de capital dos cenários de oportunidade foi definida como sendo SPE, sociedade de propósito especifico.

Esta composição específica de cenários visou à lógica de se aproveitar dos incentivos (redução da "taxa fio" e linhas de financiamento incentivas do BNDES) para uma avaliação da atratividade das fontes no melhor contexto para a RAA. Assim, teoricamente, desenhou-se o cenário com as melhores condições, e vantagens competitivas, para estas fontes, podendo-se medir a atratividade de oportunidades neste cenário ótimo.

O que se observou com os resultados do estudo, é que apenas cogeração por biomassa se apresentou atrativa dento da RAA, ainda assim requerendo atenção no contexto do cenário criado, pelas limitações de competitividade de preços da energia gerada ${ }^{56}$.

Já a geração eólica não tem perspectiva de ser atrativa a curto e médio prazo na $R A A^{57}$, e o principal impactante é o baixo fator de capacidade da geração decorrentes das baixa médias de ventos da região (velocidades abaixo do atrativo para uma exploração comercial).

Finalmente, a geração hídrica $\mathrm{PCH}$, carece de aproveitamentos economicamente viáveis na RAA, e os riscos pré-operacionais associados à

\footnotetext{
${ }_{57}^{56}$ Muito próxima do teto estabelecido (VR).

57 Se há um salto tecnológico nos geradores, que possibilite gerar mais energia com a mesma distribuição de ventos, então será necessário calcular o novo fator de capacidade desta nova tecnologia, e assim também recalculando as novas figuras de mérito para o novo cenário.
} 
obtenção de licença prévia, decorrentes de temas ambientais, se traduzem-se em altos riscos globais.

No contexto da RAA, o maior impactante na avaliação da atratividade dos recursos de geração alternativa distribuída, em geral, foi a baixa competitividade dos preços de equilíbrio da energia gerada regionalmente, face aos balizadores de preços competitivos definidos.

Assim a conclusão é que: (i) a maneira mais eficiente dos formuladores de políticas públicas incentivarem a geração distribuída de fontes alternativas é através de leilões regionais e por tipo de fonte, em que o gerador local compete contra 0 gerador local, explorando a mesma fonte primária, o que permitiria potencializar a vocação regional das fontes locais lá encontradas; (ii) o cálculo da modicidade tarifária, prevista em lei, deveria levar em conta os custos evitados/postergados com transmissão, distribuição e perdas técnicas de energia, além dos impactos ambientais, revertidos em favor das fontes renováveis locais.

Outro estímulo a atratividade de potenciais renováveis locais seria a revisão da legislação afeta a custos, e responsabilidades, da interconexão do gerador à rede do distribuidor local. Hoje este tema é um ofensor ainda em tempo de projeto, produto de seus altos custos relativos, que variam de forma locacional e não transparente, sendo arcados integralmente pelo gerador.

\subsection{MEDIDAS DE ECONOMIA DE ENERGIA ELÉTICA}

Em sua atratividade, na média, as medidas de economia de energia se saíram bem melhor que os recursos de geração, mesmo considerando que a avaliação foi conduzida pelo ponto de vista do usuário final em uma decisão solitária e que afeta a família, e não do ponto de vista da sociedade como um todo, e os benefícios da economia de energia se somam de forma sinergética.

A troca de lâmpadas incandescentes por fluorescentes compactas, dada a robustez dos resultados obtidos, deveria ser imediatamente feita, ao benefício da postergação de investimentos em geração, transmissão e distribuição.

Os custos com aquisição e instalação de sistemas de aquecimento por coletores solares merece uma atenção especial dos formuladores de políticas públicas, se considerarmos a RAA. No atual contexto, apenas as classes $A$ e $B$ têm 
acesso (alto custo inicial), o que reduz muito o mercado potencial, além de limitar o benefício dos investimentos evitados, decorrentes da adoção da tecnologia. A tecnologia está, praticamente, no limiar da atratividade, e altamente impactada pelo PBD, que encosta na vida útil da tecnologia. Com as perspectivas futuras de aumento das tarifas residenciais, a atratividade dos coletores solares deve melhorar, mas não o suficiente para uma adoção maciça, o ideal. A recomendação é o subsídio público a adoção da tecnologia, subsídio que seria recuperado por uma fórmula que contemple o cálculo dos custos evitados de geração, transmissão e distribuição de energia.

\subsection{PIR-USP NA AVALIAÇÃO DA ATRATIVIDADE DE RES}

Comparando a Tabela 51( avaliação de atratividade na visão de negócio, com a Tabela 15 (ranking ACC do PIR-USP para RAA que visa o desenvolvimento sustentável, considerando as 4 dimensões analisadas no PIR-USP) observa-se que:

1. O RE Coletor Solar, que apresenta-se como $1^{\circ}$ na ACC do PIR-USP para RAA, apresenta-se em $2^{-}$na avaliação de atratividade para negócios, e mesmo assim com atenção;

2. o $\mathrm{RE}$ geração elétrica por $\mathbf{P C H}$, que se apresenta como $5^{\circ}$ no ranking ACC do PIR-USP para RAA, não apresenta atratividade para investimento;

3. o RE Lâmpadas fluorescentes, o único recurso atrativo sem atenção, na ótica de negócios, é o 6ํㅡㄹ no ranking $A C C$ de sustentabilidade do PIR-USP;

4. o RE geração eólica (EOL), que se apresenta-se como $8^{\circ}$ no ranking ACC do PIR-USP para a RAA, e não apresenta atratividade para investimentos; 
5. o RE cogeração por biomassa de cana (BIO), que se apresenta como $11^{\text {o }}$ no Ranking da ACC do PIR-USP para a RAA, apresenta-se como atrativo com atenção para investimentos.

Assim, definitivamente a atratividade para negócios não convergiu com a busca do desenvolvimento sustentável dos REs avaliados, quando a avaliação é de curto para médio prazo. A determinação, e monetização, dos fatores que levam a esta divergência são fundamentais para o aprofundamento de políticas que busquem o desenvolvimento sustentável.

Finalmente, a coleta e análise de informações ${ }^{58}$ tabuladas regionalmente de REs é difícil e demorada, obrigando acesso a bases de dados fragmentadas e nem sempre coerentes. Nesta medida o PIR-USP para a RAA facilitou, sobremaneira, esta tarefa, poupando tempo e permitindo uma consolidação mais robusta de resultados e, consequentemente, melhores conclusões, ainda na fase de seleção de portfólio de investimentos.

${ }^{58}$ Nas 4 dimensões analisadas (técnico-econômica, ambiental, social e política) para uma ampla analise de riscos. 


\section{REFERÊNCIAS BIBLIOGRÁFICAS}

AGÊNCIA NACIONAL DE ENERGIA ELÉTRICA (ANEEL). Resolução Normativa no. 228, de 25 de Julho de 2006. "Estabelece os requisitos para a certificação de centrais geradoras termelétricas na modalidade de geração distribuída, para fins de comercialização de energia elétrica no Ambiente de Contratação Regulada - ACR".

Nota Técnica Preliminar da Audiência Pública no. 4, de 8 de Abril de 2006. "Regulamenta o inciso II do artigo 14 do Decreto no. 5.163, de 30 de julho de 2004, estabelecendo os requisitos necessários à certificação de centrais geradoras termelétricas na modalidade distribuída para fins de comercialização de energia elétrica no Ambiente de Contratação Regulada - ACR".

Nota Técnica no. 69, de 26 de Abril de 2006. "Minuta de Resolução Normativa que regulamenta as condições para a comercialização de energia elétrica, oriunda de empreendimentos de geração que utilizem fontes primárias incentivadas, com unidade ou conjunto de unidades consumidoras que possuam carga igual ou superior a 500 kW. (Audiência Pública no. 33/2005)".

Resolução normativa 235, de 14 de novembro de 2006. Estabelece os requisitos para a qualificação de centrais termelétricas cogeradoras de energia e dá outras providencias.

.Resolução normativa no 343, de 9 de dezembro de 2008. Estabelece procedimentos para registro, elaboração, aceita, análise, seleção e aprovação de projetos básicos e para autorização de aproveitamento de potencial de energia hidráulica com características de Pequena central Hidrelétrica.

.Resolução normativa no 390 , de 15 de dezembro de 2009. Estabelece os requisitos necessários à outorga de autorização para exploração da capacidade instalada de usinas termelétricas e de outras fontes alternativas de energia, os procedimentos para registro de centrais geradores com capacidade instalada reduzida e dá outras providencias.

.Resolução no 265, de 10 de junho de 2003. Estabelece os procedimentos para prestação de serviços ancilares de geração e transmissão de energia elétrica.

Resolução Homologatória no 1022, de 29 de junho de 2010. Estabelece o valor das Tarifas de Uso do Sistema de Transmissão - TUST de energia elétrica, componentes do sistema Interligado Nacional, fixa a tarifa de transporte da energia elétrica proveniente de Itaipu Binacional e estabelece o valor dos encargos de uso aplicáveis as concessionárias de distribuição.

ALVEZ, JAILSON JOSÉ MEDEIROS et al. Riscos financeiros de uma PCH no PROINFA. Revista CPRCH, № 37. 
ALENCAR FILHO, FRANCISCO; CASTILHO, WAGNER FRANCISCO. PCH Project Finance e estudo de caso. Revista do CERPCH, no 48

ANDRADE \& CANELLAS. Geração de energia elétrica a partir de Biomassa. Termo de referência TR98: Preparado para o Governo do Estado de São Paulo. Mello, João Carlos de Oliveira. (coord.). São Paulo: Andrade \& Canellas, 2007.

BAITELO, RICARDO LUCERDA.. Modelo de cômputo e valoração completa de potencias de recursos energéticos para o planejamento integrado de recursos. Tese de Doutorado. Ed. rev. EPUSP, São Paulo, 2011. 400 p.

BERNAL, JONATHAS LUIZ OLIVEIRA. Modelagem para o aproveitamento sustentável dos bicombustíveis, energia eólica e solar dentro do PIR local: estudo de caso do PIR da região de Araçatuba. Dissertação de Mestrado. PIGGE/IEE, São Paulo, 2009, 166p

BIAGE, MARIO FERNANDES.. Modelagem da carteira dos recursos energéticos no PIR: Validação do modelo PIR de Araçatuba. Tese de Doutorado. São Paulo, 2010.

BANCO NACIONAL DE DESENVOLVIMENTO ECONÔMICO E SOCIAL BNDES. Programas de financiamento. Rio de Janeiro. (http://www.bndes.gov.br, 15 de Outubro de 2011)

BREALEY, RICHARD A; MYERS, STEWART C. Princípios de Finanças Empresariais. Lisboa: McGraw Hill Portugal, 1992.

BRASIL. Decreto no 5.163, de 30 de julho de 2004. Regulamenta a comercialização de energia elétrica (lei 10.848), o processo de outorga de concessões de autorização de geração de energia elétrica, e dá outras providenciais.

Lei no. 10.438, 26 de Abril de 2002. "Dispõe sobre a expansão da oferta de energia elétrica emergencial, recomposição tarifária extraordinária, cria o Programa de Incentivo às Fontes Alternativas de Energia Elétrica (PROINFA), a Conta de Desenvolvimento Energético (CDE), dispõe sobre a universalização do serviço público de energia elétrica, e dá outras providências".

Lei no $\mathbf{1 0 . 8 4 8}$ de 15 de março de 2004. Dispõe sobre a comercialização de energia elétrica, altera as leis no 5.655 de 20 de maio de 1971, 8.631, de 4 de março de 1993, 9.074, de 7 de julho de 1995, 9.427, de 26 de dezembro de 1996, 9.487, de 6 de agosto de 1997, 9.648, de 27 de maio de 1998, 9.991, de 24 de julho de 2000, 10.438, de 26 de abril de 2002, e dá outras providencias.

. Portaria Interministerial $\mathbf{1 . 8 7 7}$ de $\mathbf{3 0}$ de dezembro de 1985 . Institui o programa nacional de conservação de Energia elétrica.

BRIGHENTI, CLADIA RODRIGES FARIA. Integração do cogerador de energia do setor sucroalcooleiro com o sistema elétrico. Dissertação de Mestrado. PIPGE/IEE, São Paulo, 2003, 166p. 
BURTON, TONY. Wind Energy Handbook. Tony Burton, David Sharpe, Nick Jenkins and Ervin Bossanyi. Chichester: John Wiley \& Sons, LTD, 2001.

CAIO, LEONARDO SANTOS. Análise das Metodologias de Previsão de Mercado de Energia Elétrica: Relações Macroeconômicas e o Novo Perfil de Planejamento no Ambiente Pós-Privatização. 1998. Dissertação (Mestrado em Energia) - Energia, Universidade de São Paulo, São Paulo, 1998..

CAMPOS, ROBERTO DE MOURA. O potencial e a viabilidade econômica da geração de excedentes de energia a partir do bagaço de cana-de-açúcar. Revista Brasileira de Energia, V 1, № 3.

CASTRO, NIVALDO JOSÉ. . Bioeletricidade: a indústria de álcool e açúcar e a bioeletricidade: possibilidades e limites. Nivaldo José de Castro..[et al,]. Rio de Janeiro: Synergia: Eletrobrás: GESEL,UFRJ, 2008.

CASTRO, N. J. ; DANTAS G. A.; BARÃO R. A dinâmica estrutural do setor sucroenergético como elemento indutor de investimentos em bioeletricidade. In: AGRENER, 2010, Campinas.

CASTRO, NIVALDE J. Leilão de energia de reserva: razões, funções e perspectivas. Revista Brasileira de Energia no 330, pp89-90, 2008.

CARMEIRO, DANIEL ARAÚJO. PCHs: pequenas centrais hidrelétricas: aspectos jurídicos, técnicos e comerciais. Daniel Araujo Carneiro. Rio de Janeiro: Synergia: Canal Energia, 2010.

CENBIO. Parâmetros econômicos para a geração de energia elétrica a partir da Biomassa - Relatório Completo. Palleta, C.E.M. São Paulo: CENBIO, 2003.

CENTRO DE REFERENCIA PARA ENERGIA SOLAR E EÓliCA. Atlas do Potencial Eólico Brasileiro. Brito, Sergio Salvo. Rio de Janeiro: CRESESB, 2002.

CICONE JUNIOR, DECIO. Modelagem e aplicação da avaliação de custos completos através do processo analítico hierárquico dentro do planejamento integrado de recursos. Dissertação de Mestrado. Ed revisado, São Paulo, 2008

COELHO, SUANI TEIXEIRA.. Mecanismos para implementação da Cogeração de eletricidade a partir de biomassa. Um modelo para o estado de São Paulo. Tese de Doutorado. São Paulo, 1999.

CORRÊA NETO, VICENTE. Análise de Viabilidade da Cogeração de Energia Elétrica em Ciclo Combinado com Gaseificação de Biomassa de Cana de açúcar e Gás Natural. Tese de doutorado. COPPE/UFRJ, Rio de Janeiro. 2001.174p 
CORREIA, SALATIEL PREDROSA SOARES. Tarifas e a demanda de energia Elétrica. Salatiel Pedrosa Soares Correia. Rio de Janeiro: Synergia, 2010.

COSTA, RICARDO CUNHA DA; PIEROBON, ERNESTO COSTA. Leilão de energia nova: análise da sistemática e dos resultados. BNDES Setorial, no 27, 2008.

COURTNEY, KRIKLAND, VIGUEIRIE. "Strategy under uncertainty"- Boston: Harvard business review, 1997

DAMODARAN, ASWATH . Gestão estratégica do Risco. São Paulo : Bookman, 2009.

DANTAS, DJOLSE NASCIMENTO. Uso da biomassa da cana-de-açúcar para geração de energia elétrica: análise energética, exergética e ambiental de sistemas de cogeração em sucroalcooleiras no interior paulista. Dissertação de Mestrado. São Carlos, 2010.

ELETROBRAS. Referencia de custos - Linhas de transmissão e subestação de alta tensão. Rio de Janeiro:- DE/DEA/DEAT - Divisão de Engenharia de Transmissão, 2004.

EMPRESA DE PESQUISA ENERGÉTICA - EPE.1 Leilão de energia de reserva 2008 - Definição do preço Inicial. EPE-DEE/DEN-067/2998-r4. Julho de 2008.

. Plano Decenal de Expansão de Energia 2019. Brasília: MME -

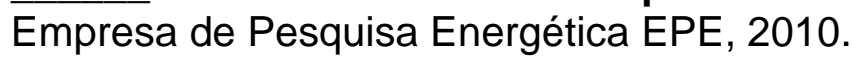

. Plano Decenal de Expansão de Energia 2020. Brasília: MME Empresa de Pesquisa Energética EPE, 2011.

Plano Nacional de Energia - PNE 2030. Rio de Janeiro : MME Empresa de pesquisa Energética EPE, 2007.

FAGUNDES FILHO, CARLOS AUGUSTO CAMINADA. Análise da estratégia de contratação de consumidores livres tendo como balizamento a formação de preços no mercado cativo. Dissertação de Mestrado. ed.rev. EPUSP, São Paulo, 2009. 132 p.

FAUSTO A. C; MENDES, C. A. B; BELUCO, A. Curvas de custo de implantação de pequenos projetos hidrelétricos em função da produção média Anual de energia. Revista CERPCH, no 39.

FUJII, RICARDO JUNQUEIRA. Modelo de caracterização sistêmica das opções de oferta energética para o PIR. Dissertação de Mestrado, EPUSP, São Paulo, 2006. 181p 
GIMENES, ANDRÉ LUIZ VEIGA. Modelo de Integração de Recursos como Instrumento para um Planejamento Energético Sustentável. Tese de Doutorado. EPUSP, São Paulo, 2004. 184p.

GITMAN, LAURENCE J. Princípios de Administração Financeira. Lawrence J. Gitman. São Paulo: editora Harbra, 1997.

HEIDEIER, RAPHAEL BRETRAND. Conceitos Básicos de Risco na Comercialização de Energia Elétrica no Setor Elétrico Brasileiro e a Atuação Governamental. Dissertação de Mestrado. EPUSP, São Paulo, 2009.126p.

IEA. 2009 Technology Roadmap: wind Energy. London: IEA - International Energy Agency, 2009.

KOTLER, PHILIP. ARMSTRONG GARY. Princípios de Marketing. Philip Kotler, Gary Armstrong. Rio de Janeiro: LTC, 1999.

LAPPONI, JUAN CARLOS. Projetos de investimentos na empresa. Juan Carlos Lapponi. Rio de Janeiro: Elsevier, 2007 - 3ªำ reimpressão.

MACHADO, F. G. Análise Econômico-Financeiro de novas PCHs em leilões do novo modelo do setor Elétrico. Machado, Fernando Giacomini; Santos Jr, Milton Francisco; Sugai, Helio Mitsuo. Anais :VI Simpósio Brasileiro sobre Pequenas e Médias Centrais Hidrelétricas. BH, 2008.

MARCONDES, MONICA; SAIDEL, MARCO ANTONIO; BREDARIOL JR, ARMINDO. Panorama dos investimentos em energia eólica no Brasil e no Mundo.. Escola Politécnica da USP, 2004.

MINISTÉRIO DAS MINAS E ENERGIA - MME. Portaria no 299, de 10 de maio de 2011. Sistemática para o leilão de compra de energia elétrica proveniente de novos empreendimentos de geração, denominado leilão A-3, de 2011

. Balanço de Energia Útil (BEU). Brasília: FDTE, 2005

NAGAOKA, M. P.T et al. Análise de viabilidade econômica em cogeração de energia elétrica. Revista cientifica eletrônica de engenharia florestal, Ano V, no 09, fev/2007.

NASCIMENTO, JOSE CARLOS ALVES DO. Análise da livre concorrência e competitividade no setor Elétrico Brasileiro. Dissertação de Mestrado. São Luiz (MA), 2007.

NELSON, VAUGHN. Wind Energy: renewable energy and the environment. Vaughn Nelson. Boca Raton: CRC Press, 2009

NETO, V. C.; TOLMASQUIM, M.T. Avaliação econômica da cogeração em ciclo combinado com gaseificação de biomassa e gás natural no setor sucroalcooleiro. 
Revista Brasileira de Energia v 8, № 2. Sociedade Brasileira de Planejamento Energético.

PELLEGRINI, MARIA CRISTINA.. Inserção de centrais cogeradoras a bagaço de cana no parque energético do estado de São Paulo: Exemplo de aplicação da metodologia para análise dos aspectos locacionais de integração energética. Dissertação de mestrado. São Paulo: PIGGE/USP, 2002.

POLITZEL, LUIZ HENRIQUE. Metodologia de prospecção e avaliação de préviabilidade expedita de geração distribuída (GD): caso eólico e hidráulico. Dissertação de Mestrado. EPUSP, São Paulo, 2007.160p.

RAMOS, DOREL; SUSTERAS, GUILHERME LUIZ. Utilização de Algoritmos Genéticos para previsão da Contratação de Energia pelas Distribuidoras. IEEE Latin America Transactions, v 4, no4. Junho 2006.

REIS, LINEU BELICO DOS. Geração de Energia Elétrica. São Paulo: Agil Gráfica, 2000.

REIS, L.B; MIELICK, O. Um modelo de gestão integrada de recursos para viabilizar o desenvolvimento sustentável. Escola Politécnica da USP. São Paulo, 1999.

REINIG, ALEXANDRE ORRICO.. Aplicação da análise de custos completos no PIR visando o gás-natural e outros energéticos não renováveis para a região administrativa de Araçatuba. Trabalho de conclusão de curso. EPUSP, São Paulo, 2008. 155p.

ROCHA, FELIPE A. A. Análise técnico-econômica da melhoria do sistema de cogeração de uma indústria de cana-de-açúcar. Anais: Rio Oil \& gás 2006.

SAATY, T. L.. The Analytic Hierarchy Process: Planning, Priority Setting, Resource Allocation. Pittsburgh, PA: RWS Publications, 1976

SANTOS JR., MILTON FRANCISCO. As opções de comercialização da energia proveniente de $\mathrm{PCHs}$ pertencentes a empresas estatais. Anais: $\mathrm{VI}$ Simpósio Brasileiro sobre pequenas e medias centrais Hidroelétricas. $\mathrm{BH}$, abril de 2008.

SILVA, EDSON LUIZ DA. Formação de preços em mercados de energia elétrica. Edson Luiz da Silva. Porto Alegre: Editora Sagra Luzzatto, 2001

SILVA, PAULO PATRICIO DA. Influência dos aspectos Regulatórios no Processo de tomada de decisão em sistemas de cogeração de energia elétrica: Um estudo de caso do setor sucroalcooleiro de Mato Grosso do Sul. Dissertação de mestrado. UFMGS, MT Sul, 2009. 138p

SOUZA, Zilmar José de. A cogeração de energia no setor sucroalcooleiro: desenvolvimento e situação atual. In: ENCONTRO DE ENERGIA NO MEIO RURAL, v4, 2002, Campinas. 
SSE/SP. Anuário Estatístico de energéticos por município no Estado de São Paulo. São Paulo: Secretaria de Saneamento e Energia SSE/SP. Revisado em 01/02/2011.

SUSTERAS, GUILERME LUIZ. Aplicação de algoritmos genéticos para previsão do comportamento das distribuidoras como apoio à estratégia de comercialização de energia de agentes geradores. Ed.rev. EPUSP, São Paulo, 2006.101 p.

TAMAROZI, RODRIGO. Identificação, modelagem e mitigação de riscos em operações de comercialização de energia elétrica no Mercado Brasileiro. Dissertação de Mestrado. Universidade Federal do Paraná, 2002. 164p.

TOLMASQUIM, MAURICIO TIOMNO. Fontes Renováveis de Energia no Brasil. Mauricio Tiomno Tolmasquim (Coordenador). Rio de Janeiro: Interciência: CENERGIA, 2003.

Geração de Energia Elétrica no Brasil. Mauricio Tiomno Tolmasquim (coordenador). Rio de Janeiro: Interciência: CENERGIA, 2005.

UDAETA, MIGUEL EDGAR MORALES. Planejamento Integrado de Recursos Energéticos - PIR - para o Setor Elétrico (pensando o Desenvolvimento Sustentável). Tese de Doutorado. EPUSP, São Paulo, 1997.

UDAETA, MIGUEL EDGAR MORALES. (Org.). Novos Instrumentos de Planejamento Energético Regional visando o Desenvolvimento Sustentável. (Trabalhos de Pesquisa Científica Finalizados e Ferramentas Metodológicas Consolidadas do PIR na USP Aplicadas a RAA): Relatório Final. São Paulo : FAPESP processo 03/06441-7, 2010.

Relatório Técnico Científico de Inventário Ambiental. Incluído no Projeto de Políticas Públicas "Novos Instrumentos de Planejamento Energético Regional visando o Desenvolvimento Sustentável - Fase 2". São Paulo, 2008a.

Relatório Técnico Científico Final da Fase 2 - ano 2. Incluído no

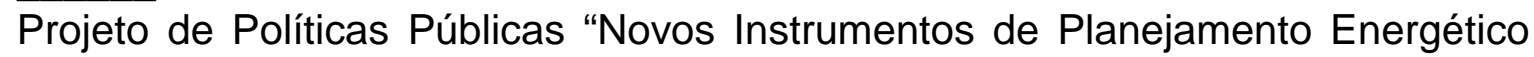
Regional visando o Desenvolvimento Sustentável - Fase 2". São Paulo, 2008b.

Relatório Técnico Científico da Fase 2 - Valoração de Recursos Energéticos de Oferta. Incluído no Projeto de Políticas Públicas "Novos Instrumentos de Planejamento Energético Regional visando o Desenvolvimento Sustentável - Fase 2". FAPESP e USP. São Paulo, 2008c.

Relatório Técnico Científico de Elaboração da Mina de Dados.

Incluído no Projeto de Políticas Públicas "Novos Instrumentos de Planejamento Energético Regional visando o Desenvolvimento Sustentável - Fase 2". São Paulo, 2008d. 
Relatório Técnico Científico Final da Fase 2 - ano 3. Incluído no

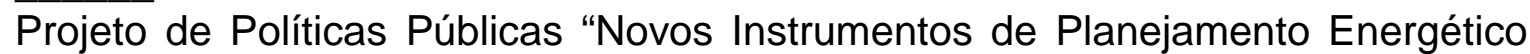
Regional visando o Desenvolvimento Sustentável - Fase 2". FAPESP e USP. São Paulo, 2009a.

Relatório Técnico Científico - Modelamento Energo-Ambiental do PIR para a RAA Araçatuba. Incluído no Projeto de Políticas Públicas "Novos Instrumentos de Planejamento Energético Regional visando o Desenvolvimento Sustentável - Fase 2". São Paulo, 2009b.

Relatório Técnico Científico de Valoração Política. Incluído no Projeto de Políticas Públicas "Novos Instrumentos de Planejamento Energético Regional visando o Desenvolvimento Sustentável - Fase 2". São Paulo, 2009c.

Relatório Técnico Científico de Valoração Técnico-Econômica.

Incluído no Projeto de Políticas Públicas "Novos Instrumentos de Planejamento Energético Regional visando o Desenvolvimento Sustentável - Fase 2". São Paulo, 2009d.

Relatório Técnico Científico de Valoração Ambiental”. Incluído no Projeto de Políticas Públicas "Novos Instrumentos de Planejamento Energético Regional visando o Desenvolvimento Sustentável - Fase 2". FAPESP e USP. São Paulo, 2009e.

Relatório Técnico Científico de Valoração Social. Incluído no

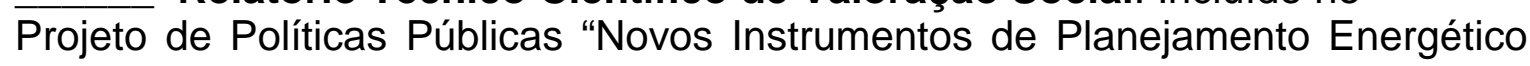
Regional visando o Desenvolvimento Sustentável - Fase 2". FAPESP e USP. São Paulo, 2009f.

Relatório Técnico Científico da Fase 2 - Plano Preferencial. Incluído no Projeto de Políticas Públicas "Novos Instrumentos de Planejamento Energético Regional visando o Desenvolvimento Sustentável - Fase 2". São Paulo, 2009g.

UTURBEY, WADAED; AGULAR, LUZ A. Incertezas na cogeração de energia elétrica: Uma abordagem via Condicional NPVaR. Fundação de Amparo a pesquisa do Estado de Minas Gerais, BH, 2004.

WEC. 2010 Survey of Energy Resources. London: World Energy Council, 2010 


\section{APÊNDICE A - Modelo de fluxo de caixa para recursos de geração}

Tabela 52 - Modelo de fluxo de caixa para avaliação dos REs de geração

\begin{tabular}{|c|c|c|c|c|c|c|c|}
\hline \multirow{2}{*}{\multicolumn{2}{|c|}{ ITEM DE FLUXO DE CAIXA }} & \multicolumn{2}{|c|}{ Pré-operação } & \multicolumn{4}{|c|}{ Operação } \\
\hline & & A-2 & A-1 & A & A+1 & ......... & $A+20$ \\
\hline a) & (+)RB - RECETA BRUTA (venda de Energia) & & & & & & \\
\hline b) & (-) IMPOSTOS/TAXAS SOBRE FATURAMENTO & & & & & & \\
\hline b.1 & (-) PIS/COFINS+CPMF (3,65\% - LR OU9,63\% - LP) & & & & & & \\
\hline b.2 & (-)CDE/PROINFA/CCC/RGR(Renováveis isentos) & & & & & & \\
\hline b. 3 & (-) ICMS (não considerado) & & & & & & \\
\hline & (E) ROL - RECETTA OPERACIONAL LÍQUIDA & & & & & & \\
\hline c) & (-) ENCARGOS/TRBBUTAÇÕ̃ES DO SEB & & & & & & \\
\hline$c .1$ & (-) TFSEE[0,5\%, base: Benefício Econômico auferido & & & & & & \\
\hline$c .2$ & (-) P\&D (isento) & & & & & & \\
\hline$c .3$ & (-)CFURH(isento) & & & & & & \\
\hline d) & (-) ENCARGOS DE CONEXÃO E TRANSPORTE DE ENERGIA & & & & & & \\
\hline d.1 & (-)TUSDg (RŚ/Kw.mês). Distribuidora. Para fontes renováveis que "injetem <3 OMW, TUDSg= 50\% & & & & & & \\
\hline d. 2 & (-)CCD (RS, apenas para 019 ano - desconsiderado neste trabalho) & & & & & & \\
\hline d. 3 & (-) TUSTRB (Locacional ao circuito p/ despacho centralizado) [RŞ/KW.mês] & & & & & & \\
\hline d.4 & (-) TUSTFR (Locacional ao circuito p/ despacho centralizado [R\$̧/KW.mês] & & & & & & \\
\hline e) & (-) DESPESA OPERACIONAL & & & & & & \\
\hline e.1 & (-) O\&M Fixo (R\$̧/Kwinst. Ano) & & & & & & \\
\hline e.2 & (-) O\&M Variável( R\$s/MWh) & & & & & & \\
\hline e.3 & (-) Seguro (1\%, base:?(investimentos) & & & & & & \\
\hline & (=) RO - RESULTADO OPERACIONAL & & & & & & \\
\hline f) & (-) DEPRECIAÇÃO FINANCEIRA[invest/no anos] & & & & & & \\
\hline g) & (-) DESPESAS FINANCERAS[pgto juros - debt] & & & & & & \\
\hline & $\Leftrightarrow$ () LTS - LUCRO TRBBUTAVEL & & & & & & \\
\hline b) & (-) IMPOSTO SOBRE LUCRO TRIBUTÁVEL & & & & & & \\
\hline b.1 & (-) IR(15\% ou $25 \%$, se LT>R\$ $240.000 /$ ano & & & & & & \\
\hline b.2 & (-) CSLL (9\%, base Lucro Tributável [LT\$̧]) & & & & & & \\
\hline f) & (+) DEPRECIAÇÃO FINANCEIRA & & & & & & \\
\hline & $\Leftrightarrow$ ) RESULTADO FINANCERO & & & & & & \\
\hline g) & (-) AMORTIZAÇÃO DO FINANCIAMENTO(Debt) & & & & & & \\
\hline h) & (-) CAPITAL PRÓPRIO (Equity) & & & & & & \\
\hline & (+) VALOR RESIDUAL DO PROJETO (NO ÚLTIMO ANO DA VIDA ÚTLL DO EMPREENDIMENTO) & & & & & & \\
\hline & (A) FLUXO DE CAIXA DO EMPREENDIMENTO & $\mathrm{FC}_{-2}$ & $\mathrm{FC}_{-1}$ & $\mathrm{FC}_{0}$ & $\mathrm{FC}_{1}$ & ..... & $\mathrm{FC}_{\mathrm{n}}$ \\
\hline
\end{tabular}

Fonte: elaboração própria, com base em Politzel, (2007)

A seguir descrevem-se os itens constitutivos da Tabela 52 - modelo de fluxo de caixa descontado de um empreendimento de geração de fontes renováveis, no contexto da Geração Distribuída (venda apenas para distribuidora local/cliente local): 


\section{Receita Bruta}

Produto anual da quantidade de energia elétrica comercializada (Ea) [para a cogeração a biomassa, também adicionar receita com vapor de processo] pela respectiva tarifa de venda $(\mathrm{R} \$ / \mathrm{MWh})$.

\section{Encargos Fiscais}

Em 2002, a sistemática dos tributos fiscais sofreu alterações visando, em essência, eliminar a cumulatividade de incidência de encargos na cadeia produtiva, criando a partir de então a possibilidade de creditamento de valores que serão deduzidos do montante final a ser recolhido. Conceitualmente, a não cumulatividade é a tributação apenas sobre o valor agregado ou adicional da atividade produtiva. Os encargos fiscais aplicáveis sobre o serviço de produção de energia elétrica podem ser efetuados em dois regimes de tributação. $O$ primeiro é quando a empresa constituída opta pelo regime de tributação com lucro real (não cumulativo), e o segundo, lucro presumido (cumulativo). No primeiro, pode-se abater no valor do tributo apurado os créditos de investimentos imobilizados (bens), cujos créditos são diferidos na forma de depreciação, custos e despesas. No segundo, não há deduções, porém este regime de tributação somente é admissível para empresas com receita anual inferior a $\mathrm{R} \$ 48$ milhões.

- PIS/PASEP (Programa de Integração Social / Programa de Formação do Patrimônio do Servidor Público): o PIS foi instituído pela Lei Complementar no 7, de 7 de setembro de 1970, e o PASEP foi instituído pela Lei Complementar no 8 , de 3 de dezembro de 1970, sendo estes dois unificados pela Lei Complementar $n^{\circ}$ 26, de 11 de setembro de 1975. O PIS/PASEP incide sobre a receita bruta, cuja alíquota é 1,65\% (lucro real) e 0,65\% (lucro presumido).

- COFINS (Contribuição para Financiamento da Seguridade Social): instituída pela Lei Complementar oㅜ 70, de 30 de dezembro de 1991, a qual incide sobre a receita bruta, cuja alíquota é $7,6 \%$ (lucro real) e 3,0\% (lucro presumido). 
- IRPJ (Imposto de Renda): incide sobre o lucro tributável (LT\$), quando este for positivo, com alíquota de 15\% (lucro real ou presumido). Caso o montante anual apurado de LT\$ for superior R $\$ 240$ mil, aplica-se a alíquota adicional de $10 \%$ (lucro real e presumido). No regime lucro real, o LT\$ é o resultado operacional $(\mathrm{RO})$ deduzido de depreciação e despesa financeira. No regime lucro presumido, o LT\$ é estimado em $8 \%$ da receita bruta.

- CSLL (Contribuição Social sobre o Lucro Líquido): incide sobre o lucro tributável (LT\$), quando este for positivo, com alíquota de $9 \%$ (lucro real e presumido). No regime lucro real, o LT\$ é o mesmo apurado para o IR. No regime presumido, o LT\$ é estimado em $12 \%$ da receita bruta.

- ICMS (Imposto sobre Circulação de Mercadorias e Serviços): não é considerada a incidência deste encargo nos estudos deste trabalho, isso porque a sua legislação é específica para cada estado brasileiro.

\section{Encargos Setoriais (setor elétrico brasileiro)}

TFSEE (Taxa de Fiscalização de Serviços de Energia Elétrica): é a taxa recolhida pela ANEEL, na seguinte forma: TFSEE $=0,5 \%{ }^{*} \mathrm{Be}{ }^{*} \mathrm{Pag}$. O valor de Be (Benefício Econômico anual auferido) é $R \$ 385,73 / \mathrm{kWinst}$ para o ano $2010 / 11$, segundo Despacho Homologatória ANEEL oㅜ 10.23, de 29 de julho de 2010 e o Pag (Produto anual da exploração) pode ser considerado a potência instalada do empreendimento (PI).

P\&D (Programa de Pesquisa e Desenvolvimento): as empresas de geração de energia elétrica ficam obrigadas a aplicar 1\% (no mínimo) da receita operacional líquida (ROL). Entretanto, a $\mathrm{PCH}$ e BIO são isentas desta obrigação e a EOL é considerada neste trabalho desobrigada.

CFURH (Compensação Financeira pelo Uso dos Recursos Hídricos): aplica-se a empreendimentos de hidroeletricidade, na seguinte forma: 6,75\% * TAR * Ea *8760. O TAR (Tarifa Anualizada de Referência, de R \$68,34 para ano de 2011). Entretanto PCH's são isentos desta obrigação. 
Cota CDE (Conta de Desenvolvimento Energético): a autoprodução e a produção independente de energia não estão sujeitas ao pagamento das quotas CDE, nos termos do art. 74 do Decreto 5.163.

Cota PROINFA / CCC (Conta de Consumo de Combustíveis) / RGR (Reserva Global de Reversão): a produção independente de fontes incentivadas é praticamente isenta destes encargos, na maioria dos casos, salvo algumas exceções, as quais não serão tratadas neste trabalho.

\section{Encargos de Conexão}

TUST (RB -Rede Básica e FR - Fronteira): apenas para energia e potência despachada centralizadamente, o que não é o caso deste estudo.

CCD \& TUSDg: incidentes sobre a potência instalada e livremente negociável com a Distribuidora local (ou clientes livres da área de concessão da Distribuidora). As despesas com O\&M de conexão da rede da distribuidora são consideradas como embutidas no CCD e serão estimados, com base nos valores de circuitos genéricos, definidos pela CPFL distribuidora local na RAA.

\section{Despesas Operacionais}

\section{O\&M Fixo e Variável}

Todas as despesas relacionadas com a geração de energia, incluindo mão de obra e manutenção. Para biomassa, incluir custo de oportunidade com combustível.

\section{Seguro do capital imobilizado}

Em geral, os agentes financeiros exigem a contratação de seguro como uma ferramenta de mitigação de riscos. Valores típicos estão na ordem de 0,5 a $1,5 \%$ do investimento total. Adota-se o valor anual de $1 \%$ do montante de investimento (equity + debt). 


\section{Depreciação:}

A depreciação financeira é considerada neste trabalho na forma simplificada, sendo parcelas anuais iguais a 1 dividido pela vida útil financeira do ativo. Valores típicos utilizados no setor elétrico são 10 anos para equipamentos e 20 anos para construções. Para efeitos deste trabalho, a vida útil dos empreendimentos será considerada de 20 anos.

\section{Despesa Financeira}

Refere-se às parcelas de pagamento de juros do financiamento e esta é calculada em função da incidência da taxa de juros sobre o saldo devedor do financiamento.

\section{Capital Próprio}

Refere-se ao recurso financeiro $(R \$)$ próprio aportado pelo empreendedor (investidor). Para os propósitos deste documento, será utilizado o valor mínimo exigido pelo BNDES. 


\section{APÊNDICE B - A contratação de Energia no $\mathrm{ACR}^{59}$}

Participam do Ambiente de Contratação Regulada - ACR - os Agentes Vendedores e Agentes de Distribuição de energia elétrica. Para garantir o atendimento aos seus mercados, os Agentes de Distribuição podem adquirir energia das seguintes formas, de acordo com o art. 13 do Decreto $n^{\circ}$ 5.163/2004:

- leilões de compra de energia elétrica proveniente de empreendimentos de geração existentes e de novos empreendimentos de geração;

- geração distribuída, desde que a contratação seja precedida de chamada pública realizada pelo próprio Agente de Distribuição e com montante limitado a $10 \%$ do mercado do distribuidor;

- usinas que produzem energia elétrica a partir de fontes eólicas, pequenas centrais hidrelétricas e biomassa, contratadas na primeira etapa do Programa de Incentivo às Fontes Alternativas de Energia Elétrica - PROINFA;

- Itaipu Binacional.

Conforme descrito no mesmo artigo do Decreto no $5.163 / 2004$, os contratos firmados pelos Agentes de Distribuição até 16/03/2004 também são considerados como energia contratada para atendimento à totalidade de seus respectivos mercados.

\section{CCEAR - Contrato de Comercialização de Energia no Ambiente Regulado}

Os Contratos de Comercialização de Energia no Ambiente Regulado CCEARs - são os contratos bilaterais celebrados entre cada agente vendedor, vencedor de um determinado leilão de energia do ACR, e todos os Agentes de Distribuição compradores, conforme demonstrado na Figura 16.

As fontes de financiamento de projetos de geração de energia elétrica não são abundantes, e os CCEARs são considerados as mais importantes garantias

\footnotetext{
${ }^{59}$ Com base em resumo do site www.ccee.gov.br
} 
financeiras pelos agentes financiadores dos empreendimentos de geração de energia elétrica no momento. Os CCEARs têm garantia conjunta das grandes distribuidoras e são de longo prazo, características que colocam estes tipos de contratos em vantagem sobre qualquer outro, no que se refere ao risco de crédito.

A Figura 16 apresenta as relações entre vendedores e compradores num contrato de CCEAR do ACR.

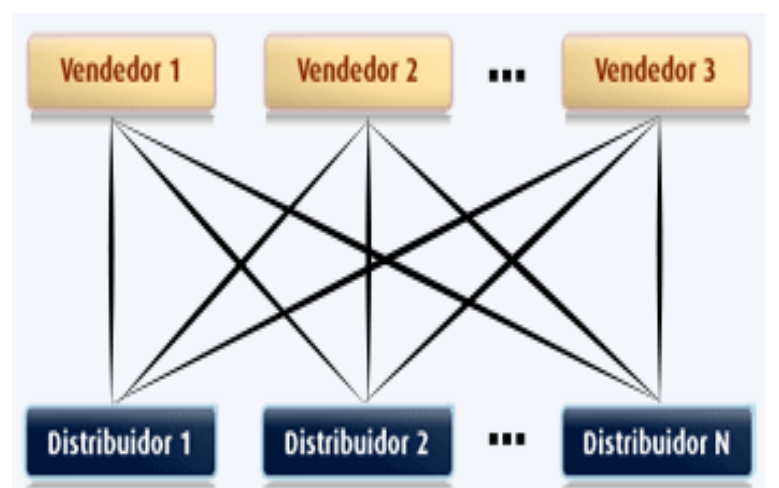

Figura 16 - Contratos CCEARs no ACR Fonte: CCEE

Para cada tipo de leilão público há CCEARs com prazos específicos de duração:

- para os leilões de compra de energia provenientes de novos empreendimentos, os CCEARs têm no mínimo quinze, e no máximo trinta anos, contados do início do suprimento de energia;

- para os leilões de compra de energia proveniente de empreendimentos existentes, os CCEARs têm no mínimo cinco e no máximo quinze anos de duração, contados a partir do ano seguinte ao da realização de tais leilões;

- os Agentes de Distribuição podem reduzir os montantes contratados de energia dos leilões de compra de energia proveniente de empreendimentos existentes nas seguintes condições:

- quando consumidores potencialmente livres venham a exercer seu direito de opção de compra de outro fornecedor;

- quando houver redução em seu mercado, situação na qual a redução será anualmente limitada a quatro por cento do montante inicialmente contratado; 
- acréscimos de aquisição de energia provenientes de contratos firmados antes de 16/03/2004.

\section{Modalidades de CCEAR}

Os vencedores de cada leilão de energia do ACR deverão firmar contratos bilaterais com todas as distribuidoras - denominados Contratos de Comercialização de Energia em Ambiente Regulado, ou CCEAR - em proporção às respectivas declarações de necessidade ${ }^{60}$. Uma exceção é o leilão de ajuste, onde os contratos são específicos entre Agente Vendedor e o Agente de Distribuição.

São especificadas as durações mínimas e máximas para os CCEAR, provenientes dos leilões "A-5" ou "A-3" (15 a 30 anos) e "A-1" (5 a 15 anos).

\section{Contratos de Quantidade de Energia}

Os Contratos de Quantidade de Energia são aqueles nos quais os riscos hidrológicos da operação energética integrada são assumidos totalmente pelos Geradores, cabendo a eles todos os custos referentes ao fornecimento da energia contratada. Os riscos financeiros são decorrentes de diferenças de preços entre submercados assumidos pelo comprador.

\section{Contratos de Disponibilidade de Energia}

Os Contratos de Disponibilidade de Energia são aqueles nos quais tanto os riscos como os ônus e benefícios da variação de produção em relação à energia assegurada são alocados ao pool de distribuidoras participantes do leilão, e repassados aos consumidores cativos/regulados.

Esse tipo de contrato tem como característica intrínseca o fato de que o vendedor somente é responsável pelos custos associados à disponibilidade de seu

60 Segundo o marco legal, as distribuidoras têm a obrigação de, periodicamente, declarar sua necessidade de contratação de energia (para atender os seus clientes cativos), a fim permitir que EPE e CCEE possam definir o consolidado de necessidades dos pool de distribuidores de cada tipo de leilão promovido. Erros são penalizados com multas. 
empreendimento e à geração inflexível declarada no momento do leilão. Assim, os custos devidos ao despacho (COP) e à liquidação das diferenças (CEC) são de responsabilidade do comprador. De modo geral, o custo associado aos contratos por disponibilidade é ilustrado na Figura 17.

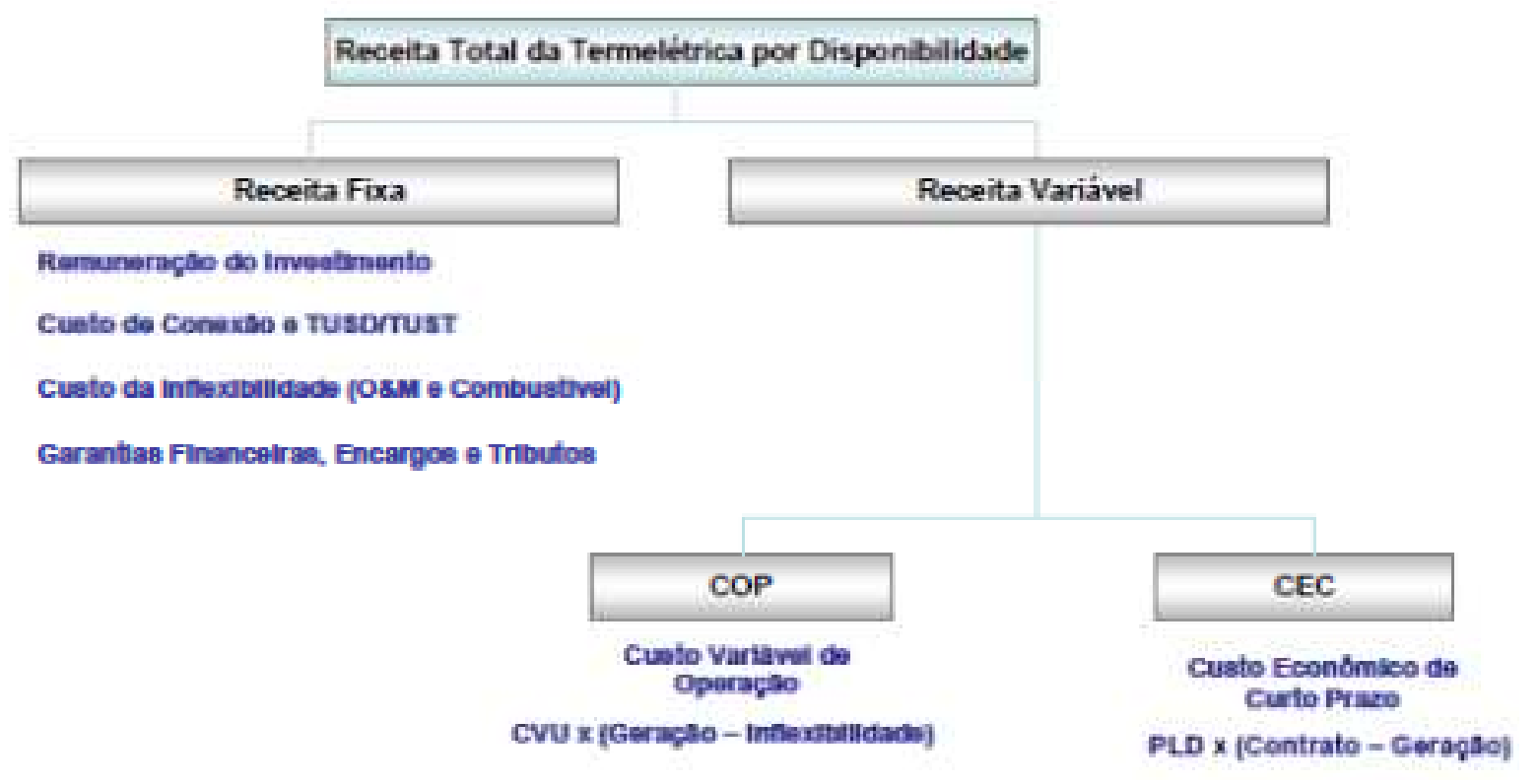

Figura 17 - Composição dos custos das UTEs com contratos por disponibilidade

Fonte: FAGUNDES FILHO, 2009 e CCEE

Através da figura 17, e pelo exposto anteriormente, pode-se concluir que os custos da Parcela Variável da energia adquirida em leilões de disponibilidade, são totalmente alocados ao comprador. Assim, os custos de um eventual despacho por ordem de mérito serão completamente assumidos, e rateados, pelos consumidores cativos, o que pode se tornar um fator de dificuldade para previsão dos custos totais reais desse tipo de contrato.

\section{Os leilões de energia}

As concessionárias, as permissionárias e as autorizadas de serviço público de Distribuição de energia elétrica do Sistema Interligado Nacional (SIN), por meio de licitação na modalidade de leilões, devem garantir o atendimento à totalidade de seu mercado no Ambiente de Contratação Regulada (ACR), de acordo com o 
estabelecido pelo artigo 11 do Decreto $n^{\circ} 5.163 / 2004$ e artigo $2^{\circ}$ da Lei $n^{\circ}$ $10.848 / 2004$.

À ANEEL cabe a regulação das licitações para contratação regulada de energia elétrica e a realização do leilão diretamente ou por intermédio da Câmara de Comercialização de Energia Elétrica (CCEE), conforme determinado no parágrafo 11 do artigo $2^{\circ}$ da Lei no $10.848 / 2004$.

O critério de menor tarifa (inciso VII, do art. 20, do Decreto № 5.163/2004) é utilizado para definir os vencedores de um leilão, ou seja, os vencedores do leilão serão aqueles que ofertarem energia elétrica pelo menor preço por MWh para atendimento da demanda prevista pelas Distribuidoras. Os Contratos de Comercialização de Energia Elétrica em Ambiente Regulado (CCEAR) serão, então, celebrados entre os vencedores e as Distribuidoras que declararam necessidade de compra para o ano de início de suprimento da energia contratada no leilão.

Tendo o ano "A" como o ano previsto para o início do suprimento de energia elétrica adquirida pelos Agentes de Distribuição, que participam dos leilões de energia, o cronograma para a realização dos leilões é o seguinte:

- no quinto ano anterior ao ano "A" (chamado ano "A" - 5), é realizado o leilão para compra de energia de novos empreendimentos de Geração;

- no terceiro ano anterior ao ano "A" (chamado ano "A" - 3), é realizado o leilão para aquisição de energia de novos empreendimentos de Geração;

- nos leilões A-5 e A-3 ocorrem distinções entre os empreendimentos de fonte térmica e Eólica, ou hidráulica. Os vencedores do leilão, que apresentam empreendimentos de fonte térmica firmam contratos por disponibilidade, enquanto os de fonte hidráulica e eólica contratos por quantidade.

- no ano anterior ao ano "A" (chamado ano "A" - 1), é realizado o leilão para aquisição de energia de empreendimentos de Geração existentes.

- no ano A existem os Mecanismos de Compensação de Sobras e Déficits (MCSD) e a Compra de Energia Ex-post por parte das Distribuidoras, para zerarem sua posição contratada e medida.

A Figura 18 apresenta os momentos de venda/contratação de energia elétrica no ACR. 


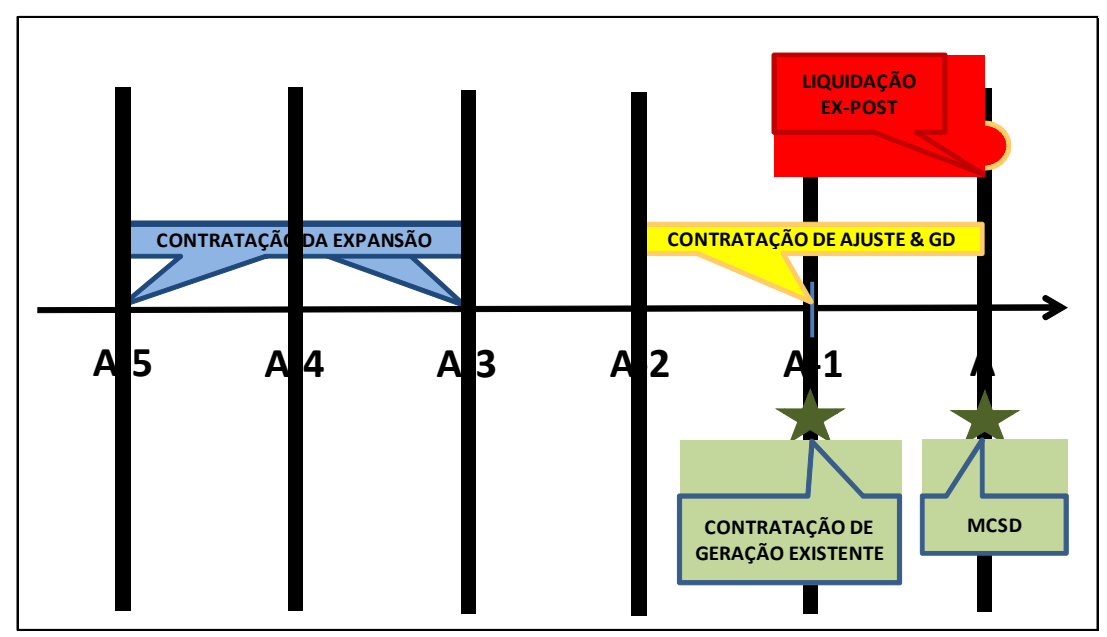

Figura 18 - Momentos de venda/contratação de energia elétrica Fonte: CCEE

A partir do ano de 2004, iniciou o novo modelo de leilões de compra de energia no Ambiente de Contratação Regulada. Estes leilões são coordenados pela EPE e CCEE e são precedidos de editais explicativos, detalhando as elegibilidades dos participantes geradores, preço teto da energia, mecânica do leilão, tipo de produto (fonte primária, início da entrega, prazos de fornecimento, reserva/quantidade) etc.

Normalmente, cada leilão tem suas especificidades, que são postas a apreciação dos participantes com antecedência ao evento. Os leilões são marcados sempre que os agentes responsáveis concluem pela sua necessidade ${ }^{61}$, sem deixar de considerar os estudos sobre a demanda futura, riscos de suprimento de energia acima do aceito, volume de projetos e/ou aproveitamentos, contratos antigos findando. Enfim, os agentes responsáveis pelos leilões, antes de os convocarem, procuram garantir que exista a demanda e que exista a oferta, dentro de uma faixa de equilíbrio e normalidade, com vistas a garantir incentivos a investimentos em geração e com vistas a garantir a modicidade tarifária (EPE, 2010).

A Tabela 53 relaciona todos os leilões de energia que ocorreram desde 0 marco legal de 2004 que os criou até o final de 2011. Exceção se faz aos leilões de ajuste (A-1).

\footnotetext{
${ }^{61}$ Baseados nas declarações de necessidades das distribuidoras.
} 
Tabela 53 - Leilões de energia no ACR desde 2005 (exceto leilões de ajuste)

\begin{tabular}{|c|c|c|c|c|c|c|c|c|c|}
\hline \begin{tabular}{c|} 
DATA DO \\
LEILÃO
\end{tabular} & LEILÕES DO ACR* & $A-5$ & A-4 & $A-3$ & A-2 & A-1 & QTD & DISP & OBS \\
\hline $7 / 12 / 2004$ & $1^{\circ}$ LEILÃO DE ENERGIA EXISTENTE & & & & & $\mathbf{X}$ & $\mathbf{x}$ & & \\
\hline $2 / 4 / 2005$ & $2^{\circ}$ LEILÃO DE ENERGIA EXISTENTE & & & $\mathbf{x}$ & & & $\mathbf{X}$ & & \\
\hline $11 / 10 / 2005$ & $3^{\circ}$ LEILÃO DE ENERGIA EXISTENTE & & & & & $\mathbf{x}$ & $\mathbf{X}$ & & \\
\hline $11 / 10 / 2005$ & $4^{\circ}$ LEILÃO DE ENERGIA EXISTENTE & & & $\mathbf{x}$ & & & $\mathbf{X}$ & & \\
\hline $16 / 12 / 2005$ & $1^{\circ}$ LEILÃO DE ENERGIA NOVA & $\mathbf{X}$ & $\mathbf{x}$ & $\mathbf{x}$ & & & $\mathbf{X}$ & & \\
\hline $29 / 6 / 2006$ & $2^{\circ}$ LEILÃO DE ENERGIA NOVA & & & $\mathbf{x}$ & & & $\mathbf{X}$ & & \\
\hline $10 / 10 / 2006$ & $3^{\circ}$ LEILÃO DE ENERGIA NOVA & $\mathbf{X}$ & & & & & $\mathrm{X}$ & & \\
\hline $14 / 12 / 2006$ & $5^{\circ}$ LEILÃO DE ENERGIA EXISTENTE & & & & & $\mathbf{x}$ & $\mathbf{X}$ & & \\
\hline $18 / 6 / 2007$ & $1^{\circ}$ LEILÃO DE FONTES ALTERNATIVAS & & & $\mathbf{X}$ & & & $\mathbf{X}$ & $\mathbf{X}$ & \\
\hline $26 / 7 / 2007$ & $4^{\circ}$ LEILÃO DE ENERGIA NOVA & & & $\mathbf{x}$ & & & $\mathbf{X}$ & & \\
\hline $16 / 10 / 2007$ & $5^{\circ}$ LEILÃO DE ENERGIA NOVA & $\mathrm{X}$ & & & & & $\mathbf{X}$ & & \\
\hline $6 / 12 / 2007$ & $6^{\circ}$ LEILÃO DE ENERGIA EXISTENTE & & & & & & & & NÃO HOUVE LANÇE \\
\hline $10 / 12 / 2007$ & LEILÃO DE SANTO ANTONIO & $\mathrm{X}$ & & & & & $\mathbf{X}$ & & \\
\hline $19 / 5 / 2008$ & LEILÃO DE JIRAU & $\mathbf{X}$ & & & & & $\mathbf{X}$ & & \\
\hline $14 / 8 / 2008$ & $1^{\circ}$ LEILÃO DE ENERGIA DE RESERVA & & & $\mathbf{x}$ & & $\mathbf{x}$ & & $\mathbf{X}$ & \\
\hline $\begin{array}{ll}17 / 9 / 2008 \\
\end{array}$ & $6^{\circ}$ LEILÃO DE ENERGIA NOVA & & & $\mathbf{x}$ & & & $\mathrm{X}$ & & \\
\hline $30 / 9 / 2008$ & $7^{\circ}$ LEILÃO DE ENERGIA NOVA & $\mathbf{X}$ & & & & & $\mathbf{X}$ & & \\
\hline $28 / 11 / 2008$ & $7^{\circ}$ LEILÃO DE ENERGIA EXISTENTE & & & & & & & & NÃO OCORREU \\
\hline $27 / 8 / 2009$ & $8^{\circ}$ LEILÃO DE ENERGIA NOVA & & & $\mathbf{x}$ & & & $\mathbf{X}$ & & \\
\hline $30 / 11 / 2009$ & $8^{\circ}$ LEILÃO DE ENERGIA EXISTENTE & & & & & $\mathbf{x}$ & $\mathbf{X}$ & & \\
\hline $14 / 12 / 2009$ & $2^{\circ}$ LEILÃO DE ENERGIA DE RESERVA & & & $\mathbf{x}$ & & & $\mathbf{X}$ & & \\
\hline $21 / 12 / 2009$ & $9^{\circ}$ LEILÃO DE ENERGIA NOVA & & & & & & & & CANCELADO \\
\hline $20 / 4 / 2010$ & LEILÃO DE BELO MONTE & $\mathbf{X}$ & & & & & & & \\
\hline $30 / 7 / 2010$ & $10^{\circ}$ LEILÃO DE ENERGIA NOVA & $\mathbf{X}$ & & & & & & & \\
\hline $25 / 8 / 2010$ & $3^{\circ}$ LEILÃO DE ENERGIA DE RESERVA & & & $\mathbf{x}$ & $\mathbf{x}$ & $\mathbf{x}$ & $\mathbf{X}$ & & \\
\hline $26 / 8 / 2010$ & $2^{\circ}$ LEILÃO DE FONTES ALTERNATIVAS & & & $\mathbf{x}$ & & & $\mathbf{X}$ & $\mathbf{X}$ & \\
\hline $10 / 12 / 2010$ & $9^{\circ}$ LEILÃO DE ENERGIA EXISTENTE & & & & & $\mathbf{x}$ & $\mathbf{X}$ & & \\
\hline $17 / 12 / 2010$ & $11^{\circ}$ LEILÃO DE ENERGIA NOVA & $\mathrm{X}$ & & & & & $\mathbf{X}$ & & \\
\hline
\end{tabular}

*Até 03/2011

Fonte: elaboração própria, a partir de dados da CCEE e EPE.

\section{Restrições ao volume de contratação}

A contratação de energia pelas distribuidoras para atender seu mercado cativo se dá em várias janelas no tempo. No entanto, os arcabouços legais e regulatórios impõem restrições ao volume de compra e ao repasse tarifário dos custos aos associados, com o objetivo de garantir a modicidade tarifária e prover sinalização antecipada para a expansão da geração. 
$\mathrm{Na}$ Tabela 54 apresentam-se os principais momentos de contratação das empresas de distribuição, associados às restrições de volume e de repasse tarifário, em relação à contratação de Energia Nova nos leilões do ACR por parte das Distribuidoras, clientes da Geração no ACR.

Tabela 54 - Limitação do repasse de energia de leilão do ACR às Distribuidoras

\begin{tabular}{|c|c|c|c|c|c|}
\hline \multirow{4}{*}{ 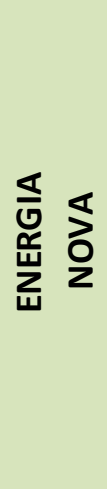 } & PRODUTO & $\begin{array}{c}\text { INÍCIO DO } \\
\text { SUPRIMENTO }\end{array}$ & $\begin{array}{l}\text { PRAZO DO } \\
\text { CONTRATO }\end{array}$ & $\begin{array}{c}\text { RESTRIÇÕES DE } \\
\text { VOLUME }\end{array}$ & $\begin{array}{c}\text { REPASSE } \\
\text { TARIFÁRIO }\end{array}$ \\
\hline & A-3 & Em 3 anos & 15 a 30 anos & $\begin{array}{c}\text { Até } 2 \% \text { da } \\
\text { carga em A-5 }\end{array}$ & $\begin{array}{l}\text { 10 ao 30 ano }=\mathrm{VR}^{*} \\
\text { Após } 40 \text { ano }=\text { Integral } \\
\text { Excedente }=\min (\mathrm{VL} 5 ; \mathrm{vl} 3)\end{array}$ \\
\hline & $A-5$ & Em 5 anos & 15 a 30 anos & Não há & $\begin{array}{l}\text { 10 } 3 \text { ANOS = VR } \\
\text { Após } 4 \text { ㅇ ano = Integral }\end{array}$ \\
\hline & $\begin{array}{c}\text { GERAÇÃO } \\
\text { DISTRIBUIDA }\end{array}$ & & & $10 \%$ da carga & Limitado ao VR \\
\hline
\end{tabular}

Fonte: FAGUNDES FILHO, 2009

(*) Valor anual de Referência

Como ainda pode ser observado na Tabela 54, foram criados alguns mecanismos indutores à contratação eficiente nos leilões de A-5 e A-3, tendo em mente o objetivo de contribuir para a expansão do parque gerador do país. Assim, o modelo setorial prevê que a distribuidora que obtiver um custo individual de contratação nos leilões "A-3" e "A-5" inferior ao Valor Anual de Referência (VR) terá um ganho na contratação, pois poderá repassar à tarifa VR, durante três anos, valor superior ao efetivamente despendido com essas contratações.

A Tabela 55 apresenta a evolução do VR, de 2005 a março/2011.

Tabela 55 - Energia elétrica - Valor anual de Referência (VR)

\begin{tabular}{|r|r|r|r|r|r|r|r|}
\hline & VR2005 & VR2006 & VR2007 & VR2008 & VR2009 & VR2010 & VR2011 \\
\hline R\$/MWh & $\mathbf{6 2 , 1 0}$ & $\mathbf{6 9 , 8 0}$ & $\mathbf{8 4 , 7 0}$ & $\mathbf{1 3 9 , 4 4}$ & $\mathbf{1 4 5 , 7 7}$ & $\mathbf{1 4 5 , 4 1}$ & $\mathbf{1 5 1 , 2 0}$ \\
\hline Base & dez/04 & dez/04 & $\mathrm{fev} / 07$ & $\mathrm{fev} / 08$ & jan/09 & jan/10 & jan/11 \\
\hline Atualização & $\mathrm{mar} / 11$ & $\mathrm{mar} / 11$ & $\mathrm{mar} / 11$ & $\mathrm{mar} / 11$ & $\mathrm{mar} / 11$ & $\mathrm{mar} / 11$ & $\mathrm{mar} / 11$ \\
\hline \%IPCA & $\mathbf{4 0 , 3 8 \%}$ & $\mathbf{4 0 , 3 8 \%}$ & $31,94 \%$ & $\mathbf{2 1 , 0 9 \%}$ & $12,07 \%$ & $14,03 \%$ & $\mathbf{2 , 4 3 \%}$ \\
\hline Atualizado* & $\mathbf{8 7 , 1 8}$ & $\mathbf{9 7 , 9 9}$ & $\mathbf{1 1 1 , 7 5}$ & $\mathbf{1 6 8 , 8 5}$ & $\mathbf{1 6 3 , 3 7}$ & $\mathbf{1 6 5 , 8 1}$ & $\mathbf{1 5 4 , 8 7}$ \\
\hline
\end{tabular}

Fonte: CCEE \& elaboração própria. 
Na prática, esse mecanismo estimula a contratação nos leilões de A-5, cujos preços tendem a serem inferiores aos dos leilões A-3 e, consequentemente, aos custos de expansão do sistema.

Outro fator que induz a contratação em "A-5" é o que limita o repasse dos custos dos leilões "A-3" ao menor valor dentre os custos relativos a "A-5" e "A-3", quando a declaração em "A-3" exceder $2 \%$ da demanda.

\section{Energia de Reserva}

A Energia de Reserva foi inicialmente prevista na Lei ํㅜ 10.848/2004, e regulamentada posteriormente por meio do Decreto no 6.353/2008. Esse decreto estabeleceu que o valor necessário para o pagamento desta contratação fosse arcado pelos consumidores finais do SIN.

A Energia de Reserva contratada só pode ser proveniente de novos empreendimentos, ou empreendimentos existentes, desde que estes empreendimentos atendam às seguintes condições:

- acrescentem Garantia Física ao SIN;

- sejam empreendimentos que não entraram em operação comercial, até 16 de janeiro de 2008 (data de publicação do Decreto 6.353/2008).

A contratação é formalizada através do estabelecimento de Contratos de Energia de Reserva (CER) entre os vencedores dos leilões e a CCEE, que representa os agentes de consumo. São previstos contratos com duração de até 35 anos, podendo serem celebrados sob forma de contratação por quantidade ou por disponibilidade. Todos os agentes do consumo (incluindo consumidores livres e autoprodutores) deverão firmar com a CCEE um contrato de Uso de Energia de Reserva (CONUER). 


\section{APÊNDICE C - Evolução dos preços médios da energia elétrica no ACR}

Gráfico 7 - Preços do R\$/MWh por tipo de Leilão do ACR

\section{Preço da Energia Elétrica}

(Por tipo de Leilão do ACR)

Em R\$̣/MWh

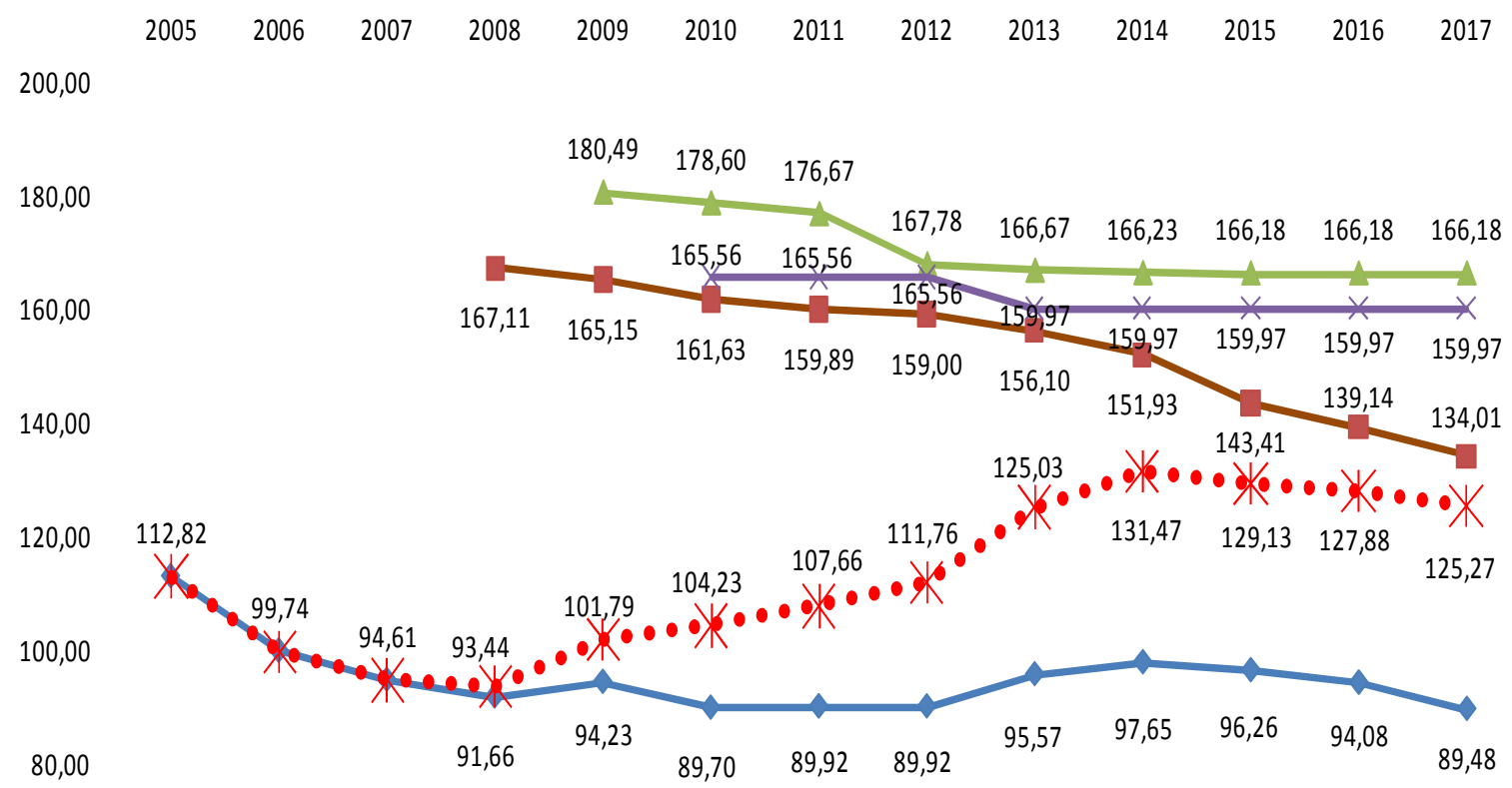

60,00

40,00

20,00

0,00

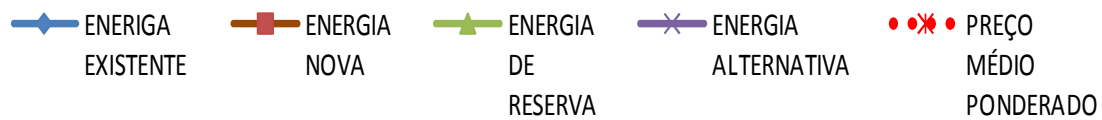

* não consideradas as renovações da energia existente que se inicia em 2013 Fonte: elaboração própria, a partir de dados da CCEE corrigidos pelo IPCA até 03/2011. 


\section{APÊNDICE D - Principais tópicos para estruturação de um negócio de Geração}

\section{Estruturação jurídica do Empreendimento}

$\mathrm{Na}$ legislação brasileira, existem várias possibilidades de se estruturar juridicamente um empreendimento de geração distribuída de energia.

Para os propósitos deste estudo, será considerado o modelo chamado de SPE (Sociedade de Propósito Específico), ou SPC (Special Purpose Company), modelo que dá o máximo de liberdade para se explorar todas as opções de comercialização de energia e acesso a linhas de crédito e financiamento. Outras opções poderão ser consultadas na legislação pertinente ${ }^{62}$.

O primeiro passo é a montagem de um consórcio ou de uma SPC, cuja estrutura deverá merecer especial atenção, na medida em que ela, a SPC, caberá assumir os riscos comerciais do projeto, dividindo, tanto quanto possível, os demais riscos associados e mesmo os riscos políticos envolvidos, com outros agentes privados ou públicos. Geralmente a formação da SPC tem em vista atender aos requisitos estruturais de um modelo de financiamento chamado de Project Finance.

Como o nome indica, neste modelo tem-se em vista não a figura do investidor, mas o projeto a ser financiado, por incidência do que se convencionou chamar de princípio da segregação. Nele, a maior garantia vem a ser o próprio empreendimento, envolvendo na sua implantação um grande número de contratos, tais como: contrato de concessão, construção, fornecimento, operação, acionistas, financiamento, truste ${ }^{63}$ garantias públicas e seguros.

A existência de um forte pacote de seguro é característica da maior importância, assim como o acordo dos acionistas e financeiros, no qual deverão estar relacionadas as prioridades de serviço da dívida sobre os dividendos e a limitação da responsabilidade dos acionistas ao capital integralizado na SPC.

\footnotetext{
62 lei das sociedades civis

${ }^{63}$ Normalmente é uma instituição financeira
} 


\section{Registro para Estudo e Projeto (ANEEL)}

Do ponto de vista legal, em primeiro lugar, o interessado deve encaminhar a ANEEL os documentos necessários ao registro dos estudos em conformidade com a resolução 343/08, para proceder ao desenvolvimento do projeto básico do empreendimento (inclusão no cadastro de registros ativos da Agência).

\section{Obtenção da licença prévia (LP) no órgão ambiental}

Para obtenção da LP, sem a qual é impossível obter a autorização (para PCH outorga) por parte da ANEEL para exploração do empreendimento, deve-se inicialmente apresentar ao órgão ambiental um Relatório de Avaliação Preliminar ou Relatório Ambiental Preliminar, conhecido como RAP, para que sejam definidos os Termos de Referência dos estudos ambientais a serem exigidos pelo órgão ambiental em questão, segundo o tipo de empreendimento.

Este RAP poderá exigir um Estudo de Impacto Ambiental/Relatório de Impacto Ambiental (EIA/RIMA) ou um Relatório Simplificado, em função da sua avaliação preliminar. Se a área de influência ambiental do aproveitamento /empreendimento situar-se na fronteira de dois estados, caso em que, além dos órgãos ambientais dos dois estados, é necessário o "de acordo" do IBAMA. Neste caso, interesses políticos divergentes podem ser um entrave ao empreendimento. No caso de $\mathrm{PCH}$, existe também a audiência pública para a qual o empreendedor precisa se preparar, municiado de um robusto conjunto de informações socioambientais, além das técnico-econômicas, regulares.

\section{Caso da PCH: Prova de disponibilidade Hídrica (ANA e Agências Estaduais)}

A obtenção da Disponibilidade Hídrica para geração hidroelétrica (no caso $\mathrm{PCH}$ ) exige uma ponderação acerca das potencialidades para outros usos da água na região. A aprovação do projeto básico está condicionada à apresentação da respectiva disponibilidade hídrica, o que transforma esta providência numa importante e fundamental peça para o desenvolvimento do empreendimento. 


\section{Caso EOL: históricas das avaliações anemométricas}

Histórico de medição contínua da velocidade e direção dos ventos, em altura mínima de 50 metros, (no caso de terrenos de superfície topográfica suave contínua, a medição em altura mínima de 30 metros) por período não inferior a 12 meses consecutivos, realizadas no local do parque eólico.

Com estes dados, pode-se desenhar a distribuição de frequência dos ventos no período de medição, informação básica para se determinar o potencial teórico do local.

Com a curva de frequência dos ventos, fazendo uso das curvas de geração dos vários tipos (e potência) dos geradores eólicos disponíveis pode-se calcular o potencial realizável de geração de energia e, por consequência, o fator de capacidade associado à tecnologia escolhida para geração eólica.

Bom seria se as medições fossem integralizadas a cada dez minutos e com índice de perda de dados inferior a dez por cento, por dois anos ${ }^{64}$ caso se queira participar de leilões de energia no mercado regulado.

Estimativa da capacidade e da incerteza padrão de geração anual declarada do parque eólico, com base nos dados do parágrafo anterior, atestada por entidade certificadora independente, desde que não tenha participação societária, direta ou indireta, no empreendimento de geração eólica, que não tenha sido e não seja responsável pelo desenvolvimento do projeto.

\section{Estudo de conexão a rede}

Este é um item muito importante, porque, pelo atual marco regulatório, a conexão à rede é de responsabilidade do gerador e seus custos iniciais, dependendo do local onde será instalado o empreendimento, podem se tornar muito relevantes, principalmente no caso deste estudo, onde a geração é de baixa escala.

Nesta medida, deve-se contatar a distribuidora local ${ }^{65}$ e compartilhar os projetos, com vistas a obter a configuração de conexão que ela, a distribuidora local, considera necessária, e suficiente, o seu critério técnico, para a conexão do empreendimento à sua rede.

\footnotetext{
${ }^{64}$ Segundo instrução da EPE No. EPE-DEE-017/2009-r7

${ }^{65}$ Ou ONS, considerando a opção de ligação direta à rede de transmissão do SIN
} 
$\mathrm{Na}$ prática, nos casos de conexão à distribuidora (o caso deste estudo: Geração Distribuída) o gerador custeia a construção da infraestrutura de conexão, que depois de pronta fica sob responsabilidade exclusiva da Distribuidora, a qual passa a cobrar uma taxa mensal pelo uso da conexão por parte do Gerador.

\section{Execução do estudo de viabilidade}

O documento final, denominado "projeto básico", deverá ser bastante detalhado, com cuidadosa avaliação de todos os aspectos envolvidos no projeto, visando minimizar ao máximo as surpresas, em particular aquelas ligadas aos aspectos ambientais e sociais, cuja avaliação imprecisa pode acarretar a inviabilização do empreendimento.

Em relação aos aspectos técnico econômico, deve-se avaliar muito bem a disponibilidade (no caso de PCH, e Eólica, ênfase na avaliação do fluxo no tempo), acesso às fontes primárias de energia. No caso das fontes primárias de origem hídrica (PCH) e eólica (EOL), é imprescindível que as avaliações históricas tenham tratamento estocástico com vistas as projeções futuras, além da correta escolha da tecnologia, com vistas a otimizar o fator de capacidade de geração elétrica.

\section{Garantias de contratação da energia a ser gerada pelo empreendimento}

O Power Purchase Agreement (PPA), ou acordo de compra e venda de energia, é um dos pontos decisivos na viabilização de um empreendimento de geração. Este acordo é a garantia de que a energia gerada, seja no ACR seja no ACL, tem destinação e, portanto, nível de receita garantida. A obtenção de um PPA, que antecede o início dos investimentos, facilita muito a obtenção de financiamento, notadamente na modalidade Project Finance. OS PPAs do Ambiente Regulado (contratos CCEEAR) têm grande aceitação por parte das instituições, por ser compromissado com o pool de distribuidoras, têm prazos contratuais longos e é balizado pelo governo. 


\section{Estruturação financeira do Empreendimento (Estrutura de Capital)}

Deve-se aqui discutir a participação de cada acionista no empreendimento e sua expectativa de remuneração. Combinada com a participação dos agentes financeiros, é outro item determinante para viabilidade ou não do empreendimento.

A modelagem adotada nesta fase, também é um ponto crítico para a viabilização do negócio. Para os propósitos deste estudo, foram considerados os requerimentos padrões do BNDES para financiamento de fontes de energia alternativa, discutidos mais a frente, em tópico específico.

\section{Montagem do fluxo de caixa}

Compõe o fluxo de caixa o investimento total, as receitas e as despesas geradas pela operação da usina, os incentivos obtidos (quando for o caso), os impostos devidos etc.

Um perfeito entendimento da legislação vigente é importante para que as características do negócio sejam fielmente representadas no fluxo de caixa da geração. Nesta fase, é importante o conhecimento das regras tributárias envolvidas, e na presença, ou não, de incentivos fiscais passíveis de serem aproveitados.

\section{Determinação das figuras de mérito econômico e decisão dos acionistas}

A análise do fluxo de caixa levará ao cálculo das figuras de mérito econômico do empreendimento (VPL, TIR, PBD, Preço de venda de energia de equilíbrio). Com estes dados em mãos, os acionistas da SPC têm finalmente o insumo para a tomada de decisão sobre o retorno proporcionado pelo negócio, decidindo pela sua execução, ou não. 


\section{Obtenção da Autorização de Exploração (ANEEL)}

Com a aprovação do projeto básico na ANEEL, obtém-se a Autorização de Exploração. No caso da $\mathrm{PCH}$ e EOL, a partir deste momento, o empreendedor passa a ter exclusividade sobre o empreendimento, estipulando-se prazos para a construção e para a entrada em operação da usina.

\section{Obtenção da Licença de Instalação (LI) no Órgão Ambiental}

Para a obtenção da LI junto aos órgãos ambientais, necessária para que se possa iniciar a construção, é preciso que tenham sido aprovadas as medidas mitigadoras apontadas nos Estudos de Impacto Ambiental. Portanto, estas medidas devem fazer parte do Business Plan.

A LI geralmente é emitida com condicionantes a serem cumpridos durante a fase de implantação do projeto.

No caso de uma $\mathrm{PCH}$, nesta fase é fundamental que as áreas de terras necessárias, e suficientes, para construção do empreendimento (prédios e reservatório) sejam de propriedade do empreendedor, e, para isto, é fundamental que seja deferido ao empreendedor a respectiva Declaração de Utilidade Pública (DUP) do aproveitamento tipo $\mathrm{PCH}$.

\section{Contratação da construção do empreendimento}

A modalidade de contrato mais recomendada para o empreendedor, na etapa de construção, vem a ser justamente, o assim denominado EPC (Engineering Procurement Constrution), ordinariamente celebrado na modalidade turn-key. Nesta modalidade, o empreiteiro contratado assume a responsabilidade por todos os aspectos do projeto, envolvendo a construção, o fornecimento de equipamentos, a montagem e a entrega do empreendimento, até a data de sua entrada em operação.

Existem outras modalidades de construção como (i) DBB [Design-Bid-Build], em que o empreendedor gerencia a obra, contratando separadamente as partes para sua construção; (ii) DBB-CM [Design-Bid-Build-Construction-Management], com divisão de riscos entre a construtora e proprietário; (iii) e finalmente a DB 
[Disign-Build], em que é contratado o projeto e a sua construção. A EPC é a evolução da DB. Para os propósitos deste estudo, estamos considerando o modelo de contratação EPC para todos os empreendimentos em geração.

\section{Obtenção da licença de Operação (LO) junto ao(s) órgão(s) ambiental (is)}

Concluída a obra de construção do empreendimento, deve ser obtida também, junto aos órgãos ambientais, a licença de operação, sem a qual não é permitido o comissionamento da planta de geração. Esta licença apenas será concedida se tiverem sido feitas todas, e cada uma, das medidas mitigadoras definidas e discriminadas na licença de instalação.

Para os propósitos deste estudo - estudo prévio - será dado foco na montagem do fluxo de caixa do empreendimento, cálculo das figuras de mérito, análise expedita dos riscos, com ênfase aos ambientais e técnico-econômicos, fazendo muito uso dos resultados do PIR-USP para a RAA. 


\section{APÊNDICE E - Principais Aproveitamentos hídricos da RAA}

Tabela 56 - Resumo ${ }^{66}$ do levantamento dos locais com potencial hídrico na RAA

\begin{tabular}{|c|l|c|c|c|c|}
\hline $\begin{array}{c}\text { Código da } \\
\text { Sub-Bacia }\end{array}$ & \multicolumn{1}{|c|}{$\begin{array}{c}\text { Nome da } \\
\text { Sub-Bacia }\end{array}$} & $\begin{array}{c}\text { Cota } \\
\text { Aproveitamento } \\
(\mathbf{m})\end{array}$ & $\begin{array}{c}\text { Diferença } \\
\text { das cotas } \\
(\mathbf{m})\end{array}$ & $\begin{array}{c}\text { Vazão } \\
\left(\mathbf{m}^{3} \mathbf{s} \mathbf{s}\right)\end{array}$ & $\begin{array}{c}\text { Potencial } \\
\text { Teórico } \\
(\mathbf{M W})\end{array}$ \\
\hline A & Corr. Pendenga & 294 & 80 & 1,53 & 1 \\
\hline B & Rib. Do Moinho & 317 & 114 & 5,35 & 5 \\
\hline C & Corr. Abrigo & 294 & 138 & 2,79 & 3,16 \\
\hline D & Corr. Da Onça & 341 & 95 & 2,7 & 2,1 \\
\hline 110 & Corr. Timboré & 341 & 95 & 2,7 & 2,1 \\
\hline 120 & R. Três Irmãos & 365 & 92 & 3,78 & 2,85 \\
\hline 131 & Corr. Macaé & 365 & 66 & 2,91 & 1,57 \\
\hline 132 & Rib. Travessa Grande & 368 & 143 & 2,31 & 2,71 \\
\hline 133 & Corr. Santista & 384 & 63 & 2,66 & 1,37 \\
\hline 134 & Rib. De Cotovelo & 347 & 87 & 1,49 & 1,06 \\
\hline 135 & Corr. Do Osório & 347 & 91 & 4,23 & 3,16 \\
\hline 140 & Rib. Água Fria & 395 & 51 & 4,18 & 1,75 \\
\hline 150 & Rib. Do Barreiro & 388 & 45 & 2,34 & 0,863 \\
\hline 160 & Rib. Água Parada & 386 & 94 & 3,92 & 3,02 \\
\hline 170 & Rib. Das Cruzes & 326 & 101 & 3,42 & 2,83 \\
\hline 180 & Rib. Lambari & 326 & 161 & 3 & 3,96 \\
\hline 190 & Corr. Do Aracanguá & 326 & 161 & 2,25 & 2,97 \\
\hline 200 & Rib. Azul ou Aracanguá & 347 & 142 & 6,61 & 7,7 \\
\hline 300 & Corr. Das Eguas & 326 & 99 & 0,997 & 0,809 \\
\hline 400 & Rib. Macaúbas & 408 & 108 & 5,56 & 4,92 \\
\hline 510 & Corr. Machado de Melo & 396 & 25 & 1,05 & 0,215 \\
\hline 520 & Rib. Mato Grosso & 422 & 75 & 4,07 & 2,5 \\
\hline 540 & Rib. Baguaçún & 374 & 129 & 4,18 & 4,42 \\
\hline 550 & Rib. Palmeiras & 404 & 71 & 2,59 & 1,51 \\
\hline 560 & Corr. Dos Baixotes & 393 & 101 & 3,04 & 2,52 \\
\hline 600 & Rib. Santa Barbara & 389 & 163 & 5,57 & 7,44 \\
\hline 700 & Corr. De Arribade & 389 & 66 & 0,947 & 0,513 \\
\hline 800 & Rib. Lajeado & 408 & 139 & 9,54 & 10,87 \\
\hline 910 & Rib. São Jeronimo & 378 & 169 & 9,54 & 13,22 \\
\hline 920 & Rib. Das Oficinas & 381 & 175 & 4,4 & 6,31 \\
\hline 930 & Rib. Da Corredeira & 381 & 134 & 6,47 & 7,11 \\
\hline 940 & Rib. Dos Patos & 410 & 89 & 4,66 & 3,4 \\
\hline
\end{tabular}

Fonte: elaboração própria, baseada BIAGUE, 2010

66 Apenas a relação dos maiores aproveitamentos por sub-bacia, conforme levantamento completo esta em UDAETA, 2008c Valoração dos recursos energéticos do lado da oferta. 


\section{APÊNDICE F - Parâmetros dos fluxos de caixa dos modelos de geração}

Tabela 57 - Parâmetros de referência para os fluxos de caixa dos REs de Geração

\begin{tabular}{|c|c|c|c|c|c|c|}
\hline & PARÂMETROS DE REFERÊNCIA PARA CÁLCULO DO FLUXO DE CAIXA & Unidade & $\begin{array}{c}\text { BIOMASSA } \\
\text { DE CANA }\end{array}$ & PCH & EÓLICA & FORMULA \\
\hline $\mathrm{A}$ & VIDA ÚTIL DO PROJETO & anos & 20 & 30 & 20 & \\
\hline B & VALOR RESIDUAL DO PROJETO APÓS A VIDA ÚTIL & $\%$ & $20 \%$ & $20 \%$ & $20 \%$ & \\
\hline c & DEPRECIAÇÃO & anos & 20 & 30 & 20 & \\
\hline \multirow[t]{2}{*}{$D$} & POTÊNCIA ELÉTRICA NOMINAL BRUTA & MW & 30 & 13 & 30 & \\
\hline & CONSUMO DE POTÊNCIA NO PROCESSO & & & & & \\
\hline $\mathrm{E}$ & Consumo (Tecnologia) & \%Potência Nom. Bruta & $19,51 \%$ & $0,50 \%$ & $0,40 \%$ & \\
\hline $\mathrm{F}$ & Consumo total & MW & 5,85 & 0,065 & 0,12 & $D^{*} E$ \\
\hline G & POTÊNCIA ELÉTRICA NOMINAL TOTAL LíQUIDA "INJETÁVEL" & MW & 24,147 & 12,935 & 29,880 & $D^{*} F$ \\
\hline $\mathrm{H}$ & FATOR DE DISPONIBLIDADE TOTAL (PROGRAMADO+FORÇADO) & $\%$ & $93 \%$ & $93 \%$ & $94 \%$ & \\
\hline 1 & FATOR DE CAPACIDADE & $\%$ & $54,52 \%$ & $55 \%$ & $24 \%$ & \\
\hline $\mathrm{J}$ & MÉDIA DE HORAS DE GERAÇÃO & horas/ano & 4.776 & 8.147 & 8.234 & \\
\hline $\mathrm{K}$ & POTÊNCIA DE EXPORTAÇÃO "INJETADA" & MWmed & 12,24 & 6,62 & 6,74 & $G^{*} H^{*}$ \\
\hline $\mathrm{L}$ & TOTAL DE ENERGIA ELÉTRICA DE REFERÊNCIA & MWh/ano & 107.253 & 57.958 & 59.051 & $8760^{\circ} \mathrm{K}$ \\
\hline $\mathrm{M}$ & PERDAS TÉCNICAS NA TRANSMISSÃO & $\%$ & $2 \%$ & $2 \%$ & $2 \%$ & \\
\hline \multirow[t]{2}{*}{$\mathrm{N}$} & TOTAL ENERGIA ELÉTRICA DE REFERÊNCIA "COMERCIALIZÁVEL" & MWh/ano & 105.108 & 56.799 & 57.870 & $\mathrm{~L}^{*}(1-\mathrm{M})$ \\
\hline & $\begin{array}{l}\text { ENERGIA PARA PROCESSO } \\
\text { VAPOR }\end{array}$ & & & & & \\
\hline 0 & \begin{tabular}{|l|} 
Preço da tonelada de vapor Suprido \\
[EPE - 1ª Leiläo de Energia de Reserva/07/2008 corrigido pelo IPCA até 02/2011]
\end{tabular} & $\mathrm{R} \$$ TonVapor suprido & 5,05 & 0,00 & 0,00 & \\
\hline$P$ & Demanda Vapor para o processo [Tecnologia] & Ton Vapor/Ton cana moida & 0,4 & & & \\
\hline$Q$ & Demanda de Biomassa de Cana por MWh gerado [Tecnologia] & Ton biomassa/MWh & 3,01 & & & \\
\hline $\mathrm{R}$ & Demanda Biomassa de Cana para geração/Safra & Ton biomassa/Safra & 431.316 & & & $D^{*} J^{*} Q$ \\
\hline s & Relação Biomassa/Cana-de-açucar [em massa] & $\%$ & $40 \%$ & & & \\
\hline$T$ & Toneladas de Cana-de-açucar processada & Ton cana/safra & 1.078 .290 & & & RIS \\
\hline \multirow[t]{2}{*}{$U$} & Total de Vapor demandado no Processo & Ton Vapor/Ano & 431.316 & & & $\mathrm{P}^{\mathrm{P} T}$ \\
\hline & E.ELÉTRICA & & & & & \\
\hline $\mathrm{v}$ & Demanda Energia Elétrica para o Processo(Tecnologia) & MWh/Ton cana & 0,032 & & & \\
\hline \multirow[t]{3}{*}{$x$} & Energia Elétrica Total fornecida para o Processo & MWh/Ano & 34.505 & & & $T^{*} \mathrm{~V}$ \\
\hline & INVESTIMENTOS & & & & & \\
\hline & Investimento na geração & & & & & \\
\hline $\begin{array}{ll} \\
\end{array}$ & Investimento Inicial & $\mathrm{R} \$ \mathrm{KW}$ inst. & $1.800,00$ & $3.150,00$ & $2.600,00$ & \\
\hline \multirow[t]{2}{*}{ W } & Sub Total & $\mathrm{R} \$$ & 54.000 .000 & 40.950 .000 & 78.000 .000 & $D^{*} Y^{*} 1000$ \\
\hline & Investimento na Conexão à rede Eletrica & & & & & \\
\hline $\mathrm{Z}$ & Investimento & $\mathrm{R} \$ \mathrm{Km}$ & 250.000 & 250.000 & 250.000 & \\
\hline $\mathrm{AA}$ & Distância Usina ? Pto.de conexão com distribuidora local & KM & 10 & 10 & 10 & \\
\hline$A B$ & Sub Total & $\mathrm{R} \$$ & 2.500 .000 & 2.500 .000 & 2.500 .000 & $Z^{*} A A$ \\
\hline \multirow[t]{2}{*}{$A C$} & Total dos Investimentos & & 56.500 .000 & 43.450 .000 & 80.500 .000 & $Y^{*} A B$ \\
\hline & Cronograma de investimentos pré-operacionais & & & & & \\
\hline $\mathrm{AD}$ & Ano-3 & $\%$ & $0 \%$ & $25 \%$ & $0 \%$ & \\
\hline $\mathrm{AE}$ & Ano - 2 & $\%$ & $40 \%$ & $25 \%$ & $0 \%$ & \\
\hline AF & Ano-1 & $\%$ & $60 \%$ & $50 \%$ & $100 \%$ & \\
\hline
\end{tabular}

Fonte: elaboração própria.

${ }^{*}$ *) As células em amarelo representam os parâmetros independentes 
Tabela 57 Parâmetros de referência para os fluxos de caixa dos RE's de Geração (cont.)

\begin{tabular}{|c|c|c|c|c|c|c|}
\hline & PARÂMETROS DE REFERÊNCIA PARA CÁLCULO DO FLUXO DE CAIXA & Unidade & \begin{tabular}{|c|} 
BIOMASSA \\
DE CANA
\end{tabular} & $\mathrm{PCH}$ & EÓLICA & FÓRMULA \\
\hline \multicolumn{7}{|c|}{ FNANCIAMENTO (Referência: BNDES - Energias Alternativas) } \\
\hline$A G$ & Percentual do Investimento (BNDES : Maxé 80\%) & $\%$ & $80 \%$ & $80 \%$ & $80 \%$ & \\
\hline $\mathrm{AH}$ & Percentual do Financimento Total & $\%$ & $100 \%$ & $100 \%$ & $100 \%$ & \\
\hline $\mathrm{Al}$ & Montante Financiado (Debt) & $\mathrm{R} \$$ & 45.200 .000 & 34.760 .000 & 64.400 .000 & $A C^{*} A G$ \\
\hline AJ & Taxa (BNDES: TJLP(6\%)+Rem. Basica(0,9\%aa)+Risco (Max =3,57\%aa) & \%.a. & $9,00 \%$ & $9,00 \%$ & $9,00 \%$ & \\
\hline AK & Amortização (Bndes) & anos & 16 & 16 & 16 & \\
\hline $\mathrm{AL}$ & Sistema de Amortização & & PRICE & PRICE & PRICE & \\
\hline \multicolumn{7}{|c|}{ CAPITAL PRÓPRIO (Equity) } \\
\hline AM & Montante & $\mathrm{R} \$$ & 11.300 .000 & 8.690 .000 & 16.100 .000 & AC-Al \\
\hline$A-N$ & Custo do Capital Próprio (CAPM) & \%a.a. & $15,43 \%$ & $15,43 \%$ & $15,43 \%$ & \\
\hline \multicolumn{7}{|c|}{ DESPESAS } \\
\hline $\mathrm{AO}$ & O\&M Variável & $\mathrm{R} \$ \mathbf{M W h}$ & 3,00 & 7,00 & 0,00 & \\
\hline $\mathrm{AP}$ & O\&MFixo & RS\$KW.ano & 25,00 & 0,00 & 46,00 & \\
\hline \multirow[t]{2}{*}{$A Q$} & Seguro Operacional & \%investimento & $0,50 \%$ & $0,50 \%$ & $0,50 \%$ & \\
\hline & Combustivel & & & & & \\
\hline $\mathrm{AR}$ & Biomassa de Cana & $\mathrm{R} \$$ Tonbiomassa & 20,00 & 0,00 & 0,00 & \\
\hline \multirow[t]{2}{*}{ AS } & Custo da Biomassa por MWh gerado & $\mathrm{R} \$ \mathrm{MWh}$ & 60,20 & 0,00 & 0,00 & \\
\hline & IIMPOSTOS FEDERAIS & & & & & \\
\hline AT & PIS [Aliquota: Lucro Real] & $\%$ & $1,65 \%$ & $1,65 \%$ & $1,65 \%$ & \\
\hline $\mathrm{AU}$ & COFINS [Aliquota: Lucro Real] & $\$$ & $7,60 \%$ & $7,60 \%$ & $7,60 \%$ & \\
\hline AV & CSLL - Contribuição Social sobre o Lucro Líquido. Alíquota : Lucro Tributável & $\%$ & $9 \%$ & $9 \%$ & $9 \%$ & \\
\hline \multirow[t]{2}{*}{$\mathrm{AX}$} & $\begin{array}{l}\text { Imposto de Renda } \\
\text { [Se Lucro líquido anual > R\$240.000, então Alíquota: Lucro Real = 25\%] }\end{array}$ & $\%$ & $25 \%$ & $25 \%$ & $25 \%$ & \\
\hline & TAXAS DO SEB & & & & & \\
\hline AY & $\begin{array}{l}\text { TUSDg [ No cenário :Inclui TUST RB, qdo despacho não é centralizado/Locacional: } \\
\text { CPFL circuito genérico para ano 2010/11] }\end{array}$ & $\mathrm{R} \$$ /KW.mês & 2,2340 & 2,2340 & 2,2340 & \\
\hline $\mathrm{AW}$ & TFSEE -Taxa de Fiscalização ANEEL [Base: $0,5 \%{ }^{*}{ }^{*} \mathrm{Bg}^{*}$ Potência InstaladaMW] & $\mathrm{R} \$$ & 57.860 & 25.072 & 57.860 & $0,5 \%{ }^{*} A Z^{*} D^{*} 1000$ \\
\hline $\mathrm{AZ}$ & $\mathrm{Bg}$ = Beneficio Econômico, definido Anualmente pela Aneel:2010/2011 & $\mathrm{R} \$ \mathbf{M W}$ & 385,73 & 385,73 & 385,73 & \\
\hline $\mathrm{BA}$ & Taxa ONS (Aliquota: PCH, Biomasa e Eólico = 0) & $\%$ & $0 \%$ & $0 \%$ & $0 \%$ & \\
\hline $\mathrm{BB}$ & $\begin{array}{l}\text { TUSTRB [Energia Exportada fora da CPFL } \\
\text { [ANEEL - Resolução Homologatória } 1022-2010 / 11 \text { R\$/KW.mes = 5,498] }\end{array}$ & $\mathrm{R} \$ / K W$. mês(médio) & 5,498 & 5,498 & 5,498 & \\
\hline $\mathrm{BC}$ & $\begin{array}{l}\text { TUSTFR [Energia Exportada fora da CPFL, } \\
\text { [ANEEL - Resolução Homologatória 1022 - 2010/11] }\end{array}$ & $\mathrm{R} \$ / K W$. mês(médio) & 1,754 & 1,754 & 1,754 & \\
\hline $\mathrm{BD}$ & P\&D (Alíquota: PCH, Biomassa e Eólico = 0) & $\%$ & $0 \%$ & $0 \%$ & $0 \%$ & \\
\hline $\mathrm{BE}$ & CFURH ( - Royalties ( Aliquota: PCH, Biomasa e Eólico = 0) & $\mathrm{R} \$ \mathrm{MWh}$ & $0 \%$ & $0 \%$ & $0 \%$ & \\
\hline $\mathrm{BF}$ & TAXA DE CÂMBIO & $\mathrm{R} \$ \mathrm{US} \$$ & 1,80 & 1,80 & 1,80 & \\
\hline
\end{tabular}

Fonte: elaboração própria.

(*) As células em amarelo representam os parâmetros independentes 


\section{ANEXO A - Figuras de Mérito Econômico Financeiro ${ }^{67}$}

\section{Geração}

O valor de uma oportunidade de negócio depende de seu fluxo de caixa futuro. Levando em consideração que $\$ 1$ recebido hoje tem mais valor que o mesmo $\$ 1$ recebido daqui a um ano, o valor da empresa poderá ser medido pelo valor presente de seu fluxo de caixa futuro. O fluxo de caixa futuro é gerado pelos ativos existentes e pelos novos ativos que serão adicionados à empresa, aproveitando novas oportunidades de investimento. Portanto, parte da geração do lucro futuro da empresa será proveniente de novos projetos de investimento. Não é suficiente que os novos projetos de investimento gerem apenas retornos positivos. Eles devem gerar bons resultados. Assim, devemos estabelecer procedimentos de avaliação que permitam determinar que os retornos dos novos projetos de investimento têm capacidade de gerar bons resultados.

Dentre os diversos métodos de avaliação existentes as chamadas figuras de mérito econômico: (i) Método do PayBack Descontado; (ii) Método do Valor Presente Líquido; e (iii) Método da Taxa Interna de Retorno.

\section{Método do Payback Descontado - PBD}

O PayBack descontado é a data (ano/mês) em que a soma dos fluxos de caixa descontados (considera o valor do dinheiro no tempo) gerados pela oportunidade supera a somatória de investimentos iniciais, necessários à criação da "oportunidade".

Para aplicar o método do PBD, é necessário estabelecer o tempo máximo tolerado (TMT), pra recuperar o custo inicial remunerado. Deve-se verificar que o primeiro capital do fluxo de caixa seja um desembolso e que o fluxo de caixa do projeto apresente uma única mudança de $\operatorname{sinal}^{68}$ (fluxo de caixa simples). Para

\footnotetext{
${ }^{67}$ Baseado em Lapponi, 2007

68 Sequência de fluxo de caixa com mais de uma mudança de sinal não são possíveis de se determinar um único valor para o PayBack descontado.
} 
decidir-se se o projeto dever ser aceito, considerando a taxa requerida i, o PBD é comparado com o valor de referência TMT, de forma que:

- se o PBD < TMT, então o projeto deve ser aceito. O PBD menor do que o prazo de análise $\mathrm{n}$ do projeto simples mostra que o VPL desse projeto é positivo e, consequentemente, criará valor;

- se o PBD > TMT, então o projeto não deve ser aceito.

\section{Vantagens e desvantagens do PBD}

\section{Vantagens}

- O método do PBD é fácil de ser aplicado, embora o procedimento de cálculo seja um pouco trabalhoso.

- O resultado do PBD é de fácil interpretação, quanto menor for o PBD, tanto melhor para o projeto.

- Dá uma noção de liquidez e do risco do projeto $^{69}$.

\section{Desvantagens}

- O PDB não considera todos os capitais do fluxo de caixa do projeto, e a definição de tempo máximo tolerado é arbitrária. Avaliando somente com o método do PBD, a empresa tenderá a aceitar projetos de curta maturação e menor rentabilidade, e tenderá a rejeitar projetos de maior maturação e maior rentabilidade.

- O PBD não é uma medida de rentabilidade do projeto.

- Não deve ser aplicado quando o projeto não for do tipo simples.

- Para selecionar o melhor de um grupo de projetos mutuamente excludentes, ou grupo de projetos independentes sob restrição orçamentária, o projeto com menor PBD poderá não ser o melhor projeto, pois não considera todo o fluxo de caixa, e o Tempo Maximo Tolerado é uma referência arbitrária.

\footnotetext{
${ }^{69}$ Liquidez é a capacidade de converter um determinado ativo em dinheiro. Risco é a incerteza de não receber o esperado
} 


\section{Método do Valor Presente Líquido - VPL}

Valor Presente Líquido (VPL) - é o valor presente da somatória de pagamentos futuros descontados a uma taxa de juros apropriada, menos o custo do investimento inicial. Basicamente, é o cálculo de quanto a somatória dos fluxos de receita futuro, subtraídos os custos iniciais, estaria valendo atualmente. Temos que considerar o conceito de valor do dinheiro no tempo, pois, exemplificando, $R \$ 1$ milhão hoje, não valeria $R \$ 1$ milhão daqui a um ano, devido ao custo de oportunidade de se colocar, por exemplo, tal montante de dinheiro na poupança para render juros. É um método padrão nas finanças para a análise do orçamento de capitais - planejamento de investimentos a longo prazo. Usando o método VPL, um projeto de investimento potencial deve ser empreendido se o valor presente de todas as entradas de caixa menos o valor presente de todas as saídas de caixa (que iguala o valor presente líquido) for maior que zero. Se o VPL for igual a zero, o investimento é chamado de indiferente, pois o valor presente das entradas é igual ao valor presente das saídas de caixa; se o VPL for menor do que zero, significa que o investimento não é economicamente atrativo, já que o valor presente das entradas de caixa é menor do que o valor presente das saídas de caixa.

Para cálculo do valor presente das entradas e saídas de caixa é utilizada a $\mathrm{TMA}^{70}$ (Taxa Mínima de Atratividade) como taxa de desconto. Se a TMA for igual à taxa de retorno esperada pelo acionista, e $\circ \mathrm{VPL}>0$, significa que a sua expectativa de retorno foi superada e que os acionistas estarão esperando um lucro adicional a qualquer investimento que tenha valor presente igual ao VPL. Desta maneira, o objetivo da corporação é maximizar a riqueza dos acionistas, os gerentes devem empreender todos os projetos que tenham um VPL $>0$, ou no caso se dois projetos forem mutuamente exclusivos, deve se escolher o com o VPL positivo mais elevado.

O valor presente líquido, para fluxos de caixa uniformes, pode ser calculado através da seguinte fórmula:

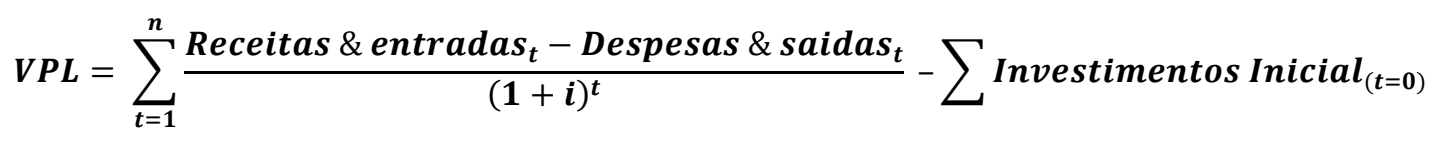

\footnotetext{
${ }^{70}$ Menor retorno percentual aceito para se investir em uma oportunidade
} 
Onde:

t: data (geralmente em anos) em que ocorrem as receitas/despesas;

i: taxa de juros usada para descontar o fluxo de caixa no tempo, no contexto, chamada de Taxa mínima de Atratividade;

n: período de tempo no qual se avalia o investimento (normalmente a vida útil do investimento).

Deve-se salientar que não se pode fazer subtração (receitas-despesas) de valores que não estejam na mesma data $(\mathrm{t})$

\section{Vantagens e Desvantagens do Método do VPL}

\section{Vantagens}

- Considera todo o fluxo de caixa do projeto, diferentemente do PayBack Descontado.

- Considera o valor do dinheiro no tempo com a taxa requerida que inclui o risco do projeto.

- Informa e mede o valor criado (ou destruido) pelo projeto.

- Pode ser aplicado na avaliação de projetos com qualquer tipo de fluxo de caixa.

- Propriedade aditiva do VPL de fluxos de caixa de um mesmo projeto;

- Seleciona o melhor projeto(com maior VPL) de um grupo de projetos mutuamente excludentes com o mesmo prazo de análise.

\section{Desvantagens}

- Necessidade de determiar a priori a taxa requerida do projeto.

- É um valor monetário em vez de uma taxa de juros ou, de outra maneira, uma medida absoluta em vez de uma medida relativa.

- É possivel reinvestir os retornos do projeto com a mesma taxa requerida para garantir o VPL. 
- Na seleção do melhor projeto do grupo de projetos com prazos de análise diferentes, os prazos de análise devem ser equiparados.

Entre vários projetos de investimento, o mais atrativo é aquele que tem maior Valor Presente Líquido.

\section{Método da Taxa Interna de Retorno - TIR}

O método da taxa interna de retorno consiste em calcular a taxa que anula o valor presente líquido do fluxo de caixa do investimento que está sendo analisado, ou seja, a TIR é a taxa para qual o VPL é igual a zero, fazendo com que a decisão sobre o investimento seja indiferente. Será atrativo o investimento cuja taxa interna de retorno for maior ou igual à taxa de atratividade do investidor. Em comparações de investimentos, o melhor investimento é aquele que tem a maior taxa interna de retorno. Essa taxa não é, no entanto, facilmente calculada, devendo ser determinada pelo método da tentativa e erro.

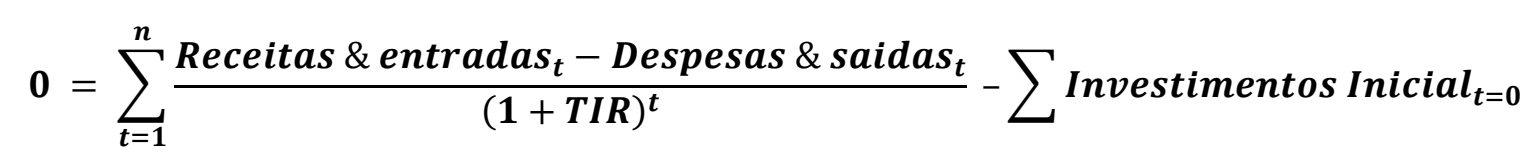

Como a TIR é a taxa de juros que faz com que o VPL iguale-se a zero, podemos dizer que a TIR é a Raiz do fluxo de caixa. Assim, se o fluxo de caixa se inverte mais de uma vez durante o período analisado, então existirão mais de uma TIR (raiz), comprometendo a avaliação do projeto pelo critério da TIR.

\section{Vantagens e Desvantagens de se utilizar a TIR}

\section{Vantagens}

- Considera o fluxo de caixa completo do projeto e o valor do dinheiro no tempo;

- Informa se o projeto simples cria ou destrói valor. 
- É uma taxa de juros, uma medida relativa, em vez de uma medida absoluta, como é o VPL. A TIR é fácil de ser comunicada e, aparentemente, pode ser bem compreendida.

\section{Desvantagens}

- Deve ser aplicado somente na avaliação de projetos com fluxos de caixa com uma única mudança de sinal, denominados projetos do tipo simples.

- É necessário determinar a priori a taxa requerida do projeto.

- Não tem a propriedade aditiva do VLP de fluxos de caixa de um mesmo projeto.

- A maior TIR não seleciona o melhor projeto de um grupo de projetos mutuamente excludentes com o mesmo prazo de análise, exceto aplicando-se a análise incremental, ou grupo de projetos independentes sob restrições orçamentárias.

- Há dificuldade em reinvestir os retornos dos projetos para garantir a rentabilidade periódica igual à TIR.

\section{Método da Demanda relevante de capital de Giro}

Capital de giro é considerado um investimento adicional do acionista, ao investimento feito para construção de um empreendimento, que não tem depreciação nem tributação, entretanto, o empreendimento assume o custo pelo uso desse capital. Assim, é importante prestar atenção ao investimento em capital de giro porque este exige uma remuneração do empreendimento e, ao mesmo tempo, senão for incluído como investimento, o VPL do projeto será superestimado.

Nos casos de oportunidades em geração, intensivas em capital, a necessidade de previsão de capital de giro torna-se ainda mais relevante.

Como a necessidade de capital de giro afeta o fluxo de caixa de uma oportunidade, a determinação de sua condição de pico deve ser cuidadosa, pois o excesso de capital de giro pode inviabilizar o projeto e a falta pode comprometer o resultado do projeto. $O$ ideal é que esta necessidade de capital de giro (investimento adicional no projeto) seja zero, ou próxima de zero.

A avaliação da necessidade de capital de giro é um subproduto da montagem da Demonstrativo de Resultado De exercício (DRE) da oportunidade de investimento 
analisada. A estimativa relevante desta necessidade é feita verificando-se na linha do resultado líquido se, em algum ano, o fluxo de caixa apresenta valor líquido negativo, e, caso positivo, qual o pico.

\section{Medidas de economia de energia elétrica}

\section{Custo de Ciclo de Vida (CCV) e Custo de Ciclo de Vida Anualizado (CCVA)}

Para auxiliar a resposta à questão das medidas de economia, foi feito uso da figura de mérito econômico-financeira: o CCV (Custo do Ciclo de Vida) de uma tecnologia considerada nas medidas de economia.

Por definição, o CCV representa o valor presente de todos os custos incorridos com a adoção de uma determinada tecnologia avaliada no contexto de medidas de economia de energia: aquisição, instalação, gastos com energia, gastos com manutenção e operação, e descarte.

Por definição, dado um período de tempo t, o CCVA é a parcela constante de uma séria de valores financeiros que (espalhados uniformemente em períodos de tempo t) representam o CCV.

Devido ao fato de as tecnologias avaliadas nas medidas de economia não terem, necessariamente, a mesma vida útil, o CCVA se apresenta como muito útil em comparações, visto que a matemática que leva a seu cálculo normaliza esta dimensão para ambas as tecnologias avaliadas: tecnologia eficiente contra tecnologia tradicional.

A expressão matemática de CCVA é dada por

$$
\mathrm{CCVA}=\mathrm{FRC} * \mathrm{CCV}
$$

Onde a expressão matemática do CCV (Custo de Ciclo de Vida) é dada por:

$$
\mathbf{C C V}=\mathrm{C}+\sum_{n=1}^{v n} \mathrm{E}_{\mathrm{n}} * \mathrm{P}_{\mathrm{n}} *(1+\mathrm{d})^{-\mathrm{n}}+\sum_{n=1}^{v n} \mathrm{CNE}_{\mathrm{n}} *(1+\mathrm{d})^{-\mathrm{n}}
$$


Onde:

- $\mathrm{C}=$ Custo do investimento inicial com a aquisição da tecnologia

- $E=$ Energia consumida no período $n$;

- $P_{n}=$ Preço da energia no período $n$;

- $\mathrm{CNE}_{\mathrm{n}}=$ Custos não energéticos no período $\mathrm{n}$;

- $\mathrm{d}=$ Taxa de desconto por período $\mathrm{n}$;

- $\mathrm{VN}=$ Vida útil espera da tecnologia, na escala de tempo de $\mathrm{n}$.

E onde a expressão matemática de FRC é dada por:

$$
\mathrm{FRC}=d * \frac{(1+d)^{V N}}{(1+d)^{V N}-1}
$$

Calcula-se o FRC, o CCV e o CCVA de cada tecnologia concorrente: tradicional e eficiente.

\section{Vantagens do CCVA}

- É um cálculo simples, uma vez obtido o valor presente líquido de todos os custos associados à tecnologia avaliada;

- Pode ser aplicado para toda e qualquer medida de economia de energia, em que se esteja comparando tecnologia eficiente contra tecnologia tradicional/obsoleta, utilizando exatamente o mesmo modelo matemático;

- Pode-se comparar tecnologias concorrentes, que tenham vida útil diferentes, de forma simples. Utilizando o modelo de fluxo de caixa tradicional, este expediente torna-se mais complicado.

\section{Desvantagem do CCVA}

- Considera que a energia terá o mesmo custo durante toda vida útil das tecnologias que estão sendo comparadas 
Assim, apenas com a figura de mérito CCVA, e análises das variáveis independentes de entrada utilizadas para cálculo do CCVA, pode-se avaliar a atratividade de uma tecnologia utilizada em uma medida de economia de energia.

Quanto menor o valor calculado do CCVA, mais atrativa é uma dada tecnologia. Entre duas, ou mais, tecnologias, competindo pela medida de economia, a que apresentar menor CCVA, deve ser a escolhida.

\section{PayBack Descontado (PBD)}

O PayBack descontado de uma medida de economia de energia representa o tempo necessário para que se recupere a diferença de custos iniciais entre a tecnologia mais eficiente e a tecnologia tradicional, considerando a economia mensal produzida pela economia mais eficiente.

Matematicamente, o PayBack (PBD) descontado para uma medida de economia de energia poder ser obtido, calculados o i da equação abaixo

$$
\left(C_{e f i c}-C_{\text {trad }}\right)=\left(C C V A_{e f i c}-C C V A_{\text {trad }}\right) * \sum_{t=1}^{i} \frac{1}{(1+d)^{i}}
$$

Onde:

- $\mathrm{i}=\mathrm{PBD}$;

- $C_{e f i c}=$ Custo de aquisição e instalação da tecnologia eficiente;

- $C_{\text {trad }}=$ Custo de aquisição e instalação da tecnologia tradicional;

- $C C V A_{\text {efic }}=$ CCVA da tecnologia eficiente;

- $\quad C V A_{\text {trad }}$ CCVA da tecnologia tradicional;

- $d=$ Taxa de desconto do dinheiro no tempo.

Se o PBD de uma medida de economia for maior que a vida útil da tecnologia mais eficiente, a economia mensal não será suficiente para pagar a diferença de custos entre a tecnologia eficiente e tradicional. 


\section{ANEXO B - Instituições e agentes do mercado elétrico brasileiro ${ }^{71}$}

O novo modelo do Setor Elétrico Brasileiro criou novas instituições e alterou funções de algumas instituições já existentes.

\section{CNPE - Conselho Nacional de Política Energética}

O CNPE é um órgão interministerial de assessoramento à Presidência da República, tendo como principais atribuições formular políticas e diretrizes de energia e assegurar o suprimento de insumos energéticos às áreas mais remotas ou de difícil acesso no país. É também responsável por revisar periodicamente as matrizes energéticas aplicadas às diversas regiões do país, estabelecer diretrizes para programas específicos, como os de uso do gás natural, do álcool, de outras biomassas, do carvão e da energia termonuclear, além de estabelecer diretrizes para a importação e exportação de petróleo e gás natural.

\section{MME - Ministério de Minas e Energia}

O MME é o órgão do Governo Federal responsável pela condução das políticas energéticas do país. Suas principais obrigações incluem a formulação e implantação de políticas para o setor energético, de acordo com as diretrizes definidas pelo CNPE. O MME é responsável por estabelecer o planejamento do setor energético nacional, monitorar a segurança do suprimento do Setor Elétrico Brasileiro e definir ações preventivas para restauração da segurança de suprimento no caso de desequilíbrios conjunturais entre oferta e demanda de energia.

\footnotetext{
${ }^{71}$ Baseado em www.mme.gov.br
} 


\section{EPE - Empresa de Pesquisa Energética}

Instituída pela Lei ㄲo 10.847/04 e criada pelo Decreto ㄲo 5.184/04, a EPE é uma empresa vinculada ao MME, cuja finalidade é prestar serviços na área de estudos e pesquisas destinadas a subsidiar o planejamento do setor energético.

Suas principais atribuições incluem a (i) realização de estudos e projeções da matriz energética brasileira (que devem ser considerados, a priori, como indicativos); (ii) execução de estudos que propiciem o planejamento integrado de recursos energéticos; (iii) desenvolvimento de estudos que propiciem o planejamento de expansão da geração e da transmissão de energia elétrica de curto, médio e longo prazo; (iv) realização de análises de viabilidade técnico-econômica e socioambiental de usinas; ( $v$ ) bem como a obtenção da licença ambiental prévia para aproveitamentos hidrelétricos e de transmissão de energia elétrica. Enfim, o principal objetivo da EPE é planejar, com viabilidade, o futuro do setor elétrico.

\section{CMSE - Comitê de Monitoramento do Setor Elétrico}

O CMSE é um órgão criado no âmbito do MME, sob sua coordenação direta, com a função de acompanhar e avaliar a continuidade e a segurança do suprimento elétrico em todo o território nacional.

Suas principais atribuições incluem: (i) acompanhar o desenvolvimento das atividades de geração, transmissão, distribuição, comercialização, importação e exportação de energia elétrica; (ii) avaliar as condições de abastecimento e de atendimento; (iii) realizar periodicamente a análise integrada de segurança de abastecimento e de atendimento; (iv) identificar dificuldades e obstáculos que afetem a regularidade e a segurança de abastecimento e expansão do setor; (v) e elaborar propostas para ajustes e ações preventivas que possam restaurar a segurança no abastecimento e no atendimento elétrico.

\section{ANEEL - Agência Nacional de Energia Elétrica}

A ANEEL foi instituída pela Lei ำ 9.427/96 e constituída pelo Decreto oㅡ 2.335/97, com as atribuições de regular e fiscalizar a produção, transmissão, distribuição e comercialização de energia elétrica, zelando pela qualidade dos 
serviços prestados, pela universalização do atendimento e pelo estabelecimento das tarifas para os consumidores finais, sempre preservando a viabilidade econômica e financeira dos Agentes e da indústria.

As alterações promovidas em 2004 pelo novo modelo do setor estabeleceram como responsabilidade da ANEEL, direta ou indiretamente, a promoção de licitações na modalidade de leilão, para a contratação de energia elétrica pelos Agentes de Distribuição do Sistema Interligado Nacional (SIN).

\section{CCEE - Câmara de Comercialização de Energia Elétrica}

A Câmara de Comercialização de Energia Elétrica (CCEE) começou a operar em 10 de novembro de 2004 - regulamentada pelo Decreto ㄲo 5.177, de 12 de agosto de 2004, sucedendo ao Mercado Atacadista de Energia (MAE).

A CCEE é uma associação civil integrada pelos agentes das categorias de Geração, de Distribuição e de Comercialização. A instituição desempenha papel estratégico para viabilizar as operações de compra e venda de energia elétrica, registrando e administrando contratos firmados entre geradores, comercializadores, distribuidores e consumidores livres.

A CCEE tem por finalidade: (i) viabilizar a comercialização de energia elétrica no Sistema Interligado Nacional nos Ambientes de Contratação Regulada e Contratação Livre; (ii) e efetuar a contabilização e a liquidação financeira das operações realizadas no mercado de curto prazo, as quais são auditadas externamente, nos termos da Resolução Normativa ANEEL no 109, de 26 de outubro de 2004 (Convenção de Comercialização de Energia Elétrica).

As Regras e os Procedimentos de Comercialização que regulam as atividades realizadas na CCEE são aprovados pela ANEEL.

\section{Atribuições da CCEE}

- Manter o registro de todos os contratos fechados nos Ambientes de Contratação Regulada (ACR) e de Contratação Livre (ACL).

- Promover a medição e registro dos dados de geração e consumo de todos os Agentes da CCEE. 
- Apurar o Preço de Liquidação de Diferenças - PLD - do Mercado de Curto Prazo por submercado.

- Efetuar a Contabilização dos montantes de energia elétrica comercializados no Mercado de Curto Prazo e a Liquidação Financeira.

- Apurar o descumprimento de limites de contratação de energia elétrica e outras infrações e, quando for o caso, por delegação da ANEEL, nos termos da Convenção de Comercialização, aplicar as respectivas penalidades.

- Apurar os montantes e promover as ações necessárias para a realização do depósito, da custódia e da execução de Garantias Financeiras, relativas às Liquidações Financeiras do Mercado de Curto Prazo, nos termos da Convenção de Comercialização.

- Promover Leilões de Compra e Venda de energia elétrica, conforme delegação da ANEEL.

- Promover o monitoramento das ações empreendidas pelos Agentes, no âmbito da CCEE, visando à verificação de sua conformidade com as Regras e Procedimentos de Comercialização, e com outras disposições regulatórias, conforme definido pela ANEEL.

- Executar outras atividades, expressamente determinadas pela ANEEL, pela assembleia geral ou por determinação legal, conforme 0 art. $3^{\circ}$ do Estatuto Social da CCEE.

\section{ONS - Operador Nacional do Sistema Elétrico}

O ONS foi criado pela Lei $n^{\circ} 9.648$, de 27 de maio de 1998 , e regulamentado pelo Decreto ํㅡ 2.655, de 2 de julho de 1998, com as alterações do Decreto ํo 5.081 , de 14 de maio de 2004, para operar, supervisionar e controlar a geração de energia elétrica no SIN, e administrar a rede básica de transmissão de energia elétrica no Brasil.

O ONS tem como objetivo principal: (i) atender os requisitos de carga; (ii) otimizar custos; (iii) e garantir a confiabilidade do sistema; (iv) definindo ainda, as condições de acesso à malha de transmissão em alta-tensão do país. 
Diagrama das instituições do setor Elétrico

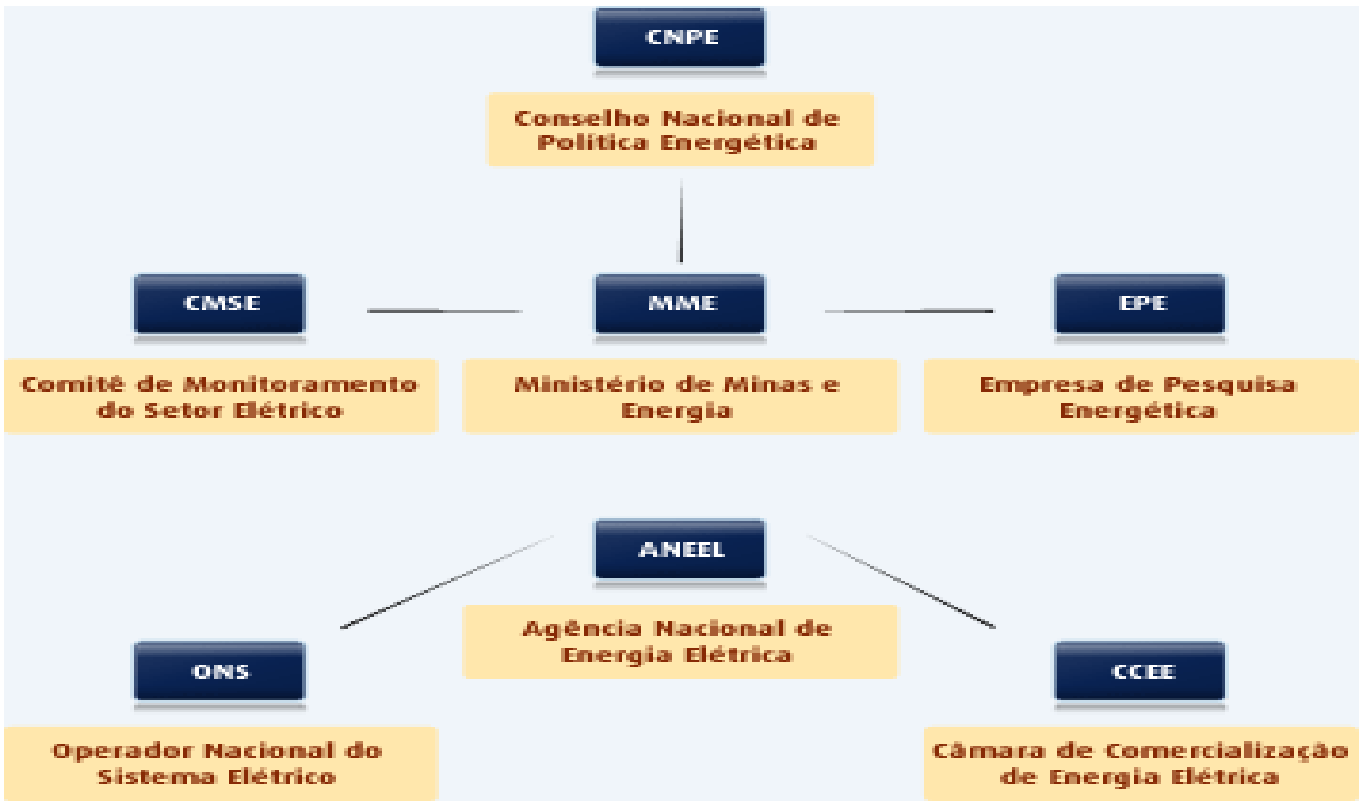

Fonte: CCEE

\section{Agentes do mercado de energia elétrica}

São os associados da CCEE, com participação obrigatória ou facultativa, previstos na Convenção de Comercialização de Energia Elétrica. Os Agentes da CCEE dividem-se nas Categorias de Geração, de Distribuição e de Comercialização. Categoria dos Agentes Geradores, Produtores Independentes e Autoprodutores. A atividade de geração de energia elétrica permanece com seu caráter competitivo, sendo que todos os Agentes de Geração poderão vender energia tanto no ACR, como no ACL. Os Geradores também possuem livre acesso aos sistemas de transmissão e distribuição de energia elétrica.

\section{Os Agentes podem ser classificados como segue.}

- Concessionários de Serviço Público de Geração: Agente titular de Serviço Público Federal delegado pelo Poder Concedente mediante licitação, na modalidade de concorrência, à pessoa jurídica ou consórcio de Empresas 
para exploração e prestação de serviços públicos de energia elétrica, nos termos da Lei 8.987, de 13 de fevereiro de 1995.

- Produtores Independentes de Energia Elétrica: são Agentes individuais, ou reunidos em consórcio, que recebem concessão, permissão ou autorização do Poder Concedente para produzir energia elétrica destinada à comercialização por sua conta e risco.

- Autoprodutores: são Agentes com concessão, permissão ou autorização para produzir energia elétrica destinada a seu uso exclusivo, podendo comercializar eventual excedente de energia, desde que autorizado pela ANEEL

- Distribuição: Categoria dos Agentes Distribuidores. A atividade de distribuição é orientada para o serviço de rede e de venda de energia aos consumidores com tarifa e condições de fornecimento reguladas pela ANEEL (Consumidores Cativos). Com o novo modelo, os distribuidores têm participação obrigatória no ACR, celebrando contratos de energia com preços resultantes de leilões.

- Comercialização: Categoria dos Agentes Importadores e Exportadores, Comercializadores e Consumidores Livres.

- Importadores: São os Agentes do setor que detêm autorização do Poder Concedente para realizar importação de energia elétrica para abastecimento do mercado nacional.

- Exportadores: são os Agentes do setor que detêm autorização do Poder Concedente para realizar exportação de energia elétrica para abastecimento de países vizinhos.

- Comercializadores: Os Agentes Comercializadores de energia elétrica compram energia através de contratos bilaterais celebrados no $A C L$, podendo vender energia aos consumidores livres, no próprio $A C L$, ou aos distribuidores através dos leilões do ACR.

- Consumidores Livres: são consumidores que, atendendo aos requisitos da legislação vigente, podem escolher seu fornecedor de energia elétrica (geradores e comercializadores) por meio de livre negociação. A tabela abaixo resume as condições para que o consumidor de energia possa se tornar livre. 


\begin{tabular}{|l||l|l||}
\hline \multicolumn{3}{|c|}{ Critérios vigentes para se tornar Consumidor Livre } \\
\hline Demanda mínima & $\begin{array}{c}\text { Tensão de } \\
\text { Fornecimento }\end{array}$ & $\begin{array}{c}\text { Data de ligação do } \\
\text { Consumidor }\end{array}$ \\
\hline $3 \mathrm{MW}$ & Qualquer tensão & após 08/07/1995 \\
\hline $3 \mathrm{MW}$ & $69 \mathrm{kV}$ & antes de 08/07/1995 \\
\hline
\end{tabular}

A partir de 1998, conforme regulamentou a Lei n 9.427, parágrafo 5ํㅡㄹ art. 26, de 26 de dezembro de 1996, os consumidores com demanda mínima de 500 kW, atendidos em qualquer tensão de fornecimento, têm também o direito de adquirir energia de qualquer fornecedor, desde que a energia adquirida seja oriunda de Pequenas Centrais Hidrelétricas (PCHs) ou de fontes alternativas (geração eólica, biomassa ou solar). Conforme disposto no inciso III do art. $2^{\circ}$ do Decreto ํㅡ $5163 / 2004$, os consumidores livres e aqueles atendidos conforme o parágrafo $5^{\circ}$ do art. 26 da Lei no 9.427 devem garantir o atendimento a $100 \%$ de seu consumo verificado, através de geração própria ou de contratos bilaterais celebrados no Ambiente de Contratação Livre que, quando necessário, deverão ser aprovados, homologados ou registrados na ANEEL.

\section{Agentes Obrigatórios}

\section{São Agentes com participação obrigatória na CCEE:}

- os concessionários, permissionários ou autorizados de geração que possuam central geradora com capacidade instalada igual ou superior a $50 \mathrm{MW}$;

- os autorizados para importação ou exportação de energia elétrica com intercâmbio igual ou superior a 50 MW;

- os concessionários, permissionários ou autorizados de serviços e instalações de distribuição de energia elétrica cujo volume comercializado seja igual ou superior a $500 \mathrm{GWh} / \mathrm{ano}$, referido ao ano anterior;

- os concessionários, permissionários ou autorizados de serviços e instalações de distribuição de energia elétrica cujo volume comercializado seja inferior a 
$500 \mathrm{GWh} / \mathrm{ano}$, referido ao ano anterior, quando não adquirirem a totalidade da energia de supridor com tarifa regulada;

- os autorizados de comercialização de energia elétrica, cujo volume comercializado seja igual ou superior a $500 \mathrm{GWh} / \mathrm{ano}$, referido ao ano anterior.

Os Consumidores Livres e os consumidores que adquirirem energia na forma do $\S 5^{\circ}$ do art. 26 da Lei ํㅜ 9.427, de 26 de dezembro de 1996.

\section{Agentes Facultativos}

São Agentes com participação facultativa na CCEE: os titulares de autorização para autoprodução e cogeração com central geradora de capacidade instalada igual ou superior a $50 \mathrm{MW}$, desde que suas instalações de geração estejam diretamente conectadas às instalações de consumo e não sejam despachadas de modo centralizado pelo ONS, por não terem influência significativa no processo de otimização energética dos sistemas interligados; e demais titulares de concessão ou autorização para exploração de serviços de geração, para realização de atividades de comercialização de energia elétrica, bem como para importação e exportação de energia. 


\section{ANEXO C - RESOLUÇÃO ANEEL 343/08}

A nova metodologia estruturada pela Resolução ANEEL 343/08 organizou as fases para implantação de empreendimentos nas características de $\mathrm{PCH}$ da seguinte forma:

\section{Registro para Elaboração do Projeto Básico}

Fase em que será registrado o interesse do empreendedor para realização de projeto básico, sendo obrigatória a apresentação de aporte de garantia de registro em favor do órgão regulador, conforme equação abaixo:

$$
V G=\left[\operatorname{Vmax}^{*}(P-1.000)-V \min ^{*}(P-30.000)\right] / 29.000
$$

Onde:

- $V G=$ Valor da Garantia em $R$ \$;

- $\mathrm{P}=$ Potência da $\mathrm{PCH}$ estimada no estudo de inventário aprovado pela ANELL, em KW;

- $\mathrm{Vmin}=$ Valor mínimo da garantia: $\mathrm{R} \$ 100.000,00$ (cem mil reais);

- Vmáx = Valor máximo da garantia: $\mathrm{R} \$ 500.000,00$ (quinhentos mil reais).

\section{Garantias de Registro e Fiel Cumprimento}

Definições e exigências técnicas para desenvolvimento do projeto básico e seus respectivos estudos fundamentadores. A garantia de registro, ou caução, será substituída pela garantia de fiel cumprimento no valor de $5 \%$ do investimento, equivalente a $R \$ 4.000 / \mathrm{kw}$ instalado, tendo com referência a potência do projeto básico aprovado, podendo este valor ser revisto a critério da ANEEL. 


\title{
Aceite do projeto básico e seleção do interessado
}

Condições para aceite, pela ANEEL, do projeto básico apresentado e critérios para seleção de interessados caso existam dois ou mais projetos básicos para o mesmo aproveitamento.

Artigo 11, da Resolução 343/08

\begin{abstract}
"Existindo dois ou mais projetos básicos para o mesmo aproveitamento, a ANEEL utilizará dos seguintes critérios com vistas à seleção e hierarquização do interessado pela ordem: (i) aquele cujo projeto básico esteja em condições de obter o aceite dentro dos prazos estabelecidos; (ii) aquele que tenha sido o responsável pela elaboração do respectivo estudo de inventário ; e, (iii) aquele que for o proprietário da maior área a ser atingida pelo reservatório do aproveitamento em questão, com documentação devidamente registrada em cartório de imóveis até o prazo de 14 meses após a efetivação do primeiro registro na condição de ativo."
\end{abstract}

\section{Análise e aprovação do projeto básico}

Fase em que a ANEEL procederá a análise do projeto básico único, ou do primeiro classificado, tendo com ênfase os aspectos definidores do potencial hidráulico. O início da análise será efetuado baseando-se nos seguintes critérios de prioridade estabelecidos pela ANEEL:

- projeto básico de PCHs outorgadas com licença de Operação (LO);

- projeto básico de PCHs outorgadas com licença de Instalação (LI);

- projeto básico de PCHs com licença de operação (LO) ou com dispensa deste licenciamento;

- projeto básico de PCHs com licença de instalação (LI);

- projeto básico de PCHs outorgadas com licença prévia (LP);

- projeto básico de PCHs outorgadas com licença prévia (LP). 


\section{Outorga da autorização}

Fase posterior à publicação da aprovação do projeto básico, na qual o interessado deverá protocolar os documentos de regularidade jurídica, fiscal, econômica, financeira e de adimplemento setorial para a efetiva outorga da resolução de autorização. 
ANEXO D - Curva de desempenho turbina-gerador Wobben E82-E2 ${ }^{72}$

Curva de desempenho eletrodinâmico do conjunto

Turbina-gerador Wobben/Enercon E82-E2

\begin{tabular}{|c|c|}
\hline $\begin{array}{c}\text { Velociade } \\
\text { vento } \\
{[\mathrm{m} / \mathrm{s}]}\end{array}$ & $\begin{array}{c}\text { Potência } \\
{[\mathbf{k W}]}\end{array}$ \\
\hline & \\
\hline 1 & 0 \\
\hline 2 & 3 \\
\hline 3 & 25 \\
\hline 4 & 82 \\
\hline 5 & 174 \\
\hline 6 & 321 \\
\hline 7 & 532 \\
\hline 8 & 815 \\
\hline 9 & 1180 \\
\hline 10 & 1580 \\
\hline 11 & 1810 \\
\hline 12 & 1980 \\
\hline 13 & 2050 \\
\hline 14 & 2050 \\
\hline 15 & 2050 \\
\hline 16 & 2050 \\
\hline 17 & 2050 \\
\hline 18 & 2050 \\
\hline 19 & 2050 \\
\hline 20 & 2050 \\
\hline 21 & 2050 \\
\hline 22 & 2050 \\
\hline 23 & 2050 \\
\hline 24 & 2050 \\
\hline 25 & 2050 \\
\hline
\end{tabular}

Fonte: Enercon. 